

\section{Feminist Existentialism, Biopolitics, and Critical Phenomenology in a Time of Bad Health}

This book explores the personal value of healthy behavior, arguing that our modern tendency to praise or blame individuals for their health is politically and economically motivated and has reinforced growing health disparities between the wealthy and poor under the guise of individual responsibility.

We are awash in concerns about the state of our health and recommendations about how to improve it from medical professionals, public health experts, and the diet-exercise-wellness industry. The idea that health is about wellness and not just preventing illness becomes increasingly widespread as we find out how various modifiable behaviors, such as smoking or our diets, impact our health. In a critical examination of health, we find that alongside the move toward wellness as a state that the individual is responsible to in part produce, there is a roll-back of public programs. This book explores how this "good health imperative" is not as apolitical as one might assume. The more the individual is the locus of health, the less structural and historical issues that create health disparities are considered. Feminist Existentialism, Biopolitics, and Critical Phenomenology in a Time of Bad Health charts the impact of the increasing shift to a model of individual responsibility for one's health. It will benefit readers who are interested to think critically about normalization to produce "healthy bodies." In addition, this book will benefit readers who understand the value of personal health but are wary of the ways in which health can be used as a tool to discriminate and fuel inequalities in health care access.

This volume is primarily of interest to academics, students, public health and medical professionals, and readers who are interested in critically examining health from a philosophical perspective in order to understand how we can celebrate the value of healthy behavior without reinforcing discrimination.

Talia Welsh is UTAA Distinguished Service Professor and UC Foundation Professor of Philosophy and Women, Gender, and Sexuality Studies at the University of Tennessee at Chattanooga, USA. She is the translator of Child Psychology and Pedagogy: Maurice Merleau-Ponty at the Sorbonne and the author of The Child as Natural Phenomenologist: Primal and Primary Experience in Merleau-Ponty's Psychology. 


\section{Interdisciplinary Research in Gender}

Freewomen, Patriarchal Authority and the Accusation of Prostitution Stephanie Lynn Budin

Spatialities in Italian American Women's Literature Beyond the Mean Streets

Eva Pelayo Sañudo

Women's Suffrage in Word, Image, Music, Stage and Screen The Making of a Movement

Edited by Christopher Wiley and Lucy Ella Rose

Intersectional Feminist Readings of Comics Interpreting Gender in Graphic Narratives Edited by Sandra Cox

Caffie Greene and Black Women Activists

Unsung Women of the Black Liberation Movement

Kofi Charu Nat Turner

Forced Migration in the Feminist Imagination

Transcultural Movements

Anna Ball

The Misogynistic Backlash to Women-Strong Films

Dana Schowalter, Shannon Stevens, and Daniel Horvath

Feminist Existentialism, Biopolitics, and Critical Phenomenology in a Time of Bad Health

Talia Welsh

https://www.routledge.com/Interdisciplinary-Research-in-Gender/ book-series/IRG 


\section{Feminist Existentialism, Biopolitics, and Critical Phenomenology in a Time of Bad Health}

Talia Welsh 
First published 2022

by Routledge

2 Park Square, Milton Park, Abingdon, Oxon OX14 4RN

and by Routledge

605 Third Avenue, New York, NY 10158

Routledge is an imprint of the Taylor \& Francis Group, an informa business

\section{(C) 2022 Talia Welsh}

The right of Talia Welsh to be identified as author of this work has been asserted by her in accordance with sections 77 and 78 of the Copyright, Designs and Patents Act 1988.

The Open Access version of this book, available at www. taylorfrancis.com, has been made available under a Creative Commons Attribution-Non Commercial-No Derivatives 4.0 license.

Trademark notice: Product or corporate names may be trademarks or registered trademarks, and are used only for identification and explanation without intent to infringe.

British Library Cataloging-in-Publication Data

A catalog record for this book is available from the British Library

Library of Congress Cataloging-in-Publication Data

Names: Welsh, Talia, author.

Title: Feminist existentialism, biopolitics, and critical phenomenology in a time of bad health / Talia Welsh.

Other titles: Interdisciplinary research in gender.

Description: New York, NY : Routledge 2022. I Series: Interdisciplinary research in gender I Includes bibliographical references and index. I

Identifiers: LCCN 2021026369 (print) | LCCN 2021026370 (ebook) I ISBN 9780367768188 (hardback) I ISBN 9780367768201 (paperback) I ISBN 9781003168676 (ebook)

Subjects: MESH: Health Behavior I Existentialism I Feminism | Attitude to Health

Classification: LCC RA776.9 (print) I LCC RA776.9 (ebook) I NLM W 85 | DDC 613--dc23

LC record available at https://lccn.loc.gov/2021026369

LC ebook record available at https://lccn.loc.gov/2021026370

ISBN: 978-0-367-76818-8 (hbk)

ISBN: 978-0-367-76820-1 (pbk)

ISBN: 978-1-003-16867-6 (ebk)

DOI: $10.4324 / 9781003168676$

Typeset in Sabon

by SPi Technologies India Pvt Ltd (Straive) 
Today, however, we are having a hard time living because we are so bent on outwitting death.

Simone de Beauvoir, The Ethics of Ambiguity. 
Taylor \& Francis

http://taylorandfrancis.com 


\section{Contents}

Preface viii

Acknowledgments xii

1 The good health imperative 1

2 A critical phenomenology of health and illness 28

3 Feminist phenomenologies and self-regulating bodies $\quad 53$

4 Biopolitics and personal responsibility 78

5 Marxism, reproductive labor, and the body as fetish object 103

6 Alternative visions of health-somaesthetics $\begin{array}{lr}\text { and innumerable healths } & 128\end{array}$

7 Toward an existential ethics of working on the self 149

Bibliography 173

Index 186 


\section{Preface: Good health in a time of bad health}

As this book goes to press, the world finds itself in the grip of a worldwide pandemic. Millions of people have died of COVID-19, millions have been sickened, and we still are unsure if we can control its spread, given the challenges of new variants, lack of vaccines, and vaccine resistance. Even surviving an infection can often mean that one is a "long-hauler" with a dizzying array of possible conditions that are created or exacerbated by having had it. No country was able to isolate itself, and even if this super-flu is defeated, we are now all too aware of just how interconnected and vulnerable we are to the next pandemic. At first, exactly how COVID-19 spread was unclear and, as everyone reads this book will recall, we were scrubbing down surfaces and hoarding supplies. What we learned is the respiratory nature of its spread-how it passes unseen from one person to another, particularly indoors. We find ourselves at the mercy of others' behaviors to protect our airways from infection. We live in a time of bad health, and we live in a time where individual health is no longer, if it ever was, possible to make merely a matter of the individual's behavior.

In this book, I will explore what I call the "good health imperative." This idea fits in well with ideas of "healthism" and "biomorality." In all these views, there is an emphasis on health and life-extension as primary goals of individuals and societies. My main contribution is to highlight the idea of individual, as opposed to collective or societal, responsibility for health production. What I call the good health imperative is the sense that it is both rational and moral to better one's health when one can. This imperative finds its inspiration both in ongoing research into how consumption, activity, sleep, air and water quality affect a wide variety of health outcomes. It also occurs alongside social and political calls to roll back our shared responsibility in favor of individual responsibility for one's "success" or "failure." One of the reasons that the good health imperative can paradoxically work against the promotion of better public health is that it encourages the justification of rolling back social welfare as everyone is now able to "take charge" and become healthier. In such a view, poor health is viewed as a personal, or familial, failing, not a social one. Systemic issues 
such as racism, classism, sexism, and ableism are seen as largely invisible backgrounds to the "real" issue-people aren't doing the right things for their own health.

However, not all forms of individual behavior designed to maximize health are acts of docility. Healthy self-care can help take a stand against a world in which we are encouraged to work for the profit of others to the detriment of our own well-being. The fear of suffering and illness is a human concern and one that will likely follow us into any social and political world. As we learn more about what kinds of behaviors permit us to obtain better health, it seems natural to pursue these activities if possible. Yet, given that the work entailed in bettering one's health is never a completed project—one can always better one's diet, one's activity, lower one's stress, better one's environment, consider the latest treatments or medicines-no obvious boundaries to this work exist. In addition, the fact of aging brings with it new challenges over time. I ask in this book-how has the value of working on one's health as a project changed our sense of self and our sense of health and illness? How does this value relate to other values that we might hold? Why are laws against smoking and anxiety about overweight and obesity such popular laws and topics in a world awash with many other pressing social issues? Finally, what might be an authentic manner to live and relate to one's health in our current condition?

\section{Overview of the book}

The book begins with "The Good Health Imperative.” This chapter explores how in the United States significant political and public health attention is spent on three behaviors that are correlated with poor health outcomes: poor food consumption/low activity and its relation to obesity, smoking, and excessive drinking. I chart how increasingly health is seen as a matter of the promotion of wellness and not simply the fight against illness. I consider the common economic arguments that such behaviors are socially costly as questionable given how difficult it is to assess if a healthy long-life is less economically costly for society than shorter unhealthier ones. Finally, chapter one outlines the idea of a "good health imperative" that exceeds economic calls for health reform and makes health a matter of individual responsibility.

In Chapter 2, "A Critical Phenomenology of Health and Illness," I discuss how health is not merely about one's state as assessed by medical professionals, but how one lives and feels. It explores phenomenologies of health and illness starting with Hans-Georg Gadamer's idea of health as a background state. It expands to Fredrik Svenaeus' account of health as a kind of being-at-home and Maurice Merleau-Ponty's insistence of health as an "I can"- the capacity to do certain desired actions. All these accounts illustrate that simply having a certain kind of body does not necessarily mean one will feel healthy, even if there is often a strong correlation between one's medically testable state and one's experience. In critical phenomenological 


\section{$\mathrm{x}$ Preface: Good health in a time of bad health}

accounts and critical disability theory, we find how ideologies of "health" and contextual environments shape the capacity for intentional movement and living. In conclusion, it explores the moralism surrounding obesity.

In Chapter 3, "Feminist Phenomenologies and Self-Regulating Bodies," I explore how feminist phenomenologies and developmental accounts of bodily control show how bodily habits develop socially. The other's selfcare rituals and the other's care of the child teach us how caring for one's body is from the beginning culturally embedded. In the second section, the example of contemporary managed female appearance will be discussed as an example of how the cultural body can be understood in relationship to bodily agency. Feminist consciousness-raising exposes problems with such modification and provides bulwarks against the commodification and objectification of women's bodies. However, in the third section, one finds that some feminists celebrate the same kind of agentic bodily self-modification if it is directed toward health rather than a model of aesthetic improvement. These arguments return us to a kind of naturalism where the body tends toward health and is inhibited by culture instead of the view proposed here that health is always contextual and social. Finally, I draw attention to how contingent "able-bodied" periods of our life are and how much they depend upon structures that have little to do with health and illness.

"Biopolitics and Personal Responsibility" is the topic of Chapter 4, wherein I outline biopolitical views on contemporary concerns with health monitoring, health promotion, and the production of healthy bodies. Michel Foucault's initial discussions of biopolitics provides a ground from which to engage in a critical assessment of the good health imperative. The chapter turns to cases of campaigns against childhood obesity as examples of how identities around good parenting are connected to the production of certain kinds of children's bodies. Using the example of campaigns against childhood obesity, this chapter charts how norms of responsible parenting are increasingly concerned with state of the child's health as a marker of good parental practice. The development of responsibility as a hallmark of health behaviors helps pass over the racist and ableist manners in which "good health" policies are carried out and enforced.

A Marxist view of work and surplus labor argue that we are encouraged to see our bodies as products is the topic in Chapter 5-"Marxism, Reproductive Labor, and the Body as Fetish Object." We objectify our bodies in order to "produce" the right kind of body. Taking up Marcuse's idea of the bourgeois aesthetic, the chapter explores how the objectified body is a delayed fantasy. One's body will become appropriately healthy in the future with just a little more work. I argue that the view that health is a transhistorical desire that arises out of a basic human need should be qualified to include the historical nature of how we satisfy our needs and desires. The contingent cultural nature of need and desire satisfaction changes those very desires and needs. Finally, the chapter concludes with a reflection on 
how our attention to future bodies narrows our focus away from systematic causes of health disparities.

The final two chapters examine possible responses to the good health imperative. The sixth chapter, "Alternative Visions of Health-Somaesthetics and Innumerable Healths," begins by considering Albert Camus' idea that the artist needs to "create dangerously." Artists can no longer ignore the suffering of the masses, but they also must be wary of becoming mouthpieces for pre-existing political arguments. This idea sets up the chapter for the consideration of somaesthetics as a kind of creative self-fashioning that could include healthy self-care, but would not be necessarily reduced to it. Somaesthetics permits a variety of ways in which to see positive self-transformation outside of restrictive norms and is one feminist manner in which to consider self-care. The third section considers the possibility of distinguishing health and sickliness as not two different biological states, but two different manners of living. In Nietzsche's view, suffering is not to be avoided; rather, suffering is intrinsic to his idea of "great health." A desire to reduce the diversity of experience is for him sickliness. This offers a way in which to think about promoting health outside of narrow ideas of illness and health. Chapter 6 considers if one challenge we face to finding an existentialist view of the good health imperative is that we might have more than one kind of existential self who is responding to our experience. In self-care as self-controlled behavior, one cannot necessarily see the desires being controlled as less authentic than the freely desired (or conditioned) self that attempts to control them. Kathi Weeks' utilization of Nietzsche's eternal return of the same as a way to argue against the inherent value of any kind of work concludes the chapter.

The final chapter, "Toward an Existential Ethics of Working on the Self," considers how we might better situate self-care neither by rejecting it wholesale, nor by assuming its necessarily moral value. Drawing on Sara Ahmed's idea of normative paths, I will explore how ableism and heteronormativity propose not just what kinds of persons are considered appropriate and valued, but also what the direction of all lives should be. The idea of ambiguity from Simone de Beauvoir permits a more expansive idea of possible other paths one might take. The chapter looks at how models of work and labor's priority in our personal and political lives make it hard to think outside models of consumption and self-improvement. Hannah Arendt's discussion of the collapse of thinking in societies organized around labor will shape the conclusion of how we can remain more open to socially engaged models of health. 


\section{Acknowledgments}

The research and writing of this book also sadly spanned the illness and death of my good friend Füsun Kösedağ, and I miss our good conversations and laughter every day. Without the capacity to discuss with my family, friends, colleagues, and students these ideas over the last couple of years, I would have never been able to think through the work present in this book. The University of Tennessee at Chattanooga's support for my research materials and travel to academic conferences also was integral to having that resources and space to learn, develop, and foster these ideas. I extend my appreciation to Landon Finke for his invaluable aid in editing. Special thanks to my parents, David and Donna Welsh, for encouraging my questioning growing up, and Jon and David Littlefield for giving me a happy home from which good ideas can flow. I often said that I should make sure to dedicate my work to my two constant helpmates-coffee and chocolate-and to them I give my final thanks. 


\section{The good health imperative}

\section{Smokers, drinkers, and the fat}

People in the developed world are enjoying good health in greater numbers than ever before. More of us survive childhood, live longer, and have access to the best medication, emergency care, and health technologies. The "demographic transition" summarizes how prior to around 1800 in Europe, "life was short, births were many, growth was slow, and the population was young." ${ }^{1}$ Prior to 1800 , it took 300,000 generations for the population to double. Yet after 1800, in only two hundred years, our population doubled again and in high-income countries a strongly linear trend toward increasingly longer lives (with the exception of the years during the two great world wars) emerged. ${ }^{2}$ One can ask, with the end of the conviction that there is a "natural" end to human longevity, will such a demographic shift continue? Are there natural limits to human life? Can we absorb, without catastrophe, even larger populations?

Yet, despite this striking change in longevity for humans in the developed world (and increasingly in much of the rest of the world), the common narrative about the state of public health in the United States, which is the main focus on this book, is one of anxiety and doom. We are too fat, illfed, and under-exercised. Too many of us are at risk for cancer, diabetes, or heart disease. Our healthcare costs are too expensive; we are too unhappy and over-medicated. We eat too much processed food and too few fruits and vegetables. There are still smokers and excessive drinkers. Even those of us who possess good health are anxiously on guard to maintain it.

What precipitates this concern over health if our longevity has risen sharply in recent decades? Part of our concern is the fact that we do live longer and hence more people will contract the illnesses associated with aging. Diseases such as cancer, osteoporosis, heart disease, arthritis, type 2 diabetes, and Alzheimer's are devastating and often expensive. In worlds ripped apart by violence, lack of sanitation, no vaccines, and lack of basic medical care, death came quickly enough for most to avoid degenerative diseases. Now, exposed to them in greater and greater numbers, it is no wonder that we feel beset by illness. 


\section{The good health imperative}

The increase in longevity has also been supported by the growth of birthto-death healthcare coverage. Healthcare insurance has permitted many to understand healthcare as not just an emergency matter only needed when one is suffering, but also as something that entails check-ups, routine care, and preventative tests. The US, long lagging behind its peers in the developed world, passed the Affordable Care Act (ACA) in 2010, which remains on precarious ground but seems likely to be preserved in some form. While far different from single-payer systems in other developed countries such as Canada, the ACA did greatly improve the possibility of being covered by healthcare insurance. In 2010 President Obama spoke about the advantages of the ACA by saying:

So, starting in September, some of the worst abuses will be banned forever. No more discriminating against children with pre-existing conditions. No more retroactively dropping somebody's policy when they get sick if they made an unintentional mistake on an application. No more lifetime limits or restrictive annual limits on coverage. Those days are over. ${ }^{3}$

The ACA, often derisively called "Obamacare," has remained a controversial piece of legislation. Parties on the political right have created numerous legal challenges to its authority. A case brought to the US Supreme Court challenging the ACA's subsidies (focusing on six sentences of the bill) was defeated 6-3 in June of 2015, leading many to think it is likely safe from significant revision, but the Trump presidency and the Republican majority in Congress in 2017 led to renewed attacks. ${ }^{4}$ Under the current Biden administration, the ACA looks likely to remain. Despite the on-going challenges to the ACA, it is largely seen as a victory by public health advocates. Many who were unable to get healthcare insurance are now able to get quality medical care. Despite a rocky initial rollout, during the first two years, the ACA increased the number of insured by 22.8 million people. Some previously insured people lost or rejected their previous coverage, about 5.9 million, for an overall increase of 16.9 million new insured persons. ${ }^{5}$ President Biden has signaled his support for the ACA and has expanded the capacity for individuals to enroll after significant cuts during the Trump presidency. ${ }^{6}$

As President Obama noted, one of the main selling features was the fact that the ACA forbids health insurance companies from denying enrollment to those with pre-existing conditions. While the ACA is celebrated as being neutral in its coverage to the healthy and the ill, it has enshrined the capacity of health insurance companies to offer incentives for individuals to substitute their behaviors for healthier ones or penalties for those who do not. The underlying ideology is that, while we should cover pre-existing conditions for all persons and not deny the sickest of us what they most need, we should try and require people to also do what is best, so they do not become ill. This draws a line between the idea that persons are responsible for their illness, at least in some part, and the idea that some are blameless. 
One should not be forbidden proper medical care if one has a genetic condition, but perhaps one should have to pay more if one has smoked and now has cancer. Alternatively, I should pay less if I engage in practices likely to lengthen my life and reduce my time in the doctor's office.

The critical importance of prevention, such as in vaccinations or good prenatal care, has become expanded to include a variety of behaviors from smoking to weight management to good sleep. The business of dedicated public health professionals has rapidly grown. Preventing disease and disability in the populace is now the business of the government, healthcare corporations, healthcare charities, education institutions, and private companies. Many workplaces now include various diet and exercise programs, workout facilities, and smoking cessation programs. Health insurance now addresses more carefully personal self-care practices, and doctors are educated to ask about drug and alcohol use, smoking habits, diet, and exercise.

The great expansion of preventative practices and the agencies charged with encouraging them is based in understanding that certain lifestyle behaviors-the kinds of foods one eats, if one smokes, if one drinks excessively-are connected to common diseases. Moderating or reducing the poor behaviors and increasing the healthy ones is clearly linked to longer life and less use of expensive pharmaceuticals and medical resources. Smoking, alcohol abuse, and overeating are three common behaviors that have high correlations to certain poor health outcomes. We also have increasing evidence that, after altering such behaviors toward healthier ones, individuals often are able to change their health for the better. The work of public health campaigns extends beyond access to basic healthcare, sanitary living conditions, and vaccinations. Public health research now extends into what one might call "lifestyles" to how to one eats, moves, and works. We are able to correlate poor health with anything from television watching to workplace stress. But it is smokers, drinkers, and the fat who are the most commonly targeted for public health interventions. Their poor health can often be avoided, and their deaths delayed.

A UK study on the costs to the National Health Service cites chronic diseases as the leading cause of death globally and goes on to note that "Many chronic diseases share common behavioral risk factors such as tobacco smoking, unhealthy diet, lack of physical activity and alcohol use." " Following the ACA, in 2011 the Surgeon General produced "the nation's first ever National Prevention and Health Promotion Strategy (National Prevention Strategy). This strategy is a critical component of the Affordable Care Act, and it provides an opportunity for us to become a more healthy and fit nation." ${ }^{8}$ This broad ranging document covers a variety of issues from environmental depredation to economic disparities as underlying issues that must be addressed to promote health. Four of its seven priorities are about lifestyle issues_-"Tobacco Free Living," "Preventing Drug Abuse and Excessive Alcohol Use," "Healthy Eating," and "Active Living." In 2012, as part of the ACA, the Prevention and Public Health Fund was created under the auspices of Health and Human Services. It is the first mandatory 


\section{The good health imperative}

funding to improve health. ${ }^{10}$ It funds numerous programs, many through the CDC, to prevent a number of poor health outcomes from Alzheimer's to smoking to depression.

The National Prevention Strategy and the funding of the Prevention and Public Health Fund clearly document the move from seeing healthcare as a matter of the ill toward the idea that it is about the well. Sickness is not a problem in itself, so much as a problem that wasn't caught early enough to be delayed. The vision is to move "the nation from a focus on sickness and disease to one based on prevention and wellness" and the goal to accomplishing this vision is to increase "the number of Americans who are healthy at every stage of life." ${ }^{11}$ Given the complexity of promoting healthy behavior and the need to address so many factors beyond individual habitual actionwhat reasons might one have to think that we can shift public behavior? The answer lies in the recent history of campaigns against cigarette smoking.

Smoking is the behavior with the clearest correlation to disease, and the change in smoking habits in the developed world is the best example of how health habits do seem modifiable with a combination of prohibition, sin taxes, and public information. In 1964, the US Surgeon General published a report Smoking and Health which summarized the overwhelming literature on the deleterious effects of smoking. In the last 50 years, adult smoking rates in the US have declined from $43 \%$ in 1965 to $18 \%$ in $2014 . .^{12}$ The Surgeon General reports that around 20 million Americans have died from smoking, and of those 2.5 million are due to second-hand smoke. (Contemporary research has called into question the correlation between exposure to second-hand smoking and lung cancer-even among those who have lived in houses with a smoker for up to 30 years. ${ }^{13}$ ) Worldwide, the WHO reports that smoking kills 5 million people a year and highlights reduction in smoking as an important goal. ${ }^{14}$

Famously tied to lung cancer, smoking affects nearly every organ of the body; it contributes to all forms of cancer, respiratory diseases, cardiovascular diseases, diabetes, immune and autoimmune disorders, adverse reproductive effects, and eye disease. Given the rise in smoking in the developing world, it has been estimated that it will cause 10 million deaths per year in 2030-making it the single biggest contributor to higher mortality. ${ }^{15}$ In the developed world, public health campaigns against smoking have been seen as overwhelmingly successful given the rapid reduction in smoking. In 1998, the largest civil litigation settlement in US history was the Tobacco Master Settlement Agreement (MSA) between four major cigarette producers (Philip Morris Inc., R. J. Reynolds, Brown \& Williamson and Lorillard) and the attorney generals of 46 US states. The states argued that the tobacco companies were liable for the tobacco-related healthcare costs that the states had absorbed. This settlement has provided over $\$ 100$ billion to state governments and is indebted to pay $\$ 246$ billion over 25 years. While the initial spirit of the settlement was to fund tobacco related healthcare and anti-smoking campaigns, most states use the settlement money to fund a variety of public services. ${ }^{16}$ 
However, two provisions of the settlement are that the companies cease in certain kinds of tobacco marketing practices and that monies are to be used to fund the anti-smoking non-profit organization now called Truth Initiative (formerly the American Legacy Foundation). This agency, along with the CDC, has been at the forefront of creating innovative public health campaigns to stop smoking in the US. The "Truth" campaign, first tried in Florida and funded by the Truth Initiative, centers around creating an anti-smoking culture among the young, and it has been largely documented as both having a far-reaching exposure and fostering anti-smoking attitudes among them. ${ }^{17}$ The CDC's 2012 campaign "Tips from Former Smokers" is reported to have driven 1.6 million to try to quit smoking. ${ }^{18}$ In these advertisements, former smokers with extraordinarily evident disabilities discuss their lives and smoking habits. In one ad, a man named Bill sits open-shirted on a bed with a clear heart surgery scar visible on his chest, the stump from his amputated leg exposed (the prosthesis sitting close to his knee). Bill tells us, "If you smoke with diabetes, plan for amputation, kidney failure, heart surgery...or all three." ${ }^{19}$ A study published in The Lancet that documented the effectiveness of this campaign noted:

The Tips campaign was the first, national, mass-media antismoking initiative to be funded by the US Government. It reached nearly $80 \%$ of US smokers and was associated with a $12 \%$ relative increase in quit attempts within a nationally representative cohort. Based on the absolute increase in quit attempts of $3.7 \%$, the public health effect of Tips was substantial, with an estimated 1.64 million quit attempts made and 220,000 smokers abstinent at the campaign's culmination. Millions of non-smokers reported talking to smokers during the Tips campaign about the dangers of smoking, with many referring friends and family to cessation services. Our results show the effectiveness and public health outcomes of a national campaign using hard-hitting messages. ${ }^{20}$

The sea change in public opinion on smoking has allowed for numerous bans on smoking in countries and states. In 2004, Ireland became the first country to ban smoking statewide in all workplaces. Following this ban, Norway (2004), New Zealand (2004), Italy (2005), Scotland (2006), Wales, (2007), Northern Ireland (2007), England (2007), India (2008) Brazil (2011), and Russia (2014) all have introduced workplace smoking bans. France (2008) and Spain (2011) announced bans on smoking in public places. ${ }^{21}$ In 2015, Beijing even announced a workplace and public area ban on smoking, which is noteworthy given that China is the world's largest tobacco consumer with approximately 300 million smokers. ${ }^{22}$ Not only have many workplaces, restaurants, and shops gone smoke free, even outside smoking has been increasingly banned or restricted tightly. Many university systems in the US have smoke-free campuses, and hospitals are increasingly banning outside smoking. 


\section{The good health imperative}

One feature of the ACA is to permit offering incentives and penalties around health behaviors, an initiative championed by right-leaning politicians and advocacy groups. Insurers can charge up to $50 \%$ higher premiums for smokers. States may ban or limit these premiums. However, states may not provide a subsidy if the surcharges exist. ${ }^{23}$ Yet protesting penalties is rare because of the overwhelming conviction of their value. Increasingly employers, insurance companies, and even states, are encouraging this "stick" approach over the "carrot" of free tobacco cessation programs. One option that many employers use is simply a direct monthly charge. Washington State's public employees' insurance plan charges a $\$ 25$ monthly surcharge for smokers and any covered family members. ${ }^{24}$ Blue Cross Blue Shield of North Carolina surcharges for smokers went from $\$ 45$ to $\$ 75$ a month over 6 years. ${ }^{25}$ The surcharges are not consistent across states or companies and often present the greatest challenges to long-term smokers and the poor. Tobacco surcharges, used as a stick to punish smokers, are becoming more common despite little evidence of the efficacy of these fees. Contemporary evidence shows greater efficacy for carrot incentives, such as bonuses for quitting, and it is only these incentives that are associated with higher rates of smoking cessation. ${ }^{26}$

A blurry line exists between what is an incentive under the ACA and what is a surcharge or penalty. If I receive a lower insurance premium because I am within what is considered by a BMI table to be a healthy weight, does that mean I am receiving an incentive, or are those colleagues of mine who do not lie in this range receiving a penalty in the form of higher insurance premiums? Moreover, is it not another way of charging for pre-existing conditions if I must go through biometric screening to obtain a lower-cost plan?

The Equal Employment Opportunity Commission (EEOC) cited concerns with the fairness of incentive programs under the American with Disabilities Act. But Republican-led support for the concept of wellness programs pushed back against the EEOC's concern over the private company Honeywell's use of biometric screening in 2014. In 2015 Representative John Kline (Republican-Minnesota), chairman of the Education and the Workforce Committee, introduced the legislation H.R.1189-Preserving Employee Wellness Programs Act which overrules the EEOC and allows employers to engage in wellness programs. Kline says that:

Employee wellness programs not only help control the cost of health insurance, but they also promote healthy lifestyles. Remarkably, executive overreach by the EEOC is actually punishing employers for offering wellness plans. Congress must take action to rein in this agency and provide the certainty necessary for more Americans to enjoy the benefits of these innovative health programs. ${ }^{27}$

Wellness has increasingly become the hallmark of proper approaches to healthcare. Smoking is not the only barrier to creating well employees. Alcohol abuse and obesity are also highlighted as the other main contributors to increased healthcare costs. 
It is these three factors in tandem that are seen as creating important barriers to a well society. On some level, one can intuit the connection-alcohol is a similarly consumed item and also has addictive qualities; insofar as obesity is a result of overeating, one might see it likewise as something to restrict. On many other fronts, it seems curious to draw this connection, since one cannot give up eating as one can give up smoking. Alcohol is not evidently a toxin in all amounts for all persons. It seems the main reason to draw the comparison is that both excessive drinking and obesity are seen as preventable conditions, and that there are strong correlations between obesity and alcohol abuse and higher incidences of illness, disability, and reduced longevity.

Health problems associated with alcohol are more complex to analyze than cigarettes since, unlike cigarettes, it is not, ceteris paribus, always bad for the individual's well-being. Some amount of alcohol might be benign or even beneficial for some people; studies vary on exactly what the health benefits of moderate alcohol consumption might be and if this can be generalized for all persons. Moderate alcohol consumption has been linked to a risk reduction in dementia, osteoporosis, atherosclerosis, myocardial infraction, and strokes. Moderate drinkers also outlive heavy alcohol drinkers and teetotalers. ${ }^{28}$ However, public health research also links any amount of alcohol consumption with an increased rate of cancer which is magnified if the individual also smokes or is overweight, thus drawing a tighter parallel with smoking, which is seen always as a detriment to health..$^{29}$

A dissimilarity between drinking and smoking is that public health officials argue that negative health consequences of alcohol abuse also go beyond what affects the body directly, from violence to risky sexual behavior. ${ }^{30}$ The WHO's report of the negative consequences of alcohol abuse ranges from diseases to a myriad of individual, familial, and social harms:

Alcohol is a cause of noncommunicable diseases, including cancers, cardiovascular diseases and liver diseases; communicable diseases, increasing the risks of HIV/AIDS, tuberculosis and community-acquired pneumonia; and all types of intentional and unintentional injury, including homicides and suicides. Alcohol harms people other than the drinker, whether through violence on the street, domestic violence in the family, or simply using government resources, notably through the costs of providing healthcare, unemployment and incapacity benefits, and dealing with crime and disorder. ${ }^{31}$

While the jury is still out regarding whether or not some alcohol consumption might be beneficial for one's health, consensus exists that excessive drinking is deleterious to one's longevity, good physical health, and the social body.

The third partner to smoking and drinking iis the growing attention to overweight and obesity. At first glance, including fat people as a group needing intervention seems like a category mistake. Smoking and drinking are 


\section{The good health imperative}

behaviors, whereas fatness is a state. Studies that document the adverse effects of higher weight do not provide as clear correlations as smoking and excess drinking do with disease and reduced longevity. Critical discussion exists about the focus on weight as an important measure of health. ${ }^{32}$ Recent data on women's weight suggests that obesity has plateaued in the last decade and that there might not be an "epidemic" of obesity. ${ }^{33}$ The data on mortality and weight has been varied, many having a U-shaped relation between BMI and mortality where the very thin and the very large are at risk and the moderately overweight living the longest. ${ }^{34}$

Despite this debate, the behaviors that are linked with increased weight are themselves clearly risk factors in poor health: overconsumption of sugars, alcohol, processed food, and fatty meats, under-consumption of vegetables, lean proteins, and fruit, and little physical activity are associated with the rise in overweight and obesity. Even if individuals are not overweight or obese, if they engage in these poor health behaviors, they are at greater risk to have the associated illnesses. Heart disease, hypertension, diabetes, sleep apnea, asthma, fatty liver disease, osteoarthritis, and polycystic ovary disease are related to obesity and have shown improvement when individuals have lost weight. ${ }^{35}$ Given these concerns and the rising rate of obesity over the last several decades, there has been a strong push to consider obesity a public health crisis. This went so far that in 2009, former United States Surgeon Generals' David Satcher and Richard Carmona called obesity a threat to national security. ${ }^{36}$ Able-bodied young men and women are in increasingly limited supply to defend the country given the rise in obesity and correlated poor health outcomes. First lady Michelle Obama made combating childhood obesity her signature program, with her Let's Move organization hoping to end childhood obesity within a generation. (One philosophy article even argued that the overweight are a special burden on the environment. ${ }^{37}$ )

\section{The cost of smokers, drinkers, and the fat}

The comparison to smoking provides the theoretical framework needed to justify a war against obesity and campaigns to limit alcohol consumption. As noted above, anti-smoking movements in the US and Europe are victories for public health advocates. ${ }^{38}$ The war against smoking encouraged a wide-spread change in what was originally a pleasurable, socially-accepted, and even celebrated pastime. Therefore, the reasoning goes that if we could use this model against other bad health habits, e.g., excessive alcohol consumption and obesity, we could reap similar gains.

Alcohol consumption is the highest in Europe, where the average of about three drinks a day for adults has remained steady for a decade. ${ }^{39}$ Obesity also remains stubbornly difficult to combat. While many positive health outcomes arise for obese persons who lose weight safely, diets almost universally fail. Study after study, in the debate about what diets are the most effective, finds that overall dieting is extremely ineffective in securing 
long-term weight loss. ${ }^{40}$ The failure of diets might be more deleterious than simply not being effective. One study argued

...the potential benefits of dieting on long-term weight outcomes are minimal, the potential benefits of dieting on long-term health outcomes are not clearly or consistently demonstrated, and the potential harms of weight cycling, although not definitively demonstrated, are a clear source of concern. The benefits of dieting are simply too small and the potential harms of dieting are too large for it to be recommended as a safe and effective treatment for obesity. ${ }^{41}$

It remains murky if the kind of success found in changes in smoking rates can easily be replicated in the other two areas of behavioral change. ${ }^{42}$ However, one might conclude that the problem is that the right practice (i.e., a program, medicine, incentive, or penalty) has not yet been devised. Once it is found, public health will make a big move forward.

Another argument for why wellness must be promoted is the claim that the unhealthy are costly to society as a whole. It is rare to read a piece of journalism or an academic report on the disease and premature death associated with smoking, drinking, and the behaviors associated with overweight and obesity without reading about the tremendous economic cost of treating such poor health outcomes. In the US there is the cost to taxpayers in the form of Medicare and Medicaid, the cost to employers in lost wages and increased healthcare costs if they include healthcare as a benefit, and the cost to families. There is even concern in the case of the overweight and obese about costs associated with jet fuel and other economic costs. ${ }^{43}$

On one level such an argument seems unequivocal when it comes to the socioeconomic costs, not the personal or familial costs of poor health habits. The World Health Organization in 2011 reported that the cost of smoking was $2.1 \%-3.4 \%$ of gross domestic product (GDP) in Australia, $1.3 \%-2.2 \%$ of GDP in Canada, and $1.4 \%-1.6 \%$ of GDP in the United States. ${ }^{44} \mathrm{~A}$ study looking just at the costs of drinking in the United States in 2006 found that the cost was, for that year alone, $\$ 223.5$ billion. Of this, $\$ 170.7$ billion, $76.4 \%$, was caused by binge drinking. "Overall, $\$ 94.2$ billion $(42.1 \%)$ of the total economic cost of excessive alcohol use was borne by government, including federal, state, and local government agencies, while almost as much $\$ 92.9$ billion $(41.5 \%)$ was borne by excessive drinkers and their family members." ${ }^{45}$ After all, it is family members who are left to pick up the pieces of lost jobs, lost wages, extra healthcare, rehab, and legal fees.

Studies about the costs of obesity vary widely—often by billions of dollars. A review article trying to piece together these costs by analyzing high quality studies stated that "we estimated that the annual direct medical cost of overweight is approximately $\$ 266$ higher, and the incremental cost of obesity $\$ 1723$ higher, than that of normal-weight persons." 46 Trying to consider these costs in the US alone, the study argued that "If only 
'nationally representative' studies had been used for this analysis, the aggregate national cost of overweight would be $\$ 48.2$ billion and obesity would be $\$ 122$ billion (i.e. $\$ 170.2$ billion total or $7.1 \%$ of healthcare spending in 2008)." " The authors cautioned that this was based in studies with wide ranges of costs. However, the authors felt the study was able to conclude with some certainty that "the results suggest that the financial burden of obesity is at least two to three times greater in the USA than in other developed countries" and that although the study did not investigate the cost-effectiveness of treatments, "they do provide data that can be used, together with economic analyses of interventions, to estimate how much of the cost of weight-related illnesses could be saved." 48

Yet the idea that smokers, drunks, and the obese are economically costly is not clear. The economic argument, if one separates it from discussions of the value of health, is that there are a certain set of behaviors-smoking, abuse of alcohol, poor food consumption, and low activity-that are correlated to expensive diseases that will likely continue to be even costlier. Since these behaviors are preventable and modifiable, it would be better for society's economic well-being if the individuals engaged in those behaviors changed their lifestyles. This argument seems so obvious it is usually not even stated, simply presenting the costs is seen as sufficient to convince the population of the need for change.

A modicum of scrutiny makes it hard to find the economic argument entirely convincing. Some controversy surrounds just how to think about such costs. The clearest habit that causes poor health, smoking, can be tracked with monies spent on what are likely smoking-related diseases. Since smoking reduces longevity and since the elderly are very costly, smokers might be very good for reducing taxpayer expenditures. ${ }^{49}$ Assuredly, smoking is highly correlated with costly illnesses, but smokers also die earlier than non-smokers, as do the obese and heavy drinkers. The costs to society of the diseases of old age far exceed the costs of cancer and heart disease. While more expensive medication and treatments for cancer and heart disease will likely be developed, elderly ill individuals often require 24-7 care and can often live for years post diagnosis with Alzheimer's. ${ }^{50}$ One could argue that the familial costs, say children without parents to raise them, is a socially borne economic cost that is a result of poor health habits. But on the other hand, long-lived parents are often a huge economic drain on families.

The longer one lives, the costlier one becomes, since even older people in good health contribute little to tax revenue while drawing upon social security and government healthcare. Cigarettes and alcohol also produce significant tax revenue for states and countries, a factor rarely cited when smoking is seen as an overall economic cost. The US legislation against tobacco companies has also been an extraordinary boon to state revenue. ${ }^{51}$ Thus, if the economic argument is meant to be that overall one's cost to society is greater if one has poor health habits, this seems hard to find definitively true. Long lived persons are not a boon to state revenues but 
typically a drain. Longevity is by no means a money maker for society. A healthy long-lived person may cost exponentially more than a smoker with cancer. Smokers are less likely to use pensions and social security as long as non-smokers. Even considering lost time in productivity due to smoking related illnesses, it does not seem necessarily accurate that reducing poor health habits will necessarily reduce spending. Instead, it seems likely the opposite will occur; as individuals live longer and contract the illnesses of old age and have long lives post work.

Since the economic argument is so often mixed with the moral argument about the importance of health, it is important to ask if it is actually appropriate to see economic costs as a reason that can stand alone for reducing bad health habits. If the appeal is to the cost to society as a whole over the course of one's life, there seems to be no definitive argument to be made for promoting healthy behavior. If the cost is to corporate wealth, then there is an argument to be made. After all, reducing healthcare spending that corporations are obligated to spend would be a benefit, as would less work time lost to illness and disease. However, studies trying to track wellness initiatives in companies tend to find that the benefit is not so much the benefit of healthier employees, but rather moving costs in the form of fees and penalties to those that already are unhealthy. ${ }^{52}$ The savings post-ACA in the US thus mirrors the savings pre-ACA-the less the employer pays for the employee's healthcare, the better. If pre-ACA it was not having health insurance, post-ACA it is increasingly moving costs to the least well employees, justified by the idea that these are "incentives" or "sticks" to get the fat and the smokers in shape.

Of course, the desire to have a long life is not, for the individual, about one's social cost. Yet it is worth underlining that the rhetoric of the good health imperative often throws in the financial cost of poor health, as if good health and longevity were costless if not actually money-generating. It is undoubtedly a financial benefit to my employer if I am rarely ill and use little from my employment supplemented health insurance, but it is not so clear that my good health makes me overall less costly to society than my poor health would. In a neoliberal capitalist economy focused tightly on generating money for economic concerns (as will be discussed more fully in Chapter 5), it is hard to see why a society would want to foster very longlived persons. Rather, modifying health habits must appeal to our sense of the inherent value of life and the value of health insofar as it makes life better and longer.

\section{The good health imperative}

What I call in this text the "good health imperative" is not a new concept. Certainly, the value of health and the fear of illness shape human experience. As Pascal writes, "Man is but a reed, the most feeble thing in nature; but he is a thinking reed. The entire universe need not arm itself to crush him. A vapour, a drop of water suffices to kill him.. ${ }^{53}$ I could die today of everything: 


\section{The good health imperative}

from someone texting while driving to poisoned food, from a brain aneurism to, as one says in the United States, an "active" shooter. So much of life's absurd ways of dying are outside of one's sphere of control. Those things that I can control, that could help better my resistances to illness or violence, are natural for me to try, such as monitoring and improving my behavior. The good health imperative works not just from a position of human fragility and fear, but also, importantly, from a position of increasing knowledges and technologies where fragility becomes something one can and should overcome.

Above, it was noted that the move toward prevention is seen as a move away from an illness-centered model toward a wellness-centered model. Techniques of managing the body and bodies of the social whole come to the forefront. In contrast, after contemplating the fragility of human life, Pascal calls upon the reader to contemplate the powerlessness of the human condition and the nobility of thought. Rather than extending into time and space, as pursuing good health encourages, we should thoughtfully reflect:

But, if the universe were to crush him, man would still be more noble than that which killed him, because he knows that he dies and the advantage which the universe has over him; the universe knows nothing of this. All our dignity consists, then, in thought. By it we must elevate ourselves, and not by space and time which we cannot fill. Let us endeavour, then, to think well; this is the principle of morality. ${ }^{54}$

For the good health imperative, by contrast, one's improvement is not mental or spiritual, but rather a matter of one's embodiment. Its call to arms is not "consider your soul" but "attend to one's mortal coil carefully."

Other terms have been used to encapsulate this contemporary move toward seeing health promotion as a moral demand. Concerns over the individual well-being of persons who have bad health and the social well-being of a society composed of people who fail to maximize their health foster the sense that something should be done to promote a population that is healthier. The idea of "healthism" has been discussed for decades in English-language literature.$^{55}$ Healthism is, like racism or sexism, the idea that one's health is a measure of one's value. Often considered to be the most-valued part of one's existence, healthism celebrates behaviors, policies, attitudes, and philosophies that espouse health promotion. A 1980 paper by Robert Crawford describes his understanding of healthism as "the preoccupation with personal health as a primary-often the primary-focus for definition and achievement of well-being; a goal which is to be attained primarily through the modification of life styles, with or without therapeutic help." ${ }^{56}$ Crawford draws attention toward how the positive attention toward health is based in a classist ideology of self-promotion and individual duty over social, political, and structural disparities that truly underline good health for all.

Crawford highlights how in the 1970s largely white middle and upperclass persons grew increasingly interested in health as a lifestyle. Running became something for everyone, rather than just for athletes, and attention 
to diet, exercise, and emotional well-being became personal projects to be attended to as seriously as one's career and family. He highlights two main trends: "holistic" and "self-care." Both movements see individuals as the focal point of healthy change, not the medical field, social services, or the community. While these "healthists" acknowledge that many health problems have origins outside individuals, such as the average fare at a fast-food restaurant, "since these problems are also behavioral, solutions are seen to lie within the realm of individual choice." ${ }^{77}$ One can know about the poor-quality food and possibly even lobby or advocate for better fast food, and hence it is individuals who are the locus of control over their health.

One of the most forceful features of healthism is this focus on choices: choices one makes about one's body, one's purchases, one's behavior toward one's body, and one's time. One does not blame a dog for its obesity or its moral cowardice, but one can blame the individual human for failing to make proper choices. Contemporary health promotion policies enshrine this focus that better health is primarily a matter of getting people to choose well. The National Prevention and Health Promotion strategy calls this part of its plan "Empowered People" as it notes that:

Although policies and programs can make healthy options available, people still have the responsibility to make healthy choices. People are empowered when they have the knowledge, ability, resources, and motivation to identify and make healthy choices. When people are empowered, they are able to take an active role in improving their health, support their families and friends in making healthy choices, and lead community change. ${ }^{58}$

The proposals that follow include making activity more accessible (such as safe stairwells, safe places to walk in dangerous communities), increasing the dissemination of basic health information, and making sure the community is involved in healthy living promotion. All seem eminently reasonable. But the idea of "empowering" individuals to make the right choices suggests that it is the individual that is the main point of change. Instead of providing the funds and resources and altering the community for the better, the individuals should be "empowered" to change it themselves.

Crawford's explanation of the individual as the locus of choice model is defended now some thirty-plus years later in US government strategy. Some concerns of healthists go against current medical advice, often citing their freedom of choice as grounds. Holism is often seen as an alternative to mainstream medicine, perhaps even opposed to it. The children of holism can be found in various movements that define some aspects of what is healthy in strong opposition to well-received and well-researched medical advice-such as certain diets and the anti-vaccination movement. These movements focus on the centrality of choice, a limited comprehension of statistics, partial information, and often skepticism about the quality of medical advice because of a sense that there are non-health related political plays truly motivating common medical recommendations. 


\section{The good health imperative}

Yet it is difficult to think about how someone could be empowered according to the above definition and ever make the unhealthy choice. Indeed, what one would hope to do with those espousing unhealthy practices (such as refusing vaccination) is to help empower them through education. The debate between something like the anti-vaccination movement and the pro-vaccination movement is one about just what is the healthiest, not that one should do what is unhealthy as a matter of personal whim. Would one with proper information ever do anything other than "identify and make healthy choices"? In the collection Against Health, Richard Klein explores the difficulty of thinking outside of healthism:

To be against health is to utter a sharp stupidity because, almost by definition, we cannot be against health. The very concept of health implies a positive value that one cannot but choose, as when Socrates argues that one can only choose the good. What is bad may be chosen only when it is a better evil, as in cutting off your arm to save your life. ${ }^{59}$

We certainly acknowledge the difficulties the poor face in affording good quality food and having time and safe spaces in which to exercise. Perhaps the desire for overeating, smoking, and drinking are expressions of lives with few affordable pleasures. But such tales should impel us to make the world such that this is not the case for these people. If they could, these individuals would not just want to be healthy; the good health imperative suggests they would rightly want to make themselves healthier.

Crawford notes that what healthism really promotes is praising and blaming individuals for how they manage their health. In so doing, healthism "functions as dominant ideology, contributing to the protection of the social order from the examination, critique, and restructuring which would threaten those who benefit from the malaise, misery, and deaths of others." ${ }^{60}$ If I am to be praised for proper attention to my health-eating well, exercising, ceasing smoking and excessive drinking, it follows that those who fail to do these activities are to be blamed for their health. This protects the social order and fails to even question why white, middle-class, well-educated persons like myself are in such a position to easily engage in such activities and others are not. If my only task in seeing health disparities is to "empower" the poor, then when they fail to immediately seize upon new options, I can abandon them to their "chosen" fate.

In her book Weighing In: Obesity, Food Justice, and the Limits of Capitalism, Julie Guthman reviews a contemporary version of healthism. She takes to task the ideology of health being fundamentally a matter of good and bad choices. The increased focus on providing better choices in the fight against obesity obscures much more fundamental political issues that lie beneath the growth of overweight and obesity:

Healthism makes personal health attainment the highest goal, sees poor health outcomes as a result of behaviors, and conflates personal 
practices of self-care with empowerment and good citizenship. Recall that healthism is itself a reflection of neoliberal norms of governance, since it concedes the rollback of public-sector responsibility for supporting and protecting the health of all and instead places responsibility on individuals for their own health outcomes. In doing so, healthism tends to neglect-or write off-those without the means or the desire to share in these norms. ${ }^{61}$

Guthman notes that the demonization of fat people becomes more and more normal since one can see them as immoral, not just as violating aesthetic standards. Most clever 12-year-olds can express the conviction that one should be evaluated based on one's character rather than one's looks and explain that beauty is a contingent standard (even if those same children will be subjected to the difficulties of restrictive beauty norms). It seems to be the expression of a foolish, petulant, and insecure teenager to judge someone on her looks. But to judge someone for being fat-well, that seems more acceptable as long as one uses health, and not beauty, as the justification. Much like a liar or thief, the fat woman clearly has made the wrong set of choices in life.

Guthman points out that those who have, for historical reasons, had the best health, the best access to excellent medical care, and the time for attention to diet and exercise are the healthiest. The poor are the least healthy. This is because of systematic, long-term disenfranchisement. She strongly criticizes the alternative food movement for encouraging this kind of attitude that one simply must provide the poor with organic food markets (and not say, well-paid labor, excellent education, safety and the host of other structural reasons why the well-to-do are also well) so they can now make the proper choices. What this kind of choice-based ideology fosters is not just the blaming of the unhealthy, but the moral uprightness of the healthy. "Bolstered by the ideology of healthism, which suggests a lack of personal responsibility and knowledge among the fat, those who are not fat are positioned as more responsible and knowing, regardless of what, if anything, they do to be thin." ${ }^{62}$ Since the thin, the nonsmokers, those with moderation in their habits, or those with good biometric screenings are now moral exemplars, they are even more justified to be the guides to the unhealthy in their movement toward better selves.

As Guthman writes, the patina of doing what is best might have a dark underbelly; its moral authority justifies inequalities, promotes special interests, and often even fails to really promote health overall. Jonathan M Metzl explains that "even the most cursory examination of health demonstrates how the term is used to make moral judgements, convey prejudice, sell products, or even to exclude whole groups of persons from healthcare." ${ }^{63}$ The most celebrated feature of the ACA was coverage to all persons, even those with pre-existing conditions. However, by allowing for higher rates for the unhealthy, the ACA has effectively continued to allow the unhealthy and the poor take on the greater burden of paying for their healthcare. This 


\section{The good health imperative}

ACA policy is both legitimate and even morally praise-worthy if it is at the level of the individual that good health occurs. The state, the health insurance companies, and corporations are responsible to create "empowered" choosers-individuals who have the capacity to make the correct healthy decisions. Individuals can then be appropriately penalized or praised for their choices.

Carl Cederström and André Spicer refer to what above has been called healthism as "biomorality," or "the moral demand to be happy and healthy." " ${ }^{4}$ If biomorality is the overall philosophy underpinning healthism, the command is "the wellness command." This command is both perceived as coming from external forces-by the health insurance industry and public health programs, and also from internal forces. The guilt felt at failing to quit smoking or overeating is a personal guilt-a sense that one did not take care of oneself correctly. Even if no one else benefits or is harmed, there is a sense that one didn't do right by the best interests of one's own body. If one has properly interiorized the wellness command, then one sees knowledge as tied to one's personal actions. If I am to be praised for good health, any illness is potentially a scarlet letter testifying to my lack of dedication to my well-being.

Spicer and Cederström see biomorality as tied to a larger cultural neurosis of the self as something to constantly be perfected in all aspects-citing how trend-setting companies are bringing in not just gyms, smoking cessation programs, and health coaching, but also "productivity gurus." Google and Zappos want their employees not just to be healthy, but also to be their very best selves. What this implies is that at any moment, one is not one's very best self. One can always improve. Spicer and Cederström say "What is crucial is not what you have achieved, but what you can become. What counts is your potential self, not your actual self." ${ }^{65}$ Like many in the US, my lower cost of healthcare is part of a wellness program called "The Partnership Promise." I have to undergo biometric testing and health coaching. While I am by their measurements reasonably healthy, I am encouraged in my required health coaching phone conversations, to have "wellness goals." I suggested once that since I have other interests than my health, why should I have other goals? Wouldn't just continuing to do what I am doing be sufficient? I was told that everyone can be healthier, that one can always do more for one's health. Finally, the coach said, "but don't you want to be better?"

Medical knowledge-the well-documented knowledge about smoking, excessive drinking, and obesity to the less well-documented knowledge about stress and unhappiness-becomes moral knowledge. Not wanting to live up to the idea of being better seems not just immoral but also simply unreasonable. "We go from a medical statement that smoking is bad for your health, to the shorthand version that smoking is bad; followed, finally, by the assertion that smokers are bad." ${ }^{66}$ As one can always be a more moral person, one can also always be a healthier person and one can always fall away from good behavior and become a worse person. If I can 
always be better, it implies, I am constantly in danger of becoming worse. If some healthy behavior-exercising, eating fruits and vegetables-is good, then more healthy behavior would be better. While Spicer and Cederström note that often the kind of moralizing to create an ever better self can be distanced from any kind of empirical research or critical thought; one is encouraged to "find one's inner purpose," to be "mindful." ${ }^{67}$ These ideologies have no empirical research demonstrating that they produce "better" people, rather they serve, as healthism does, to praise those on the top and chastise those on the bottom and thus to preserve the status quo.

But, in the case of health, often the recommendations are based in medical knowledge. After all, we do know that smoking is bad for one's health. Given the growth of work documenting certain behaviors and certain kinds of consumption with certain outcomes, it might indeed be the case that I could always be better, that is, healthier. I certainly could eat better, or be more directed in my exercise, or drink less. Since, like the rest of living things, I am aging, my body naturally presents me with more challenges that need to be monitored. The decaying body-my new arthritis and difficulty sleeping are simply now signs of exactly why I do need to have wellness goals. I can indeed become better.

While this book expands upon these discussions of healthism and biomorality, I call this "the good health imperative" rather than healthism or biomorality. The good health imperative is a moral injunction that calls individuals to better themselves and to make sure others can engage in the same practices. My guilt at failing to maximize my health extends to guilt at failing to provide a world where everyone is capable of such self-directed change. My last health coaching call allowed me to repeat my thought that perhaps I don't need goals, as I seem to be acceptably healthy. I have no interest in becoming an athlete or doing any kind of special event like a marathon. The coach suggested that perhaps my goal should be to get other people I know to engage with me in my healthy practices. "You could help others!" the coach cried.

Aside from people who cannot be healthy due to barriers (educational, economic, physical, environmental), why might "empowered" people continue to overdrink, overeat, and smoke? What stops us from being our "best" selves? Is it pleasure? The delight of a nice cigarette after dinner, the lovely enjoyment of a very full stomach, being drunk, and hanging out with friends instead of exercising - these pleasures interrupt and get in the way of the constant clear awareness and self-control needed to be healthy in a society awash with excess. In Immanuel Kant's ethical duties to oneself, one can see a similar imperative to treat oneself as an end-in-itself-to not use oneself as a means simply for passing pleasure, but to make the most of oneself and to be worthy of one's status as a rational being. Unlike Spicer and Cederström's equation of happiness and health, Kant's duties to oneself are not dependent upon happiness, but upon rational self-fulfillment. While most of the social and public health injunctions to be healthy do include the argument that one will be happier, the grounds for enforcing good health 
habits must, at least initially, obtain its grounds beyond happiness since it is obvious that many are content and even take great pleasure in their behaviors.

Even in the absence of happiness in poor health, changing habits is a difficult and restrictive process. The imperative toward health argues that one should do such behaviors even if one doesn't enjoy them. Thinking of unhealthy excessive consumption as a sign of addiction assumes that not all pleasurable moments can be read as moments of "real" happiness. If I get pleasure from drug use, that pleasure must be "false" happiness, since drugs are bad for one's health. Thus, one is able to continue to see healthy behavior as being properly happy despite the seeming pleasure of those that engage in excessive behavior. This kind of pleasure is not real pleasure, but signs of a mental health disorder. Klein argues that America's love affair with health promotion revives "an old strain of American Puritanism...this new morality views the least indulgence in adult pleasure as the sign of a nascent habit on the way to becoming a dangerous compulsion." ${ }^{\prime 8}$ This morality is not without empirical ammunition. Adult pleasures-smoking, drinking, drug use, and sex-can be dangerous. Their danger may be integral to their pleasure. Now, even our most childish pleasures are labeled sources of possible compulsion, such as concerns over sugary treats, fried foods, and too much time playing video games.

Yet the good health imperative does not leave us with duties as free from happiness as Kant's ethical duties might long term. It provides the promise of future, better pleasure. If one does enjoy excessive, unhealthy practices, then one should learn to see that unhealthy enjoyment as part of the problem. Perhaps it is addiction and not "proper" enjoyment. The guilt that functions in disobeying the good health imperative is not just that one probably should put down that beer, but that one would feel so much better if one did. Future, far better enjoyment, is to be had at the end of one's journey to wellness. In his famous wager, Pascal admits that while it would be better to believe in God if God does exist, this doesn't foster true belief in most people. What he then counsels is to act as if one has such faith, which means to do what true believers do-go to church, read the Bible. Hopefully faith will come. ${ }^{69}$ Likewise, the good health imperative tells one to go to the gym, to stop eating that stuffed crust pizza washed down with Coke-to do as the good do and hopefully, like them, your pleasures will be properly molded to enjoying the good. As Pascal lectures the cautious non-believer who might say "But this is what I am afraid of" Afraid of what? Of losing one's pleasures, one's life before health? Pascal's more spiritual advice is "And why? What have you to lose?" ${ }^{70}$ Indeed, what does one have to lose but poor health?

The good health imperative calls us to promote our own health as a matter of personal choice and thus personal responsibility. It also calls on us to pursue the health of others. The critique of healthism is often an examination of how healthism obscures the causes of poor health. Guthman, Klein, Crawford, and Metzl are not against health and for illness (a false 
distinction discussed further in Chapter 2). Rather their criticisms center on how the moralizing about individual health obfuscates the systemic issues-political, historical, economic, and environmental-that underline health disparities. The focus on health as a matter of individual know-how and gumption creates a myth that celebrates the status quo, justifies in some cases reducing spending on public healthcare, and draws attention away from the enormous profits that are being made at the expense of those with poor health from food workers' untenable conditions around the world, toxic pollution that causes innumerable illnesses, and poverty that creates inhospitable conditions for thriving. If it is just a matter of individuals being "empowered" then these issues appear secondary instead of rightly primary.

$S$ Lochlann Jain and Barabara Ehrenreich take to task both the foolishness and the real cruelty of the rhetoric surrounding cancer survivors who "fight" their disease through strength of their will. By suggesting that one can battle cancer with good thoughts, laughter, and the right mindset one initiates extraordinary shame in those who don't succeed. If cancer is winning, is it because I didn't want to live enough? Did I fail to be positive in the right manner ${ }^{71}$ Ehrenrich speaks of her own experience having advanced breast cancer in her attack on the cult of positive thinking in Bright-Sided. ${ }^{72}$ She writes of how survivors became so enchanted with the (completely unproven) idea that one could will cancer away that some called it a "gift" that lets one realize one's true purpose and live one's true life. ${ }^{73}$ One can immediately understand the person with cancer clinging to such ideas, hoping that good thoughts and the will to live will suffice. But the cruelty is the implication that those who die, well, they just didn't "work" hard enough.

Ehrenreich and Jain argue against such childish mythical thinking and argue for real approaches to cancer treatment. Jain notes that if we turned our attention away from "hope" and made inroads into combating the environmental causes of cancer we could do better for others.

What if, instead of some broad and grammatically, if not affectively meaningless aim as marching and riding "for hope," fundraises attempted to ban any one of the thousands of known carcinogens in legal use? What if we walked, ran, swam, road not for hope, but against PAH, MTBE, BPA or any other common carcinogen? Such an effort would require naming the problem rather than the symptom, and recognizing how we are all implicated. It would require that we invest in cancer culture not as a node of sentimentality but as a basic fact of American life. ${ }^{74}$

Guthman draws extensive attention to food policy and the way in which food is not just consumed but produced. In the case of obesity instead of cancer, Guthman notes how pollution has caused our bodies to alter, making obesity more likely for individuals today than in earlier times. "Given the profits that have been made on the binge and purge economy and the inattention to regulating body-changing pollution, it is clear that we must 
turn away from the current obsession with individual consumption habits and body sizes and engage more deeply with policy." 75 Anti-healthism is not anti-health. As Guthman notes, the focus on policy, Ehrenreich's work against the cult of positive thinking, and Jain's discussion of toxic pollution are themselves part of the good health imperative. Anti-healthism is against false pseudo-science of the causes of poor health and the pointless politically conservative tendency to blame the unhealthy for their ailments.

Health, properly diagnosed and understood, is rarely itself critiqued. The debate is about just what is health, what promotes it, what excesses are allowable, and what excesses should be avoided. A certain sense of the naturalness of our desire for health and longevity pervades most discussions on health. But just how do we experience health? How do we experience modifying our behaviors if we understand them to be deleterious to our well-being? How do we experience the good health imperative? Chapter 2 discusses phenomenologies of health and illness to better explore the nuances of what we understand as health.

\section{Notes}

1 Ronald Lee, "The Demographic Transition: Three Centuries of Fundamental Change," Journal of Economic Perspectives 17, no. 4 (2003): 167-190.

2 Caleb E. Finch, "Evolution of the Human Lifespan and Diseases of Aging: Roles of Infection, Inflammation, and Nutrition," Proceedings of the National Academy of the Science of the United States of America 107, no. 1 (April 2009): 1718-1724. John Bongaarts, "How Long Will We Live?," Population and Development Review 32, no. 4 (2006): 605-628.

3 Barack Obama, "Remarks by the President on the Affordable Care Act and the New Patients' Bill of Rights,” Whitehouse.gov, June 22, 2010, https://www. whitehouse.gov/the-press-office/remarks-president-affordable-care-act-and-newpatients-bill-rights

4 King v. Burwell, 576 _US (4 $4^{\text {th }}$ Cir. 2015).

5 Katherine G. Carman, Christine Eibner, and Susan M. Paddock, "Trends in Health Insurance Enrollment, 2013-15” Health Affairs 35, no. 6 (June 2015): 1044-1048.

6 Susannah Luthi, "Biden takes first step toward bolstering Obamacare.” Politico, January28,2021.https://www.politico.com/news/2021/01/28/joe-biden-bolsteringobamacare-health-care-463287.

7 Peter Scarborough et al., "The Economic Burden of Ill Health Due to Diet, Physical Inactivity, Smoking, Alcohol and Obesity in the UK: An Update to 2006-07 NHS Costs," Journal of Public Health 33, no. 4 (November 2011): $527-535$.

8 Surgeon General, “National Prevention Strategy,” National Prevention Council, June 16, 2011, http://www.surgeongeneral.gov/priorities/prevention/strategy/ report.pdf

9 The others are "Injury and Violence Free Living," "Reproductive and Sexual Health," and "Mental and Emotional Well-Being." Surgeon General, "National Prevention Strategy," 7.

10 American Public Health Association, "Prevention and Public Health Fund: Dedicated to Improving our Nation's Public Health,” APHA, Feb 19, 2015, https://www.apha.org/ /media/files/pdf/topics/aca/2015_pphf_fact_sheet.ashx

11 Surgeon General, "National Prevention Strategy," 7. 
12 Surgeon General, “The Health Consequences of Smoking-50 Years of Progress: A Report of the Surgeon General," US Department of Health and Human Services, 2014, http://www.surgeongeneral.gov/library/reports/50-years-ofprogress/exec-summary.pdf

13 Judy Peres, "No Clear Link between Passive Smoking and Lung Cancer," JNCI Journal of the National Cancer Institute 105, no. 24 (June 2013): 1844-1846.

14 World Health Organization, "The World Health Report 2003: Shaping the Future," (Geneva: 2003), 91.

15 Prabhat Jha and Frank J. Chaloupka, Curbing the Epidemic-Governments and the Economics of Tobacco Control (Washington, DC: World Bank, 1999).

16 Carolyn Kaster, "15 Years Later, Where Did All The Cigarette Money Go?," NPR,lastmodifiedOctober13,2013,http://www.npr.org/2013/10/13/233449505/15years-later-where-did-all-the-cigarette-money-go.

17 Matthew C. Farrelly et al., "Getting To the Truth: Evaluating National Tobacco Countermarketing Campaigns," American Journal of Public Health 92, no. 6 (2002): 901-907.

18 Tim McAfee et al., "Effect of the First Federally Funded US Antismoking National Media Campaign," The Lancet 382, no. 9909 (2013): 2003-2011.

19 “Campaign Resources," CDC.gov, last modified October 23, 2015, http://www. cdc.gov/tobacco/campaign/tips/resources/index.html.

20 McAfee et al., "First Federally Funded US Antismoking National Media Campaign," 2007.

21 Patrick Freyne, Ronan McGreevy, “A History of Smoking Bans: Ireland and the World." The Irish Times, last modified March 22, 2014, http://www.irishtimes. com/life-and-style/a-history-of-smoking-bans-ireland-and-theworld-1.1733943.

22 Megha Rajagopalan, "China Capital to Roll out Tough Anti-smoking Laws," Reuters, May 31, 2015, http://www.reuters.com/article/us-china-smoking-idUS KBN0OF0WN20150531\#YMg7ZIWmpFz5EHkz.97.

23 Reed Abselsonnove, “The Smokers' Surcharge." New York Times, Nov. 16, 2011. http://www.nytimes.com/2011/11/17/health/policy/smokers-penalizedwith-health-insurance-premiums.html?_r=1 And The Public Health Law Center at Hamline University published the following fact sheet. http://publichealthlawcenter.org/sites/default/files/resources/tclc-fs-aca-\&-tobacco-control-2014_0.pdf

24 "PEBB - Tobacco Use Premium Surcharge," Washington State Health Care Authority, 2015, http://www.hca.wa.gov/pebb/Pages/surcharge_tobacco.aspx.

25 "Martin Marietta Personal Choice Benefits Program Medical Plan Summary Plan Description 2015," BCBSNC.com, last modified January 2015, http://www. bcbsnc.com/assets/members/public/pdf/martinmarietta/summary_plan_description.pdf

"Martin Marietta Personal Choice Benefits Program Medical Plan Summary Plan Description 2009," BCBSNC.com, last modified January 2009, http://www. bcbsnc.com/assets/members/public/pdf/martinmarietta/FAQ.pdf

26 Kevin G. Volpp et al., "A Randomized, Controlled Trial of Financial Incentives for Smoking Cessation,” New England Journal of Medicine 360, no. 7 (2009): 699-709.

Scott D. Halpern et al., "Randomized Trial of Four Financial-Incentive Programs for Smoking Cessation," New England Journal of Medicine 372, no. 22 (2015): 2108-2117.

27 "Senate, House Leaders Introduce Bill to Provide Certainty to Employers Offering Innovative Employee Wellness Programs," Education and The Workforce Committee, Congress, USA, March 3, 2015. http://edworkforce. house.gov/news/documentsingle.aspx? DocumentID=398504.

28 A. Poli et al., "Moderate Alcohol Use and Health: A Consensus Document," Nutrition, Metabolism and Cardiovascular Diseases 23, no. 6 (2013): 487-504. 


\section{The good health imperative}

29 Surgeon General, “The Health Consequences of Smoking,"

30 "Fact Sheets-Alcohol Use and Your Health," CDC.gov, last modified December 17, 2015, http://www.cdc.gov/alcohol/fact-sheets/alcohol-use.htm.

31 World Health Organization, The Regional Office for Europe, Alcohol in the European Union: Consumption, Harm and Policy Approaches, ed. Peter Anderson, Lars Møller, and Gauden Galea. Denmark, 2012. http://www.euro. who.int/_data/assets/pdf_file/0003/160680/e96457.pdf?ua=1.

32 Wayt W. Gibbs, “Obesity: An Overblown Epidemic?," Scientific American 292, no. 6 (2005): 70-77, doi:10.1038/scientificamerican0605-70.

Gina Bari Kolata, Rethinking Thin: The New Science of Weight Loss-and the Myths and Realities of Dieting (New York: Picador/Farrar, Straus and Giroux, 2008).

Gordon R. Mitchell and Kathleen M. McTigue, "The US Obesity 'Epidemic': Metaphor, Method, or Madness?," Social Epistemology 21, no. 4 (2007): 391423, doi:10.1080/02691720701746557.

J. Eric Oliver, Fat Politics: The Real Story behind America's Obesity Epidemic (Oxford: Oxford University Press, 2006).

33 Katherine M Flegal, "Prevalence and Trends in Obesity among US Adults, 19992008," Journal of the American Medical Association 303, no. 3 (2010): 239.

34 Ancel Keys, Seven Countries: A Multivariate Analysis of Death and Coronary Heart Disease (Cambridge, MA: Harvard University Press, 1980).

A. Menotti et al., "Indexes of Obesity and All-Causes Mortality in Italian Epidemiologic Data," Preventive Medicine 22, no. 3 (1993): 293-303.

H.T. Waaler, "Height. Weight and Mortality the Norwegian Experience," Acta Medica Scandinavica 215, no. S679 (2009): 1-56.

35 S.D.H. Malnick and H. Knobler, “The Medical Complications of Obesity,” QJM: An International Journal of Medicine 99, no. 9 (2006): 565-579.

36 Penny Starr, "Health Experts Call Obesity a Threat to National Security," CNSNews.com, September 10, 2009, http://cnsnews.com/news/article/healthexperts-call-obesity-threat-national-security. (Satcher and Carmona both earn livings in their post surgeon general careers working for corporations, public health organizations, and universities that benefit from grants and investments surrounding weight-loss and obesity prevention.)

37 Philip J. Cafaro, Richard B. Primack, and Robert L. Zimdahl, “The Fat of the Land: Linking American Food Overconsumption, Obesity, and Biodiversity Loss," Journal of Agricultural and Environmental Ethics 19, no. 6 (2006): 541-561.

38 Sadik A. Khuder et al., "The Impact of a Smoking Ban on Hospital Admissions for Coronary Heart Disease," Preventive Medicine 45, no. 1 (2007): 3-8.

Valery Lemmens et al., "Effectiveness of Smoking Cessation Interventions among Adults: A Systematic Review of Reviews," European Journal of Cancer Prevention 17, no. 6 (2008): 535-544.

39 World Health Organization, "Alcohol in the European Union."

40 Deirdre K. Tobias et al, "Effect of Low-fat Diet Interventions versus Other Diet Interventions on Long-term Weight Change in Adults: A Systematic Review and Meta-analysis," The Lancet Diabetes \& Endocrinology 3, no. 12 (2015): 968-979.

41 Traci A. Mann et al., "Medicare's Search for Effective Obesity Treatments: Diets Are Not the Answer," American Psychologist 62, no. 3 (2007): 230.

42 Sarah Boseley, "Low-carb and Mediterranean Diets Beat Low-fat Plans for Losing Weight-Report," The Guardian, October 29, 2015, http://www.theguardian. com/lifeandstyle/2015/oct/30/low-fat-diets-slammed-major-new-report.

43 Ross Hammond and Levine Ruth, "The Economic Impact of Obesity in the United States," Diabetes, Metabolic Syndrome and Obesity: Targets and Therapy DMSOTT, no. 3 (2010): 285-295. 
44 World Health Organization, Tobacco Free Initiative, Assessment of the Economic Costs of Smoking, By Ayda Yurekli and Anne-Marie Perucic, 2011. http://apps. who.int/iris/bitstream/10665/44596/1/9789241501576_eng.pdf.

45 Ellen E. Bouchery et al., "Economic Costs of Excessive Alcohol Consumption in the US, 2006." American Journal of Preventive Medicine 41, no. 5 (November 5, 2011): 516-524, 520, doi:10.1016/s0749-3797(11)00692-1.

46 A. G. Tsai, D. F. Williamson, and H. A. Glick, "Direct Medical Cost of Overweight and Obesity in the USA: A Quantitative Systematic Review," Obesity Reviews 12, no. 1 (2010): 50-61, doi:10.1111/j.1467-789x.2009.00708.x.

47 Tsai, Williamson, and Glick, "Direct Medical Cost," 50-61.

48 Tsai, Williamson, and Glick, "Direct Medical Cost," 58.

49 "Smokers and the Obese Cheaper to Care for, Study Shows," New York Times (London), February 05,2008, http://www.nytimes.com/2008/02/05/health/05ihtobese.1.9748884.html.

Daniel Fisher, "Fewer Smokers Means Higher Taxpayer Costs, Study Finds," Forbes, November 29, 2012, http://www.forbes.com/sites/danielfisher/2012/11/29/fewer-smokers-means-higher-taxpayer-costs-studyfinds/\#46ca1deb2d6f

50 Gina Kolata, "Costs for Dementia Care Far Exceeding Other Diseases, Study Finds," New York Times, October 26, 2015, http://www.nytimes.com/2015/10/27/ health/costs-for-dementia-care-far-exceeding-other-diseases-study-finds.html?_r=1.

51 Daniel Fisher, "Fewer Smokers Means Higher Taxpayer Costs"

52 Jill R. Horwitz, Brenna D. Kelly and John DiNardo, "Wellness Incentives in the Workplace: Cost Savings through Cost Shifting to Unhealthy Workers," Health Affairs 32, no. 3 (2013): 468-472, doi:10.1377/hlthaff.2012.0683.

53 Blaise Pascal, Pensées, \#347. Project Gutenberg, http://www.gutenberg.org/ files/18269/18269-h/18269-h.htm

54 Pascal, Pensées.

55 An early mention of the idea of healthism is found in a reference to Thomas Szasz's critique of psychiatry as in "mental healthism" (Orla McDonnell, "Thomas Sasz's The Myth of Mental Illness," in Fiona Dukelow \& Orla O’Donovan, eds. Mobilising Classics: Reading Radical Writing in Ireland. Manchester University Press: Manchester, UK, 1966.) An even earlier comment in the Journal of the American Medical Association finds the idea of healthism in a critique of the homeopath James Munyon as espousing a religious kind of zeal for health. "But, with a supreme disregard for the petty troubles of business, Munyon announces in large advertisements that he is "organizing a Hope Cult, whose mission is to preach Health-ism, Hope-ism and Love-ism." Talk about optimism!" (“Current Comment," JAMA, 56, no. 4 (1911), 1042.

56 Robert Crawford. "Healthism and the Medicalization of Everyday Life," International Journal of Health Services, 10, no. 3 (1980): 368.

57 Crawford, "Healthism and the Medicalization of Everyday Life," 368.

58 Surgeon General, "National Prevention Strategy," 24.

59 Richard Klein, "What Is Health and How Do You Get It?," in Against Health: How Health Became the New Morality, eds. Jonathan Metzl and Anna Rutherford Kirkland (New York: New York University Press, 2010), 15.

60 Crawford, "Healthism," 369.

61 Julie Guthman, Weighing In: Obesity, Food Justice, and the Limits of Capitalism. (Berkeley: University of California Press, 2011), 193.

62 Guthman, Weighing In, 193.

63 Jonathan Metzl, "Introduction: Why Against Health?," in Against Health: How Health Became the New Morality eds. Jonathan Metzl and Anna Rutherford Kirkland (New York: New York University Press, 2010), 2.

64 Carl Cederström and Andre Spicer, The Wellness Syndrome (Polity, 2015), 5.

65 Cederström and Spicer, The Wellness Syndrome, 21. 


\section{The good health imperative}

66 Cederström and Spicer, The Wellness Syndrome, 29.

67 Cederström and Spicer, The Wellness Syndrome, 22-26.

68 Klein, "What is Health," 19-20.

69 "True. But at least learn your inability to believe, since reason brings you to this, and yet you cannot believe. Endeavour then to convince yourself, not by increase of proofs of God, but by the abatement of your passions. You would like to attain faith, and do not know the way; you would like to cure yourself of unbelief, and ask the remedy for it. Learn of those who have been bound like you, and who now stake all their possessions. These are people who know the way which you would follow, and who are cured of an ill of which you would be cured. Follow the way by which they began; by acting as if they believed, taking the holy water, having masses said, etc. Even this will naturally make you believe, and deaden your acuteness.- "But this is what I am afraid of."-And why? What have you to lose?" Pascal, Pensées, \#233.

70 Pascal, Pensées.

71 Jain S. Lochlann, "Be Prepared," in Against Health: How Health Became the New Morality, eds. Jonathan Metzl and Anna Rutherford Kirkland (New York: New York University Press, 2010), 171. Crawford, "Healthism," 369.

72 Barbara Ehrenreich, Bright-sided: How the Relentless Promotion of Positive Thinking Has Undermined America (New York: Metropolitan Books, 2009).

73 Ehrenreich, Bright-sided, 29.

74 Jain, “Be Prepared,”181.

75 Guthman, Weighing In, 195.

\section{Bibliography}

Abselsonnove, Reed. “The Smokers’ Surcharge.” New York Times, November 16, 2011. http://www.nytimes.com/2011/11/17/health/policy/smokers-penalized-with-health-insurance-premiums.html?_r=1.

American Public Health Association. "Prevention and Public Health Fund: Dedicated to Improving our Nation's Public Health.” APHA.org, 2015. https://www.apha. org/ /media/files/pdf/topics/aca/2015_pphf_fact_sheet.ashx.

Boseley, Sarah. "Low-carb and Mediterranean Diets Beat Low-fat Plans for Losing Weight - Report." The Guardian, October 29, 2015. http://www.theguardian. com/lifeandstyle/2015/oct/30/low-fat-diets-slammed-major-new-report.

Bouchery, Ellen E., Henrick J. Harwwod, Jeffrey J. Sacks, Carol J. Simon, and Robert D. Brewer. "Economic Costs of Excessive Alcohol Consumption in the US, 2006." American Journal of Preventive Medicine 41, no. 5 (November 5, 2011): 516-524. https://doi.org/10.1016/S0749-3797(11)00692-1.

Cafaro, Philip J., Richard B. Primack, and Robert L. Zimdahl. "The Fat of the Land: Linking American Food Overconsumption, Obesity, and Biodiversity Loss." Journal of Agricultural and Environmental Ethics 19, no. 6 (2006): 541-561. https://doi.org/10.1007/s10806-006-9008-7.

“Campaign Resources.” CDC.gov. Last modified October 23, 2015. http://www. cdc.gov/tobacco/campaign/tips/resources/index.html.

Carman, Katherine G., Christine Eibner, and Susan M. Paddock. "Trends in Health Insurance Enrollment, 2013-15." Health Affairs 35, no. 6 (June 2015): 10441048. https://doi.org/10.1377/hlthaff.2015.0266.

Cederström, Carl, and Andre Spicer. The Wellness Syndrome. Cambridge: Polity Press, 2015. 
Crawford, Robert. "Healthism and the Medicalization of Everyday Life." International Journal of Health Services 10, no. 3 (1980): 365-388. https://doi. org/10.2190/3H2H-3XJN-3KAY-G9NY.

Ehrenreich, Barbara. Bright-sided: How the Relentless Promotion of Positive Thinking Has Undermined America. New York: Metropolitan Books, 2009.

Farrelly, Matthew C., Cheryl G. Healton, Kevin C. Davis, Peter Messeri, James C. Hersey, and M. Lyndon Haviland. "Getting To the Truth: Evaluating National Tobacco Countermarketing Campaigns.” American Journal of Public Health 92, no. 6 (2002): 901-907. https://doi.org/10.2105/AJPH.92.6.901.

Finch, Caleb E. "Evolution of the Human Lifespan and Diseases of Aging: Roles of Infection, Inflammation, and Nutrition." Proceedings of the National Academy of the Science of the United States of America 107, no. 1 (April 2009): 1718-1724. https://doi.org/10.1073/pnas.0909606106.

Fisher, Daniel. “Fewer Smokers Means Higher Taxpayer Costs, Study Finds.” Forbes, November 29, 2012. http://www.forbes.com/sites/danielfisher/2012/11/29/ fewer-smokers-means-higher-taxpayer-costs-study-finds/\#46ca1deb2d6f.

Flegal, Katherine M. "Prevalence and Trends in Obesity Among US Adults, 19992008." Journal of the American Medical Association 303, no. 3 (2010): 235-241. https://doi.org/10.1001/jama.2009.2014.

Freyne, Patrick, and Ronan McGreevy. "A History of Smoking Bans: Ireland and the World.” The Irish Times, Last modified March 22, 2014. http://www.irishtimes. com/life-and-style/a-history-of-smoking-bans-ireland-and-the-world-1.1733943.

Gibbs, Wayt W. “Obesity: An Overblown Epidemic?” Scientific American 292, no. 6 (2005): 70-77. https://doi.org/10.1038/scientificamerican0605-70.

Guthman, Julie. Weighing In: Obesity, Food Justice, and the Limits of Capitalism. Berkeley: University of California Press, 2011.

Halpern, Scott D., Benjamin French, Dylan S. Small, Kathryn Saulsgiver, Michael O. Harhay, Janet Audrain-Mcgovern, George Loewenstein et al. "Randomized Trial of Four Financial-Incentive Programs for Smoking Cessation.” New England Journal of Medicine 372, no. 22 (2015): 2108-2117. https://doi.org/10.1056/NEJMoa1414293.

Hammond, Ross, and Levine Ruth. "The Economic Impact of Obesity in the United States." Diabetes, Metabolic Syndrome and Obesity: Targets and Therapy (DMSOTT) no. 3 (2010): 285-295. https://doi.org/10.2147/DMSOTT.S7384.

Horwitz, Jill R., Brenna D. Kelly and John DiNardo. "Wellness Incentives in the Workplace: Cost Savings through Cost Shifting to Unhealthy Workers." Health Affairs 32, no. 3 (2013): 468-472. https://doi.org/10.1377/hlthaff.2012.0683.

Jha, Prabhat, and Frank J. Chaloupka. Curbing the Epidemic - Governments and the Economics of Tobacco Control. Washington, DC: World Bank, 1999.

Kaster, Carolyn. "15 Years Later, Where Did All The Cigarette Money Go?" NPR. Last modified October 13, 2013. http://www.npr.org/2013/10/13/233449505/15years-later-where-did-all-the-cigarette-money-go.

Keys, Ancel. Seven Countries: A Multivariate Analysis of Death and Coronary Heart Disease. Cambridge, MA: Harvard University Press, 1980.

Khuder, Sadik A., Sheryl Milz, Timothy Jordan, James Price, Kathi Silvestri, and Pam Butler. "The Impact of a Smoking Ban on Hospital Admissions for Coronary Heart Disease." Preventive Medicine 45, no. 1 (2007): 3-8. https://doi.org/10.1016/j. ypmed.2007.03.011.

Klein, Richard. "What Is Health and How Do You Get It? " In Against Health: How Health Became the New Morality, edited by Jonathan Metzl and Anna Kirkland, 15-25. New York: New York University Press, 2010. 


\section{The good health imperative}

Kolata, Gina. "Costs for Dementia Care Far Exceeding Other Diseases, Study Finds.” New York Times, October 26, 2015. http:/www.nytimes.com/2015/10/27/health/ costs-for-dementia-care-far-exceeding-other-diseases-study-finds.html?.

Kolata, Gina Bari. Rethinking Thin: The New Science of Weight Loss-and the Myths and Realities of Dieting. New York: Picador/Farrar, Straus and Giroux, 2007.

Lee, Ronald. "The Demographic Transition: Three Centuries of Fundamental Change.” Journal of Economic Perspectives 17, no. 4 (2003): 167-190. https:// doi.org/10.1257/089533003772034943.

Lemmens, Valery, Anke Oenema, Inge Knut, Klepp Knut, and Johannes Brug. "Effectiveness of Smoking Cessation Interventions among Adults: A Systematic Review of Reviews." European Journal of Cancer Prevention 17, no. 6 (2008): 535-544. https://doi.org/10.1097/CEJ.0b013e3282f75e48.

Lochlann, Jain S. "Be Prepared.” In Against Health: How Health Became the New Morality, edited by Jonathan Metzl and Anna Kirkland, 170-182. New York: New York University Press, 2010.

Luthi, Susannah. "Biden Takes First Step toward Bolstering Obamacare." Politico, January 28, 2021. https:/www.politico.com/news/2021/01/28/ joe-biden-bolstering-obamacare-health-care-463287.

Malnick, S.D.H., and H. Knobler. "The Medical Complications of Obesity." QJM: An International Journal of Medicine 99, no. 9 (2006): 565-579. https://doi. org/10.1093/qjmed/hcl085.

Mann, Traci A., Janet Tomiyama, Erika Westling, Ann-Marie Lew, Barbra Samuels, and Jason Chatman. "Medicare's Search for Effective Obesity Treatments: Diets Are Not the Answer." American Psychologist 62, no. 3 (2007): 220-233. http:// dx.doi.org/10.1037/0003-066X.62.3.220.

McAfee, Tim, Kevin C Davis, Robert L Alexander, Terry F Pechacek, and Rebecca Bunnell. "Effect of the First Federally Funded US Antismoking National Media Campaign.” The Lancet 382, no. 9909 (2013): 2003-2011. https://doi. org/10.1016/S0140-6736(13)61686-4.

McDonnell, Orla. "Thomas Szasz's The Myth of Mental Illness.” In Mobilising Classics: Reading Radical Writing in Ireland, edited by Fiona Dukelow \& Orla O’Donovan, 88-104. Manchester University Press: Manchester, UK, 1966.

Menotti, A., G.C. Descovich, M. Lanti, A. Spagnolo, A. Dormi, and F. Seccareccia. "Indexes of Obesity and All-Causes Mortality in Italian Epidemiologic Data." Preventive Medicine 22, no. 3 (1993): 293-303. https://doi.org/10.1006/ pmed.1993.1024.

Metzl, Jonathan. "Introduction: Why Against Health." In Against Health: How Health Became the New Morality, edited by Jonathan Metzl and Anna Kirkland, 1-12. New York: New York University Press, 2010.

Mitchell, Gordon R., and Kathleen M. McTigue. "The US Obesity "Epidemic": Metaphor, Method, or Madness?" Social Epistemology 21, no. 4 (2007): 391423. https://doi.org/10.1080/02691720701746557.

Obama, Barack. "Remarks by the President on the Affordable Care Act and the New Patients' Bill of Rights.” Whitehouse.gov. June 22, 2010. https://www. whitehouse.gov/the-press-office/remarks-president-affordable-care-act-and-newpatients-bill-rights.

Oliver, J. Eric. Fat Politics: The Real Story Behind America's Obesity Epidemic. Oxford: Oxford University Press, 2006.

Pascal, Blaise. Pensées, \#347. Project Gutenberg. (n.d.) http://www.gutenberg.org/ files/18269/18269-h/18269-h.htm. 
"PEBB-Tobacco Use Premium Surcharge." Washington State Health Care Authority. 2015. http://www.hca.wa.gov/pebb/Pages/surcharge_tobacco.aspx.

Peres, Judy. "No Clear Link Between Passive Smoking and Lung Cancer." JNCI Journal of the National Cancer Institute 105, no. 24 (June 2013): 1844-1846. https://doi.org/10.1093/jnci/djt365.

Poli, A., F. Marangoni, A. Avogaro, G. Barba, S. Bellentani, M. Bucci, R. Cambieri et al. "Moderate Alcohol Use and Health: A Consensus Document." Nutrition, Metabolism and Cardiovascular Diseases 23, no. 6 (2013): 487-504. https://doi. org/10.1016/j.numecd.2013.02.007.

Rajagopalan, Megha. "China Capital to Roll out Tough Anti-smoking Laws." Reuters, May 31, 2015. http://www.reuters.com/article/ us-china-smoking-idUSKBN0OF0WN20150531\#YMg7ZIWmpFz5EHkz.97.

Scarborough, P., P. Bhatnagar, K. K. Wickramasinghe, S. Allender, C. Foster, and M. Rayner. "The Economic Burden of Ill Health Due to Diet, Physical Inactivity, Smoking, Alcohol and Obesity in the UK: an Update to 2006-07 NHS Costs." Journal of Public Health 33, no. 4 (November 2011): 527-535. https://doi. org/10.1093/pubmed/fdr033.

New York Times, "Smokers and the Obese Cheaper to Care for, Study Shows." London, February 5, 2008. http://www.nytimes.com/2008/02/05/health/05iht-obese.1.9748884.html

Starr, Penny. "Health Experts Call Obesity A Threat to National Security." CNSNews.com, September 10, 2009. http://cnsnews.com/news/article/ health-experts-call-obesity-threat-national-security.

Surgeon General. "National Prevention Strategy." National Prevention Council, June 16, 2011. http://www.surgeongeneral.gov/priorities/preventions/strategy/ report.pdf.

Surgeon General. "The Health Consequences of Smoking-50 Years of Progress: A Report of the Surgeon General." US Department of Health and Human Services. 2014. http://www.surgeongeneral.gov/library/reports/50-years-of-progress/ exec-summary.pdf.

Tobias, Deirdre K., Mu Chen, Joann E. Manson, David S. Ludwig, Walter Willett, and Frank B. Hu. "Effect of Low-fat Diet Interventions versus Other Diet Interventions on Long-term Weight Change in Adults: A Systematic Review and Meta-analysis." The Lancet Diabetes \& Endocrinology 3, no. 12 (2015): 968979. https://doi.org/10.1016/S2213-8587(15)00367-8.

Tsai, A. G., D. F. Williamson, and H. A. Glick. "Direct Medical Cost of Overweight and Obesity in the USA: A Quantitative Systematic Review." Obesity Reviews 12, no. 1 (2010): 50-61. https://doi.org/10.1111/j.1467-789x.2009.00708.x.

United States Court of Appeals 4th Circuit. King v. Burwell, 2015.

Volpp, Kevin G., Andrea B. Troxel, Mark V. Pauly, Henry A. Glick, Andrea Puig, David A. Asch, Robert Galvin et al. "A Randomized, Controlled Trial of Financial Incentives for Smoking Cessation.” New England Journal of Medicine 360, no. 7 (2009): 699-709. https://doi.org/10.1056/NEJMsa0806819.

Waaler, H.T. "Height, Weight and Mortality the Norwegian Experience." Acta Medica Scandinavica 215, no. S679 (2009): 1-56. https://doi. org/10.1111/j.0954-6820.1984.tb12901.x.

World Health Organization. "The World Health Report 2003: Shaping the Future." Geneva, 2003. 


\section{A critical phenomenology of health and illness}

One of the challenges to thinking about the good health imperative is to ask the question: what is health? Is health something only medical professionals can determine? Does health always "feel" a certain way? One argument is that health is an objective, medical matter. To know what health is, consult the most current and well-documented research in the health sciences. We know that medical tests can reveal a disease that isn't perceived by the individual. An all-too-common experience that journalist and activist Barbara Ehrenreich reports is the surprise at receiving a diagnosis of an aggressive form of breast cancer despite feeling well and having followed normal health recommendations-"I have no known risk factors, there was no breast cancer in the family, I'd had my babies relatively young and nursed them both. I ate right, drank sparingly, worked out..." ${ }^{1}$ Much of our condition passes far beneath the level of conscious awareness. It is beneficial that I do not have to organize my breathing or remind my heart to beat or my stomach to digest food; however, this blindness to my own biological functioning also means that cancer can grow without my knowledge. Drew Leder discusses just how much of our body is truly absent from our consciousness-the stomach, kidneys, bone marrow, spleen, and liver all remain typically entirely hidden from our awareness. "Unlike the completed perception of the proprioceptive body, our inner body is marked by regional gaps, organs that although crucial for sustaining life, cannot be somesthetically perceived." ${ }^{2}$ Of course, in the case of a disorder, these hidden aspects of my body might give me signs indicating something is not normal, but it is also possible that they might not. To know my own condition appears to require the use of medical tools and the interpretation of the results. Health can be understood as a biological state of the body that may or may not present its wellness or illness to the individual's subjective awareness.

However, while the state of our bodies understood through the best current medical science is an important part of a discussion of health, it quickly seems that such a concept fails to really encompass what we understand as health. Someone who feels dreadful and is hardly able to make it through a day but passes every test as "healthy" may have met the clinical standard of health as judged by "passing" tests, but not health as an

DOI: $10.4324 / 9781003168676-2$ 
experience of something like wellness, or a lack of suffering. A man finds out at 65 that he has slow-growing prostate cancer. This cancer will not kill him, and the chances of him even experiencing any side effects are negligible. On one reading, he does have a disease, but since this illness does not affect his life in any determinable manner, it isn't existentially relevant for him. He might feel completely healthy. A woman, on the other hand, suffers from headaches and body pains that routinely disrupt her day, yet no test has found any source. We could also consider two women who each have a common cold. The professional triathlete finds the cold deeply disruptive to her future race, whereas the editor finds only mild discomfort. In short, while one might be able to declare some general truths about health's desirability, how one experiences health varies and cannot be understood only through what medical testing we currently have available. "Healthiness is—as is its opposite also- a totally individually made situation," writes Hubertus Tellenbach. ${ }^{3}$

In the standard dissemination of the good health imperative, health is often described as not having certain ailments, illnesses, physical limitations, and disabilities. The imperative prescribes activities to avoid them. One should eat healthily and be active so that one does not contract type II diabetes or heart disease. One should stop smoking so that one does not get lung cancer. One should avoid excessive alcohol abuse to avoid cirrhosis. In the promotion of better health, it might seem that wanting health is an obvious personal goal for everyone. But is this because of health or because of sickness? Does one desire to be healthy or does one really desire not to be sick? Some subjective states are desirable since they are perceived as positive-such as the joy at seeing an old friend. And some are obviously not desired-such as a stomachache. But health is trickier since it isn't clear if there is a positive subjective state called "health," as there is one we could label "joy" or "sickness."

Hans-Georg Gadamer argues that health is defined best as a kind of absence which makes it hard to define in itself. "Health does not actually present itself to us." ${ }^{4}$ Illness is what presents itself as an object, a Gegenstand, something to be addressed, quantified, measured, and mastered. We find this distinction in English-one says, "I have a cold" not "I am a cold." Illness can often stand opposed to myself and be a hindrance to my plans as so often common ailments like a bad cold throw one's life into mild disarray. Work is missed, dates are cancelled, and one cannot enjoy standard pleasures.

Health, on the contrary, does seem to produce a "general feeling of well-being" but is not a condition one can easily objectify. "This distinction exists in the English language. We say, "I am well" not "I have wellness." Wellness is indistinguishable from the self. I don't capture the state easily in-itself. Gadamer thinks the upshot of reflecting on health means we cannot grasp wellness as an object to be contemplated in the manner that one can discuss how it feels to have a fever. Health operates as a background state from which we attend to the other events, issues, desires, and 
ambitions we have in our lives. Unlike illness which directs us back to the body; health often takes us away from the body toward experiencing the world with others.

This chapter will describe health as a background state that permits extension in the world and with others. In this exploration, I will draw attention to how virtual elements of our situation, including our imagined futures, color both health and illness, and shape how we extend into the world. I consider the case of obesity as an example that is often understood as a condition that limits extension in the world; however, in order to understand such limitations, I argue that one must consider the cultural manner in which obesity is understood and situated in order to move from a phenomenology of health and illness to a critical phenomenology which expands beyond the individual situation to the complexity of our social situation. Finally, I conclude with a discussion of critical disability theory where disability is understood not as a matter of individual bodies, but a matter of the way in which those bodies are constituted in our society.

\section{Phenomenologies of illness and disease}

In order to address the manner in which one's experience and the health sciences interact, phenomenologists draw a distinction between illness and disease. Illness is experienced, whereas disease is what can be known through theoretical health sciences. One might have both an illness and a disease. One might have something that can be tested and understood through contemporary medical practice and one's experience might be also altered. Or, one might have a disease for which one has no experiential correlates, such as a slow-growing prostate cancer that is only known through testing. One might have an illness that presents no clear markers of a disease such as fibromyalgia, known only through symptoms and the treatments looking to alleviate symptoms. Or, one might have an illness for which no diagnosis is (yet) provided-struggling to express and have the medical community take one's experience seriously. While disease and illness are often conjoined, the value of having two categories allows for the rich and varied ways in which individuals experience diseases and helps provide better and more caring treatments. It also helps to better understand diseases that are greatly impacted or even caused by experiences, such as stress, and better allows one to address the virtual aspects of illness that are not subsumable to the concept of disease.

Illnesses caused by emotional and situational conditions demonstrate how often matters that extend beyond the individual's body permit health. An example of the close ties between the external and internal worlds of one's body is stress cardiomyopathy, also referred to as "broken heart syndrome":

[A] condition in which intense emotional or physical stress can cause rapid and severe heart muscle weakness (cardiomyopathy). This condition can occur following a variety of emotional stressors such as grief 
(e.g. death of a loved one), fear, extreme anger, and surprise. It can also occur following numerous physical stressors to the body such as stroke, seizure, difficulty breathing (such as a flare of asthma or emphysema), or significant bleeding. ${ }^{6}$

One can test for cardiomyopathy, but the stress that caused it cannot be so viewed through any kind of medical testing. One can speak in terms of causality, but the causality of stress cardiomyopathy is not the same as the causality behind a sprained ankle. Moreover, in order to understand the cause and to care for the patient, one must engage with an individual's life experience and not the body as an object.

If illness is only understood as identical to disease, then the body becomes the container of it. When stress is considered a factor in health, such as in the above example, it is often seen as something that "enters" the body and that should be eliminated, like an infection. However, this doesn't adequately capture the fact that stress cannot be investigated under a microscope or found with an $\mathrm{x}$-ray. One can track the effects of stress, but stress arises from a shifting complex of experiences including an individual's relationships, ambitions, and environment, as well as imagined futures. The agony of a broken heart is constituted in part by knowing that the beloved will no longer be there to shape one's future. One's habitual manner of envisioning the future has been broken.

The underlying problem with a natural model where the body is a thing that can be best understood by medical science is that it separates out the body that can be monitored from the body as it is lived. In what phenomenology calls the natural attitude, what frames experience, and thus also constitutes it, is invisible. For instance, I do not often attend to the fact that much of the way I understand myself and others is dependent upon the possibilities and the limits of the English language. When I learned a foreign language reasonably well, I encountered the curious fact that it might very well be that I have not ever considered certain emotive states, relationships, things, or even senses of time because of my native language. In the phenomenological attitude, I must bracket out my investments to try and highlight how I am really seeing the world, and it becomes clearer that my language is not a transparent tool that allows me to get to the truth of things, but rather something that partially shapes my experience.

In many cases, curing the body seems to be an objective, biological matter-is there a medication or operation that can end or delay the disease? However, these cases should not tempt us to forget that the cure is only sensible in a particular individual context. Cases like stress and cardiomyopathy remind us of this clearly. Even seemingly completely "objective" diseases such as cancer are not lived by each person in the same manner. Medical practice always is occurring in an existentialist frame-it is about certain, particular living individuals and their own unique situations. The seeming clarity of medical tests is easily disputed when one thinks about the first-person experience of being told one's test results. What should I do, 
as will be discussed in Chapter 7, if I find my fetus has a propensity for a certain disability? What course of action should I take if I find out I have a chronic illness? Life is inherently uncertain and the meaning of any medical test must be interpreted in context of the individual's particular situation.

One tendency is to try and separate my life as a body-the body that has this cold, that has this high blood pressure—and my "real" life-my family, friends, and work. But this separation doesn't make much sense, as it is only by means of this body that I can engage with others and with my work and hence why one cannot clearly draw divisions between the medical and lived body. Helen Fielding argues that the body as lived cannot be read like a medical chart because "the body we live is always enmeshed in varying degrees of ambiguity; it is the site of possibilities and potential relations that by definition can never all be actualized or even explicitly articulated." ${ }^{7}$ Part of the difficulty of grasping what defines health is that it is inseparable from the complexities of being a sentient being. Getting a bad result at the doctor's office produces fear, since even if the science of one's ailment is known to some degree of certainty, it remains a question how one will actually live with that disease. Hence, we need a method to discuss how the body is lived to get a sense of just what health and illness are.

This is not to dispute the value of scientific inquiries into promoting health and fighting illnesses. Douwe Tiemersma points out that medical interventions and prescriptions, "specialized and reductionistic as they may be," have greatly improved the lives of many. ${ }^{8}$ However, he cautions that the only way to understand the value of the health sciences is its connection to curing. One cannot understand the cure without thinking about the patient as a human, not simply as an object to be understood in the same way one might be curious to understand the position of the planets or the atomic weight of gold. For Tiemersma, this is why the health sciences cannot be part of the natural sciences. "Without this perspective medicine loses its own basis and vanishes among the natural and technical sciences. The human, curative intention is constitutive for medicine." ${ }^{9}$ There are sciences whose pursuit is simply out of interest-that is, one wishes to understand, say, the nature of matter or the origin of the universe as we know it. But health sciences do not operate in this context, since to introduce the idea of health is to introduce a human value. ${ }^{10}$ If one meets a doctor who studies cancer, one automatically assumes that the intention behind the study is to help cure, or at least better treat humans with cancer, and is not an intellectual curiosity about how cancer operates.

The challenge to trying to integrate experience is the variance subjective accounts provide. Who is to say that one account of one's experience with illness is more accurate than another? If one is committed to the validity of experience, it seems one is left in a kind of vague relativist approval of the importance of experience without any way of really continuing a critical discussion of it. What a critical phenomenology provides is a way to consider the relevance of experience thoughtfully. It examines not just first-person accounts of sensations of pains and pleasures, but also a way to include the 
manner in which moralities about how we care for our bodies, policies and laws about our bodies, and the way in which we are enculturated to see our bodies also affect our experiences of health and illness. This does not result in fixed dictates about health, but ongoing collaborative examinations that provide insight into how to think about health and illness as lived. Linda Fisher summarizes this point saying that phenomenology provides:

...the capacity to move from the singularity of the standard first-person narrative to an account that seeks to identify, describe, and analyze generalities and typical features of the experience as such, while examining how this experience resides within and intersects with the broader lifeworld. ${ }^{11}$

Phenomenology looks to acknowledge the relevance of the first-person perspective without collapsing into relativism. Above, Fisher discusses the idea of this work "intersecting" with the broader "lifeworld." A lifeworld here can be understood as how one's ideas of health are determined by the way health is meaningful for oneself based on one's social, cultural, and particular position in society.

The phenomenologist who set the standard for thinking critically about the body was Maurice Merleau-Ponty, who said in his first book-length work, The Structure of Behavior, that the body is the bearer of "a dialectic" that is negotiating the ambiguous and fluid experience of being alive. He writes, "All the problems seem to be eliminated: the relations of the soul and body-obscure as long as the body is treated in abstraction as a fragment of matter-are clarified when one sees in the body the bearer of a dialectic." ${ }^{12}$ Building off this quote, the standard objective medical model is to see the body as such an abstract "fragment of matter." But for a phenomenologist, we do not experience our bodies as "matter." I encounter my car as a material thing, and when the mechanic reports about trouble with engine these facts are about its objective constitution. But what my doctor says about the test results does not refer to the same kind of object. As a living thing, I do carry with me facts that are in every way physical and hidden from my subjective introspection-such as my blood pressure or glucose level-but also this information is only meaningful when understood in its relationship, its dialectic, between myself and my situation. No test can "find" anxiety about one's loved one, concern about one's job, or affection toward one's favorite writer even if these parts of one's lifeworld loom large in one's sense of what a life worth living is.

Literature inside and outside academia has focused on the importance of thinking seriously about our embodied condition. In Western philosophy, this is often juxtaposed with certain trends emerging from post-Cartesian philosophy. Famously in the Meditations, René Descartes drew a separation between the mind, or soul, and the body, arguing that they are distinct metaphysically. One can use this discussion to argue for the immortality of the soul and the death of the physical body in religious contexts, but 
more relevant for the contemporary Western epistemology and ethics is the philosophical tradition which considers "mental" discussions as separate from "physical" discussions. Thus, one can investigate Kant's categories of understanding and his ethics without needing to talk about the kinds of bodies that think such thoughts. One would thus refer to "subjects" rather than to "humans." To speak of humans is to refer, at least implicitly, to certain kinds of bodies. Many philosophers do not follow Descartes in thinking that the mental inhabits a different kind of reality from the physical, arguing that what we think of as mental content is indeed bodily. They are materialists insofar as they assume that with the death of the human body comes the death of the thinking subject, but they still conduct their philosophical work without believing that it is important to consider how the thinking thing is constituted by its lived body.

The move in phenomenology toward taking the body seriously might lead one to assume a kind of additive study where the phenomenologist is also interested in how the brain functions or how the digestive system operates. Despite phenomenology's insistence that one must take into account bodily being to contemplate thought, its approach to embodiment is not simply to study the body as a scientist would do and add this knowledge to philosophical insight. Indeed, Descartes himself was a dedicated scientist of the body-one of his earliest works being a study of the eye in the Optics. ${ }^{13}$ Knowing the workings of the brain and the body may be compelling, but phenomenology's focus is on the experiencing body. This would neither be how one thinks abstracted from how one lives, but also would not be how one is physically abstracted from how one thinks, feels, and interprets one's experience. Consider the previous examples regarding health. The science of a disease is of critical importance to those that currently have that disease and to those that may in the future. However, the very reason one has a science of diseases is because of the precarity of human life-that is, existential issues of birth, development, suffering, and death.

The "why me?" that passes the lips of anyone hearing a dismal diagnosis is not fully answered by learning the science of one's condition. The "why" refers not to a question about the body as an object understandable to some degree by medical science, but to what it is to be human-that is a thing whose existence extends ultimately, without desire or intent, to death. Tellenbach argues that health is about overcoming illness, which itself only makes sense within the backdrop of death. "And because life and death are very strongly connected, health is basically: overcoming illness." ${ }^{14}$ As one does not offer a healthy lifestyle prescription to a pebble, neither does one to a god. It is our eventual demise that makes the project of health relevant for us, and that demise is about being a sentient, thinking being not simply having a body. As Fisher argues "...health is defined in opposition to illness, as the absence of or resistance to this ever-threatening Other, the negative foregrounding and delineating the positive." ${ }^{15}$ The threat of suffering, perhaps death, of being abnormal, of no longer being able to do what one loves colors not just illness, but health as well. 


\section{Health as a being at home and being capable}

A few years ago I sprained my ankle, which was irritating. I couldn't find a good way to sleep and found hobbling around tiresome. However, as a professor it didn't really make that much of a difference for my life and long-term projects. If I were a professional athlete, such a common injury could end my career and could cause me to enter into a depression-trying to assess how to structure my now completely altered life. When speaking to an athlete about this example, she told me that she expects injuries and to work toward recovery. If she worried excessively about avoiding possible injuries, this would inhibit her performance. I found this quite different from how I relate to possible injuries; I would find it not surprising to live my entire life without ever needing rehabilitation for injuries. Thus, sprains are both more common and more disruptive for athletes. When Merleau-Ponty insists upon the body as a dialectic, he asserts that all thought requires the body as a ground to orientate it and provide it with its precondition for meaning. What the sense of what a sprain is depends upon the lived situation. When Gadamer discusses how health is a background state that permits the rest of living to occur, this highlights how the body also operates in the background as a horizon. It guarantees our normal activity and when it is disrupted we find ourselves uprooted. Merleau-Ponty writes that the body is a "latent horizon of our experiences, itself ceaselessly present prior to all determining thought." ${ }^{16}$ In health, the body is in the background, hidden from conscious awareness, and thus individuals can extend themselves into the world and busy themselves with projects. Leder describes how our body in its ecstatic extension toward the world "moves off to the side." ${ }^{17}$ The more I become engaged with a project, the less my bodily functioning comes to the forefront. Athletes in particular must allow their habitual styles of embodiment fade out of conscious awareness (including consciousness of the possibility of injury) in order to perform.

In illness, the breakdown of normal functioning reminds us of our body. Leder describes how pain places what he calls an "affective call" on the individual. ${ }^{18}$ In an example of a tennis player playing before pain and then after, Leder explores how the relationship to the world around him and his own body shift:

The feelings of wind, sweat, and breath, and effort placed no great affective demand on the tennis player. His attention was free to roam elsewhere despite strong bodily sensations. However, when the character of these changed from those of vigorous well-being to the unpleasant, it is as if a magnet had reserved poles, reorganizing the experiential field inward. ${ }^{19}$

When one's well-being is altered, an illness, a broken heart, a stressful situation at work, an ill friend, one is aware how much health as a background bodily state connects to what one intends to do, not just what one 
is doing at that moment. The future does not stretch out like a series of interesting possibilities to the depressed, but rather seems altogether unappealing. Hence why simply saying "oh look, there is so much to enjoy!" is at minimum unhelpful and at maximum hurtful. In depression, the desire to extend into the world, to think, to experience, and to be, is interrupted. One is trapped in the present, unable to make bodily what one might be able to grasp intellectually. Health and illness must be understood within the framework of the body as lived in order to grasp what is at stake for the individual.

In order to see what illness exposes, we must see how intentionality plays a role in how the body cannot be understood as disconnected from its situation, both in its real and virtual aspects. In the example of my ankle sprain, I quickly found all types of activities to be challenges that I never would have considered before, since my body was well habituated to move around in the world without my direct attention. David Morris notes that illness changes one's access to the world: "But in experiments, illness and disruptions, something pre-philosophical can intrude and testify against this subject-object distinction. Specifically, illness reveals itself not simply as an absence of the proper function of the body or its parts, but as a vividly experienced change in one's access to the world." ${ }^{20}$ What was injured was the unreflective "I can" of my body, and it was replaced by an "I cannot" of my normal activities. Many phenomenologists, such as Husserl and Merleau-Ponty, have described the corporeal (or bodily) "I can." This is a form of motor intentionality that is pre-personal in the sense that the individual has no personal knowledge of how the action is physically executed. The body can completely fade into the background, not because it is not relevant, but because it encompasses the entire experience. In habitual walking, I do not think about walking; I think about where I am going or what has been on my mind lately. But when I cannot walk, I realize that my object—going to the kitchen—was only possible with a body that could do so. Gadamer says "Health is not a condition one introspectively feels in oneself. Rather, it is a condition of being involved, of being in the world, of being together with one's fellow human beings, of active and rewarding engagement in one's everyday tasks." ${ }^{21}$ One can go out with friends, go for a walk, take care of one's children, and put in extra hours at a project. Illness disrupts such activities. When I'm ill, I often can't do my everyday activities. My body becomes a kind of thing that imposes itself between myself and my plans.

Merleau-Ponty argues that motor intentionality is actually the basis upon which later mental intentionality finds its ground. Merleau-Ponty thinks that the body's mute connection with the world precedes our conscious, cognitive manners of taking up the world: "In our opinion Husserl's originality lies beyond the notion of intentionality; it is to be found in the elaboration of this notion and in the discovery, beneath the intentionality of representation, of a deeper intentionality, which others have called existence." 22 First, I move and connect with the world, and upon this directional, 
instinctual level I find my conscious intentionality such as having an attitude, a conscious desire, or a plan. Thus, when Merleau-Ponty states that "Consciousness is in the first place not a matter of 'I think that' but of 'I can," he highlights that first we act in the world and use this to build our later abstract capacity to reason. ${ }^{23}$

Work in child development is interesting to consider from this perspective, limitations in early movement in cases of disease, disability, or abuse often are strongly correlated with difficulty taking up higher-order cognitive tasks. ${ }^{24} \mathrm{An}$ impediment to habitual ways of interacting with the world through illness exposes the need for motor intentionality for our other projects. In my ankle example, one must include not just the immediate thing I cannot do-walking without pain - but also the impact this had on my possible and virtual life. Getting to my office, driving, and teaching standing up, all became objects of uncertainty, when normally I would not think of these behaviors, but rather what I hoped to do at the office, what I was going to lecture about, or where I was going to drive. Merleau-Ponty describes this larger part of intentionality - toward the situation and world, both in its immediacy and in its possible worlds as the intentional arc.

Let us therefore say rather, borrowing a term from other works, that the life of consciousness-cognitive life, the life of desire or perceptual life-is subtended by an 'intentional arc' which projects round about us our past, our future, our human setting, our physical, ideological and moral situation, or rather which results in our being situated in all these respects. It is this intentional arc which brings about the unity of the senses, of intelligence, or sensibility and motility. And it is this which 'goes limp' in illness. ${ }^{25}$

In illness, the body does often appear as this type of thing since it is stopping me from doing those things my healthy background body permitted me to do. In illness, I no longer extend out into the world, but I collapse into myself. A specific illness does not affect every similar body in the same way since everyone's intentional arcs are not parallel. Since having a child, I dread common illnesses like a cold or flu, and suffer far more. There is not enough space to simply relax and get well, rather one has to figure out how to drag oneself through taking care of another person and in the process expose one's dependent as well to one's illness. If one has a precarious employment that requires consistent attendance, illness is likewise much more devastating than for someone who can take time off work and be assured of an income. From the phenomenological point of view, to suggest that objective illness (the condition of the body) and subjective illness (the stress that one has dependents or that one is worried about paying rent) are possible to distinguish is false.

Working between an acknowledgment of the role of the doctor and the experience of the patient, phenomenologist Fredrik Svenaeus argues that Martin Heidegger provides us with the most valuable way of thinking about how 
the lived body experiences health and illness and what happens when one's intentional arc "goes limp." Heidegger's idea of "Unheimlichkeit"—unhomelikeness-is key to Svenaeus' account of illness, and he argues that through a certain reading of this concept we can "understand how illness is experienced precisely as a not being at home in my own world." ${ }^{26}$ This is not only to associate illness with an anxious, uncanny sentiment, but it is also to elucidate how sickness changes one's attunement, one's background. The focus on home is important in Sveneaus' account. The idea of unheimlich in German presents a translation difficulty. In the typical translation, "uncanny," one retains the idea of the peculiarity of the unheimlich but loses the "heim" or "home" that is present in the German. This is an important association for the idea of attunement that shifts in illness. With Heidegger, there is an existential issue at hand, "an unfamiliarity with the world-the very world that is a part of my own being as a being-in-the-world." ${ }^{27}$ Being ill is not being-at-home, not being able to attend to the world or to allow one's embodied nature to fade into the background. In a similar vein, when one is in a foreign environment, all sorts of mundane activities which are thoughtless at home-moving from place to place, purchasing goods, consuming food-become difficult. As a tourist, I might enjoy these challenges since they are based in my desire to experience something new, but illness as "unhomelike" presents a much more persistent and undesirable set of difficulties. I can't go to work, I can't care of my son, I can't even eat-I am myself and yet my body seems like a foreign burden, calling to mind Delmore Schwartz's poem "The Heavy Bear": "The secret life of belly and bone, /Opaque, too near, my private, yet unknown." ${ }^{28} \mathrm{I}$ am not at home even in the most familiar of locales: my own body.

In health, as Gadamer and Merleau-Ponty note, one's body fades into the background in order to take up projects in the world. Thereby, one feels "at home" in as much as one doesn't have to conceptualize one's embodied situation; one rather attends to the tasks at hand. Illness, in Svenaeus' reading of Heidegger, would generally be characterized by an attunement of unhomelikeness. Since "attunement" in Heidegger means attuned understanding as a being-in-the-world, we would here find an outline for conceptualizing illness as a mode of understanding. After all, my understanding of walking and its relevance changes dramatically when I can no longer so do easily. In my ankle case, I was at my house and yet found myself not at home as it had become a space of inhospitality. Attunement is also about how the world is open or closed to me. S Kay Toombs eloquently describes how when her multiple sclerosis advanced to the point that she required a wheelchair, the world became entirely reshaped. Space was not objective, it was a matter of the composition of the space and how it framed her bodily motility.

The answer to the question, "Is it too far to go?" has little to do with the distance that can be measured in feet or yards. For the person in a wheelchair, the answer depends in large part on what is between here and there. Are there obstacles that prevent the use of a scooter, is the terrain suitable for a wheelchair ${ }^{29}$ 
It is easy to fall into the naturalist tendency to see space as a matter of objective measurements and fail to see how one's tacit, background embodiment is contributing to that bias. To the person whose body does not fit easily into our current world, the background world is evident. Thus, in illness our nature as embodied beings is often disclosed with more clarity than when we are caught up in our everyday ambitions and plans.

Svenaeus argues that while it is true that one's existential condition of finitude is brought to light by illness in a way that is often ignored in health, another aspect of our being-in-the-world, being at home, is ignored. I am not always experiencing a world of foreign intrusion where my body is a heavy burden; I often blend harmoniously with the world and others. I feel at home with myself and others. In cases of bodily disruption, we see how even when one can take up a cognitive content, one cannot make "sense" of it because one's basic bodily intentionality is disrupted. When I am not attending to my body and engaged in the world, it seems particularly objectified when my body "breaks" - that is, interferes with what I want to do. In some kinds of experiences, I might turn toward the unattended-to aspects of my experience, such as thinking about the walls of the coffee shop or some small noise the person next to me is making rather than remaining focused on my task. Maurice Merleau-Ponty's work on a healthy body schema is similar to the idea of home-ness in Svenaeus and Heidegger, where home is not just about the current physical situation, but also the anticipated future that is virtually experienced. In the Phenomenology of Perception, Merleau-Ponty's analysis serves to point out that positivist, mechanical accounts are unable to account for the way dysfunctional bodies behave. Moreover, they fail to even understand normal, everyday embodiment.

In her description of her chronic and degenerative illness, LAM (lymphangioleiomyomatosis), Havi Carel notes that not only did her world shrink due to physical inability to engage in the biking and hiking she had previously enjoyed, but her relations to others in the larger social world radically changed, leaving her-as Svenaeus would say-homeless with her friends. Her illness became a strange elephant in the room that no one wanted to address:

The status quo seems to be this: don't talk about your illness and we won't talk about our health, our healthy children, our pleasingly predictable lives. We won't talk about how everything worked out fine for us, give or take a difficult labour, a premature baby, or a divorce. This bitterness in me has nowhere to go. It has no place, no name. It is verboten. The strict limitations on what I may or may not say to my closest friends manoeuvre me into a more socially palatable position: being courageous. How brave I am. How uncomplaining. How cheerful in the face of a heavy, sometimes unbearable load. First I am set up in a social context that forbids me from talking about my illness. Then, when I turn to other topics, I discover the social reward: I am seen as brave, graceful, a good sport. ${ }^{30}$ 
The homelessness that Carel experiences is not just a personal condition: the ill disrupt the homelikeness of those in their close circles with their unruly bodies that require constant care with their inability to engage together in previous activities or to fall into traditional topics of conversation.

Part of my bodily background includes the bodily backgrounds of those I love. I am co-constituted by them. There are few ways to express how shattering it is when someone you love is seriously hurt or how little anything else matters when this happens. Merleau-Ponty writes that my intentionality and that of others are connected-"It is precisely in my body which perceives the body of another, and discovers in that body a miraculous prolongation of my own intentions, a familiar way of dealing with the world." ${ }^{11}$ Recently a good friend of mine died after a long-term, devastating bout with cancer. Her children and husband became ill too; not of cancer, but of the stress of their worlds collapsing. Things after a good week seemed more possible and open. After a bad week: everyone was lost again. This took her body sharply out of the background, placing it front and center. No one was at home anymore; everyone felt homeless and at the same time incapable of making the world more hospitable for her. To expand upon the idea of hidden harmony and body schemas, the way that both health and illness intend out into the lived situation and into possible, imagined situations involves not just the individual but also all those who have built their own lives with her as a key member. One cannot discuss human health and illness as a series of discrete individuals having closed experiences, but one in which bodily backgrounds are intertwined.

In phenomenologies of illness, illness is seen as a disruption and breaking of habitual modes of being, interacting, and doing. Some phenomenologically inspired suggestions for better care are not in-themselves revolutionary, as they fit into other contemporary concerns about the reductive state of medical practices that encourage treating the body as a problem to be corrected. Too often, healthcare workers are not provided with the training or time to consider the ways in which illness as an experience reaches far beyond perceived pains or disruptions that can be monitored by specialized testing and equipment. While much actual medical practice often remains reductive and treats the body as an object, theories, both popular and academic, about how to provide better care have increasingly embraced what can be called holistic and interpersonal approaches. In such approaches, patient and physician are encouraged to search for, as S Kay Toombs describes it, a shared world that requires the physician to gain insight into the lived experience of the patient, including the patient's close family and friends. ${ }^{32}$

In the phenomenological description of the experience of not-being-athome, the disruption in one's intentional arc and breakdown of easy beingwith-others-is not only a revelation of dysfunctional experience, but also an inversion of the thematic and unthematic. In health, the everyday operations of one's body fade into the background. When I'm having a cocktail with friends or lecturing, I neither attend to nor consider my body schema unless I trip, cough, or have some other little awkwardness befall me. This isn't to 
say that in the natural attitude one lives like a disembodied mind coincidentally inhabiting a body. Of course I feel hungry; I have to find a restroom; my feet hurt after standing too long. But these bodily reminders are at best ones that I hope to take care of so as to no longer have to be conscious of them. While it is true that illness brings to the forefront the embodied nature that we can often forget when occupied with our plans and invested in our ideologies, the way it narrows experience so sharply to the immediate also often occludes the manner in which we are often at home in our bodies and in the world. The intentional arc that connects the embodied subject to the world is disrupted-referring endlessly back to the body as an obstacle. In the cases where an illness is overcome, such as in the use of a cane, what is valuable is when that cane becomes a natural extension of the subject and thus causes the disability to fade into the background. Cases where the illness makes itself constantly known seem to disrupt Merleau-Ponty's understanding of the role of the importance of the unthematic in normal bodily functioning.

In his discussion of the work of Gelb and Goldstein regarding Zeigen (to point) and Greifen (to grab), Merleau-Ponty illustrates that we cannot understand the disparity between the two with mechanical models alone. A patient might, for instance, be incapable of pointing to his nose unless he is allowed to grab it. ${ }^{33}$ The more concrete movement-grabbing-is possible, whereas the more abstract one-pointing-is not. This is curious, since it does not seem evident that physiological differences alone could cause this discrepancy. In Gadamer's language, we can see how the patient who cannot point cannot take up projects in the world. In Merleau-Ponty's words, the body schema allows my body to become an "attitude" that is "directed toward a certain existing or possible task." ${ }^{34}$ This makes the healthy, normal body schema concerned with one's situation in the world, including one's not-yet-actualized future intentions. Mechanistic explanations cannot understand the possible, the imagined, or the not-yet. It is impossible to explain why one can grab (indicate what does exist here) but not point (indicate the possible future) on physiological descriptions alone.

Any physiological explanation becomes generalized into mechanistic physiology, and any achievement of self-awareness into intellectualist psychology. Such mechanistic physiology or intellectualist psychology then brings behavior down to the same uniform level and wipes out the distinction between abstract and concrete movement, between Zeigen [to point] and Greifen [to grab]. This distinction can survive only if there are several ways for the body to be a body, and several ways for consciousness to be consciousness. ${ }^{35}$

In this passage, Merleau-Ponty draws our attention to the diversity of styles of embodiment and leads us toward questioning unitary understandings of health. Possibility is not just a matter of the physical capacity to do a certain skill but also the imagination's understanding of a complex set of lived future possibilities. 
Academic discussions of the value of Merleau-Ponty's work often de-emphasize the social and imaginative aspects of the "I can" in favor of thinking of isolated cases of active embodiment as the guide for non-ill experience. Hubert Dreyfus's famous article "Intelligence without Representation" sets the ground for later discussions about the way normal or healthy embodiment is characterized by "maximal grip" on a situation. ${ }^{36}$ The idea is that through habituation one learns a skill-say, how to walk-and that once it is normal and at its best functioning, one no longer has to attend to it. Any skilled bodily activity-such as playing tennis or piano-one finds that the more one attends to one's grip or the position of one's fingers, the less the body can fade into the background and be the location for where the "I can"-I can play this song, I can walk to work, I can serve this ball-happens. This kind of space one inhabits to feel comfortable is to feel at home in one's body, to feel that one can reach out and be in the world safely and surely. Both illness caused by a physical impairment and objectification can cause one to be unable to feel at home, and in a more limited sense, can cause one's body to feel awkward and lumbering while trying to learn a new physical skill.

Gayle Salamon evocatively presses what she calls the "fallacy of maximal grip" in Merleau-Ponty studies, pointing out that the model of an individual trying to make an action habitual is neither reflective of Merleau-Ponty's work nor of the experience of disability. ${ }^{37}$ Merleau-Ponty's work can be used to stress grip in Dreyfus' sense, but the discussion of grip in the Phenomenology is about how the world grips me. My healthy embodiment is very much about being in the kind of situations not just where I can, but where I am pulled (or pushed) to do certain things. Salamon examines a case of Mary Felstiner's memoir of living with rheumatoid arthritis where the standard individual-centered idea of maximal grip is obviously disturbed. In Dreyfus' terms, Felstiner's inability to effortlessly do basic movements like dress, grasp an orange, and write would seem to lead her to a lack of a coherent body schema.

However, in Merleau-Ponty's description of the case of Schneider, the patient whose lack of normal embodiment exists-it isn't that he can't grip the world, rather it is that he has to, like Felstiner, actually grip his own body to put himself into a situation. Many people can enter into a social conversation easily - attending to the other but not having to organize one's body to respond appropriately. Schneider has to "grip" himself-to consciously recall what is supposed to happen in an everyday conversation and try to organize his body to do what is appropriate, which usually results in failure. Describing Schneider's attempts at friendship, Merleau-Ponty notes that they usually end poorly because he makes the decision to engage "in the abstract" and never "spontaneously." ${ }^{38}$ Likewise, Felstiner must consciously grip her body's chronic condition and the degree that it may or may not be able to do certain movements. Salamon writes, "Grip is deployed in both cases not as a way of enmeshing seamlessly with the world, but as a means of methodically composing the body as a substitute for an unthought, and 
not foreclosed, enmeshment with the world." ${ }^{39}$ Thus, it is hard to think of grip as solely a matter of unthematic healthy bodily functioning. So often grip is the means by which the body must deliberately negotiate its fissures with the environment, not just its effortless connection. In addition, use of sports metaphors often employs behaviors that are isolated from normal, complex social situations. It is true that individual skilled motor activities like playing a sport, an instrument, or riding a bike demonstrate the way in which learning and habituation work with each other. However, outside those exclusively employed in such activities most of us spend much of our waking hours engaged in ambiguous social situations, even those with which we are quite familiar. Negotiating a meeting with co-workers isn't exactly effortless in the same way that mastering a song is because the piano's reaction to my efforts is predictable; my colleagues are not. Our lives even without chronic illnesses often require a kind of taking one's body consciously, even awkwardly, as we consider how to behave in situations with other individuals. Without attention to the possible worlds that constitute the present, including the worlds of others, one might consider health to phenomenologically be something about one's current capacity to do some physical set of actions. While this may be part of health in some respects, health requires a lifeworld that considers not just the lived body interaction with predictable instruments, but with persons who are rarely so clearly understandable or capable of being "mastered."

As our lifeworld includes others, it also is situated in the larger social-political-cultural world. One's position in that world is not the same as everyone else has but largely determined by histories of how privilege and power have made certain positions more likely to be in situated where the path of healthy behavior is easier. For instance, when considering health, research clearly documents that if we examine statistics of health outcomes in any society, we can often find significant disparities. Half the countries in the world have a longer life expectancy than the poorest in the United States. The connection between communities and health has long been documented, where communities with few health services, little food access, and simply the stresses of poverty are highly correlated with poor health outcomes. Even cases of individuals who had no previous history of heart failures were found to have their cardiovascular health risk level to be far higher if they lived in impoverished neighborhoods. ${ }^{40}$ Hence, we can see that if we pursue a phenomenology of health from solitary positions, like a phenomenology of bike-riding, we will likely not think to explore structural reasons that shape our abilities in such a way that we can only see them in comparative analyses.

\section{Health as morality: obesity and disability}

In the quote from Ehrenreich that began the last chapter, we see that part of her surprise was that she had been healthy-she had worked out, ate well, and refrained from excess. So what can we conclude about those who didn't do as well as Ehrenreich? How do we approach those who fail the good 
health imperative? Donald McKenna Moss discusses from a phenomenological framework his work with morbidly obese patients who had undergone weight-loss surgery. Patients expressed how they felt they were "something from outer space" and wanted to "rejoin the human race." ${ }^{41}$ Moss argues that the obese in his study express a broken sense of bodily ownership. The non-obese person, Moss argues, has a fluid sense of the body where it fades into the background, but at the same time it is fundamentally possessed and gripped. In distinction, Moss writes:

The obese individual frequently distorts the basic ambiguity and fluidity of the human body, to seize fluid lines and set them into a permanently fixed self-definition: I am always this attractive face, I am never this grossly obese body; this body that you see is never me, I am always this beautiful personality that resides invisibly inside this hulk. ${ }^{42}$

Moss ties the experiences of the obese-both their objectification in the social world as well as their failures at dieting-to augment this feeling of not having, or being capable of, responsibility for the body. He doesn't argue that everyone is always responsible for their bodies-rather that what seems to be off-kilter in the obese is their rigidity about their bodies and self-image. ${ }^{43} \mathrm{He}$ concludes that these problems with ownership might arise from early childhood where the child had conflicts with parents in various ways about who has control over the child's body (noting that anorexics also often find themselves in power struggles with their parents). ${ }^{44}$

What is interesting to consider here is how the ownership is tied to a lack of spaces where the patient is at home. Moss strongly connects a sense of not-being-at home to their feelings of being incapable of moving easily as well as being objectified by others. Not-being-at-home is not only tied to reduced motility and physical suffering, it is also connected to the situation. So few places did the obese feel at home, usually it was only at their actual home and while there, due to family members, often only in their room alone. Other spaces were ones of objectification, of "mirrors"-be they other persons, family members, or actual mirrors-that remind the obese their bodies are not acceptable. ${ }^{45}$ From a phenomenological point of view, it seems less that the experience of being obese needs to be understood as an issue of perceived agency and more of unheimlichkeit (homelessness).

A widely discussed study found that prior to the introduction of television in Fiji, women were praised for being large, dieting was rare, eating big meals that would by some standards be considered excessive was normal, and body dissatisfaction was low. Within a surprisingly short amount of time, the female islanders increasingly saw themselves as needing to diet, purge, and refuse to engage with long-standing traditions surrounding food. ${ }^{46}$ When thinking about Moss' patients, one wonders that if they lived in Fiji prior to television, what would that have meant for their senses of being-at-home? Is it possible to neatly separate out the "real" distortions to intentionality caused by being large and those caused by worlds who 
refuse to be hospitable to certain bodies? When obesity is called a "disease" by public health officials, one must wonder if one can understand illness as something one can objectively distinguish from the historical and social situation, including the moralization about certain kinds of behavior and bodies. $^{47}$

One could argue as Karen Synne Groven and Gunn Engelsrund do that many women who pursue weight loss surgery due to obesity are obviously affected by fat-phobic worlds and objectification, but that the justification for many women was also that they wanted to be able to do more, to live more literally and figuratively lightly in the world in order to accomplish their ambitions. ${ }^{48}$ The authors argue that one cannot neatly dissect the cultural obsession with women being slim from the personal desire for movement. Yet, Groven and Engelsrund argue that radical weight loss surgery is a way to transcend their situation and acquire greater freedom, they have not "given up" and lack willpower. ${ }^{49}$ Movement is, as already discussed, necessary for our primary intentional connection to the world and others and hence weight loss surgery can enable that extension even if weight bias unjustly contributes to a sense of limitation. A distinction is drawn here between aspects of one's embodiment that are limited by unjust biases and those that are limited by one's individual embodied condition. Even if these two are intertwined, one might conclude that bettering the parts of one's individual embodied condition, such as becoming lighter, would be of benefit.

In the acclaimed computer-animated science fiction film WALL-E, one encounters a dystopian future where round people fly around in chairs to support themselves, looking at screens instead of doing physical activity. This strong association of fatness with laziness and moral ineptitude colors the film. Since the future fat people require chairs, they cannot dance, and it is dancing that most enchants the charismatic lonely robot WALL-E, who watches old clips of Hello, Dolly! In order to watch the film as it is intended, we must see these flying chairs as negative, as signs of the future humans' distorted and unhealthy style of living. We perceive the fat persons flying in chairs, drinking what appears to be sodas, and watching individual TVs, as buffoonish and morally culpable for not realizing the true magic of life.

But of course, is it not possible to watch WALL-E and see these flying chairs and think-well, wouldn't that be beneficial to many? Little personal flying chairs! Wheelchairs are integral parts of embodiment for many persons with disabilities who do not see them as impositions on their bodies, but ways they can extend into the world. Surely technological advances like glasses, canes, and prosthetic limbs are not unhealthy signs of illness, but rather means through which one can extend more fruitfully into the world. I am at home with my glasses and dreadfully lost without them. Glasses augment my motor intentionality. As one ages, one will likely need more aids for movement, sight, and hearing.

Merleau-Ponty writes that movement is just as bodily when it uses devices to interact with the world citing, for instance, the movements of a blind man. ${ }^{50}$ The tip of the cane becomes the end of the body's schema, 
much like the tennis racket is a natural extension of the movement of the tennis player. In Toombs' description of moving around the airport in her scooter many of the impediments were design flaws; it is easy to conceive of spaces where she could extend more fluidly into the world. Likewise, one could imagine the world becoming more hospitable for the obese with assistance in movement, larger aisles, and better seats, so they too would be at home in the world. In Toombs' accounts of her degenerative multiple sclerosis, we read of the decline of her ability to do certain movements. She writes, "For instance, attempting to put on pantyhose on immobile legs requires the most elaborate contortions and exceptional patience." ${ }^{51}$ In addition, Toombs notes how it is not her physical limitations, but it is instead just as importantly the reactions of other persons to her difference. At the airport, people without asking will pick her up like a thing to move her from one seat to another. She has become dehumanized and objectified. If her husband or another upright person accompanies her, strangers will not speak to her but rather address the standing person. "Can she transfer from a wheelchair to a seat? Would she like to sit at this table? What would she like us to do?" 52 The "I can" that Merleau-Ponty speaks about above is interrupted not only by the condition of her body, but also by others in their refusal to see her as someone capable of either motor or mental intentionality. One's possibility of extending into the world is highly dependent on the normative structure in which others have shaped our shared world, including the possible technologies, spaces, and social norms that shape our abilities. Jenny Slatman writes that it is a mistake to think of bodily aids and adjustments as rare and used only as a means to ideally return bodies back to "normal," noting that "it is actually more normal to meet someone with a prosthesis than without one." ${ }^{53}$ Glasses, canes, hearing aids, artificial hips and knees, are commonplace. Slatman says that many still attach a kind of nostalgic investment in a "natural or untouched, pristine body." ${ }^{44}$ Often the labor of the good health imperative wants to return us to a state that does not exist. Instead, it is an operative ideal where if only under the right care, medical intervention, and aid we can finally get back to "good," that is undisturbed, "pristine" embodiment.

This idea of health as a matter of good directed work that will end up in producing pristine bodies influences our conception of disability. Persons with disabilities are often considered blameless, unlike the obese, but still considered persons who one would assume would want to organize their lives to minimize their disability and if possible get rid of it if there is work that could be done to accomplish this. Such a move is often based in the assumption that disability is a species of illness-and as such is always a detriment to the one who has a disability. In critical disability studies, we can consider the idea of "compulsory able-bodiedness" which functions, as Robert McRuer says, "on a logical contradiction-able-bodiedness is simultaneously assumed to be the supposed 'natural state' of any body and yet is a state that all of us are striving to attain or maintain." ${ }^{55}$ The idea of compulsory able-bodiedness helps us question the idea of independent 
movement as a requirement for both a healthy and flourishing life. Importantly it also draws our attention to the ways in which able-bodiedness is often invisible to us even as it constitutes our socially shared existence. Lisa Guenther points out - the way in which something like systemic racism, or here able-bodiedness, affects one's subjective and intersubjective experience is about "ways of seeing, and even ways of making the world that go unnoticed without a sustained practice of critical reflection." ${ }^{56}$ In order to critically examine health and illness, we have to likewise consider how the push for health may in fact deepen marginalization of non-able bodied persons.

Ableism not only produces discrimination, but also fails to actually capture how disabilities are lived. One reason is likely that for the able-bodied, one might imagine disability like being oneself, but with a lack or reductionthat is parallel to illness. In such imaginings, disability is thus seen as a deprivation. Joel Michael Reynolds calls this the "ableist conflation," where one assumes that disability is primarily a deprivation. ${ }^{57}$ We can see the influence of some forms of phenomenology in this conflation if we understand individual aid-free skilled movement as indicative of health. In such a view, those who cannot execute certain kinds of movement — walking, seeing, hearingmight be seen to be somehow unable to intersect as meaningfully with the world. Sean Aas has pointed out that disabled people are often understood falsely as unhealthy because a certain view of impairment encourages this view. ${ }^{58}$ Even in phenomenologies of disability, phenomenologies of illness are often the points of departure to talk about disability which again underlines the idea that illness and disability are inherently connected. ${ }^{59}$ If illness is always to be avoided, mitigated, and controlled, then disability would always seem to be a problem-like obesity-hopefully to be solved.

In conclusion, one way to distinguish between intentionality that is disturbed due to illness and that due to an ill society would be to ask: What would need to change in order for people to be more at-home in their situation? In the case of a mass-marketed ideal of beauty creating a sense of personal self-loathing, it seems that it is something external that needs alteration - those very economically driven ideals of beauty whose real aim is to sell us products and practices. After all, if I were comfortable with my body, I might wish to buy this face cream, but I would not feel shameful if I did not. But if the answer is that something could be promised, like a greater capacity for extension in the world, then it would seem to be about health rather than social norms. This idea underlies much work in thinking about the value of the unthematic functioning of the body as the heart of healthy embodiment. However, while such models work well for individual pursuits that can be discussed abstractly from one's embedded cultural situation, say, piano playing or driving, it is hard to clearly separate out something like movement from the engineered social spaces in which we all live and all were raised, the technologies that aid or hinder us, and the biases that shape how we are viewed and treated.

Feminist phenomenologies of the body, such as Salamon's discussion above, highlight how the kind of models of abstract individual performance repeat the 
problem of thinking that one can perform a phenomenology of illness or health without thinking about discrete concrete bodies. Instead, we are not a generalized capacity for health or agentic, self-directed action, but are always individuals whose natures are not independent of the meaning of the differences between us. The challenge for a critical phenomenology is to explore how differences that might appear "natural" and about individual bodies, such as the idea that health is something one either has or has not, are often determined by models of "natural" or "normal." Exploring other kinds of embodiment can help dislocate this idea of a singular kind of "right" body, as Elizabeth Grosz writes:

There are always only specific types of body, concrete in their determinations, with a particular sex, race, and physiognomy. When one body (in the Western, the white, youthful, able male body) takes on the function of model or ideal, the human body, for all other types of body, its domination may be undermined through a defiant affirmation of a multiplicity, a field of differences, of other kinds of bodies and subjectivities. ${ }^{60}$

Instead of thinking simply of movement as the way in which we can situate what is an extension of health or one of social oppression, such as in the case of obesity above, we can consider how the specificity of situations makes saying what a body capable of movement is much more complex. There is certainly, as Julia Jansen and Maren Wehrle note a manner in which normality represents “an individual 'I can', that is, the dispositions and acquired abilities of a subject that enable her actions and movements within a given situation and environment." ${ }^{61}$ In such a manner, we can think about a capacity such a bike-riding or feeling at home outside worrying about the "field of differences" raised above. However, they also point out that from a Husserlian point of view, the possibilities, the "I can," of any individual is always about the "existent norms and power relations of the respective society and time." 62 In Chapter 3, I will look more into the work in feminist theory to think about the work women do for beauty as similar to the work one is encouraged to do for health—work that is neither simply coerced, nor simply free.

\section{Notes}

1 Ehrenreich, Barbara. Bright-sided: How the Relentless Promotion of Positive Thinking has Undermined America (New York: Metropolitan Books, 2009), 15.

2 Drew Leder, The Absent Body (Chicago: University of Chicago Press, 1990), 43.

3 Hubertus Tellenbach, "The Phenomenology of States of Health and Its Consequences for the Physician," Morality within the Life-and Social World 22 (1987): 374, doi: 10.1007/978-94-009-3773-4_27.

4 Hans-Georg Gadamer, The Enigma of Health, translated by Jason Gaiger and Nicolas Walker (Stanford: Stanford University Press, 1996), 107.

5 Gadamer, The Enigma, 112.

6 "Frequently Asked Questions about Broken Heart Syndrome," Acute Stress Cardiomyopathy, John Hopkins Medicine, retrieved 6-13-2015, http://www. hopkinsmedicine.org/asc/faqs.html, 
7 Helen Fielding, "Depth of Embodiment: Spatial and Temporal Bodies in Foucault and Merleau-Ponty," Philosophy Today 43, no. 1 (1999): 80, doi: 10.5840/ philtoday199943138.

8 D. Tiemersma, "Phenomenology and the Foundation of Medicine: Structures of the Lived Body and the Life-world and the Moral a Priori," Man and World 16, no. 2 (1983): 108, doi: 10.1007/bf01260323D.

9 Tiemersma, "Phenomenology," 108.

10 Ibid.

11 Linda Fisher, “The Illness Experience: A Feminist Phenomenological Perspective.” In Feminist Phenomenology and Medicine, eds. Kristin Zeiler and Lisa Folkmarson Käll (Albany: SUNY Press, 2014): 28.

12 Maurice Merleau-Ponty, The Structure of Behavior. Translated by Alden L. Fisher (Pittsburgh: Duquesne University, 1983), 204.

13 René Descartes, "Optics," in The Philosophical Writings of Descartes: Volume 1, translated by John Cottingham, Robert Stoothoff, and Dugald Murdoch (Cambridge U.K.: Cambridge University Press, 1985), 152-176.

14 Tellenbach, "The Phenomenology," 371.

15 Fisher, "The Illness Experience," 31.

16 Merleau-Ponty, Phenomenology of Perception. Translated by Donald Landes (New York: Routledge), 92.

17 Leder, Absent, 69.

18 Leder, Absent, 73.

19 Leder, Absent, 73.

20 Morris, David. “Body.” In Merleau-Ponty: Key Concepts, eds. Rosalyn Diprose and Jack Reynolds (Stocksfield: Acumen, 2008): 113.

Morris, “Body," 113.

21 Morris, "Body," 107.

22 Merleau-Ponty, Phenomenology, 121.

23 Merleau-Ponty, Phenomenology, 137.

24 Wayne Dennis, Children of the Crèche (New York: Appleton-Century-Crofts, 1973).

25 Dennis, Children, 136.

26 Fredrick Svenaeus, "Das unheimliche-Toward a Phenomenology of Illness," Medicine, Health Care and Philosophy 3, no. 1 (2000): 9.

27 Svenaeus, "Das unheimliche," emphasis mine.

28 Cited from Susan Bordo's Unbearable Weight. Susan Bordo, Unbearable Weight: Feminism, Western Culture, and the Body (Berkeley: University of California Press, 1995), 1.

29 S. Kay Toombs, “The Lived Experience of Disability," Human Studies 18, no. 1 (January 1995): 12, doi: 10.1007/bf01322837.

30 Havi Carel, Illness (Stocksfield: Acumen, 2008), 55.

31 Merleau-Ponty, Phenomenology, 354.

32 S. Kay Toombs, The Meaning of Illness: A Phenomenological Account of the Different Perspectives of the Physician and Patient (Dordrecht: Kluwer, 1992), 89.

33 Merleau-Ponty, Phenomenology, 103.

34 Merleau-Ponty, Phenomenology, 100.

35 Merleau-Ponty, Phenomenology, 124.

36 Hubert Dreyfus, "Intelligence without Representation-Merleau-Ponty's Critique of Mental Representation," Phenomenology and the Cognitive Sciences 1, no. 4 (2002): 367-368.

37 Gayle Salamon, "The Phenomenology of Rheumatology: Disability, MerleauPonty, and the Fallacy of Maximal Grip," Hypatia 27, no. 2 (Spring 2012): 223-260.

38 Merleau-Ponty, Phenomenology, 160.

39 Salamon, "Phenomenology of Rheumatology," 248. 
40 Shaneda Warren Andersen et al., "Associations between Neighborhood Environment, Health Behaviors, and Mortality," American Journal of Preventative Medicine 54, no. 1 (January 2018): 87-95.

41 Donald McKenna Moss, "Distortions in Human Embodiment: A Study of Surgically Treated Obesity." In Vol. 8 Phenomenology: Dialogues and Bridges, eds. Ronald Bruzina and Bruce W. Wilshire (Albany: State University of New York Press, 1982), 253.

42 Moss, "Distortions," 256.

43 Moss, "Distortions," 260.

44 Moss, "Distortions," 260-262.

45 Moss, "Distortions," 255.

46 Anne E. Becker et al., "Eating Behaviours and Attitudes following Prolonged Exposure to Television among Ethnic Fijian Adolescent Girls," The British Journal of Psychiatry 180, no. 6 (June 2002): 509-514, doi: 10.1192/bjp.180.6.509.

47 For instance, one can consider the historically recent categorization of homosexuality as a pathology by medical professionals in the United States. It was only in 1973 that the American Psychiatric Association removed it from the Diagnostic and Statistical Manual (DSM). https://www.ncbi.nlm.nih.gov/pmc/ articles/PMC4695779/

48 Karen Synne Groven and Gunn Engelsrud, "Negotiating Options in Weight-loss Surgery: 'Actually I didn't have any other option,'” Medicine, Health Care and Philosophy 19, no. 3 (2016): 361-370.

49 Groven and Engelsrud, "Negotiating Options," 369.

50 Merleau-Ponty, Phenomenology, 144, 152-153.

51 Toombs, “The Lived Experience," 13.

52 Toombs, "The Lived Experience," 17.

53 Jenny Slatman, Our Strange Body: Philosophical Reflections on Identity and Medical Interventions (Amsterdam: Amsterdam University Press, 2008), 73.

54 Slatman, Strange Body, 73.

55 Robert Mc Ruer, “Compulsory Able-Bodiness.” In 50 Concepts for a Critical Phenomenology, eds. Gail Weiss, Ann V. Murphy, and Gayle Salamon (Evanston: Northwestern University Press. 2020): 62.

56 Lisa Guenther, "Critical Phenomenology." In 50 Concepts for a Critical Phenomenology, eds. Gail Weiss, Ann V. Murphy, and Gayle Salamon (Evanston: Northwestern University Press. 2020): 12.

57 Joel Michael Reynolds, "Merleau-Ponty, World-Creating Blindness, and the Phenomenology of Non-Normate Bodies," Chiasmi International 19 (2017): 421.

58 Sean Aas, "Disabled-Therefore, Unhealthy?" Ethical Theory and Moral Practice 19 (2016): 1259-1274.

59 Kristian Moltke Martiny, "How to Develop a Phenomenological of Disability," Medicine, Health Care and Philosophy 18 (2015): 553-565.

60 Elizabeth Grosz, Elizabeth. Volatile Bodies: Toward a Corporeal Feminism (Bloomington, IN: Indiana University Press, 1994): 19.

61 Julia Jansen and Maren Wehrle, "The Normal Body: Female Bodies in Changing Contexts of Normalization and Optimization.” In New Feminist Perspectives on Embodiment, eds. Clara Fischer and Luna Dolezal (Cham: Palgrave Macmillan, 2018): 40.

62 Jansen \& Wehrle, “The Normal Body,” 42.

\section{Bibliography}

Aas, Sean. “Disabled-Therefore, Unhealthy?" Ethical Theory and Moral Practice 19 (2016): 1259-1274. 
Acute Stress Cardiomyopathy, John Hopkins Medicine. "Frequently Asked Questions about Broken Heart Syndrome.” (n.d.), Accessed June 13, 2015. http:// www.hopkinsmedicine.org/asc/faqs.html.

Andersen, Shaneda Warren, William J. Blot, Xiao-Ou Shu, Jennifer S. Sonderman, Mark Steinwandel, Margaret K. Hargreaves, and Wei Zheng. "Associations between Neighborhood Environment, Health Behaviors, and Mortality." American Journal of Preventative Medicine 54, no. 1 (January 2018): 87-95. https://doi.org/10.1016/j.amepre.2017.09.002.

Becker, Anne E., Rebecca A. Burwell, David B. Herzog, Paul Hamburg, and Stephen E. Gilman. "Eating Behaviours and Attitudes following Prolonged Exposure to Television among Ethnic Fijian Adolescent Girls.” The British Journal of Psychiatry 180, no. 6 (June 2002): 509-514. https://doi.org/10.1192/bjp.180.6.509.

Bordo, Susan. Unbearable Weight: Feminism, Western Culture, and the Body. Berkeley: University of California Press, 1995.

Dennis, Wayne. Children of the Crèche (New York: Appleton-Century-Crofts, 1973).

Descartes, René. “Optics.” In The Philosophical Writings of Descartes: Volume 1, translated by John Cottingham, Robert Stoothoff, and Dugald Murdoch. 152176. Cambridge: Cambridge University Press, 1985.

Drescher, Jack. “Out of DSM: Depathologizing Homosexuality.” Behavioral Sciences (Basel, Switzerland) vol. 5,4. (2015): 565-575. doi:10.3390/bs5040565

Dreyfus, Hubert. "Intelligence without Representation-Merleau-Ponty's Critique of Mental Representation." Phenomenology and the Cognitive Sciences 1, (2002): 367-383. https://doi.org/10.1023/A:1021351606209.

Ehrenreich, Barbara. Bright-sided: How the Relentless Promotion of Positive Thinking has Undermined America. New York: Metropolitan Books, 2009.

Fielding, Helen. "Depth of Embodiment: Spatial and Temporal Bodies in Foucault and Merleau-Ponty." Philosophy Today 43, no. 1 (1999): 73-85. https://doi. org/10.5840/philtoday199943138.

Fisher, Linda. "The Illness Experience: A Feminist Phenomenological Perspective.” In Feminist Phenomenology and Medicine, edited by Kristin Zeiler and Lisa Folkmarson Käll. Albany: SUNY Press, 2014.

Gadamer, Hans-Georg. The Enigma of Health, translated by Jason Gaiger and Nicolas Walker (Stanford: Stanford University Press, 1996), 107.

Grosz, Elizabeth. Volatile Bodies: Toward a Corporeal Feminism. Bloomington, IN: Indiana University Press, 1994.

Groven, Karen Synne, and Gunn Engelsrud. "Negotiating options in weightloss surgery: 'Actually I didn't have any other option.'” Medicine, Health Care and Philosophy 19, no. 3 (2016): 361-370. https://doi.org/10.1007/ s11019-015-9677-y.

Guenther, Lisa. "Critical Phenomenology." In 50 Concepts for a Critical Phenomenology, eds. Gail Weiss, Ann V. Murphy, and Gayle Salamon, 11-16. Evanston: Northwestern University Press. 2020.

Jansen, Julia and Maren Wehrle, "The Normal Body: Female Bodies in Changing Contexts of Normalization and Optimization.” In New Feminist Perspectives on Embodiment, eds. Clara Fischer and Luna Dolezal. Cham: Palgrave Macmillan, 2018): 37-55.

Leder, Drew. The Absent Body. Chicago: University of Chicago Press, 1990.

Martiny, Kristian Moltke. "How to Develop a Phenomenological of Disability." Medicine, Health Care and Philosophy 18 (2015): 553-565. 


\section{A critical phenomenology of health and illness}

Mc Ruer, Robert. "Compulsory Able-Bodiness." In 50 Concepts for a Critical Phenomenology, eds. Gail Weiss, Ann V. Murphy, and Gayle Salamon, 61-67. Evanston: Northwestern University Press, 2020.

Merleau-Ponty, Maurice. Phenomenology of Perception, translated by Donald Landes. New York: Routledge, 92.

Merleau-Ponty, Maurice. The Structure of Behavior, translated by Alden L. Fisher (Pittsburgh: Duquesne University, 1983), 204.

Morris, David. "Body.” In Merleau-Ponty: Key Concepts, edited by Rosalyn Diprose and Jack Reynolds. 111-120. Stocksfield: Acumen, 2008.

Moss, Donald McKenna. "Distortions in Human Embodiment: A Study of Surgically Treated Obesity.” In Vol. 8 Phenomenology: Dialogues and Bridges, edited by Ronald Bruzina and Bruce W. Wilshire, 253-268. Albany: State University of New York Press, 1982

Reynolds, Joel Michael. "Merleau-Ponty, World-Creating Blindness, and the Phenomenology of Non-Normate Bodies.” Chiasmi International 19 (2017):419-436

Salamon, Gayle. "The Phenomenology of Rheumatology: Disability, Merleau-Ponty, and the Fallacy of Maximal Grip." Hypatia 27, no. 2 (Spring 2012): 223-260. https://doi.org/10.1111/j.1527-2001.2012.01266.x.

Shaneda, Warren, Andersen, William J. Blot, Xiao-Ou Shu, Jennifer S. Sonderman, Mark Steinwandel, Margaret K. Hargreaves, and Wei Zheng. "Associations Between Neighborhood Environment, Health Behaviors, and Mortality." American Journal of Preventative Medicine 54, no. 1 (January 2018): 87-95. https://doi.org/10.1016/j.amepre.2017.09.002.

Slatman, Jenny. Our Strange Body: Philosophical Reflections on Identity and Medical Interventions. Amsterdam: Amsterdam University Press, 2008.

Svenaeus, Fredrick. "Das unheimliche-Toward a Phenomenology of Illness." Medicine, Health Care and Philosophy 3, no. 1 (2000): 3-16. https://doi. org/10.1023/A:1009943524301.

Tellenbach, Hubertus. "The Phenomenology of States of Health and Its Consequences for the Physician." Morality within the Life and Social World 22, (1987): 371381. https://doi.org/10.1007/978-94-009-3773-4_27.

Tiemersma, D., "Phenomenology and the Foundation of Medicine: Structures of the Lived Body and the Life-world and the Moral a Priori." Man and World 16, no. 2 (1983): 105-112. https://doi.org/10.1007/bf01260323D.

Toombs, S. Kay. The Meaning of Illness: A Phenomenological Account of the Different Perspectives of the Physician and Patient. Dordrecht: Kluwer, 1992. 


\section{Feminist phenomenologies and self-regulating bodies}

To consider how self-control is learnt and why certain kinds of self-control, like healthy habits, are celebrated above others, first, one must ask-how does any kind of self-control develop? How does our basic bodily capacity for healthy (or unhealthy) behavior form? What possibilities for alteration are there? The first section of this chapter will argue that control over one's basic bodily movements and thereby the capacity to alter one's habits is a developmental acquisition. Attention to the development of self-control exposes how much of bodily self-control develops prior to intellectual capacity for representing one's action and is learnt in familial and social settings. One's own self-care was first and foremost learnt through care and witnessing the other's self-care rituals. Our bodies are from the beginning culturally embedded and understood. In the second section, the example of contemporary managed female appearance will be discussed as an example of how the cultural body can be understood in relationship to bodily agency. Feminist consciousness-raising has explored the problems with such modification and provides bulwarks against the commodification and objectification of women's bodies. However, in the third section, one finds that some feminists celebrate the same kind of agentic bodily self-modification if it is directed toward health rather than a model of aesthetic improvement. These arguments return us to a kind of naturalism where the body tends toward health and is inhibited by culture. The chapter will conclude thinking about feminist discussions which try and distinguish between bodily agency in health promotion as constituted by repressive and limiting cultural norms, but also as a possible site of feminist self-care.

\section{The development of agency to care for the body}

In the Phenomenology of Perception, Merleau-Ponty states that he views the first 25 years of his life as "a prolonged childhood that had to be followed by a difficult weaning process in order to arrive finally at autonomy." ${ }^{1}$ Certainly, this idea meshes well with our intuitive understanding that if there are agents that can be held responsible for their actions; adults have this burden in a way that children do not. In Beauvoir's Ethics of Ambiguity, a similar disjunction between the agency of an adult and that

DOI: $10.4324 / 9781003168676-3$ 


\section{Feminist phenomenologies and self-regulating bodies}

of a child exists. ${ }^{2}$ For Beauvoir, while children are not free as adults are, we cannot compare them to enslaved adults. Children are not oppressed in their lack of relative freedom with adults, but rather they are ignorant because they have not had sufficient time to acquire the knowledge needed to see a situation as malleable instead of as a given fact. The oppressed person has had time "refused to him," whereas the child has not had enough time to understand her agency. ${ }^{3}$

Beauvoir does not conclude that therefore the child is to be treated as being without agency, as perhaps one might treat an animal. She writes that although they have not acquired enough time to be free in the way adults are, "the child has a right to his freedom and must be respected as a human person," and continues to write that childrearing itself is a practice of opening freedom to the child. ${ }^{4}$ But what constitutes helping children become free? Certainly, the kind of intellectual freedom one might have to refuse inauthenticity and embrace one's existential condition is not something one can teach right away. To open up freedom to a child is not so much providing the child with intellectual choices first and foremost, but helping the child become capable of performing basic movements-eating, dressing, walking, sitting, toilet training, and speaking. These key aspects of motility and self-care provide the groundwork for more sophisticated decisions and plans. If we understand agency as something that develops over time but is, in some nascent form, present in the child, how does the adult form of motor agency arise - the kind that could be turned toward the methods of self-care that one associates with healthy behavior?

Some philosophers have thought that what must be occurring in any kind of willed, free, intentional action is what is called a "representation," or a type of thought that then is relayed to the relevant neurological network to activate the action. So, when I wash my face, some kind of fairly complex, but largely unconscious, set of thoughts occurs that are connected to the kinds of willed movements it takes to wash my face-something akin to "now I shall wash my face." This makes deciding to wash my face and deciding who to vote for the same kind of free action. One can explain reasons why I'm more likely to wash my face this way or choose this candidate since representations that I have experienced that have become sedimented and unconscious (say, when my parents told me how to wash my face, or what my social circle thinks politically). Mental representation seems appropriate for considering some of my actions and many of my judgments-after all, one often does ponder certain aspects that involve choice, or one wants more clarity in what one is considering-whom to vote for, what car to purchase, what this author means.

Yet, if one thinks about our habitual actions that are agentic but not evidently the result of conscious deliberation, Merleau-Ponty's work on embodiment labors against thinking that bodily freedom can be explained in the same way that we can imagine intellectually choosing one idea over another. He provides a compelling alternative to thinking about agency without reducing all willed action to mental representations that are somehow 
communicated to an obedient body. Consider the following example from Komarine Romdenh-Romluc where she intends to go for a picnic by bicycle. On her way, her mind wanders, and she bikes to work before remembering her original destination. ${ }^{5}$ Many of us are familiar with such an example of a conscious thought being interrupted by the body reproducing its habitual action; I often find myself driving to my son's school when I mean to go somewhere else, since it is a common destination.

Romdenh-Romluc uses this everyday example to ask what is going on in the distracted bike-riding. It doesn't seem that one can say she had two sets of mental representations that were unconscious-one saying to her "ride your bike to the picnic!" and the other "ride your bike to work!" and somehow the latter thought won. Instead, alongside Merleau-Ponty she argues for a different kind of intelligence-that of bodily habit that took over when she got on her bike. However, this habit is not some kind of unconscious reflex. After all, when one drives accidentally to work instead of the store, one attends to all the normal varying signs-traffic, lights, etc. The bike reminds the body of its usual purpose and the body "takes over" once the mind is distracted. In another example, while I might think to myself, "shall I have some coffee?" once the coffee is made, I don't need to think about drinking from the cup. Rather my body intuitively knows how to manage a cup, and I can attend to other matters. If you said- "now use your coffee mug as a hat!"- this would require me to represent it to myself and think about what movements I should make to engage in "hat-coffeecup," but normally I don't think about how to use a mug. My body knows; I'm free to think about other things.

My facility with coffee drinking is because I have drunk coffee for over 25 years not only every day, but typically for most of the day. I drink about four cups of coffee a day, which means I have successfully negotiated the drinking of tens of thousands of cups of coffee (give or take a few that I managed to spill). However, the world acquires its hues of salient affordances over time. I was not always so expert at drinking from cups. As every parent will testify, young children are terrible at drinking and eating without making a gigantic mess. Developing the skillset to help them become expert enough so that the objects of cup, spoon, and plate do not need to be attended to directly requires the formation of certain kinds of deliberate bodily control. In continuing her story, Romdenh-Romluc writes, "Suppose, e.g., that in turning down the road toward work, I knock over a small child. I am worthy of blame." ${ }^{6}$ She points out that even though her bike riding has occurred in a non-representational, tacit manner, she is still responsible for her actions, just like if I accidentally intuitively drive to work instead of the store, I am still in control of my driving and rightly responsible for any accidents I cause. However, if we reverse the ages and the characters and suggest the small child is the one who inadvertently knocks Romdenh-Romluc over, we would not hold the child accountable. The right to hold someone responsible for their actions suggests we consider them capable of some kind of control—both mental and physical. An adult has both the mental 
wherewithal to pay attention and the physical capacity to control one's movement. The child's agency, on the other hand, is developing, and certain forms motor control and attention are not expected.

As it seems hard to imagine that one is representing one's everyday intuitive actions in the world to oneself, Merleau-Ponty additionally argues against the idea that the complex kind of reasoning of someone who believes in representational theories of action could be present in the young infant. Already in his early work, The Structure of Behavior, Merleau-Ponty argues against thinking that the child is representing objects or in some fashion "cross-checking" objects in a "logical" manner to determine the use of an object. ${ }^{7}$ Rather, babies explore the world with their bodies both by their haphazard movements letting them encounter objects as well as their increasing capacity to direct their attention to compelling objects. As they develop greater motor control, the world increasingly opens up to them. When teaching an infant to hold a spoon to eat, one works on coordinating the increasing muscle strength and control with the goal of eating with the food (mostly) going in the mouth. This repetitious social experience is always accompanied with an adult to aid the child, and usually this adult is opening her mouth in tandem, perhaps unconsciously, saying some version of "open up!" The most basic agentic movements required for survival, such as eating, occur as social events with constant feedback from the caregiver. Merleau-Ponty writes that biting has an intersubjective significance for the fifteen-month-old upon seeing the adult do so. ${ }^{8}$ Indeed, even very young infants will open their mouths in imitative response to adults. Adults too will kiss and mock bite infants' toes as a form of care and connection.

Merleau-Ponty argues that certain expressions, like smiles, are not interpreted but understood immediately. If I had to understand a smile the way I understand a foreign language, one would expect children to have delayed responses to common human expressions like smiles and frowns since they would need to devote time to interpret such gestures. For neurologically typical persons, smiling is like laughter-its meaning is understood immediately, without additional effort. The contagiousness of laughter demonstrates how joy can transferred immediately, just as the sight of someone weeping does not require us to ponder what such an action means, but only to wonder at its cause.

A mother smiling at her baby, talking to it, caressing it, and feeding it all model the baby's first experiences as building a sensible world, with the mother's bodily extension into the world the path on which the infant will build hers. The other's movement is what Merleau-Ponty terms "the completion of the system. Others can be evident because I am not transparent myself." " Others provide the key of how to take up objects in the world by their behavior toward such objects, including how they look at the world, and how they move in the world. ${ }^{10}$ Moreover, the other's body as a bearer of behavior is how I learn to move purposefully myself. It isn't just that I mastered drinking from cups in my own private trial and error, rather I sat at a table with my parents for countless meals watching them eat and drink. 
It is hard to think of many basic self-care movements—eating, drinking, dressing, washing - that are not also movements that one witnessed others countless times enacting in the course of one's childhood. In learning bodily self-care habits that then can become sedimented to the degree that we need to attend to them minimally as we consider our other life projects, we can see how interpersonal experience shapes motor intentionality. Extensive discussion in developmental literature considers the importance of the other's behavior for healthy development. In particular, the formative role of imitation in development has been stressed to indicate how from the very beginning, prior to language or even most gross motor control, we are responding to the other's actions with our own. ${ }^{11}$

In the Sorbonne lectures in child psychology and pedagogy, Merleau-Ponty argues that in the case of the child working between understanding her body through a mirror and thus working toward understanding how one is seen, no "reduction takes place permitting the convergence of two givens into one via some sort of intellectual effort." 12 Merleau-Ponty argues that one must over time come to understand this "duality" between one's sense of natural extension in the world, and the fact that for others we appear as a discrete object in the world. If it were about acquiring a kind of intellectual representation of one's image, then the child would either "understand it or not understand it." ${ }^{13}$ The baby would either look at herself and think, "Oh yes!" or "What?" Instead, following the work of Henri Wallon, Merleau-Ponty argues that the infant's specular image is understood first and foremost by attention toward the familiar image of the parent who is likely holding the child and saying, "there you are!" The infant looks to the parent and through comparison increasingly comes to make sense of her own image. Understanding oneself as something that can be viewed requires "the reorganization of the personal life and relations with others as well." ${ }^{14}$ One sets the stage upon which the infant starts to increasingly understand that her cries can only be attended to if someone is present, or the young toddler who looks around for an audience before crying over a small fall. This requires not just understanding that unless heard, a cry doesn't elicit a response, but also that one is something seen, and thus in some sense like others. This is not just the case for the important understanding of one's body as a thing in the world like other bodies, but also for all basic motor actions. Our first movements in the world are within this social space, not individual explorations.

Merleau-Ponty's thesis of a non-representational motor intentionality that underlies our conscious deliberate actions can be understood as both primal in the adult as well as primary as it constitutes our earliest experiences. The interpersonal nature of development can often be missing from discussions such as the bike-riding example, which is a rather solitary event. Motor intentionality's development is deeply tied to the experience of the other's movement before one comes in complete possession of one's own. In Chapter 2, I argued that while these phenomenological descriptions are critical to understand how one experiences health, often they use adult, 
individual pursuits as a model and pass over the developmental and social nature of our actions. When I interact with objects, it is through the other's interactions with objects that I come to form my own capacities. Merleau-Ponty centers my first capacity to grasp any object, to move in the world at all, as coming from "the very first cultural object, and the one by which they all exist, is the other's body as the bearer of a behavior." ${ }^{15}$ What I learn from others is not just how to hold a spoon or cup, but what these cultural objects do. In addition, the other as a cultural object means I learn how bodies are situated in our social world. Since my own understanding of my body occurs with others, my own body is also a cultural object.

Right after Merleau-Ponty writes that he finds his past to be the grounding for his current autonomy in the Phenomenology, he notes that he is never quite acting either voluntarily or rationally: "voluntary and rational life thus knows itself to be entangled with another power than prevents it from being completed and that always gives it the air of a work in progress." ${ }^{16}$ This other power is natural time. Unlike the child in Beauvoir's account who has not yet grasped time, adult time has agency but at the same time has a kind of closure that the child does not experience. The difference is that the child has not acquired habitual action and is capable of spontaneity - the concept wherein Merleau-Ponty places freedom in development. The polyphonic babbling of infants and the random explorations of space in toddlers demonstrate not just that they have less bodily control than adults, but also that they are less trained about how to use their bodies and what objects are acceptable to interact with in what ways. If one has ever witnessed in horror when children decide to lick something like a public handrail or stick some random pebble from the ground in their mouths, one sees a kind of spontaneous move toward engagement with the world that has been well educated out of adults. Handrails are for putting hands on. Stones are for stepping on. But to toddlers, such a knowledge is not yet present, and they are merely using their propensity to engage with the world. Development and the formation of habitual bodily self-control that provide the ground for complex agency are based upon the loss of some of the natural spontaneity one witnesses in the child because children have not fully sedimented what cultural objects are meant for in their society. North Americans often discover that our compulsions about showering daily, changing clothes daily, standing with some distance from strangers, infrequent touching of others, wearing swimsuits in saunas and at beaches, and eating in a certain manner with certain utensils are often quite different in other cultures. One may have no particular intellectual investment in one's culture's bodily training but will still find it very hard to alter, even if one can appreciate another manner of being with others.

Merleau-Ponty cites that the work of J.L. Moreno's psychodramatic therapy as providing useful lessons in spontaneity, "We must consider as an acquisition of child psychology to have learned, with Moreno, to reveal the avatars of spontaneity in social integration." ${ }^{17}$ Moreno would set up dramas not just to help a family overcome relationship trouble-but to explore social conflicts like racism with individuals who volunteered to participate. 
By putting people in settings where they are free to play out a role, Moreno's work reveals how it is possible to recapture our social spontaneity. ${ }^{18}$ Simply intellectualizing what is possible does not reveal the same kind of spontaneity that the acting out of roles does. Like the toddler, when presented with a new situation and asked to act it out, adults find themselves surprisingly more capable of acting freely when asked to perform, rather than simply asked to consider a different perspective. Later in his discussion of method in child psychology, Merleau-Ponty argues that we must stop seeing the child as a reflection of our adult state and instead "awaken our proper spontaneity" in order to understand how our behavior is not fated. ${ }^{19}$

What is the relevance of this developmental account for the good health imperative? If our primary and primal bodily agency is largely non-representational and based on the developmental acquisition of understanding both the body and its actions in a cultural space, it becomes more obvious that it is harder to modify. The demand to eat differently, move in another fashion, or alter how I care for my body can be hard to reconcile with a long history of living in a certain manner. It is fairly easy to have to complete some travel reimbursement paperwork that I never was previously required to fill out. I will strongly object to the absurdity of the bureaucratic excess and probably complain about it to anyone who I think may be sympathetic, but it isn't difficult for my body to coordinate itself to enter in some information on a form. Yet to be asked to eat differently or stand closer to strangers is effortful for me, even if I might very well be able to understand, and even desire the better digestion or happier connections with others.

Unlike children we have a long sedimented history of living in our bodies in a certain manner, change is not easy. The good health imperative is asking individuals to work against sedimented behavior toward conscious and deliberate new behaviors. Yet, in order to change our behaviors to healthy ones, spontaneity is not called for by the good health imperative. Deliberate change is dictated by experts of how to act with assorted tools, practices, metrics for evaluation, and tests. This encouragement to work on behavior modification for health is difficult to explore due to the complexity of developmental agency, our cultural bodies, and the intersection with medical advice and social pressures. As our bodies are cultural objects, it would be helpful to examine a parallel practice in the case of female aesthetic self-management as an example of socially mandated body modification that arises from a particular time and culture.

\section{Female self-regulation}

Merleau-Ponty lectures that gender tells one little at birth about the child, but when one considers the situation, one sees how a child will be pulled in particular directions-particular cultural "vectors."

To say at birth, "It is a boy" or "It is a girl" is to say almost nothing at all. However, whoever says "boy" or "girl" speaks of a situated individual. 
The child is situated in a force field which at every moment represents a particular nuance of masculinity or femininity. In this field, the child is subjected to vectors that draw him in different directions. ${ }^{20}$

In The Second Sex, Beauvoir documents the disparity between the expectations of what a woman sees as her major life goals and what a man does. She writes regarding marriage that "No young man, however, considers marriage as his fundamental project." ${ }^{11}$ In France in 1949, women were encouraged to see their "adult" goals as being dedicated to the establishment of a marriage and then a family. Without a husband, a woman would occupy an abject space of spinsterhood and possible impoverishment. Beauvoir's seminal point that grounded all later feminist thinking was to indicate that being a good woman was a matter of training, not of anatomy. When Beauvoir writes about becoming a woman, she writes about how the endless prescriptions about how to be a woman indicate its contingent nature as a cultural set of actions rather than a causal result of a certain biology. If a lack of a husband is seen as a failure for being a "real" woman, it encourages anxiety on the part of all women-married or not—-to make sure to obtain and retain a man.

Modern mores on marriage have changed, and even in my conservative state of Tennessee, I meet few female students who consider marriage as their only important goal in life, even if it remains a primary one. My female students are likely to describe themselves through their majors, their friends, and their hobbies, much more in keeping with their male counterparts. Does that mean that women are now experiencing themselves as equals to men? That being a woman isn't a project? While marriage may not hold as central a role, women in developed societies must have strict discipline when it comes to be sufficiently womanly. Women-young, old, married, single, with children, childfree, educated, poor, professional, laborer-work on their looks. To be a woman today is to be a self-regulated product.

To dress nicely, to tend to one's face and hair, the removal of some body hair and maintenance of skin, and to maintain a certain size is never finished, and is repetitive and wildly asymmetrical to the demands made of men. Roslyn Diprose points out that when understanding the position of women, we must not attend just to what any rational person would consider obvious forms of oppression. ${ }^{22}$ As Sandra Lee Bartky concisely states-" $O f$ course women are persons; of course blacks are human beings. Who but the lunatic fringe would deny it?" ${ }^{23}$ The situation of women in the developed world is a disparity in expectations. Diprose writes that "I think the central issue in redressing women's social subordination within patriarchal social relations is not so much male control of women's bodies as the ways in which women's bodies are socially constituted in relation to men." ${ }^{24}$ The skeptic of the gender-specific nature of such discussions might point out that exclusive models of ideal looks exist for both men and women, thus, one could not argue that women "have it worse" than men. These models 
provide varying degrees of policing of certain kinds of behavior and punishments for those that violate them. Short men face discrimination in job applications as do Black men. Thus, obviously certain ideals of appropriate "male" appearance regulate behavior like appropriate "female" appearance. In some cases, men who violate masculinity norms are met with far more violence than simply not being sufficiently well-kept as a woman. The difference in how men's bodies are monitored is, however, not primarily one that is concerned with agentic grooming - that is, one might discriminate against a short man or a Black man, but one does not assume he could be otherwise. A fat woman, a woman without makeup, a woman who fails to monitor her facial hair-these are all women who are judged as not failing to be "right" but failing to do the right thing in their bodily self-control.

The one parallel that some men experience about grooming is appearing "effeminate"-wearing makeup, walking a certain way, or wearing certain clothes. However, women who fail to maintain their appearance do not threaten the male psyche in the same manner. Indeed, the disapprobation they meet comes from all genders. Women who do not display certain kinds of grooming are seen as failures rather than threats. Thus, the responsibility of women for self-regulation is vastly disproportionate to men. This is not to say that men are not also perceived as being responsible for agentic bodily molding. However, in the case of fatness as being a signal of inappropriate grooming, women are more likely to have internalized anti-fat attitudes, to see themselves as needing change and substandard. Studies in industrialized Western societies on gendered differences in relation to antifat attitudes have tended to find that women are more likely to have internalized the idea that their bodies are insufficient, and men less likely to have internalized thinness norms and to perceive their own bodies as needing change. ${ }^{25}$ Women are more likely than men to diet, express concerns about their weight, and more likely to seek weight loss. ${ }^{26}$ Alejandro Magallares and José-Francisco Morales note that this "helps explain why anorexia nervosa and bulimia nervosa occur predominately among women." ${ }^{27}$ While certainly everyone is shaped by norms of what "normal" or "healthy" or "beautiful" bodies should be, women are more likely to see these issues as something about their own relationship to their bodies.

The inferiority complex well described by feminist philosophers is that the female body is something that is in itself insufficient. What young girls learn from older women, and what women learn from each other, men, and the market is that their bodies require modification according to an ever-expanding set of products, techniques, and practices. To be a woman is to work on one's appearance. This demand is increasingly one that should be practiced at all ages-infant girls have pierced ears and teenagers have sweet 16 spa parties (complete with make-overs). Waxing one's pubic hair is now for many women simply another common ritual, and all cities and most American towns have waxing salons devoted exclusively to this practice. Older women are provided with products, surgeries, and techniques to ameliorate the effects of aging. One might point out that the delight in female beauty, 


\section{Feminist phenomenologies and self-regulating bodies}

just or not, like sexuality, is a fundamental element of human nature. One might as well yell at water for being too wet. However, what is unique about today's ideas of women is not the objectification of women, but the idea that all women of all ages should devote their time modifying their looks. This is not the delight in Nefertiti, Aspasia, or Lucrezia Borgia as rare instances of fine female beauty. Rather, the idea is that even the housewife, the 60 -yearold, the student, the doctor, and the cook should all make more of themselves even if they won't go down in the annals of great beauties of world history.

Consider, for instance, our contemporary interest in the beautiful bodies of female celebrities. Gossip about the king's beautiful mistress or the ingénue of the opera is not a new phenomenon. We can think too of the old stories we tell young girls of beautiful princesses who are loved simply because they are beautiful and passively needing aid. However, what marks our contemporary accounts is the documentation of the mechanics of their beauty. Sleeping Beauty is born beautiful, just as she born a princess. Her tale justifies both the adoration of beauty and the rightness of the monarchy and the status quo. Unlike Sleeping Beauty, however, our interest in contemporary beautiful celebrities is very much a concern with how they work on their bodies, not just that they have those bodies as a gift from God. Beautiful women are no longer just objects to be viewed or possessed, as in a museum, they are objects to become. How does Kim Kardashian contour her face? What is Halle Berry's exercise routine? How can I too lose my post-baby weight? In a typical woman's magazine, the delight in the beautiful celebrity is married to the other pages with detailed discussion of how to be that beautiful woman (accompanied naturally by advertisements for such products). As the self-help guru Oprah likes to say: "be your best self!" since the one who is reading this magazine clearly won't do.

Beauty as labor in the contemporary capitalist market, or according to the French maxim-il faut souffrir pour être belle (one must suffer to be beautiful) - suggests that we can and should select a beauty ideal and then work to approximate it. Any particular body is just a different set of issues to be addressed with different products and practices. Bartky explains:

It is a fact, that women in our society are regarded as having a virtual duty "to make the most of what we have." But the imperative not to neglect our appearance suggests that we can neglect it, that it is within our power to make ourselves look better-not just neater and cleaner, but prettier, and more attractive. ${ }^{28}$

For this to make sense, women must be convinced that they are not good enough already; how they appear to others is a problem, but most importantly a problem that they can (and therefore should) fix. Even a woman whose appearance is considered to fit the ideals of youth, weight, skin tone, hair luxuriousness, and curvaceousness is under no less pressure. She too must engage in rituals of defense against aging and work constantly to maintain and perfect her look. 
What the objectification of women creates is not only women feeling observed and separated from their bodies, but also women believing in a tremendous amount of agency on their part to achieve the right body. It is only their lack of sufficient effort, willpower, or the right combination of diet, exercise, and body modification that is holding them back. Luna Dolezal notes that one of the features of having a female body is pervasive shame. ${ }^{29}$ This shame requires that I devote time and the attendant series of deliberate bodily movements to bodily self-care to lessen my feeling of not having done enough. Why wouldn't I want to improve myself if I can? If I want to look a certain way and fail, I have only myself to blame.

Women consider how they appear to others even when the others who wait in judgment are not likely or potential sexual partners because looking competent for a woman is to look managed. After all, if one isn't interested in finding a potential mate who wants a certain socially sanctioned aesthetic, one still has strong reasons to monitor one's appearance. Failing to look maintained as a woman means failing to be taken seriously. While earlier theorists, such as Beauvoir, pointed out the futileness of female narcissistic practices-someone will always be more beautiful, and age catches up with every woman - parts of appearance management are very practical. Johanna Oksala correctly points out that such rituals are themselves no longer necessarily futile endeavors that will never "pay" women for the time invested. Rather, looking a certain way has simply become another tool in a successful neoliberal woman's tool belt-not designed to please the male gaze but to pass into situations that will be economically successfully for her. ${ }^{30}$ Looking old, hairy in the wrong places, fat, unkempt, and makeup-less have all been highly correlated with less success in professional circumstances. ${ }^{31}$

Simone de Beauvoir's The Second Sex is a developmental tale of womenfrom young girl to teenager to married woman to old age-to highlight the way women are oppressed by restricted social norms and also how they participate in their own submission. Since one is enculturated from birth to understand that one needs to make one's own body reflect the cultural body of ideal women, the progression of docility in women is a matter of training. In our contemporary view of bodily agency and responsibility, a woman sees her body modification as a choice-hence, to reject it seems to reject liberation. Why wouldn't I want to improve myself? When Merleau-Ponty discusses the infant at the mirror, we can extend that original nascent attention to that image to the particularities of the discipline women are taught and teach themselves. My image in a mirror I see is not simply as I'm seen by others-for better or for worse- but rather a work in progress, a tableau on which I can perform an art. For many women, it is as normal to see one's body as something to be worked on as it is to drink from a cup. In English, one can say "I have to put my face on," which means I have to put my makeup on. This idea of putting one's face on underlines the idea that one's essence is very much how one makes oneself.

Merleau-Ponty doesn't just write that I learn from the other's behavior, say, by imitation, but that the other is the first cultural object that permits 


\section{Feminist phenomenologies and self-regulating bodies}

other cultural objects to have their significance. Understanding the roles between men and women is not a matter of understanding the difference in their bodies. Rather, one must understand the difference in their actions which will be constituted in the social world, not as a set of reflexes reacting to particular levels of testosterone or arising from the possession of a uterus. For instance, one can think of how gender identity is perceived, as Sara Heinämaa discusses, not as a permanent substance, "but the continuity of a mode of acting - comparable to that of a habit, a style, or a tradition." 32 What I learned from my parents primarily is not any set of ideologies about the relative differences between men and women, but how my parents moved, talked, and engaged with each other and others in the world. I learned how to attend to my body as my mother attended to hers: not as ideology about women, but as an everyday practice.

In the Phenomenology, Merleau-Ponty speaks about how sedimentation in our life makes the habitual manner of acting "privileged" for us but is still capable of being "shattered" by freedom. However, he also notes, "And yet, after having built my life upon an inferiority complex, continuously reinforced for twenty years, it is not likely that I would change." 33 The Merleau-Ponty who views the last 20 years of his life as permitting his autonomy also sees how his freedom is possibly constrained by habits whose long development might make it difficult to perceive them, much less change them. As noted above, certain ingrained habitual responses to the environment-how I walk and how I hold a cup-are difficult to modify. In a more complex manner, how I attend to my body-how I care for it, how I view its status-developed in a world in which sex roles are one of the most significant ways in which we organize our society. To liberate myself from any particular body management ritual at any one time is easy, to liberate myself from a world in which I am habituated to see my very self as a project is as hard as to change the way I walk.

While certainly many find beauty work a source of pleasure, it is also work that takes away from other pursuits and very often is met with ambivalence and self-degradation. Feminist thought permits another manner of thinking about these rituals. Many women, when learning of institutional sexism, find a language to help express their frustration and alienation within environments that are supposed to be "normal." The recent \#metoo movement highlighting the pervasiveness of sexual harassment led many women to reflect that they had been subject to harassment, but failed to really identity it since it was seen as simply "the way things are." Articulating personal stories and exploring them can help uncover those fields of experience for which no name has been given but that still structure our worldviews. Elizabeth Grosz has argued that an indispensable part of any structural critique is that it connects with the lived experience of individuals. One has to show how such norms affect a woman's embodiment, even women who do not identify with feminism, by exploring the experiences of women. Grosz argues that we must attend to experiences- “...I would contend that without some acknowledgement of the formative role of experience 
in the establishment of knowledges, feminism has no grounds from which to dispute patriarchal norms." ${ }^{34}$ To bother objecting to the intensity of the demands of beauty rituals, one must connect to the experiences of women and explore manners in which what might seem "just how things are" is in fact merely one culturally contingent way of organizing our social life and by no means the only one we can imagine. Moreover, a full exploration of such rituals can explore their negative aspects instead of simply seeing them as one of many choices women may make.

Normalization works to minimize the relevance of the diversity of actual experiences into encouragements to repeat the pre-determined path. It encourages us to point toward a similar goal of beauty rituals where "spontaneity" is read as pre-packaged options of say choosing a different hair style, having tattoos or not, or running or lifting weights for fitness. The idea that agency is contained within worlds where one has "choices" tends to develop a model of agency qua consumer consumption. I can choose "how I look" like I can choose what sandwich I want. Not only is my body obviously not an infinitely moldable object, but the choices are also established before I arrive-just like what sandwiches I can purchase at the café. However, there is not an alternative "right" or "natural" way to be. The idea that not wearing makeup is the solution to the tyranny of beauty simply reinstitutes the moral norm of a particular right way of being. Rather, feminist thought helps us identify these processes and render them contingent. In so doing, their bonds over our senses of self and other are loosened, and we can explore new ways of living.

If one considers the time, attention to detail, and requirement for being considered sufficiently presentable, let alone attractive, one sees how it is a training that refuses other alternative ways of caring for oneself. Importantly, women are not themselves in charge of the structure of the choice itself. Thus, to say one chooses to care for oneself through beauty labor is dissimilar from saying one chooses to read a particular book, since there are real social costs to not engaging in the practice of body modification. Oksala points out that idea of personal choice "effectively masks the systematic aspects of power-domination, social hierarchies, economic exploitation-by relegating subjects the freedom to choose between different options while denying them any real possibility for defining or shaping those options." ${ }^{35}$ I can choose this makeup or that shirt, but if I wish to enter into normal social discourse, I must modify myself to certain standards. Opting out is not a viable possibility.

A feminist view is not to argue against beauty rituals themselves. Beauty rituals are not inherently degrading, or unnatural, or sites of submission. However, if we do not see them as contingent, they may they narrow our experiences and limit the possibilities of spontaneous agency in our embodied condition. Oksala argues that "the aim of feminist practices of consciousness-raising is not the exposure of a deep inner self or an original and authentic womanhood, but rather the problematization of the normalized self." ${ }^{36}$ Choice models that present the subject within a pre-given choice 
do not permit spontaneous new manners of engagement with the world and others, since the model places the agency in the decision about options over which we have no control. While certainly some of life is about deciding between options, much of life is characterized by living in sedimented, habitual, culturally contextualized manners in which we continue along certain paths. These paths need to be brought out of the background and into the forefront where we can examine them, a topic explored more fully in the last chapter with reference to Sara Ahmed's discussion of orientation.

One can surmise that one of the vast contributors of the managed female aesthetic is not the desire of men as much as the desire of corporations to find new products to sell. It appears that the body becomes a site of infinite improvement. It seems that there is no end to finding problems; ones that did not exist before and can now become sources of products for sale. Lines in an aging woman's face, hair everywhere but the head, and cellulite throughout the body are all now sites of betterment. We see routines formerly devoted just for athletes, models, porn stars, or actors now becoming part and parcel of everyday practice with all the attendant purchases required-contouring one's makeup, removing one's pubic hair, obtaining a completely tight body, getting aesthetic plastic surgery, and using Botox. We see men's bodies too become landscapes of improvement and the attendant assumption of a lack of willpower in men who fail to discipline themselves appropriately.

One question that faces a critical examination of the way in which we are trained to take care of ourselves is-how does one determine what kinds of self-care in fact limit our experiences and which ones broaden them? If I am raised from infancy to embody a certain style of self-care, change is a struggle against sedimented habits and norms. In addition, self-care is often sold to women as a kind of empowerment and thereby dieting and exercise are sold not as means to obtain a certain look, but as ways to be healthier. There are manners in which this is evidently merely a means to sell more products, but feminists also have championed self-care as a kind of self-transformation. Below I will discuss how feminists have used health as a tool to argue against beauty rituals and some dieting and exercise and what might be emancipatory rather than limiting styles of living.

\section{Feminist alternatives}

Susan Bordo's book Unbearable Weight highlights how the obsession with "perfect" managed bodies increases women's sense that their bodies are something to be molded into submission. ${ }^{37}$ The National Eating Disorders Association (NEDA) reports that around 10 million women live with eating disorders such as anorexia or bulimia. The highest rates are among girls and young women. ${ }^{38}$ Only a minority of people who meet "stringent diagnostic criteria" for eating disorders receive mental health care. ${ }^{39}$ What is alarming about the lack of treatment for persons with eating disorders is just how dangerous having an eating disorder is: anorexia nervosa has the highest mortality rate of any psychiatric condition, including schizophrenia 
and bipolar disorders. ${ }^{40}$ However, the funding to cure anorexia pales in comparison to less common but more widely publicized disorders such as Alzheimer's disease and schizophrenia. In 2005, approximately 2.2 million people lived with schizophrenia, and the NIH funded 250 million dollars for research. Approximately 10 million people have eating disorders, but only 12 million dollars was given to study anorexia nervosa. ${ }^{41}$ Anorexia may receive little funding because it is seen as an exaggeration of "normal" dieting practices. Moreover, since women suffer from anorexia disproportionately to men, and since the model of a good woman is someone who correctly regulates her body, then anorexics, like the fat or the hairy, are just failing to take up their agency properly.

Bordo discusses how "female" disorders that vary in time can be understood as forms of protest. The rise of agoraphobia after women were encouraged to adopt hyper-stylized forms of domestic perfection, passivity, and deference to male authority in the post-World War II era can be read as a kind of embodied protest: "The housebound agoraphobic lives this construction of femininity literally. 'You want me in this home? You'll have me in this home-with a vengeance!"”42 In our contemporary age of eating disorders, one can read these excessive demands to perfect one's body as extending the idea to its conclusion-"my body will know no limits; it will be thin to the point of disappearance!" To know that the evaluation of one's worth is tied to the evaluation of one's appearance makes women self-conscious in situations where such concerns limit their free behavior, similar to how an illness can restrain one's extension in the world. Iris Marion Young's famous piece "Throwing Like a Girl" describes how this habitual self-consciousness affects basic bodily motility, from throwing to confidently jumping over a stream..$^{43}$ Only under reflection can she expose this tendency. Normally, her hesitancy would not be an object of consideration, but rather her habitual and undisclosed manner of being in the world. Part of the work of feminist phenomenology has been to expose how the feminization of women has resulted not just in particular sexist ideologies, but practices and disciplines that shape women's relationships to themselves, others, and the environment that surrounds them.

Since beauty labor is designed to create a certain appearance, one would learn to think very carefully about how one looks rather than how one feels to the point that one cannot feel good unless one considers oneself to look good. One cannot be at home in one's body without the attendant vigilance to make sure one's appearance meets a certain standard. Considering how potentially unhealthy such hyper-self-consciousness is, the feminist trend in the last several decades has been to raise consciousness about how constantly needing to monitor and manage one's looks fails to permit one to live a flourishing life. One cannot confidently use one's body in strenuous physical settings or work deliberately toward complex projects that demand one's full attention if one cannot feel comfortable without monitoring one's appearance. In addition, such body work excludes one from working in other arenas. Bordo writes, "Through the exacting and normalizing disciplines of diet, makeup, and dress—central organizing principles of time and 
space in the day of many women-we are rendered less socially orientated and more centripetally focused on self-modification." ${ }^{44}$ Feminism directs our attention also to what we are not attending to when we are working on our bodies- to the rest of our lives, to politics, to work, to the greater world. Feminist theory has enabled one to see not just the contingency of aesthetic practices, but also the harms of them. Women's sense of selves as bound up in plastic and impossible ideals of female beauty affect not just their identity, but their time, effort, and ultimately their freedom. Consider here Cressida Heyes' discussion of Weight Watchers where Foucault's ideas of biopower, as will be discussed in the subsequent chapter, can be used to explain the way our bodies become normalized.

...normalization is enacted through ever-finer measurement and closer surveillance of the subject population. For example, standard height/ weight tables are themselves a macro-tool for normalizing the population-for taking a vast and diverse group of people and establishing a 'normal range' to which every individual bears some relationship. Deviation from the norm is then (falsely) read as proof of behaviors that can be pathologized, just as conformity is (falsely) taken as evidence of health and good conduct. Bio-power here thus operates both at an epidemiological level, and at the level of the production of a weight-based moral identity in the individual. ${ }^{45}$

The charts of weight help establish bodies that are "normal" and that are within what is considered the healthy range and bodies that are not-that is those that exceed it. One is being "good" if one gets one's weight to be within the right part of the chart and "bad" if one does not. Since the whole endeavor is not just about one's moral goodness, but one's health, one should be especially contrite to fail to have taken proper care of oneself.

In the above quote, Heyes obviously suggests that such charts themselves do not promote good health. After all, Heyes writes how this encourages an unhealthy normalization with her parenthetical "falsely." Most people regain the weight they lose on a diet, which is not healthy. Alongside this physical failure is the moral shame one has for failing to do what is right by one's very well-being. "Losing weight and regaining it is not only bad for one's physical health, or disappointing as a failure to conform to a beauty norm. It is also an ignominious defeat for one's efforts to create an ethical way of life." ${ }^{46}$ For Heyes, it is not that the self-care that diets espouse is unethical. In fact, she calls for more careful attention to self-care as part of the pursuit of an ethical way of life. What Heyes argues against is the false bill of sale that diet programs provide when they argue that they provide one with more freedom (to run around with the grandchildren!). Instead, they not only operate through normalization procedures that are directed at wide scale public control, but they also don't even provide the original promise-that of weight loss-and hence produce not just a lack of healthy benefit, but actual reduction in one's well-being. 
Bartky suggests that if women are able to reject beauty standards, they might find more a more natural kind of happiness:

Repressive narcissistic satisfactions stand in the way of the emergence of an authentic delight in the body, too: The woman unable to leave her house in the morning without 'putting on her face' will never discover the beauty, character, and expressiveness her own face already possesses. ${ }^{47}$

Popular forms of body appreciation often stress ways in which one can learn to enjoy one's body for what it can do instead of what is looks like to others. Indeed, the success of feminist consciousness-raising helps to explain the shift in the marketing of the diet-exercise industry away from dieting as about looks toward the idea of dieting (and its attendant other forms of size management) as about wellness. I'm not dieting to fit into a bikini; I'm dieting to play with my son! While certainly there is no shortage of products and practices devoted toward changing one's appearance, there is a growing interest in body modification, such as dieting, as being about a kind of healthy self-care. No feminist would argue one must spend time modifying one's body to fit into a limiting view of what a woman should be, but perhaps one should do so if it is about health. Indeed, if a sense of health or nature underlies the argument against excessive beauty work-then feminist might in fact call for healthy labor as valuable. Rosemarie Tong has argued that despite risks to the infringement of individual rights concerning body image and a weight-obsessed population, the costs of an increasingly overweight society justify certain initiatives. She argues for "common-sense" approaches like legislation that bans soft drinks at schools, funds nutrition education in schools, subsidizes walking and bike paths, and provides tax incentives to employers that allow for fitness breaks. ${ }^{48}$ We also can see other feminist takes on the need to create healthier bodies represented in blogs such as "Fit is a Feminist Issue," where the authors sell items for purchasesuch as coffee mugs-to celebrate their new fitness achievements, and promote others to achieve their fitness goals in a feminist manner. ${ }^{49}$ Bordo reads obesity alongside self-starvation for achieving a certain weight as a kind of symbol of the "contradictions" of the social body: "contradictions that make self-management a continual and virtually impossible project." 50 The unhealthiness of each body is seen as self-evident in her work, as is the idea that health is something we should work to obtain. Bordo does not put the blame on women for their size or suggest that their freedom is misused, rather she points out the impossible situation that women are forced into where ill-health is a likely outcome.

Samantha Murray's The "Fat" Female Body explores the example of fatness as it is constructed both within the fat activist movement and within the larger anti-fat world. Murray writes that public health policies directed toward encouraging "proper" eating and exercise are not educational so much as disciplinary. ${ }^{51}$ But this discipline is not to be administered centrally 
by the government; rather, it is to be instituted at the individual level. People in the developed world are aware of the correlation of obesity and overweight with poor health. Thus, public health policies do not inform people of the problem; rather, they provide different methods, rules, and tools for how to master the wayward body that are similar to aesthetic self-regulation. Murray notes that despite the seemingly population-wide focus of public health policies, they depend upon a certain idea of the self-agentic individual controlling herself.

Murray writes that this kind of "humanist/individualist logic" is so powerful that any data provided to contradict it is often rejected. ${ }^{52}$ The overwhelming evidence of the failure of diets is such an example. The blind insistence that the individual has the power to change her weight and thus should underlines how the the good-health imperative is a moral issue, obedience to it both a mark of both health and goodness. "Given the oft-proclaimed 'objectivity' of medicine, it is telling that the very ways in which we separate 'pathological' bodies from 'normal' bodies is just as much about upholding morality as it is about 'health." " ${ }_{53}^{3}$ The consequence of fatness being something one can overcome with proper action implies that those who have not overcome it are to blame. The fat itself is not the problem-it is the individual within the fat or the self who controls the fat. This creates a divided self, where the true self is some kind of disembodied will that exerts, or fails to exert, its influence over the mundane body.

In her discussion of fat activism, which is often explicitly feminist, Murray draws a different face on the same problem. Fat activists argue for fatness as simply a descriptor that holds no necessarily normative value about a body any more than curly hair or freckles should. Fat bodies can be healthy, beautiful, and sexy. If fat people are ill, they should be treated with the same care and dignity as anyone else. When the topic of health is approached, fat activists are often allied with movements such as the Health at Every Size (HAES) movement. ${ }^{54}$ HAES and other researchers, critical of the war against obesity, argue that dieting is largely deleterious for one's health, rarely successful, and that little evidence exists that proves fat people are doomed to lives of poor health. ${ }^{55}$ Contrasting with the war against obesity's focus on using weight as a measurement for health, critics stress healthy activity and eating for all people of all sizes and draw attention to studies indicating that the link between health and weight is not as conclusive as is often argued. But these arguments are themselves well situated within the good health imperative, the debate is merely what kinds of agentic control are possible and what promotes the best health.

Murray argues that the autonomous liberal subject haunts the seemingly emancipating politics of such fat activism. She points out that a type of disembodied agency underlies fat activism, where one is replacing one set of negative stereotypes with positive, celebratory ones. In order for such a model to work, a type of Cartesian dualism must be implicit, where the mind is seen as free in relation to the body. The celebration of fleshliness and of fat is counter to the dominant norms. "The 'fat goddess', standing 
firm against the world with her cottage-cheese thighs akimbo refuses normative ways of knowing: the knowledge others believe they have of her." ${ }^{56}$ But to celebrate one's fatness against the dominant aesthetic norm requires the now-liberated fat person to be separated in a different fashion from her body. "One must be 'fat and proud,' with no grey areas, no contradictions, no questions, no ambivalence." ${ }^{57}$ Such a project is based in the idea that the core self is the individual's will. I am what I judge myself to be; I am not what others judge me to be. Murray observes that the same humanist/individualist logic appears to be at play in much fat-positive literature, and the true nature of our embodied selves remains hidden. "As women, our bodies have been made strange to us: projects we are set apart from, and even the language we employ to talk about our bodies constantly moves from our flesh to ourselves." ${ }^{58}$ The female cultural body is still a project, one is encouraged to now see one's "attitudes" as the project, instead of one's fat. Thus, I can either, in the case of the war against obesity, modify my eating and exercise to fit a certain model of health and beauty, or in the case of fat activism, I can alter my mind to stop seeing my body as loathsome. If the public health outcry tells us to change our bodies, fat activists tell us to choose to change our minds. If we have not managed to easily do so, then more intensive work on the self is needed to now "love" ourselves.

The idea that one must change, one's body or mind or body, is drawn out in Heyes work where she notes the co-opting of feminist self-care in the rituals of mass-marketed dieting in Weight Watchers. She argues that while the patriarchal disciplinary practice in dieting produces an "appropriate feminine behavior and appearance," dieting is not only about achieving a culturally sanctioned look, but is "also a process of working on the self, marketed and sold to women with particular resonance, that cleverly deploys the discourse of self-care feminists have long encouraged." ${ }^{59}$ Feminists encourage women to work toward good self-care against the dominating, normalizing ideals of what a woman must be. There is something positively emancipating about taking care of my health in the face of a society demanding that I should devote my time to the care of others or some impossible ideal of beauty. Women learn not just how to modify their behaviors when working on dieting, but also an empowerment that comes with detailed careful attention to self-regulation-the "active, creative sense of self-development, mastery, expertise, and skill that dieting can offer." ${ }^{60}$ We can see these pleasures too in abundance in other forms of body work such as mastering a difficult piano piece or running a marathon. One cultivates new capacities, new pleasures, and new ways of taking up consciously one's habits and finding joy in new attitudes. Heyes contrasts docility with capacities to care for the self. She argues that a type of self-care is desired, one that would be agentic and chosen for feminist rather than normalized aims. She writes that some of the practices obtained in weight loss meetings- "improving awareness of one's own habits and feelings, or assuming responsibility for choices about how to live" - should be refocused. ${ }^{61}$ She says that increasing awareness of good self-care will produce individuals who are not docile 


\section{Feminist phenomenologies and self-regulating bodies}

and can find good ways to care for themselves. "Central to this awareness is the possibility of uncoupling new capacities from docility, and of recruiting those capacities to care for the self." ${ }^{2}$

Yet, how is one to tell if one's labor is self-care or docility? One idea might be to suggest that an activity, such as excessive beauty rituals, is unhealthy promotes docility if it limits one's capacity to engage with the world in a variety of ways, including ones that have not yet been explored. In distinction, self-care permits one to extend more meaningfully and happily into the world. As discussed in Chapter 2, health is often marked as the capacity for the body to rest in the background and in some kinds of body modification, the body may always be an object to be disciplined into submission, never allowing one to fully engage in the world. Thus, it isn't that there is a "natural" self that should not be covered with make-up or a particular way in which you should eat or move. For some, the delight in self-modification is one of life's charms: for others, a set of oppressive rituals. Whether such activities are expanding or restricting must be answered based in the individual lived circumstances, not abstracted from it.

Yet, one of the problems with beauty labor is that there are no natural boundaries to it even if it can often be pleasurable. One can take minimal time attending to one's appearance, or one can take most of one's free time. Makeup, hair, wardrobe, skin care, and also the work that could be for either beauty or health (or both)—exercise, these activities can be argued to create docile bodies-bodies who willingly regulate themselves and in so doing fail to challenge the status quo by supporting capitalist motivations, encouraging shame and self-loathing, and reducing one's possibilities to explore new ways of being. Yet, health work is so similar to this kind of labor it is hard to view it at not producing docility even if it does promote health. Health work also has no obvious limits. One's diet can always receive further care; one can work on sleep, on exercise, and as our research progresses, we can find in further detail other aspects of diet and exercise as well as other parts of caring for our human bodies that could receive improvement. Both require purchasing certain items and avoiding others (such as certain foods) and practices (quitting smoking, beginning yoga). Both are socially sanctioned and praised and entail real economic benefits. Failure, or perceived failure, is penalized with social and professional marginalization and higher medical care costs. Both require seeing the self as a constant project that can never be completed.

The actual agentic actions that one engages in for health versus for beautification do not present a clear line in their enactment, even if the ethos behind them is different. The kind of deliberate, educated, practice, and product centered work that we see with beauty rituals also surrounds good health behaviors-in particular if one's body or behavior is judged to be unhealthy. The discipline to get an unhealthy body healthy is structurally similar to the discipline to beautify oneself. I must educate myself, or be educated, on how to reduce my blood pressure by learning what food to buy and how to eat it. Instead of a tutorial on how to straighten my hair, I can follow the gym instructor on how to get fit. In both cases, one works 
to rid oneself of bad habits and work to build new and better ones. Both require a concern for one's body as it meets some external standard, say, BMI, or how far one approximates an external beauty ideal. Both require constant modification based on physical changes—age, illnesses-and environmental changes-work schedule, physical location.

Changing one's habits to healthier ones can often produce pleasures and capacities that were rare or even unknown in one's former state. In Chapter 6, I discuss somaesthetic philosophies that can be understood to focus and delight in such new pleasures in a potentially less normalized manner. It could be that docility can be avoided if one's self-care produces such a pleasurable and capable self. However, docility is also defined by adherence to certain norms in our contemporary biopolitical state discussed further in the next chapter. Given how pervasive the norm of the good health imperative is and its constant demands, it is unclear if it is a state that produces more capacities, or those newly discovered capacities are merely the sign that one's body now "fits" into a contingent, narrow world which will be discussed in the last section of the following chapter.

The concept of health can be used to work against the unhealthy ways in which bodies are normalized. My longevity and very existence depends on my health, and those can be threatened or at least diminished in quality if I cannot relate to my body in a way other than as a bad, imperfect object to be beautified. Yet, the concept that there is a healthy me underneath the normalized me that could be unveiled with the right consciousness-raising or phenomenological exploration is a curious proposition. If I am actively suffering, there may exist a pull away from such suffering and toward a more stable state where the ill body no longer renders my plans impossible to achieve. But, as discussed at the conclusion of Chapter 2 regarding obesity and disability-is my suffering obviously a result of some natural condition, or the social context wherein I am encouraged to view myself as unattractive and/or unhealthy, and thus I will suffer? In Chapter 4, I delve into work in biopolitics to better understand the view of personal responsibility inherent in the good health imperative.

\section{Notes}

1 Merleau-Ponty, Phenomenology of Perception. Translated by Donald Landes (New York: Routledge, 2012), 361.

2 Simone de Beauvoir, The Ethics of Ambiguity (New York: Citadel, 1976).

3 Beauvoir, The Ethics, 141.

4 Beauvoir, The Ethics, 141-142.

5 Komarine Romdenh-Romluc, "Habit and Attention." In The Phenomenology of Embodied Subjectivity, eds. R.T. Jensen and D. Moran (Dordrecht: Springer, 2013), 5.

6 Romdenh-Romluc, "Habit," 7.

7 Maurice Merleau-Ponty, Structure of Behavior. Translated by Alden L. Fisher. (Pittsburgh: Duquesne University, 1983): 166-167. See also Talia Welsh, The Child as Natural Phenomenologist: Primal and Primary Experience in MerleauPonty's Psychology (Evanston: Northwestern University Press, 2013), 8. 


\section{Feminist phenomenologies and self-regulating bodies}

8 Merleau-Ponty, Phenomenology, 368.

9 Merleau-Ponty, Phenomenology.

10 Merleau-Ponty, Phenomenology, 371.

11 See Andrew Meltzoff and Wolfgang Prinz, eds., The Imitative Mind: Development, Evolution, and Brain Bases (Cambridge: Cambridge University Press, 2002). I remain skeptical of some of the conclusions drawn about neonatal imitation as indicating a sense of self; however, I would agree with the consensus that infants use their tongues and mouths, what seems to be most open to their control, to explore the other and to explore the world. See Talia Welsh, "Do Neonates Display Innate Self-Awareness? Why Neonatal Imitation Fails to Provide Sufficient Grounds for Innate Self and Other-Awareness," Philosophical Psychology 19, no. 2 (2006): 221-238.

12 Maurice Merleau-Ponty, Child Psychology and Pedagogy: The Sorbonne Lectures 1949-1952. Translated by Talia Welsh (Evanston: Northwestern University Press, 2010): 424.

13 Merleau-Ponty, Child Psychology.

14 Merleau-Ponty, Child Psychology, 424. See also: Welsh, Child as Natural, 63-66.

15 Merleau-Ponty, Phenomenology, 364. Emphasis mine.

16 Merleau-Ponty, Phenomenology, 362.

17 Merleau-Ponty, Child Psychology, 130.

18 J.L. Moreno, Psychodrama (New York: Beacon House, 1975).

19 Merleau-Ponty, Child Psychology, 381.

20 Merleau-Ponty, Child Psychology, 381.

21 Simone de Beauvoir, The Second Sex. Translated by Constance Borde and Sheila Malovany-Chevallier (New York: Knopf, 2010), 444.

22 Rosayln Diprose. The Bodies of Women: Ethics, Embodiment and Sexual Difference (London: Routledge, 1994).

23 Sandra Lee Bartky, Femininity and Domination (New York: Routledge, 1990), 30.

24 Rosayln Diprose, The Bodies of Women: Ethics, Embodiment and Sexual Difference (London: Routledge, 1994), 119.

25 M. Aruguete, A. Yates, and J. Edman, "Gender Differences in Attitudes about Fat," North American Journal of Psychology 8 (2006): 183-192; Alejando Magallares and José-Francisco Morales, "Gender Differences in Antifat Attitudes," Revista de Psicología Social: International Journal of Social Psychology 28, no. 1 (2013): 113-119; W. Agras, S. Bryson, L. Hammer, and H. Kraemer, "Childhood Risk Factors for Thin Body Preoccupation and Social Pressure to be Thin," Journal of the American Academy of Child \& Adolescent Psychiatry 46 (2007): 171-178; V. Buote, A. Wilson, E. Strahan, S. Gazzola, and F. Papps, "Setting the Bar: Divergent Sociocultural Norms for Women's and Men's Ideal Appearance in Real-world Contexts," Body Image 8 (2011): 322-334.

26 T. Von Soest and L. Wichstrom, "Gender Differences in the Development of Dieting from Adolescence to Early Adulthood: A Longitudinal Study," Journal of Research on Adolescence 19 (2009): 509-529; G. Dutton, M. Perri, M. Dancer-Brown, M. Goble, and N. Van Vessem, "Weight Loss Goals of Patients in a Health Maintenance Organization," Eating Behaviors 11 (2010): 74-78; N. Sira and C. White, "Individual and Familial Correlates of Body Satisfaction in Male and Female College Students," Journal of American College Health 58 (2010): 507-514.

27 Magallares and Morales, "Gender Differences," 117.

28 Bartky, Femininity, 29.

29 Luna Dolezal, The Body and Shame: Phenomenology, Feminism, and the Socially Shaped Body (New York: Lexington, 2015).

30 Johanna Oksala, Feminist Experiences: Foucauldian and Phenomenological Investigations. (Evanston: Northwestern University Press, 2016), 118-119.

31 Barry Harper, "Beauty, Stature and the Labour Market: A British Cohort Study," Oxford Bulletin of Economics and Statistics 62, no. 1 (2000): 771-800. 
32 Sara Heinämaa, Toward a Phenomenology of Sexual Difference: Husserl, Merleau-Ponty, Beauvoir (London: Roman \& Littlefield, 2003), 68.

33 Merleau-Ponty, Phenomenology, 467.

34 Elizabeth Grosz, Volatile Bodies: Toward a Corporeal Feminism (Bloomington, IN: Indiana University Press, 1994), 94.

35 Oksala, Feminist Experiences, 122.

36 Oksala, Feminist Experiences, 48.

37 Susan Bordo, Unbearable Weight: Feminism, Western Culture, and the Body (Berkeley: University of California Press, 1995), 277-300.

38 H.W. Hoek and D. van Hoeken, "Review of the Prevalence and Incidence of Eating Disorders," International Journal of Eating Disorders 34, no.4 (2003): 383-396; NEDA (National Eating Disorders Association), "Eating Disorders Information Index," NEDA (2011), http://www.nationaleatingdisorders.org/.

39 Hoek \& Hoeken, "Eating Disorders," 394.

40 Denise C. Park, "Eating Disorders: A Call to Arms," American Psychologist 62, no. 3 (2007): 158.

41 NEDA, "Eating Disorders."

42 Bordo, Unbearable Weight, 170.

43 Iris Marion Young, Throwing Like a Girl and Other Essays in Feminist Philosophy and Social Theory (Bloomington, IN: Indiana University Press, 1990).

44 Bordo, Unbearable Weight, 166.

45 Cressida J. Heyes, Self-Transformations: Foucault, Ethics, and Normalized Bodies (Oxford: Oxford University Press, 2007), 73.

46 Heyes, Self-Transformations, 86.

47 Bartky, Femininity and Domination, 42.

48 Rosemarie Tong, "Taking on 'Big Fat': The Relative Risks and Benefits of the War against Obesity," Public Health Policy and Ethics 19, (2005): 53. See further discussion in Talia Welsh, "Healthism and the Bodies of Women: Pleasure and Discipline in the War against Obesity," The Journal of Feminist Scholarship 1 (Nov 2011): 33-48.

49 Fit is a Feminist Issue (blog), https://fitisafeministissue.com/

50 Bordo, Unbearable Weight, 187.

51 Samantha Murray, The "Fat" Female Body (London: Palgrave Macmillian), 29.

52 Murray, The "Fat," 71.

53 Murray, The "Fat."

54 Linda Bacon, Health at Every Size (Dallas: BenBella, 2008).

55 Wayt Gibbs, "Obesity: An Overblown Epidemic?," Scientific American 292, no. 6 (2005): 70-77; Gina Kolata, Rethinking Thin: The New Science of Weight Lossand the Myths and Realities of Dieting (New York: Farrar, Straus and Giroux, 2007); Eric J. Oliver, Fat Politics (Oxford: Oxford University Press, 2006).

56 Murray, The "Fat," 97.

57 Murray, The "Fat," 99.

58 Murray, The "Fat," 166.

59 Heyes, Self-Transformations, 63.

60 Heyes, Self-Transformations, 78.

61 Heyes, Self-Transformations, 87.

62 Heyes, Self-Transformations.

\section{Bibliography}

Agras, W., S. Bryson, L. Hammer, and H. Kraemer. "Childhood Risk Factors for Thin Body Preoccupation and Social Pressure to be Thin." Journal of the American Academy of Child \& Adolescent Psychiatry, 46 (2007): 171-178. 


\section{Feminist phenomenologies and self-regulating bodies}

Aruguete, M., A. Yates, and J. Edman. Gender Differences in Attitudes about Fat. North American Journal of Psychology, 8 (2006): 183-192.

Bacon, Linda. Health at Every Size. Dallas: BenBella, 2008.

Bartky, Sandra Lee. Femininity and Domination. New York: Routledge, 1990.

De Beauvoir, Simone. The Ethics of Ambiguity. New York: Citadel, 1976.

De Beauvoir, Simone. The Second Sex, translated by Constance Borde and Sheila Malovany-Chevallier. New York: Knopf, 2010.

Bordo, Susan. Unbearable Weight: Feminism, Western Culture, and the Body. Berkeley: University of California Press, 1995.

Buote, V., A. Wilson, E. Strahan, S. Gazzola, and F. Papps. "Setting the bar: Divergent Sociocultural Norms for Women's and Men's Ideal Appearance in Real-World Contexts." Body Image, 8 (2011): 322-334.

Diprose, Rosayln. The Bodies of Women: Ethics, Embodiment and Sexual Difference. London: Routledge, 1994.

Dolezal, Luna. The Body and Shame: Phenomenology, Feminism, and the Socially Shaped Body. New York: Lexington, 2015.

Dutton, G., M. Perri, M. Dancer-Brown, M. Goble, and N. Van Vessem. "Weight Loss Goals of Patients in a Health Maintenance Organization.” Eating Behaviors, 11 (2010): 74-78.

Fit is a Feminist Issue, (n.d.). https://fitisafeministissue.com/

Gibbs, Wayt. “Obesity: An Overblown Epidemic?," Scientific American 292, no. 6 (2005): 70-77.

Grosz, Elizabeth. Volatile Bodies: Toward a Corporeal Feminism. Bloomington, IN: Indiana University Press, 1994.

Harper, Barry. "Beauty, Stature and the Labour Market: A British Cohort Study," Oxford Bulletin of Economics and Statistics 62, no.1 (2000): 771-800.

Heinämaa, Sara. Toward a Phenomenology of Sexual Difference: Husserl, MerleauPonty, Beauvoir. London: Roman \& Littlefield, 2003.

Heyes, Cressida J. Self-Transformations: Foucault, Ethics, and Normalized Bodies. Oxford: Oxford University Press, 2007.

Hoek, H.W., and D. van Hoeken, "Review of the Prevalence and Incidence of Eating Disorders," International Journal of Eating Disorders 34, no.4 (2003): 383-396

Kolata, Gina. Rethinking Thin: The New Science of Weight Loss-and the Myths and Realities of Dieting. New York: Farrar, Straus and Giroux, 2007.

Magallares, Alejando, and José-Francisco Morales. "Gender Differences in Antifat Attitudes." Revista de Psicología Social: International Journal of Social Psychology, 28:1 (2013): 113-119.

Marion Young, Iris., Throwing Like a Girl and Other Essays in Feminist Philosophy and Social Theory. Bloomington, IN: Indiana University Press, 1990.

Meltzoff, Andrew, and Wolfgang Prinz, eds. The Imitative Mind: Development, Evolution, and Brain Bases. Cambridge: Cambridge University Press, 2002.

Merleau-Ponty, Maurice. The Structure of Behavior, translated by Alden L. Fisher. Pittsburgh: Duquesne University, 1983.

Merleau-Ponty, Maurice. Child Psychology and Pedagogy: The Sorbonne Lectures 19491952, translated by Talia Welsh. Evanston: Northwestern University Press, 2010.

Merleau-Ponty, Maurice. Phenomenology of Perception, translated by Donald Landes. New York: Routledge, 2012.

Murray, Samantha. The "Fat" Female Body. London: Palgrave Macmillian, 2008.

NEDA (National Eating Disorders Association). Eating Disorders Information Index. NEDA, 2011. http://www.nationaleatingdisorders.org/. 
Oksala, Johanna. Feminist Experiences: Foucauldian and Phenomenological Investigations. Evanston: Northwestern University Press, 2016.

Oliver, Eric J. Fat Politics. Oxford: Oxford University Press, 2006.

Park, Denise C. "Eating Disorders: A Call to Arms," American Psychologist 62, no. 3 (2007): 158.

Romdenh-Romluc, Komarine. "Habit and Attention." In The Phenomenology of Embodied Subjectivity, edited by R.T. Jensen and D. Moran, 3-20. Dordrecht: Springer, 2013.

N. Sira, and C. White. "Individual and Familial Correlates of Body Satisfaction in Male and Female College Students." Journal of American College Health, 58 (2010): 507-514.

Von Soest, T., and L. Wichstrom. "Gender Differences in the Development of Dieting from Adolescence to Early Adulthood: A Longitudinal Study." Journal of Research on Adolescence, 19 (2009): 509-529.

Tong, Rosemarie. "Taking on "Big Fat": The Relative Risks and Benefits of the War against Obesity," Public Health Policy and Ethics 19, (2005): 53.

Welsh, Talia. "Healthism and the Bodies of Women: Pleasure and Discipline in the War against Obesity," The Journal of Feminist Scholarship 1, (November 2011): 33-48. 


\section{Biopolitics and personal responsibility}

It is true that $\mathrm{I}$ (and most other persons free from any debilitating illness and with sufficient means) could better my (their) health. The idea that through a series of choices, I can responsibly improve my well-being might seem as obvious as any state I wish to improve-such as my piano skills, my parenting, or my teaching. For all of these, I need to attend to my current practice, inform myself of what information or training I need, and apply myself. However, these other examples are not universally shared, desired future states for others. Not everyone is a parent, teacher, or pianist. There is nothing inherently unreasonable about not wanting to embody these things. On the other hand, being healthier appears to be something universally desired. If it is not, we might wonder if the person is ill-informed or irrational.

Biopolitics is a wide-ranging field of study that encompasses many different disciplines, but its common thread is understanding the connection between scientific/social interests in life and political/economic interests. This chapter examines how biopolitics explains that our current state is not only a continuation of existential human concerns, but rather a new way of policing bodies. This chapter is not a summary of the vast multidisciplinary discourse on biopolitics, but an examination into how this work can help elucidate how the human subject becomes a modifiable object of policies, norms, and laws. It discusses how we are normalized and why we do not reject normalization as oppressive. Using the example of campaigns against childhood obesity, this chapter will explore how norms of responsible parenting require the good health imperative as part of proper parental behavior. Visible responsible parenting takes ideological precedence over invisible reproductive labor. While desiring the health and well-being of one's children is not necessarily culturally or historically located, the current model of responsible parenting passes over the racial disparities in parenting, health, and reproductive labor.

\section{Foucault's biopolitical revolution}

Michel Foucault's thought provides an analysis of the regime of self-improvement that colors our contemporary experience. In many of his earlier works, Foucault explores how shifts in power (such as power in the

DOI: $10.4324 / 9781003168676-4$ 
hands of the government) and knowledges-in particular the growth of the sciences surrounding the human-underwent significant transformations over time. On a certain level, this claim tells us nothing new. Obviously, systems of governance and the sciences have changed radically. I am not ruled by a king; I know that the earth rotates around the sun. Foucault, however, does much more than this kind of evident historical analysis in his works. He argues for a certain understanding of the relationship between power and knowledge that comes to shape not just practices and policies, but actual ways in which we understand ourselves. While only some of his work directly addresses biopolitics, much of his writing works against the tradition of thinking that there is a kind of universal "human nature." Few reject that we are conditioned by our culture, but Foucault argues that we are deeply constituted, shaped, and molded. His work traces how changes in political regimes arise not from "better" ideas, but from a complex of what we would think about as traditionally political and economic interests, "power," as well as "knowledges." Knowledges, in particular the human sciences of medicine, psychiatry, psychology, and the social sciences, in both their academic and applied settings, come to shape political investments and in turn are shaped by those investments. Instead of viewing sciences as independent of politics or politics as independent of the sciences, Foucault sees them as intertwined. In addition, this combination of knowledges and power comes not just to rule, well or poorly, subjects but to actually transform their subjectivity. Before considering his work on biopolitics, I will discuss his understanding of discipline and docility.

While Foucault's texts Discipline \& Punish and Madness and Civilization are concerned with carceral institutions and asylums for the mad, he also appealed to the way in which such concern for bodily control was used in other institutions like schools and the military for the large-scale control of various populations. He tracked how innovations in research as well as political and historical shifts moved power from being about rulers and their whims to a systematic control of the population as a whole. Such broad control requires a means to monitor the population, track its performance, and refine its control. Most importantly, it requires that the subjects of control become different kinds of subjects-they must become trained to self-monitor and control themselves.

The discipline in Foucault's research is about how we are trained, without explicit force, to control our bodies in routine and precise ways-such as a student who learns to sit, listen, and write for defined periods and then move for other defined periods, or an employee who learns how to do the same at work. One might also think of the precise and long-term training that an athlete or musician learns in order to execute without attention complex motions for certain kinds of performance. However, in these cases, there is no assumption that such training should apply to all persons. One may become a musician, but one isn't abnormal if one doesn't become one. Foucault is interested in not how bodily training works and becomes habitual in various optional activities (like hobbies), but the ways in which 
certain kinds of bodily training arise as ways in which a large number of diverse bodies are disciplined to conform.

This kind of control is not perceived for many reasons. Since its purpose is to manage at the population level, if it is effective, it appears simply as the way things are. Consider the way in which our bodies are taught through education and workplaces to control themselves in certain ways within certain time frames. In school, one learns how to sit and listen, how to consider the day to begin in the morning and to end in the evening, and how eating, using the restroom, talking, and running all have certain predetermined times and places in which these activities are acceptable. In addition, one learns to see education as a series of tasks with various grades attached to these tasks. This provides a good training to easily accommodate oneself to professional workplaces where one similarly needs to control one's body, for instance at meetings, at one's desk, the particular ways to complete various tasks, projects, and assignments. After all, who doesn't go to school and sit, who doesn't wake up and go sit at a desk at work? It isn't just normalizing-it is normal.

Another reason it is hard to perceive how individuals are trained is that variations are permitted, and any individual thus has the sensation of choosing particular activities. After all, one can choose a major in college, and one can choose to vote for this candidate over that one. What Foucault underlines is that it is at the level of controlling the body that we find power, not at the level of controlling opinions or attitudes. If one uses explicit force or explicit indoctrination, one exposes the vulnerability of power. If one understands from where power emanates, one can try to hide, work against it, fight it, or at minimum intellectually reject it. In addition, it is inefficient for controlling large numbers of persons. What one really needs is a populace that obeys without constant monitoring or force. One needs trained persons who do not perceive their situation as a result of oppression, but rather focus on the small set of choices they have and concern themselves on how their choices compare to others. Conformity is based not in a conscious obedience, but in blindness to disciplinary regimes.

In pre-Modern eras, one might wish for a better king or a better government in the way that one might wish for a better parent. The rights of the king were absolute but also located within him. The bloody infighting of many royal families testifies to the need to physically be in the role to have the power. The people's affection or hatred may promote, impede, or even overthrow a ruler, but the ruler did not "manage" the people-he ruled them well or poorly. However, as populations grew and condensed in cities, previous forms of controlling the mad and the criminal were insufficient. Populations were now not only in need of more systematic control for reasons of taxation, managing criminality, and insanity, but also for the spread of disease. A beneficent or cruel ruler alone could do little to monitor and manage the population. One needs some way to understand what the constitution of the population is, what means could better manage it, and also what could better foster it to various ends. One needs human sciences and a stable bureaucracy that will enact the role of population management. 
Foucault argues that in order for new forms of disciplinary power to take shape, one needs an interplay of the growth of power and more sophisticated forms and knowledges about how to enact such power. Without refinement, power would remain in its essentialist and brute form where one only obeys out of fear of a particular actor or actors.

In the case of schools and workplaces, sciences-such as pedagogy and management science-arise alongside the increasing number of individuals within those institutions. Since we now exist in such social and easily monitored spaces it isn't just that we are trained, we are subjects from which to obtain more information. Studies are conducted which permit continual modification and refinement that allow us to be trained with greater efficacy. Academics study management science, the performance of various existing management structures, and produce research which finds its way into popular management books and journals for managers to consider in their workplaces. Education researchers track, monitor, and assess various ways in which students perform well or poorly. Foucault notes that the ongoing refinement by the social sciences provides a means "not to punish less, but to punish better; to punish with an attenuated severity perhaps, but in order to punish with more universality and necessity; to insert power to punish more deeply into the social body." ${ }^{1}$ While corporeal punishment in schools has been on the wane, if not outright forbidden, one might argue that punishment has been greatly lessened at schools. However, a Foucauldian analysis would point to how the growth of monitoring, tracking, measuring, and requiring various benchmarks for students, teachers, schools, and school systems is a much deeper way in which students, teachers, and systems are controlled even if this punishment is "attenuated." Foucault already documented, in the early sciences surrounding mental illness and criminal justice, movements away from corporeal punishment and torture as ineffective in rehabilitating individuals toward systems of observance and behavior training that better control individuals and (if possible) make them capable of re-entering the social body.

While it can seem only rational to collect information on populations for research, Foucault documents the extraordinary difference this now commonplace collection of demographic data is from previous eras where only those of prestige were considered models for scrutiny and documentation. Now each individual in a workplace, school, hospital, or prison is a possible case study. Not only that, but every insurance holder, credit card user, and internet user are cases to be monitored, studied, and used for disciplinary techniques. ${ }^{2}$ Unknown to Foucault but well known to us now, we can monitor the population with clearer and finer detail through our interactions with technologies to produce ever expanding sets of big data for researchers, corporations, and governments to use. Ultimately, one does not want to obtain individuals who are simply automatons through our educational and workplace environments, but ones who retain and effectively use their training. One wants individuals who are normalized but also productive and innovative when it would be economically valuable for the worker to be so. 
The political investment of the body is bound up, in accordance with complex reciprocal relations, with its economic use; it is largely as a force of production that the body is invested with relations of power and domination; but, on the other hand, its constitution as labour power is possible only if it is caught up in a system of subjection (in which need is also a political instrument meticulously prepared, calculated and used); the body becomes a useful force only if it is both a productive body and a subjected body. ${ }^{3}$

A well-taught student should become a productive prospective employee, flexible to the demands of a changing job market. It would be poor practice to produce students with no capacity for reflection on their labor or capacity to change their work. Good employees are productive within the system, willing to take on new responsibilities and find new solutions to potential problems.

If we consider this discussion in reference to the good health imperative, we can see how self-monitoring and modification are considered to be de rigueur for proper behavior. To return to the example of the athlete who trains her body, we can see how we have moved in the last decades to a space in which it is commonplace for average persons to engage in athletic practices that previously would have been reserved for the professional or hobbyist in the 1950s and 1960s. In a world where only athletes work out, one would feel no particular need to engage in such practices unless such a hobby appealed to one any more than one feels the compulsion to practice an instrument if one has no inclination.

The manner in which it is typically considered completely acceptable to chide, encourage, and monitor bodies that fail to adhere to health standards of self-regulation-smokers, drinkers, the obese-demonstrates that the social body willingly accepts that attention to one's health is no longer just a practice for the few. As research has allowed us to track the effect of certain behaviors on likely health outcomes, we can increasingly develop an idea of the responsibility of the individual to practice the right behaviors and the moral duty of the society to create worlds in which this is possible. Normalization in the case of health should be understood not as producing identical bodies - which is, as of yet, impossible-but producing the right kind of identity in relation to one's body.

It is acceptable in such a model of a proper identity that one may have greater or smaller challenges, like those due to genetics, but as long as one understands that taking proper care of one's body is important and behaves accordingly, one has adopted the right kind of identity. One can think here too of our ideas about wealth. While it would be foolish to think that the person born into millions and the person born into poverty have the same starting ground for personal wealth accumulation, both persons can adopt the right identity toward their actions by taking it upon themselves to make the most of their options and thus to increase their personal wealth. If wealth and health are perceived to be gifts of birth, then one can't really encourage normalization. Rather they must be achievable states that everybody can work toward. 
Yet how does the individual experience such a demand if she does not find herself in the group of the healthiest performers? The role of comparisons is critical to the labor of good health, much like how career successes and failures reduces the sense of being normalized by the workplace and increases focus on the behaviors of particular individuals in the workplace. I can attend to my recent paper publication or my appointment on a committee at work. I can determine whether my colleague seems to be doing better or worse than I and consider what I could do to improve my situation. In the case of health, I will never be a world class athlete, but I can engage in a variety of activities to improve my physical fitness. In addition, I can monitor others in my workout classes, my work, my social world, and place myself in relative comparison to them. This will provide me with an assortment of possibilities of minor improvements, both on my own condition and in relation to others. Foucault notes that in order for docility to be encouraged, one needs levels of micro-control, and individuals must be invested in such levels of difference if they are to be properly docile. This is because it not only provides finer capacities for control, but also for our purposes fosters the sense of personal control which is born out of distinguishing one's behavior from one's neighbor. ${ }^{4}$ In the case of health, one can work toward monitoring one's own physical states and then improving upon them: if one has gained or lost a $1 / 2$ pound, if one has done yoga or CrossFit today, if last week, one didn't eat any candy, if one ran a 5-k, a marathon, or an Ironman. Within those highly regulated competitions, did one best one's previous time? Has one's blood pressure reduced since the last test? "The judges of normality are everywhere," Foucault writes-from the person on the street to your face in the mirror that judges if you have succeeded or failed. ${ }^{5}$

One finds a sense that previous forms of government, while often random and brutal, provided a certain amount of freedom from normalization as these forms of governments had not the knowledge, nor the means to manage the populations so completely. Unless one received the attention of the sovereign or another power source, little was provided, and similarly, little was expected. In his discussion of madness in the Middle Ages in Madness \& Civilization, Foucault romanticizes the "ship of fools" (Narrenschiff) and the idea that mad people were seen as features of nature rather than persons to investigate and alter. ${ }^{6}$ As the mad presented no challenge to the sovereign's power, they didn't demand his gaze. However, as societies became larger and more integrated, the mad could be destabilizing and thus became an object of study and regulation. In addition, his work on normalization and biopolitics makes any knowledge and any use of power to reject another form of power as always themselves establishing new modalities of possible normalization. After pointing out the way in which we can see biopolitics played out in the Nazi concern with health and hygiene to justify their racism, Foucault claims that socialism likewise uses biopower for its own ends. He lectures that not only did socialism not critique biopower, but also, that it took it up, "developed, reimplanted, and modified it in 


\section{Biopolitics and personal responsibility}

certain respects," and that like Nazism its guidance is "the essential function of society or the State, or whatever it is that must replace the State, is to take control of life, to manage it, to compensate for its aleatory nature, to explore and reduce biological accidents and possibilities..." This kind of discussion has led some to connect with and explore contemporary anarchist ideology of rejecting the state in any form and others to ask about Foucault's libertarian streak. ${ }^{8}$

We find a common experience of subjectivity in certain histories and times that organize themselves around the norms prevalent at that time. This work is called "subjectivation": to highlight in our contemporary biopolitical times how we are encouraged to see certain parts of us as things to control and work on and others as optional. Thomas Lemke writes that subjectivation is "the manner in which subjects are brought to work on themselves, guided by scientific, medical, moral, religious, and other authorities and on the basis of socially accepted arrangements of bodies and sexes." ${ }^{\prime 9}$ In writing about sexuality, Foucault notes that in retrospect we can wonder at all the devices used by religion to make the body an object of sin, mistrust, and condemnation. To think that my body, my desires, and my very being is something sinful that I should see it as a problem rather than a space of happiness, joy, and connection is almost impossible for me to imagine. As a secular person, I read such discussions with interest but find no particular space upon which I can connect to them other than a historical oddity and feel relieved I don't have to endure such superstitious beliefs.

However, Foucault writes that this body-positive/sex-positive ideology today is also constricting, even if its appearance is liberatory. We are now encouraged to see ourselves as needing to love our sexuality, to spend time fostering it, and to make it a centerpiece of our identity. Foucault challenges us to ask if this is actually more freeing that the sex-as-sin ideology of the past.

We are often reminded of the countless procedures which Christianity once employed to make us detest the body; but let us ponder all the ruses that were employed for centuries to make us love sex, to make the knowledge of it desirable and everything said about its procedures. Let us consider the stratagems by which we were induced to apply all our skills to discovering its secrets, but which we were attached to the obligation to draw out its truth, and made guilty for having failed to recognize it for so long. These devices are what ought to make us wonder today. ${ }^{10}$

We can likewise ask about health and loving care for our bodies. While there are many pleasures and benefits to such behavior, it is certainly markedly different than living in a time where one is encouraged to work on the state of one's soul, one's intelligence, or one's status as a citizen. While all promote a feeling of inadequacy that must be met by self-control and discipline, their contents and the way in which they work in conjunction with other economic and social pressures is quite different. 
Yet, while this discussion helps elucidate some aspects of the way in which bodies are disciplined to be healthy, one might return to the question of why so many institutions, from governments, to employers, to schools, to non-profits, take this call so seriously. What justifies this particular increasing interest in encouraging exercise among the non-professional athlete population and not the demand that we should instead spend our free time educating ourselves? From a personal point of view, one could simply point to the increase of research that documents certain behaviors with longer, healthier lives. But Foucault's later work in biopolitics helps explore just why this became an interest for systems of power and thus how institutions take this call more seriously and systematically than other obvious pressing social issues.

In the History of Sexuality Volume I, Foucault discusses how the right of the sovereign moves from the right to take life-say to order an executiontoward a kind of government rationality that views its purpose managing all lives. ${ }^{11}$ Previously the sovereign's right would be seen in his power to kill, to forgive, and to enact policies that suited him without any interest or research into the population as a whole. Foucault sees contemporary politics as increasingly about management of populations in order to obtain better control over them. "Biopolitics," Foucault lectures, "deals with the population, with the population as a political problem, as a problem that is at once scientific and political, as a biological problem and as power's problem." ${ }^{2}$ The population - rather than the glory of the King, or God, or the interests of the few-is the proper target of biopolitical control.

In his lectures at the Collège de France, Foucault discusses various ways in which changes at the end of the eighteenth century created an interest in managing endemics as well as epidemics. Foucault takes epidemics to be cases of disease that quickly spread, killing many. The development of better means to address plagues or similar epidemics developed with improved science and methods of enforcing public order. Endemics are illnesses that were difficult to eradicate that "sapped the population's strength, shortened the working week, wasted energy, and cost money, both because they led to a fall in production and because treating them was expensive." ${ }^{13}$ Obesity, smoking, and alcohol/drug abuse are all often called epidemics, but this term endemic helps distinguish them from pandemics or plagues. The poor health of the obese, alcoholics, or smokers don't require a single cure, like a disease might, but a range of institutions, policies, and practices to defeat them. In order to work on the health of the population, biopolitics "will establish not only charitable institutions (which had been in existence for a very long time), but also much more subtle mechanisms that were more economically rational...insurance, individual and collective savings, safety measures, and so on." ${ }^{14}$ Foucault argues that it is critical for biopolitics to establish "regulatory mechanisms" which will "establish an equilibrium, maintain an average, establish a sort of homeostasis, and compensate for variations within this general population and its aleatory field." ${ }^{15} \mathrm{He}$ calls these "security mechanisms" that are designed to produce regularized populations. ${ }^{16}$ 
While Foucault is considering the past as the birth of these biopolitical movements toward monitoring, controlling, and fostering health in the population, we can see today similar concerns. The growth of public health, the interests of corporations, governments, health insurance agencies, charities, and schools all contribute to a complex set of policies, norms, and laws that are designed to police unhealthy behavior and encourage proper behavior. However, one might conclude that while producing conformity and perhaps also senses of guilt, such as the shame discussed in the previous chapter for not "producing" the right body, it is better for governments, and other institutions, attend to the health of the populace. However, as Foucault and other thinkers of biopolitics have underlined, biopolitical regimes are filled with extraordinary tolerance and appetite for death, such as in the case of the Nazi regime which in part promoted itself as about health. We have learned in the wealthiest country in the world, we are completely fine with well over half a million people dying from COVID-19. It is actually possible to let many people die, many others suffer, and still stock market prices will increase, well-to-do people will be fed, clothed, and cared for and can continue pursue their concerns. In reference to COVID-19, Antonio Pele and Stephen Riley write, "Biopolitics has been designed and evolved only and strictly for economic purposes and to enable the ongoing development of capitalism." ${ }^{17}$ Preventable deaths and illnesses are not in principle problems. They rise to the status of being problems only if they threaten the neoliberal capitalist development and well-being of those who are its main beneficiaries; a trend that will be explored further in the next chapter.

\section{The case of childhood obesity}

If the body is the paper on which the script of health normalization is written, one comes to an immediate difficulty. Bodies are wildly variable. Friedrich Nietzsche rails against the moralizing of not just Christianity but all of Western morality for desiring uniformity, and in the pursuit of such uniformity, moralists have to create shadow worlds of souls and gods to try and handle the uncomfortable fact of diversity: "Reality shows us an enchanting wealth of types, the abundance of a lavish play and change of forms-and some wretched loafer of a moralist comments: 'No! Man ought to be different.'”18 The moralist strives for uniformity and will insist on it even in the face of reality demonstrating the wild variations in human life and experience. For Nietzsche, the only way to achieve this uniformity is to create false worlds and false things, like souls. The concern of the good health imperative seems eminently practical and does not promote unreal beings. However, as the religious moralist finds, the moralist of the good health imperative must deal with the fact that bodies vary in any population in health, and also any one body varies widely over the course of its life. To discipline all this variety for a well-managed population seems an impossible task.

Promoting healthy behavior is not going to produce identical bodies the same way a factory could produce identical automobiles. What biopower needs is the capacity for bodies to be carefully distinguished and each 
fostered in relative comparison to alleviate their disparities and to motivate better performance. Such a power needs "continuous regulatory and corrective mechanisms" in order to "qualify, measure, appraise, and hierarchize." 19 Diversity is not eliminated; rather it is reorganized as "distributions around the norm." ${ }^{20}$ If the encouragement was to compete at the Olympic level, I wouldn't even bother trying. My body is not going to do such things. But, if the point is to be better than other bodies to obtain lower cost health care, this I can do. I can also distinguish myself from previous states. Researchers can track various kinds of bodies and various interventions and see which bodies respond best to various policies. One can track groups of persons over time and determine what carrots and sticks produce the best behavioral outcomes and then return to refine the system.

To move from this more general discussion to a particular one that explores the rationale of a biopoliticized world and its effects on our everyday lives-consider the radical increase in interest in children's weight and thereby the various metrics to measure, determine, and influence it and, in so doing, change parental behavior. The number of children classified as overweight or obese has grown in a relatively short time frame, some calling it a pandemic of this millennium. ${ }^{21}$ Overweight and obese children are more likely to become overweight and obese adults and suffer from a variety of poor health outcomes. This body of research in the demographics of children's biostatistics is used to justify a variety of interventions in the bodies of children, their schools, and their homes. But it isn't just the bodies of overweight or obese children that are targeted, rather the rationale is that all children's bodies must be safeguarded against overweight and obesity in order to ensure a properly healthy future.

We can see in the regulation of children's bodies the biopolitical concern with population management in the policies and interventions to create disciplined bodies. However, a problem with this is that children are not seen to be capable of taking up the burden of the good health imperative, as they are not in control of their food consumption and activity levels in the way adults are. Since children are not seen as responsible for their behavior in the same way as adults, and because children become adults, targeting their parents as the locus of proper healthy behavior is increasingly common. In the United Kingdom over a five-year period, 74 children were removed from their homes on the basis of obesity. ${ }^{22}$ In the Journal of the American Medical Association, a defense of such a practice was published in a commentary citing the dramatic health outcomes possible for a life of obesity and federal law that defines child abuse and neglect. In this defense, Lindsey Murtagh and David S Ludwig argue that there are cases where removal of the child from the home may be necessary. Interestingly, they acknowledge the possibility that some obese children (although they note a small percentage) may have an unrecognized genetic disease that contributes to their weight, but except for leptin deficiency, "no new therapeutic options" are typically available and thus "an intensification of the home-based behavioral interventions" are needed which have already "proven unsuccessful in these families." ${ }^{23}$ Citing 
extensive research on the psychological toll that removal from one's house produces in a child, not all physicians agree with the conclusion of these authors that removal from the house would produce better health for the child, but the general rationale is not uncommon. If a child is found to be obese, an intense program of training at home is demanded, and if the child has a special disease that makes weight loss difficult, an even more intensive home practice is needed in conjunction with medical care. In addition, this work calls upon all parents to monitor their behaviors noting "Even relatively mild parenting deficiencies, such as having excessive junk food in the home or failing to model a physically active lifestyle, may contribute to a child's weight problem." ${ }^{24}$ When drawn to a story about a child whose obesity is shocking, any parent reading the story is reminded of the dangers of obesity in children and exhorted to take up the mantle to monitor the weight of one's child more carefully. The authors conclude with the justification for further governmental programs calling for "investments in the social infrastructure and policies to improve diet and promote physical activity among children." 25

Another possible tactic to encourage good parental behavior is shaming. ${ }^{26}$ The State of Georgia, like the rest of the southeast United States, has a high percentage of overweight and obese children. A controversial campaign in 2012 placed billboards with fat children in black and white photos looking grim and headlines that all start with "WARNING", followed by lines such as "It's hard to be a little girl, if you are not", "My fat may be funny to you, but it is killing me", "Fat prevention begins at home, and the buffet line." A television spot has a child asking his mom, "Mom, why am I fat?" Children's Healthcare of Atlanta designed the program Strong4Life specifically targeting obesity and overweight in children. Their flashy and engaging webpage provides a series of tips and strategies for parents to promote health from birth onward. The justification for the ad campaign was the rationale that parents were not taking childhood obesity seriously and needed to be reminded how devastating it is for children's health. If one can attach proper nutrition and exercise to the identity of what a good parent does (and thus what constitutes a bad parent), one foreseeably could achieve better compliance with health behavior recommendations.

Another trend in the US is to put the child's weight on their report card or to provide a weight report card. Arkansas was the first state to do so in 2004 to work toward stopping the advancement of overweight and obesity in children. ${ }^{27}$ The letters provided some general tips on how to increase exercise, reduce screen time, and provide better nutrition. Dr Joe Thompson argues that "I think the alarm bell should be sounded that this epidemic may be advancing much more quickly than previously predicted." ${ }^{28}$ This trend unites the concern for future populations with the demand for parents to make sure such future populations are properly healthy. The non-profit Trust for America's Health whose motto is "Preventing Epidemics. Protecting People" echoes the idea of the oncoming epidemic nature of childhood obesity with their report " $\mathrm{F}$ as in Fat: How Obesity Threatens America's Future 2010.”29 It argues for the alignment of non-profits, schools, state and federal governments to work together to create a good future. 
Foucault uses the term "apparatus" to discuss "a thoroughly heterogeneous ensemble consisting of discourses, institutions, architectural forms, regulatory decisions, laws, administrative measures, scientific statements, philosophical, moral and philanthropic propositions." ${ }^{30}$ An apparatus is how one can see within this ensemble a certain discourse about sexuality emerging. "Thus, a particular discourse can figure at one time as the programme of an institution, and at another it can function as a means of justifying or masking a practice which itself remains silent, or as a secondary re-interpretation of this practice, opening out for it a new field of rationality." ${ }^{11}$ These different fields not only take up sexuality differently, but they also inform each other and cause changes in its contemporary constitution and force. Foucault also says that the apparatus has a "strategic function" that responds to an urgent need." ${ }^{32}$

We can see an apparatus surrounding childhood obesity as well as a growth of regulatory mechanisms that track bodies and track the success of various interventions. Some of its players are charities, but particularly in the US, charities function hand-in-hand with governmental operations, specifically within schools. We see the role of medical and health care research, interest among the exploding academic and professional field of public health, the pressure of insurance agencies, the moral calls to take better care of children, the economic concern about future healthy workers, and military concern about future sufficiently healthy soldiers. We can see increasing interest in legislation from banning junk food at schools and policies to bring back more recess forming. While the institutions involved do not overall necessarily share the same missions or goals, we see a webbed relationship around this issue of obesity in a shared drive to creating a slimmer population. Foucault lectures that the norm is what circulates between the disciplines of particular bodies-such as exercise programs for children and teaching nutrition in schools-and the regulatory mechanisms are what track and encourage population wide behavior. "The norm is something that can be applied to both a body one wishes to discipline and a population one wishes to regularize." ${ }^{33}$ Johanna Oksala explains that

What distinguishes Foucault's analyses of social practices from those of a number of other thinkers is not only the idea that practices always incorporate power relations directly and causally manipulate the subjects in them, but that the rules of discursive practices are intimately tied to social norms. ${ }^{34}$

A norm determines how a scientific knowledge by becoming accepted will come to have sway over certain policies and decisions. However, the discovery itself will not be digested or acted upon unless it participates in the norm which serves other interests, as many a frustrated research scientist will lament when a well-documented concern receives no attention, but one with little scientific substance hits the headlines. 


\section{Problematizations}

Foucault pointed out that what any apparatus creates ends up also producing certain ways it can be rejected. After all, the good health imperative does not always easily dovetail into the kinds of desires that corporations and governments may share. The productive nature of docile bodies-ones that will not just obey, but be good workers-also means a certain inherent possibility to destabilize the system that creates them. Foucault briefly discusses how the increasing interest in using power as biopower created individuals who see their rights as tied to not just the right to not be killed, but the right to live in a certain way- "The 'right' to life, to one's body, to health, to happiness, to the satisfaction of needs, and beyond all the oppressions or 'alienations,' the 'right' to rediscover what one is and all that one can be..." 35 The apparatus that stresses health promotion might cause the normalized health-centered individual to turn against work at the workplace arguing for better health care, longer vacations, better leave for pregnancy-all things that may run counter to some of the interests of economic forces that may wish to maintain a certain productive level of health, but not one that is too costly.

In A Brief History of Neoliberalism, David Harvey points out that for any theory to sway vast amounts of the population and policy makers, it must appeal to us on some level-it must satisfy us in some intuitive, and I would say existential, way. Harvey writes that for a "way of thought to become dominant, a conceptual apparatus has to be advanced that appeals to our intuitions and instincts, to our values and our desires, as well as to the possibilities inherent in the social world we inhabit." ${ }^{36}$ Indeed, the language of biopolitics for the individual is often cast in terms of the individual now being capable of being in charge of her health, or that of her children as discussed above. While one might skeptically wonder if this very idea of self-control and freedom is the ultimate indoctrination of the neoliberal program to roll back all governmental support to allow the flowers of the free-market bloom unhindered-the desire for control over one's circumstances is hardly a newly created emotion. While certainly not every person in every period of time found the concept of freedom central, it seems also rush to assume that we desire something like free control of our situation simply because of our current historical era.

Contrary to the highly individualistic way of thinking enshrined in neoliberal approaches to the population, ancient Daoist texts are filled with various means to caution humans against their desire to mold and control and to encourage proper leaders to permit things to occur with as little interference as possible. In the Zhuangzi, Hui Sui asks Zhuangzi if one can be without the impulses of man. Zhuangzi replies that, "What I mean by being without the essentials of man is that the man does not inwardly wound his person by likes and dislikes, that he constantly goes by the spontaneous and does not add anything to the process of life." ${ }^{37}$ However, Zhuangzi acknowledges while it is desirable to be in this state, it would be impossible for almost everyone 
but a Daoist sage. In the Daodejing, the sage understands like heaven and earth to not be humane. The sage "regards all the people as straw dogs" thus emphasizing the foolishness of rituals obsessed over human life and death. ${ }^{38}$ However, like in the Zhuangzi, only the sage can take such a step. Humans are partial and filled with preferences, desires, and fears. But if one is a sage, one can learn that error doesn't come from bad policies, but more from the human desire to shape and make policies. Humans came out, in a sense, wrong with this arrogance that we do not see the much more harmonious and self-less universe. While today we caution people to take control, not to wu wei-non-action-still such a different cultural reference suggests that very different persons in different times did see the human desire for control as something common about human experience, even if this example above indicates, something, perhaps counter-intuitively, to be avoided.

To many, the kind of self-determination espoused in the good health imperative is a champagne of ideas-something we want but now are finding out that we can obtain. Harvey thus points out that if a way of thought successfully feeds on desires, then when it becomes dominant it "...becomes so embedded in common sense and is not open to question." ${ }^{39}$ Feeling that we could take charge of our bad habits and replace them with good ones is psychologically satisfying. While Foucault might not agree with the concept that there is something inherently human about certain norms that gives them part of their appeal, a critical phenomenological approach is able to accept the idea both that one is shaped by one's circumstance, even to the point of one's desires and sense of self, but that there can also be found a shared set of existential concerns and desires that span, with obviously large modifications, across cultures and peoples. How then do we separate out what is constituted by a culture bent on political and economic aims that have little to do with well-being and the possible value of such self-directed action toward health?

Foucault argues in an interview close to his death that he is not looking to find the right solution, but rather to "problematize" the ways in which regulatory and monitoring systems of power achieve their ends. He does not argue for a set of alternative policies, governmental structures, or social norms, but points out that certain problems cannot be erased by the influence of certain kinds of policies and disciplinary practices.

It is true that my attitude isn't a result of a form of critique that claims to be methodical examination in order to reject all possible solutions except for the valid one. It is more on the order of "problematization"-which is to say, the development of a domain of acts, practices, and thoughts that seem to me to pose problems for politics. For example, I don't think that in regard to madness and mental illness there is any "politics" that can contain the just and definitive solution. ${ }^{40}$

Sexuality, madness, and criminality are not elements of individual psyches that "exist apart from a relationship to political structures, requirements, 


\section{Biopolitics and personal responsibility}

laws, and regulations that have a primary importance for it." ${ }^{41}$ However, even if one's sexuality is thoroughly understood and lived within such structures, the wild diversity of humanity suggests that no politics can create a space in which sexuality, for instance, will cease to be a problem, and within this space one can think about how one is constituted without requiring that one can take some kind of universal, God's eye view, of humankind. Foucault points out that while one cannot exist outside one's situation, to think that one's sense of one's own body is problematic-one's experience must have become uncertain, have lost its familiarity, or provoked some kinds of difficulties. ${ }^{42}$

To problematize the good health imperative, we can consider what is not discussed that might equally, if not more so, demand the attention of the social whole. Tracking of the population has permitted us to see trends in weight gain among children. Parallel research in the issues associated with high weight gain encourage the conviction that something should be done. However, such a move requires not just the documentation of weight and overweight-related illnesses, but the rationale that it is this kind of issue, and not others, that justifies governmental and social intervention. For that to work and to compel individuals, we must see a certain kind of attitude and accompanying behavior toward one's health as universally imperative. With the right measures, it should be necessary for all individuals to have the responsibility and competence to address their health which requires that they identify with this responsibility. In the case of individuals who are not capable of such responsibility—such as children—their caregivers need to pick up this mantle. While this reasoning might seem obvious to many, what a society attends to and what it ignores reveals that this focus excludes while it includes.

Consider the overwhelming documentation about the increasing gap between the richest and poorest in society, and the how the latter's situation worsens each year, and with minorities having the least gains, the most losses, and the greatest disparities with the wealth which we see magnified under COVID-19. The typical net worth of a white family is "nearly ten times greater than that of a black family" in $2016 .{ }^{43}$ During the recession, from 2007 to 2013, median net worth for Black families fell $44.3 \%$, whereas it fell comparatively only $26.1 \%$ for white families. The Brookings Institution reports that, "the ratio of white family wealth is higher today than at the start of the century." ${ }^{44}$ Little organized action on poverty exists, even despite repeated documentation on its adverse effects and its growing racial disparities. Under COVID-19, which kills Blacks at a rate three times that of whites, we also find that job losses are concentrated at the bottom fifth of earners-jobs that are largely held by Black and Latino workers. ${ }^{45}$ Despite these alarming long-term and short term trends, neither the mainstream Democratic nor Republican party have made alleviating the situation of the poor a rallying cry for decades, preferring to focus on the concerns of the middle-class. Corporations are not interested in paying their workers more, governments look for ways to reduce support for the poor 
in order to support tax cuts to promote business and middle-class interests, and charities fight in disparate, uncoordinated ways to aid the needy. One possible solution to the problems facing minorities with poor work and health prospects is to address systemic racism and poverty, rather than providing farmer's markets, but because no such apparatus exists around poverty-no coordinated action exists as well as no coordinated sense of obligation is imparted to us to address it.

The relative lack of an apparatus to support alleviating poverty and the increasingly robust one to promote health demonstrates how discriminatory power can be present even with everyone having the very best intentions. Someone who personally takes it as a calling to help the poor is certainly not reviled and is praised, but such an inclination does not command as universally as that of working on health. One may feel a deep guilt for not helping the poor, but not helping the poor as a central life project is quite normal. One may be lauded for charity for the poor, but it would be a kind of morally beneficial hobby and not seen socially as necessary for acceptance in polite society. To work on ameliorating the condition of the poor is like playing an instrument that helps others. Smoking, however, is an affront to any public space, any workplace, and is a scarlet letter for the smoker as a personal failing. Someone who despite the capacity to do better fails to ameliorate her behavior to improve her poor health is generally judged to be guilty. My workplace, like most in the developed world, makes no particular effort to encourage us to care for the disadvantaged, but it does provide a series of initiatives, including recently becoming smoke-free, to encourage our better health. To judge someone based on her or his health, or perceived health, is simply normal, and to hate oneself for one's fatness or bad health is much more common than to hate oneself for one's lack of commitment to improving the condition of the least fortunate. Parental responsibility is thus not a global responsibility-but a targeted one. One may or may not raise one's children to be advocates for the poor, but one must raise them to be healthy and in so doing be capable of seeing health as a personal imperative.

\section{Parental responsibility}

At the time of finishing this book in August 2021, over 4.43 million people have died from COVID-19 globally, 628,625 in the United States. ${ }^{46}$ The United States is also currently under the highest growth in cases during the pandemic due to the Delta variant, vaccination hesitancy, and a lack of public health protocols being enforced in the hardest hit states like masks and social distancing. In the United States, many of the deaths and serious illnesses caused by COVID-19 were preventable by basic public health recommendations such as mask-wearing and not gathering in large crowds. A study by Columbia University published on October 21, 2020, estimates that $130,000-210,000$ deaths were preventable and, since that publication, we have seen the numbers of new cases and deaths skyrocket. ${ }^{47}$ Cases and 


\section{Biopolitics and personal responsibility}

deaths have mainly been born by the elderly, the disabled, and racial, and ethnic minorities. These disparities have laid bare the vast disparities in lives that are valued and those that are seen as disposable in the United States. Studies have revealed the intersectional nature of this burden. For instance, people with disabilities who are Black, Asian, Hispanic, Native American, below poverty, young, and female have greater incidences of COVID-19 than older white men with disabilities even when one controls for social distance and community. ${ }^{48}$ Moreover, front-line workers in meatpacking and food production have higher rates and those workers are more likely to be non-white. ${ }^{49}$

Infamously, white male Republican and staunch Trump supporter, Dan Patrick the Lieutenant Governor of Texas argued that given the fears of economic turndown, old people should be willing to die in order for us not to have to endure the financial fallout of shut-downs..$^{50}$ In Texas as well, a (now former) mayor Tim Boyd of Colorado City said that "no one owes you or your family anything" during a devastating state-wide power shut down with much of the state in single-digit (Fahrenheit) temperatures. ${ }^{51}$ After quick outcry, Boyd, after quitting, tried to clarify what he meant by saying,

I was only making the statement that those folks that are too lazy to get up and fend for themselves but are capable should not be dealt a handout. I apologize for the wording and some of the phrases that were used! $!^{52}$

No one can pull themselves up by the bootstraps if they are freezing to death, so one must assume that the background for Boyd is that one wouldn't be in such a position if one had previously led one's life well. In other words, if one had of been responsible and organized one's life accordingly. Likewise, Patrick gave himself as an example since he was a grandfather, he had lived a good life, so he could sacrifice it for the economy. What is striking too is that these politicians did not see themselves as needing to do something, as politicians-to help those who need help. Instead, it was those that need help were in fact understood as the problem to good government. In biopolitical regimes the management of life is not the promotion of life-it is about management. Lives are simply to be managed or left to die as needed.

White people and Republicans (who are overwhelmingly white) are the least likely to consistently wear masks. ${ }^{53}$ Important work is being done in understanding just how misinformation has complicated basic public health protocol compliance as well as how the politicization of COVID-19 by Republicans has muted effective responses. While misinformation, lying, and politicization have certainly contributed to many having a strongly held view on something that they might not have bothered to otherwise, I argue also that mask wearing to attend to the health of others is a violation of the path of personal responsibility, and thus, personal control that makes thinking systemically and structurally anxiety provoking. There is, following Linda 
Martín Alcoff, an epistemology of ignorance, of refusal to understand, accept, or even engage with public health recommendations paradoxically in a world awash with celebrations of "healthy behavior." ${ }^{54}$ I argue that while such ignorance can result in illness and death, it is not opposed to the good health imperative, but continuous with its main conclusion that it is the individual who is master of his fate (and here I use "his" purposefully) and by his own hands can create his bodily state for better or for worse. Likewise, children who have poor health outcomes, being that they cannot take up individual responsibility themselves, have guilty parents who have failed to take up their responsibility properly. Race, social class, and environment fade out of any kind of analysis if the target is the individual's freedom and responsibility. And as we see in the rejection of vaccines, even basic scientific information cannot override the sense that an individual or a family can control their own fate and any "interference" is met with skepticism, if not anger.

One common justification for such intertwining of charities, schools, and governments about the weight of children is that fact that most parents of overweight children report finding their children to look fine. ${ }^{55}$ This has changed significantly in the last ten years, in particular among African Americans and lower-income parents. The shift is attributed to the overall growth of obesity and overweight in society. Thus, being overweight and obese is actually the norm, so one's child being this way is as well. Many parents are suspicious of the medically received charts, seeing them as misrepresentative of what is normal. ${ }^{56}$ The authors of one study on parental perceptions argue in their conclusion that "Novel strategies should be developed to target parental recognition of their child's weight status. Sensitive and culturally competent dialogues to encourage parental involvement are needed to unleash parental power." ${ }^{57}$

This rationale that parents have "power" and that the right policy would harness that power and make parents more responsible caretakers underlines a certain conception of what the identity of a good parent is: a good parent is the protector of the child's health and thereby from the apparatus's point of view a good protector of the future health of the population. Parental power is thus refining a certain kind of responsible behavior. The parents serve to uphold long-standing moralizing about the sanctity of the family and benefit the preferred minimal investment from insurance agencies and social support systems. Thus, the shift to the "power" of the parents and away from the children with actual or likely future poor health is a subtle move. The obvious goal is to help the children achieve healthy weights, but if it is parents who are responsible, then structural issues such as the larger social, economic, and political world are less important. Charities, government agencies, health agencies, and doctors are responsible only insofar as they have not communicated the responsibility of parents to take up their "parental power" and provided the necessary incentives for them to do so.

Nikolas Rose documents how the biopolitics of health has become a matter of a moral necessity that trumps all other concerns with ideologies of choice and responsibility as its hallmarks: 
...[T] he rise of a secular morality in which life and health are the only ends thought worth pursuing, and so forth-in the process we are seeing the emergence of an innovative new ethics of biological citizenship and genetic responsibility. Our somatic, corporeal, neurochemical individuality now becomes a field of choice, prudence, and responsibility. ${ }^{58}$

Rose explains how personal striving for health and wellness are closely allied with political, scientific, medical, and economic interests; he documents the convergence of a variety of factors that encourage seeing biology as merely a starting point toward greater and greater perfection. Our popular media devours stories of heroic parents who against all odds are able to find a solution to a child's illnesses through fatigueless devotion and careful attention to detail. These stories have for the American spirit an almost opioid quality - anything is achievable with the right mix of moxie and determination. But even beyond this Horatio Alger quality of such tales, there is something all-too-human-who doesn't want to think it is possible to aid one's loved ones if just enough effort is made? Who wouldn't make that effort? Hence, it is no wonder that the parents who fail to control their children's weight are seen, and may see themselves, as failures.

Frieder Vogelmann argues that contemporary responsibility in work is not a simple continuation of something inherent in adult, rational beings, but rather a form of self-understanding, self-making, and social normalization. ${ }^{59}$ Of interest for our study here, he draws attention to how the intensification of practices of instilling responsibility (he takes up labor, criminality, and philosophy as three practices) is uneven between the attributors of responsibility, say management, and the bearers, say the workers. ${ }^{60}$ For instance, in the 2008 recession, white-collar financiers who created the situation often made out quite well, whereas working class persons who lost their jobs are now "responsible" for finding new ones. Likewise, in the COVID-19 pandemic, workers in food service, health care, food production, and nursing homes find themselves faced with the responsibility of caring for their own health and being responsible workers (two things that are opposed) in a way vastly unequally borne by professionals who are now able to telecommute. While Vogelmann does not take up Marxist critiques of wage-labor, reproductive labor, parenting or schooling, his analysis of how "the spell of responsibility" functions in contemporary management ideologies for wage-laborers provides a fertile ground for considering just what a good child product is for the wealthy and why children's health is read as a central matter of responsible parenting.

Vogelmann uses a largely Foucauldian perspective to argue that one's development of self increasingly occurs as a set of practices. The stability of a subject is a process of a small number of practices in which a core of identity forms around, but is also constantly reproduced in "a whole web of practices." ${ }^{61}$ These practices are not indoctrinations that create uniform subjects, but patterns of intensifying one's relationship to oneself in such a manner that one sees oneself as responsible for oneself. This 
responsibility is not an only a burden, but a productive place of self-formation and self-transformation. The change toward a responsible self is a self who thinks of oneself reflexively. One can think of the process of encouraging young children to think of others in their acts-would you like it if Jane hit you? - which requires the capacity to think of oneself from outside. The child's hitting Jane upon the frustration of her having a favored toy must develop into a space in which the "I should not hit" intervenes. Responsibility might appear merely prohibitive at times-that is when it would be nicer to not need to think about oneself-but also can be very productive as one can see oneself as something to transform, not just to obey.

One crisis that we face today as parents who wish our children to have good employment is the constantly shifting nature of the workforce for educated and wealthy persons. Fewer and fewer white-collar wage-laborers work for a single company for life, often changing careers, not just jobs. The problem becomes what Vogelmann calls in relation to the unemployed-the "transformation problem"-that is how does one turn the capacity to work into real work ${ }^{62}$ How does one raise one's children to be adaptable to their future wage labor? Vogelmann argues that the training of employees to be see their labor not as toil, but as a source of value and of personal value. The subjectification of labor that "by way of recoding and attaching more and more importance to the employee's relation to self." ${ }^{33}$ The unemployed that depend upon taxpayer dollars are problems of the wrong kind of subject, not individuals luckily freed from toil who might be costly to the rest of us. They should not just work; they should want to work. However, the more one sees one's labor as one's personal project, the more responsibility becomes intensified in those least situated to be in charge and those who suffer most from economic and social contingencies.

The following chapter will begin by expanding upon the idea of parental responsibility and its connection to work by exploring reproductive labor in general. In reproductive labor, we find that it is, as Vogelmann notes, those most vulnerable to their situation as most responsible for their work and health. The role of working on one's health in our neoliberal capitalist society will be seen as a manner in which to obtain surplus labor and is encouraged by fetishizing the body as a product. In conclusion, the next chapter will discuss the idea of the healthy body as a fetish that organizes our behavior under the sway of an ideology of affirmative culture.

\section{Notes}

1 Michel Foucault, Discipline \& Punish: The Birth of the Prison. Translated by Alan Sheridan (New York: Vintage, 1995), 82.

2 Foucault, Discipline \& Punish, 191.

3 Foucault, Discipline \& Punish, 25-26.

4 Foucault, Discipline \& Punish, 222-223.

5 Foucault, Discipline \& Punish, 304.

6 Michel Foucault, Madness and Civilization. Translated by Richard Howard (New York: Vintage, 1988), 7-10. 


\section{Biopolitics and personal responsibility}

7 Michel Foucault, "Society Must Be Defended": Lectures at the Collège de France 1975-1976. Translated by David Macey (New York: Picador, 1997): 261.

8 For instance, the recent book Foucault and Neoliberalism explores Foucault's relationship with such policies. (Daniel Zamora and Michael C. Behrent, eds., Foucault and Neoliberalism (London: Polity, 2015).) Todd May explores Foucault's influence in contemporary poststructuralist anarchism. (Todd May, The Political Philosophy of Poststructuralist Anarchism (University Park: Penn State Press, 2005).)

9 Thomas Lemke, Biopolitics: An Advanced Introduction (New York: New York University Press, 2011).

10 Foucault, History of Sexuality I, 159.

11 Michel Foucault, The History of Sexuality: An Introduction, Volume I. Translated by Robert Hurley (New York: Vintage, 1990), 135-136.

12 Foucault, History of Sexuality I, 245.

13 Foucault, History of Sexuality I, 244.

14 Foucault, History of Sexuality I.

15 Foucault, History of Sexuality I, 246.

16 Foucault, History of Sexuality I.

17 Antonio Pele and Stephen Riley, "For a Right to Health Beyond Biopolitics: The Politics of the Pandemic and the "Politics of Life," Law, Culture and the Humanities (2021), 3.

18 Friedrich Nietzsche, "Twilight of the Idols," In The Portable Nietzsche, translated \& ed. Walter Kaufmann (New York: Penguin, 1976), 491.

19 Foucault, History Sexuality I, 144.

20 Foucault, History Sexuality I.

21 Sue Y.S. Kimm and Eva Obarzanek, "Childhood Obesity: A New Pandemic of the New Millennium," Pediatrics 110, no. 5 (2002): 1003-1007.

22 News agencies, "Obese Children Removed from Families," The Telegraph, February 28，2014, http://www.telegraph.co.uk/foodanddrink/healthyeating/10667066/Obese-children-removed-from-families.html

23 Lindsey Murtagh and David S. Ludwig, "State Intervention in Life-Threatening Childhood Obesity,"JAMA 306, no.2 (2011):206-207. doi: 10.1001/jama.2011.903

24 Murtagh and Ludwig, "State Intervention," 206.

25 Murtagh and Ludwig, "State Intervention."

26 Kathy Lohr, "Controversy Swirls Around Anti-Obesity Ads," NPR, January 9, 2012,https:/www.npr.org/2012/01/09/144799538/controversy-swirls-around-harshanti-obesity-ads

27 Rosie Mestel, “Arkansas Schoolchildren Getting Weight Report Cards,” Los Angeles Times, June 4, 2004, http://articles.latimes.com/2004/jun/04/science/sci-obese4

28 Mestel, "Arkansas Schoolchildren."

29 Elle Hogan, Laura Segal, and Susan Levine, "F as in Fat: How Obesity Threatens America's Future 2010," Trust for America's Health, June 29, 2010, http:// healthyamericans.org/newsroom/releases/?releaseid=216

30 Michel Foucault. "The Confession of the Flesh," In Power/Knowledge: Selected Interviews \& Other Writings 1972-1977, translated by Colin Gordon, Leo Marshall, John Mepham, and Kate Soper, ed. Colin Gordon (New York: Vintage, 1980), 194.

31 Foucault, "The Confession," 195.

32 Foucault, "The Confession."

33 Foucault, Society Must Be, 253.

34 Johanna Oksala, Feminist Experiences: Foucauldian and Phenomenological Investigations (Evanston: Northwestern University Press, 2016), 31.

35 Foucault, History of Sexuality I, 145.

36 David Harvey, A Brief History of Neoliberalism (Oxford: Oxford University Press, 2005), 5. 
37 Chuang-Tzŭ: The Inner Chapters. Translated by A.C. Graham (Indianapolis: Hackett, 1989), 82.

38 Daodejing. Translated by Hans-Georg Moeller (Chicago: Open Court, 2007), 15. Hans-Georg Moeller writes that "The Daoist sages acknowledge these human characteristics and do not aim in abolishing them. However, they remain untouched by them... The Daoist sage is thus not an 'overman' but rather an 'underman' who remains below the threshold of human individuation-as opposed to all other human individuals." Hans-Georg Moeller, The Philosophy of the Daodejing (New York: Columbia, 2006): 134-135.

39 Harvey, Neoliberalism, 5.

40 Michel Foucault, "Polemics, Politics, and Problemizations: An Interview," In The Foucault Reader, translated by Lydia Davis, ed. Paul Rabinow (New York: Vintage, 2010), 384.

41 Foucault, "Polemics."

42 Foucault, "Polemics," 388, 390.

43 Kristin McIntosh, Emily Moss, Ryan Nunn, and Jay Shambaugh, "Examining the Black-white Wealth Gap," The Brookings Institute, February 27, 2020. https:/www.brookings.edu/blog/up-front/2020/02/27/examining-the-blackwhite-wealth-gap/

44 McIntosh et al., "Examining."

45 Greg Rosalsky, "How The Crisis Is Making Racial Inequality Worse," Planet Money-National Public Radio, May 26, 2020, https://www.npr.org/sections/ money/2020/05/26/860913793/how-the-crisis-is-making-racial-inequality-worse

46 Johns Hopkins Coronavirus Resource Center. 2021.Global Map. https://coronavirus.jhu.edu/map.html

47 Irwin Redlener, Jeffrey D. Sachs, Sean Hansen, and Nathaniel Hupert. “130,000210,000 Avoidable COVID-19 Deaths and Counting in the U.S," October 21, 2020. https://ncdp.columbia.edu/custom-content/uploads/2020/10/AvoidableCOVID-19-Deaths-US-NCDP.pdf

48 Jayajit Chakraborty, "Social Inequalities in the Distribution of COVID-19: An intra-Categorical Analysis of People with Disabilities in the U.S," Disability and Health Journal 14, 7 (2021). https://doi.org/10.1016/j.dhjo.2020.101007

49 Michelle A. Waltenburg, Charles E. Rose, Tristan Victoroff, Marilee Butterfield, Jennifer A. Dillaha, Amy Heinzerling, Meagan Chuey, Maria Fierro, Rachel H. Jervis, Kristen M. Fedak, Andrea Leapley, Julie A. Gabel, Amanda Feldpausch, Eileen M. Dunne, Connie Austin, Caitlin S. Pedati, Farah S. Ahmed, Sheri Tubach, Charles Rhea, Julius Tonzel, Anna Krueger, David A. Crum, Johanna Vostok, Michael J. Moore, Hannah Kempher, Joni Scheftel, George Turabelidze, Derry Stover, Matthew Donahue, Deepam Thomas, Karen Edge, Bernadette Gutierrez, Erica Berl, Meagan McLafferty, Kelly E. Kline, Nichole Martz, James C. Rajotte, Ernest Julian, Abdoulaye Diedhiou, Rachel Radcliffe, Joshua L. Clayton, Dustin Ortbahn, Jason Cummins, Bree Barbeau, Stacy Carpenter, Julia C. Pringle, Julia Murphy, Brandy Darby, Nicholas R. Graff, Tia K.H. Dostal, Ian W. Pray, Courtney Tillman, Dale A. Rose, Margaret A. Honein, and CDC COVID-19 Emergency Response Team, "Coronavirus Disease among Workers in Food Processing, Food Manufacturing, and Agriculture Workplaces," Emerging Infectious Diseases, January 27(1) (2021), 243-249.

50 Bess Levin, "Texas Lt. Governor: Old People Should Volunteer to Die to Save the Economy," Vanity Fair. March 24, 2020. https://www.vanityfair.com/ news/2020/03/dan-patrick-coronavirus-grandparents

51 Graig Graziozi, “Texas Mayor Resigns after Telling Residents he Owed them 'nothing' Following Storm Power Outage," Independent, February 17, 2021.

52 Jamie Burch, "Colorado City Mayor Resigns, Responds to His Controversial Facebook Post,” KTXS12-ABC News, February 16, 2021. https://ktxs.com/ news/local/colorado-city-mayor-resigns-after-controversial-facebook-post 
53 Megan Brenan, “American's Face Mask Usage Varies Greatly by Demographics,” News Gallup, July 13, 2020. https://news.gallup.com/poll/315590/americansface-mask-usage-varies-greatly-demographics.aspx

54 Linda Martín Alcoff, "Epistemologies of Ignorance-Three Types," In Race and Epistemologies of Ignorance, ed. Shannon Sullivan and Nancy Tuana (New York: State University of New York Press, 2007), 39-57.

55 Andrew R. Hansen et al., "Generational Shift in Parental Perceptions of Overweight Among School-Aged Children," Pediatrics 134, no. 3 (September 2014): 481-488, doi:10.1542/peds.2014.

56 Hansen et al., "Generational Shift," 485.

57 Hansen et al., "Generational Shift," 488.

58 Nikolas Rose, The Politics of Life Itself: Biomedicine, Power, and Subjectivity in the Twenty-First Century (Princeton: Princeton University Press, 2009), 39-40.

59 Frieder Vogelmann, The Spell of Responsibility: Labor, Criminality, Philosophy. Translated by Daniel Steuer. In Essex Studies of Contemporary Critical Theory (New York: Rowman \& Littlefield, 2018).

60 Vogelmann, Spell of Responsibility, 5.

61 Vogelmann, Spell of Responsibility, 39.

62 Vogelmann, Spell of Responsibility, 79.

63 Vogelmann, Spell of Responsibility, 79.

\section{Bibliography}

Alcoff, Linda Martín. "Epistemologies of Ignorance-Three Types.” In Race and Epistemologies of Ignorance, ed. Shannon Sullivan and Nancy Tuana. New York: State University of New York Press, 2007, 39-57.

Brenan, Megan. “American's Face Mask Usage Varies Greatly by Demographics.” News Gallup. July 13, 2020. https://news.gallup.com/poll/315590/americans-face-mask-usage-varies-greatly-demographics.aspx

Burch, Jamie. "Colorado City Mayor Resigns, Responds to his Controversial Facebook Post.” KTXS12-ABC News. February 16, 2021. https://ktxs.com/news/ local/colorado-city-mayor-resigns-after-controversial-facebook-post

Chakraborty, Jayajit. "Social Inequalities in the Distribution of COVID-19: An Intra-categorical Analysis of People with Disabilities in the U.S." Disability and Health Journal 14, 7 (2021). https://doi.org/10.1016/j.dhjo.2020.101007

Chuang-Tzŭ. The Inner Chapters, translated by A.C. Graham. Indianapolis: Hackett, 1989. Foucault, Michel. "The Confession of the Flesh.” In Power/Knowledge: Selected Interviews \& Other Writings 1972-1977, translated by Colin Gordon, Leo Marshall, John Mepham, and Kate Soper, edited by Colin Gordon. 194-228. New York: Vintage, 1980.

Foucault, Michel. Madness and Civilization, translated by Richard Howard. New York: Vintage, 1988.

Foucault, Michel, The History of Sexuality: An Introduction, Volume I, translated by Robert Hurley. New York: Vintage, 1990.

Foucault, Michel. Discipline \& Punish: The Birth of the Prison, translated by Alan Sheridan. New York: Vintage, 1995.

Foucault, Michel. "Society Must Be Defended": Lectures at the Collège de France 1975-1976, translated by David Macey. New York: Picador, 1997.

Foucault, Michel. "Polemics, Politics, and Problemizations: An Interview." In The Foucault Reader. translated by Lydia Davis, edited by Paul Rabinow, 381-390. New York: Vintage, 2010. 
Graziozi, Graig. "Texas Mayor Resigns After Telling Residents He Owed Them 'Nothing' Following Storm Power Outage.” Independent. February 17, 2021.

Hansen, Andrew R., Dustin T. Duncan, Yelena N. Tarasenko, Fei Yan, and Jian Zhang. "Generational Shift in Parental Perceptions of Overweight Among SchoolAged Children.” Pediatrics 134, no. 3 (September 2014): 481-488. https://doi. org/10.1542/peds.2014.

Harvey, David. A Brief History of Neoliberalism. Oxford: Oxford University Press, 2005.

Hogan, Elle, Laura Segal, and Susan Levine. "F as in Fat: How Obesity Threatens America's Future 2010.” Trust for America's Health, June 29, 2010. http:// healthyamericans.org/newsroom/releases/?releaseid=216.

Johns Hopkins Coronavirus Resource Center. 2021. Global Map. https://coronavirus.jhu.edu/map.html

Kimm, Sue Y.S., and Eva Obarzanek. "Childhood Obesity: A New Pandemic of the New Millennium.” Pediatrics 110, no. 5 (2002): 1003-1007.

Lemke, Thomas. Biopolitics: An Advanced Introduction. New York: New York University Press, 2011.

Levin, Bess. "Texas Lt. Governor: Old People Should Volunteer to Die to Save the Economy." Vanity Fair. March 24, 2020. https:/www.vanityfair.com/ news/2020/03/dan-patrick-coronavirus-grandparents

Lohr, Kathy. “Controversy Swirls Around Anti-Obesity Ads.” NPR, January 9, 2012. https://www.npr.org/2012/01/09/144799538/controversy-swirls-around-harshanti-obesity-ads.

May, Todd. The Political Philosophy of Poststructuralist Anarchism. University Park: Penn State Press, 2005.

McIntosh, Kristin, Emily Moss, Ryan Nunn, and Jay Shambaugh, "Examining the Black-white wealth gap," The Brookings Institute, February 27, 2020. https://www. brookings.edu/blog/up-front/2020/02/27/examining-the-black-white-wealth-gap/

Mestel, Rosie. “Arkansas Schoolchildren Getting Weight Report Cards.” Los Angeles Times, June 4, 2004. http://articles.latimes.com/2004/jun/04/science/sci-obese4.

Murtagh, Lindsey, and David S. Ludwig. "State Intervention in Life-Threatening Childhood Obesity.” JAMA 306, no. 2 (2011): 206-207. https://doi.org/10.1001/ jama.2011.903.

News Agencies. “Obese Children Removed from Families.” The Telegraph, February 28, 2014. http://www.telegraph.co.uk/foodanddrink/healthyeating/10667066/ Obese-children-removed-from-families.html.

Nietzsche, Friedrich. "Twilight of the Idols." In The Portable Nietzsche, translated and edited by Walter Kaufmann. New York: Penguin, 1976.

Oksala, Johanna. Feminist Experiences: Foucauldian and Phenomenological Investigations. Evanston: Northwestern University Press, 2016.

Pele, Antonio, and Stephen Riley, "For a Right to Health Beyond Biopolitics: The Politics of the Pandemic and the "Politics of Life." Law, Culture and the Humanities (2021), 1-17.

Redlener, Irwin, Jeffrey D. Sachs, Sean Hansen, and Nathaniel Hupert, "130,000210,000 Avoidable COVID-19 Deaths and Counting in the U.S." October 21, 2020. https://ncdp.columbia.edu/custom-content/uploads/2020/10/AvoidableCOVID-19-Deaths-US-NCDP.pdf

Rosalsky, Greg. "How The Crisis Is Making Racial Inequality Worse," Planet Money-National Public Radio, May 26, 2020, https://www.npr.org/sections/ money/2020/05/26/860913793/how-the-crisis-is-making-racial-inequality-worse 


\section{Biopolitics and personal responsibility}

Rose, Nikolas. The Politics of Life Itself: Biomedicine, Power, and Subjectivity in the Twenty-First Century. Princeton: Princeton University Press, 2009.

Tzu, Lao. Daodejing, translated by Hans-Georg Moeller. Chicago: Open Court, 2007.

Vogelmann, Frieder. The Spell of Responsibility: Labor, Criminality, Philosophy, translated by Daniel Steuer. In Essex Studies of Contemporary Critical Theory. New York: Rowman \& Littlefield, 2018.

Waltenburg, et al. "Coronavirus Disease among Workers in Food Processing, Food Manufacturing, and Agriculture Workplaces." Emerging Infectious Diseases, January 27(1) (2021), 243-249.

Zamora, Daniel, and Michael C. Behrent, eds. Foucault and Neoliberalism. London: Polity, 2015. 


\section{Marxism, reproductive labor, and the body as fetish object}

\section{Reproductive labor-dirty and clean work}

If I can take better care of my children and I do not, it is I who is to blame, not the government, or charitable agencies. Hence, even though academic researchers who work on childhood health highlight the need for more intervention within poor and minority populations, the logic of "parental power" also argues at cross purposes. While the child can be understood to be blameless, policies shift the responsibility to the parents under the guise of parental autonomy. Thus, large scale systematic inequalities are rarely addressed since it is at the level of the bodies of children via parental responsibility that intervention is the most justified, not at the level of addressing the historical and economic factors that make for such wide disparities in standards of living.

Poor and minority populations do not only have larger numbers of childhood obesity in the United States, they have across the board significant health disparities with wealthier white children. ${ }^{1}$ In addition, minority children have less insurance coverage and it is less consistent. ${ }^{2}$ While sensitive public health policies are concerned with such disparities and advocate for increasing insurance and providing support for better healthcare, food access, and safe streets, research is also finding that poverty and access are not sufficient to explain disparities in health between white and minority children. For example, in a study on childhood asthma, researchers found that living above the poverty line is related to less asthma in children. However, they found that living above the poverty line provided a greater association of less asthma for white families than for Black families. ${ }^{3}$ They cite the "Minorities' Diminished Return Theory" that argues that the protective effects of socioeconomic status are weaker for racial minorities than for white families. ${ }^{4}$ Shervin Assari writes

In nearly 20 papers, my colleagues and I have found that in the United States, economic resources and psychological assets systematically result in a smaller health gain for Blacks compared to Whites. These findings hold for a wide range of SES (socio-economic status) resources (eg, education, employment, neighborhood safety) as well as psychological 
assets (eg, emotions, anger management, sleep quality, self-efficacy, perceived control over life, and self-rated health) on health. ${ }^{5}$

Disparities in healthcare access between white and Black and Hispanic children is also correlated with higher rates of unusual childhood illnesses, longer treatment cycles, and higher rates of infant mortality. ${ }^{6}$ In order to consider how this particularly affects parenting, I turn to a discussion of reproductive labor and health. The bifurcation of reproductive labor into what I will call "visible, responsible parenting" and "invisible reproductive labor" is often ignored in discussions of parental power.

What is reproductive labor? I take here a definition from Mignon Duffy that it encompasses two main branches-"Work that maintains daily life (physical or mental health, food preparation and service, cleaning, personal care), or work that reproduces the next generation (care of children and youth)." With Duffy's definition, we can think of the work of parentingthe education, feeding, and raising children as visible, responsible parenting and the dirty work of producing and harvesting food, preparing it, and providing basic physical care as invisible reproductive labor.

Reproductive labor has a place in Marx and Engels's theory, but times have significantly changed. Marx and Engels understood the family household as the locus of both visible and invisible reproductive labor, for both for the wealthy and the poor, even if the wealthy often have servants to perform this labor. However, most contemporary American children spend a great amount of their lives in school, and even insofar as children are raised at home, the work that maintains daily life is largely outsourced outside the house. Duffy documents in the United States, among the middle and upper classes, either single women for the less affluent or a collection of servants for the wealthy, were commonly employed in both visible and invisible labor at the turn of the twentieth century. ${ }^{8}$ Food preparation, cleaning, and caring for children was laborious and required significant time and energy. Today live-in servants are rare. Statistically, in the United States, since the 1900s much of the invisible reproductive labor that constituted household work has been outsourced. Food is much more packaged and prepared than ever before, children are often cared for in daycares or schools rather than at home, and if one has cleaners, they do not usually live in one's house.

With the changing makeup of reproductive labor, the dirty work of reproductive labor has significantly shifted the racial-ethnic makeup of reproductive laborers. In addition, the gendered nature of such work from almost exclusively female in the past to today larger percentages of the food preparation being performed by men, and in particular Hispanic men. ${ }^{9}$ Duffy notes that what she calls the "dirty work" of reproductive labor done behind the scenes such as cleaning and basic hospital care is increasingly done by racial-ethnic persons and the front room work by white women such as nursing and childcare. In addition, much of the goods we use every day are produced not just by minority workers, but by people from the global south. Among white, wealthy parents in the United States, the tight 
focus on individual success qua economic success and personal fulfillment encourages individuals and families to focus on their futures exclusively, seeing children as a product to be protected from any social threats to the child's promotion. Chandra Montany points out that the focus on freedom as a personal affair of self-promotion, or in the case of the good health imperative, one's health, makes it challenging to think collectively about our freedom, saying, "ideology and popular culture emphasize the individual maximization of options for personal success. Individual success is thus severed from union activity, political struggle, and collective relations." ${ }^{10}$ Mohanty notes that the division between the first and third worlds creates two kinds of workers-there are those citizen-consumers, that is those of us in the first world who dedicate ourselves toward personal fulfillment and family promotion, and the worker-producers of the third world upon whose backs our lives of individual freedoms to pursue family advancement are based..$^{11}$ We can see the visible responsible parents as the citizen-consumers and the invisible, reproductive laborers as the worker-producers. It is no wonder that the focus of parental responsibility focuses on the visible kinds of parental work-what one purchases in snacks for one's children, how one's child performs at school and not on who is growing, cultivating, and packaging the food the child needs to live.

Using the invisible labor of the less fortunate, parents in affluent situations are not largely free from the demands of parenting as perhaps one might imagine they were in households staffed by servants where expectations of time with children were minimal. If anything, parenting has become an even more complex and regulated social practice with a myriad of ways in which we measure good and bad results. Juliet Mitchell writes, "Parenthood becomes a kind of substitute for work, an activity in which the child is seen as an object created by the mother, in the same way as a commodity is created by the worker." ${ }^{12}$ After all, just keeping children alive is not considered sufficiently proper parenting. Indeed, the demand to take very seriously childrearing and to continue to work on one's parenting has become the norm for upper- and middle-class parents. This "intensive parenting" is where raising a child is a complex carefully mapped journey involving time, money, and attention to details such as extracurricular sports and hobbies, good work in school, healthy meals, and structured family time around growth-inducing activities. ${ }^{13}$

Consider the way in which we understood food as "good" or "bad" and what we imagine responsible families feed their children. On the one hand, we have ample documentation that the kinds of things promoted as good food-fresh fruits and vegetables, lean meats, whole grains—do seem linked to variety of positive health outcomes. Likewise, sugary processed foods have been linked to poor health outcomes. The healthy food movements in the United States often call for a reimagining of what we feed our children and locate those kind of choices at the grocery store (or farmers' market) as key to this vision. But this means turning away from the capitalist system that produces the disparities in wealth. Kim Q. Hall argues that healthy 
food movements in the US have fallen into individual-centered concerns about what to consume- "the mainstreamed alternative food movement in the United States is a neoliberal hygienic eating project fixated on the achievement of virtue, health, and good citizenship through appropriate consumer choices at the table and in the (farmers') marketplace." ${ }^{14}$ The more that popular ideologies claim that the right kind of consumption can prevent illness or cure current ailments, the more likely, Hall points out, that disabled bodies will be seen as sites for even more intensive proper-choice models to aid them to become as "healthy" as possible.

Hall argues that the idea of alimentary ableism tends to evoke a metaphysics of purity, where "bad" food consists of kinds more removed from their "natural" state. Thus, fast-food and other kinds of heavily processed food are the worst of bad foods, and organic fresh produce is the best. In their extremes, such purity models can themselves foster horrible health outcomes such as in the anti-vaccination movement and cases of child endangerment or death based on strict ideals of "healthy" food. In their more moderate forms, they tend to not promote political calls for change toward the kind of world in which healthy food can be produced fairly by workers in a safe manner for the environment and in forms for all kinds of bodies. Instead, health is tightly tied to the practices of citizen-consumers and distanced from the most pressing concerns of worker-producers.

For women, very often gendered perspectives on the value of seeing family as a key personal goal encourages the lack of demand for compensation for the care work involved in raising children; hence, women's positions are economically more fragile. Women are encouraged to see family and devotion to good mothering as something desirable and natural; hence to not want to participate in the family qua personal project is to be abnormal. While it is true that affluent white women still take on the larger share of visible, responsible parenting, Black and Hispanic women in the United States are engaged more frequently in invisible, reproductive labor and are thus unable to find their or their children's futures as neatly pointed toward lives of personal fulfillment and transformative work. In addition, Black and Hispanic women are more likely to themselves be the single parents. Women overall are more likely to be solo parents than men $(81 \%$ of solo parents are women), solo mothers are twice as likely to be Black. ${ }^{15}$ Thus, simply to call for more help in visible, reproductive labor does not actually address the inequalities at the heart of reproductive labor. As Elizabeth Spelman points out, when white feminists call for the value of meaningful labor and rejection of the demands of domesticity, "exactly who do we think is going to do it? Have we attended to the role that racism and classicism historically have played in settling that question?" 16

Invisible labor in all these discussions above remains obscured in this language of personal responsibility. The brutal nature of our bifurcated system of reproductive labor is shown in the deaths of COVID-19 in the United States. ${ }^{17}$ In a comprehensive study, researchers found that 
Black and Latino people have been disproportionately affected by the coronavirus in a widespread manner that spans the country, throughout hundreds of counties in urban, suburban and rural areas, and across all age groups. Latino and African-American residents of the United States have been three times as likely to become infected as their white neighbors, according to the new data, which provides detailed characteristics of 640,000 infections detected in nearly 1,000 U.S. counties. And Black and Latino people have been nearly twice as likely to die from the virus as white people, the data shows. ${ }^{18}$

Not only is the Minorities' Diminished Return Theory helpful in thinking about these disparities, but the actual way in which invisible reproductive labor is much more likely to be performed by minorities also contributes to the disparity in rates of COVID-19. In an examination of the wealthy suburb of Washington, DC-Fairfax County-where three times as many white people live than Latinos, at the end of May 2020, four times as many Latino residents had tested positive for the virus. The authors note that "Across the country, 43 percent of Black and Latino workers are employed in service of production jobs that for the most part cannot be done remotely, census from 2018 shows. Only about one in four white workers held such jobs." ${ }^{19}$ COVID-19 has increased discussion of "essential workers" but often the focus is upon healthcare workers rather than farm laborers, grocery store workers, or food preparation workers, truck drivers, and other workers who produce, package, and deliver what we need to live. The visibility of doctors and nurses makes it much more likely for us to identify their labor in a pandemic. Like many, my interactions with invisible laborers are infrequent and in the case of farm workers and workers in the global South non-existent. This is even more the case in the pandemic when online shopping and grocery deliveries have become frequent. The ideal of health as being about good personal responsibility wherein I can control my health, or good parenting being about parents making good decisions, require not attending to all the manifold and complex structural requirements that make something like pursuing a new eating plan or providing your children with quality time possible for only citizen-consumers. Below, I discuss how a certain view of the body as a product has fostered ignoring the kinds of racial, ethnic, class, and structural disparities behind poor health outcomes.

\section{The evolution of human need}

Marx argues that the connection between need and consumption is historical, not simply natural. In addition, he argues that the act of consumption transforms the individual. One might assume that consumption is simply an extension upon our most basic form of consumption-that of eating and drinking. In such a view, one might separate out needs (such as sufficient food and water) from desire (another pair of shoes)—but assume that both need and desire are structurally similar. Marx agrees that in consumption, one's 
desire is evoked by the object, but argues that many objects must be learned to be objects of consumptive desire. As discussed in Chapter 3, we learn our bodily habits of self-care in socially intimate fashions as children. In addition, we learn what objects are and how they are to be used. Objects are cultural, not natural, even if they appear to satisfy a natural need like hunger.

Marx gives the example of appreciation of art as something that arises from the introduction of the product to the public who can then create a need for more art. In so doing, he writes that one produces a different kind of subject.

When consumption emerges from its original primitive crudeness and immediacy - and its remaining in that state would be due to the fact that production was still primitively crude-then it is itself as a desire brought about by the object. The need felt for the object is induced by the perception of the object. An objet d'art creates a public that has artistic taste and is able to enjoy beauty-and the same can be said of any other product. Production accordingly produces not only an object for the subject, but also a subject for the object. ${ }^{20}$

The interest in art cannot precede the exposure to art. In addition, I am now a different kind of subject who appreciates art. The production of art produces both art and the lover of art. Marx discusses how need can be understood existentially — that is, about the human condition as such—but also about the way it becomes transformed in the cycle of production and consumption in a contemporary society that changes our identities and thus our needs. This provides a helpful guide to thinking about how one lives in a society where the good health imperative shapes one's view not just of health, but of one's sense of self. As discussed in Chapter 3, body image dissatisfaction is real and significant, but it is also learned through habituating women to the idea that they must work on their looks to be acceptable.

Looking at how contemporary life is constructed around a distance from food in its natural forms both in consumption as well as in production, we will see how reducing activities like eating as responding to a transhistorical human need for survival obscures the historical development of our relation to food. My existence is conditioned by the need to survive, but my current identity as a citizen-consumer is much more connected to the socially conditioned experience of consumption in the twenty-first century. Consider one of the most common foci of the good health imperative-the individual's food intake. Eating, the most basic need of all—even the infant comes to the world having an instinct to suck-would seem to be ahistorical, one of the most basic parts of the human's extension toward the world. While smoking, drug, and alcohol consumption are possible to avoid, one cannot stop eating. If any need transcends the need for a historical analysis it would seem to be eating. The most basic kind of consumption is certainly in its rawest form a natural tendency or intentionality toward survival. However, Marx argues that once hunger is satisfied by a historically mediated and 
produced meal, such as "cooked meat eaten with knife and fork," it is actually a different hunger than that which is found in the devouring of "raw meat with the help of hands, nails, and teeth," because one has become a different kind of human who consumes processed food with utensils. ${ }^{21}$ To reduce eating down to the demand to survive is to forget to acknowledge that eating, as discussed in Chapter 3, is a deeply social and developmental acquisition.

Of course, one could imagine insisting that no one "needs" meat cooked and served on a plate with a knife and fork to continue mortal existence. In such a manner, any amount of food that allows for the continuation of existence satisfies this need, and hunger remains something ahistorical. I would eat raw meat with my hands if I found myself in a situation of starvation where this was my only option. But if one really thinks about living in such an example and how radical this moment would be-how it would shape one's very sense of self. If I found myself at some future point, surviving by eating raw meat with my hands with no other means to continue living-in this possible world, this future Talia would inhabit such a different kind of existence, it is hard to imagine my identity could remain the same. What would have possibly led to me being in such a situation? Some kind of apocalypse? Was I lost in the wilderness? To read a story of concentration camp survivors, as in Viktor Frankl's Man's Search for Meaning, struggling to stand on a diet of watery soup is not a story where those that survived and ate again normally had not been radically altered by the experience. ${ }^{22}$ One cannot separate the starvation from the situation that produced it. Even a study where the participants willingly underwent starvation are transformed by it for the rest of their lives. ${ }^{23}$

Food consumption is highly mediated by technologies of food production as well as perhaps the more evident cultural differences in foods and traditions that surround it. In addition, the need to survive that encourages eating as an activity is not just a repetition of fulfilling that need but takes place within a world in which that need is understood to be satisfied in a very mediated fashion. I, like most everyone I know, have no connection to food production. Other than a few tomatoes and some peppers, I produce no food, rather purchasing it in stores or restaurants. I cook most days, so I do engage with food in raw forms, but even this food has been, at minimum, grown, picked, transported, and displayed in a store. All the food I consume has been transformed by other hands than my own. In the developed world there are some people who hunt, garden extensively, raise livestock, or farm, yet this production only constitutes some of their food consumption.

Many economists try to see a generic human experience in complex historically situated exchanges. Marx takes up political economists' love of the Robison Crusoe stories in Capital as a way that they hide the social nature of commodities. Crusoe's story allows one to focus on how labor responding to needs permits this small "economy" to occur. By thinking that they can reduce the essence of labor down to the work a man might 
do to continue his survival alone on a desert island, these economists think they have isolated the essence of production and consumption. ${ }^{24}$ They then conclude that contemporary commodity exchanges, production, and consumption are more complex formulas for solving basic human needs. However, as Marx points out, we do not relate to commodities in any complex society in such a manner. I do not produce the food I eat directly, rather I am dependent upon social labor to produce food for my consumption.

There is another way we can highlight the curiosity of thinking that Robison Crusoe tells us much about what is essential in human activity, beyond its use in political economy. When I am hungry, I have very specific foods that interest me. Since my habitual background is one where I never worry about having enough food, my attitude toward food does not appear so much as satisfying a primal need than as selecting from a variety of options to find the one that at that moment is the most tasty, healthy, convenient, and provides a certain amount of variety. If I were a castaway like Crusoe, I would obviously not be concerned with these secondary issues but rather with sheer survival on all fronts. Everything would be different. Real-life stories of castaways are compelling reads for their drama, for the lengths to which people go, and for the sheer detail and impressive ingenuity some show in figuring out how to survive. Yet, the narrative from the castaways is one of constant pining and hope to be rescued from their plight or to figure out a way to liberate themselves from it. ${ }^{25}$ They want to return to the social world-to their families, to occupations, to a varied diet and comfortable living: to move beyond a situation where death is always intimate.

Need is not just the need to continue living, but the need that an individual perceives to continue being that individual. I need my son to be safe; I need to work at something I consider valuable; I need to enjoy myself; I need to have some time with my family. These are needs in so far as they constitute who I am as a mother, a wife, a friend, and a professor. Moreover, they require that in the anticipated future these things will largely stay stable. In phenomenological terms, my extension into the world requires a background of stability where my projects can be both lived, but also imagined. Removing the stability of the most important things that constitute my identity would be to change myself significantly. To reduce me down to what one might assume sheer existence is in its rawest form would perhaps expose what a human can endure, but surely I would not be this Talia anymore. The loss of one's social world with all its attendant affections and investments is not just removing extraneous levels of social complexity from primal need, but it is what constitutes a person as that person and not simply as a being who is managing to survive.

This primitive concept of need fostered by some economists assumes that a linear causality exists between an individual's needs and her actions. Since on the most basic animal level it is true that one can see the need to eat as connected to "doing things to get food" it is appealing to then extend it to our complex, historical social world in which "doing things to get food" is never just an individual action. To raise my fork full of food to my mouth 
depends upon contemporary food production, not just my motor actions. When health behaviors are employed, all sorts of really optional behaviors are read as somehow mystically part of the original need-that is, some kind of need to do things to survive. Our needs have a heritage that we share with all animals, but they are not experienced as raw need coming from a sentient animal. A particular individual with a particular historically and personally located identity had developed needs and desires. The individual's identity is importantly not just some set of "internal" characteristics one often hears about as personality types (such as an introvert), but a way of being in the world, so one's temporality is shaped around that sense of identity. Someone who is introverted is anxious about future spaces in which social interaction is demanded - thus it is her imagined virtual extension into this upcoming future that is upsetting. This only makes sense if her identity is tied not to who she is in some moment now, but who she will be in the moments in the future. In the case of being food insecure, whether due to poverty or an extreme situation, one might experience moments of not being hungry when one is able to obtain food, but one's days are constantly colored by the concern for future food. To think that the food insecure individual is the same as the one who has never experienced true need misunderstands that satisfying needs is not just about any one need, but about the how one experiences the world as a place in which one's needs will or will not reliably be met.

\section{Body as fetish object}

If one thinks about the actual acts one engages in to produce good health, then the picture is a complex series of actions that only are possible and make sense within certain historical environments. If one is counseled to take certain preventative and largely self-directed practices to better one's health-stop smoking, lose weight, increase exercise, reduce alcohol consumption-then one enters into a cycle of certain kinds of consumptive and productive behaviors. One needs information on what programs, products, and appropriate measures are needed in order to produce the proper set of activities. One needs to alter one's consumption as well—perhaps one needs a treatment program, a patch from the drug store, a gym membership, a new diet book, or different foods. One notes one's progress with various metrics in order to determine whether the product—one's body—is on the right track or not. Typically, these programs and products must be purchased by the individual, even if there is some kind of financial incentive or health insurance payout. One must go to the store to get one's medication, purchase healthier food, and buy those sneakers. In such a manner, as noted above in Chapter 3 , these consumptive practices are common in beautification regimes, but the moral is different for food consumption as health promotion.

The consumption of healthy food and the activity of exercise are not static things. One must continually re-engage with such practices, shifting and moving the identity of the healthy performer. The idea that I am 


\section{Marxism, reproductive labor}

somehow responsible for my health also arises in a world in which we have come to understand ourselves as a project, as a production. I make myself healthy by doing certain things to and with my body; I am not healthy as a static state but a moving one. It is the affirmative ideal of the future healthy body that motivates my need to continue engaging in certain productive actions. In the Grundrisse, Marx connects consumption and production as having a dynamic relation where consumption is not the end of the production but actually tied to the positing of an ideal. "If it is clear that production offers consumption its external object, it is therefore equally clear that consumption ideally posits the object of production as an internal image, as a need, as drive, and as purpose. It creates the objects of production in a still subjective form." ${ }^{26}$ In this parallel, I become healthy through the labor of health which is motivated by the internal image of a certain future body as having such health. I cannot cease this labor, or I cease to be a healthy person. Thus, I am not acquiring health, but health is only within the relation between a self who decides upon the object of health, engages in certain practices, evaluates, and then repeats. If I am engaged in a complex consumptive set of processes to produce a healthy body, there can be no separation from the dialectical process of health behavior and health itself. Health no longer exists as a state that I either have or do not have. I have to produce health constantly by engaging in proper consumptive activities. The healthy body-object I have come to appreciate and endeavor to obtain is always just beyond me, which encourages my continual labor.

Marx points out that when the worker produces an object, say, a hamburger at a fast-food restaurant, she does not own that object and has no say over how she produces it, and thus is alienated both from the product and the activity of her labor. Marx says in such a position the worker is in servitude because "it is only as a worker that he can maintain himself as a physical subject and that it is only as a physical subject that he is a worker." ${ }^{27}$ Only because my body is capable of performing some tasks for remuneration can I continue to exist. While this works for hamburgers, does it work for the healthy self-controlled labor? When it comes to self-regulation for health, it is evidentially about continuing one's existence or at least continuing one's existence in a preferable form-less fat, less chance of cancer, more mobile. But it seems nonsense to say that one is alienated from the object of one's labor, as one is the object of one's labor. Indeed, one might think of this as the most freeing way in which to live-where one can just attend to oneself.

The odd thing about health as a process of health work on oneself is that any one state is insufficient in itself. Even a good biometric screening will require continued effort to maintain that score. If health is constituted by the activity of producing health and is as such never achieved, it might be said that one does not possess health at any moment but is constantly working to produce it in the next moment which will then extend again into the next one. As one has the additional issue that one's body is itself a fluid and aging thing subject to illness and disease, even those with the most fortunate 
genetics will face an object that requires more health labor for diminishing returns. What is the body that we are trying to produce? I will argue here that it is the body taken as a future fetish object.

I must engage with others in the market where products of my labor and products of others are exchanged through the exchange of money. However, once we do this, we now do not relate to each other but through things, including money. In his discussion of commodities and money, Marx notes how commodity-objects often become fetishes-that one takes their value to be disconnected from the systems that make them possible. To follow this argument, Marx requires that we perform a phenomenology, as Christopher Durante Araujo points out, to look into the essences of things that constitute their outward appearances. ${ }^{28}$ The commodity is such a thing that is evident and meaningful, but when one stops to simply examine it, one finds it is a very odd thing whose seemingly natural and evident state is much more complex: "A commodity appears at first sight an extremely obvious, trivial thing. But its analysis brings out that it is a very strange thing, abounding in metaphysical subtleties and theological niceties." 29 The commodity is in many of Marx's examples, a tangible thing, like an iPhone or a hamburger, but its value has become abstracted from the conditions in which is it made and consumed.

The fetish arises when we forget any real connection that we have to our own labor or that of others, and we take our true objects of desire to be natural objects with self-evident value. It is objective since commodities do have at any particular moment a socially determined value in a system but abstract since there is nothing in the commodity that demands that it has that value other than its real or potential exchange at the moment. In such a way, I relate to things as persons-as things with inherent value. A fetish object, say, an iPhone, so understood is not some kind of pathological delusion. iPhones are valuable in our society because of the social relations that constitute this commodity as an object of exchange where other cell phones and the internet permit their usage. Marx wishes to underline not that produced objects are useless outside of capitalism, but rather that capitalism has abstracted their value but takes it as concrete and natural. In this abstraction, the object's true genesis is obscured.

If my own body becomes an object to me, it is because I have interiorized the view that my body is not me but some kind of thing that carries the real me around and this thing has value only insofar as it is the right kind of thing. One's current body is now substandard given a new, better one is perceived to be possible with the right actions. Under the good health imperative, the body is indeed me, but its value is a matter of it conforming to an abstract ideal. In executing my responsibilities, I do have to objectify my body by disciplining it, having it evaluated, and measuring my performance. In every way I am my living body, the question is how well that body is doing. This parallels a religious person who concerns herself with the state of her soul, worried that her actions are sinful and insufficient to provide her entrance into heaven. She labors to be the kind of person who will be provided God's grace, but until judgment day she will need to be vigilant since 
some good actions, thoughts, and deeds could always be overwhelmed in the next moment by temptation. Producing a healthy body has one also living in limbo since any good production is never sufficient. Healthy behavior must be a "lifestyle" - that is, a continual reproduction of healthy behavior.

In Marx's example above, he employs an idea that what one gets from art, once one has developed a taste for it, is the appreciation of beauty. While this might be the case for some forms of art appreciation, many body-objects we are presented with are perhaps beautiful but also indicative of something else we should do, as opposed to simple enjoyment of the object. A body that demonstrates a fit physique can be enjoyed as an object, but if it is advertising a product, practice, or workout facility, then one is supposed to move from the appreciation to self-examination. Does one's own body-object appear like this attractive one? What might one do to obtain a better body-object? The interest in a manicured, highly managed body is achieved after the exposure to such objects and importantly the apparatuses that allow for one to see one's own body as being something that can achieve such a state. Such body-objects are valuable in our economy-as objects for selling. What is critical is that such bodies appear to be possible to obtain but in fact are not. Their exclusivity is part of why one can continue to sell products. Some kind of hole in the populace must exist in order to justify selling something. This works well in health labor as well as we are encouraged to not just be sufficiently well enough to live our lives and engage in our projects, but to be really well—well enough to run a marathon or well enough to have a diet free from preservatives and fast food. The more bodies that run marathons, the more that run Ironmans, and then Ultramarathons. In 2014, the number of Ultramarathons (any race longer than a marathon's 26.2 miles) doubled from the previous decade. Some of these races are over 150 miles and cross desserts. ${ }^{30}$ In the face of such activities, running a few miles a day seems positively frail. Running as an identity now is often about running in these expensive, mediated, and competitive situations.

In such a manner, one might see the body as a fetish object of desirebut this object is one that is continually postponed as one never is finished with the labor to produce the right one. How one actually produces such a body-the complex economic situation wherein only citizen-consumers have such an option, where the diet-exercise industry, food production, safety, means, and resources to engage in such activities-fade into the background with the body-object front and center. In the next section, I will discuss how this ideal of a body as a fetish object can also help create more surplus labor in capitalism. However, given we often have to spend our limited time and resources on such work, the chapter will turn to Marcuse's idea of an affirmative culture to explain why we do so.

\section{Affirmative culture and the good health imperative}

I relate to my body not directly but through received ideas of what I should feel and experience, including names of just what those feelings are. As La 
Rochefoucauld famously opined, "Some people would never have fallen in love if they had never heard of love." ${ }^{11}$ Whatever feelings we have that arise from the body alone without cultural interference, to think about them requires an overlay of culture's language and morals. In the case of the work involved to have a healthy body, I can come to see such work as necessary for good "self-care." One problem is that the more one emphasizes health work, the more it may become apparent that the other work one does limits one's health. Many kinds of labor are themselves inherently unhealthy-exposure to toxic chemicals, long hours, and sedentary jobsto name a few common health concerns at workplaces. The genius of the good health imperative is that if one's own body is a fetish object of desire, then one will willingly take up the labor, or at least feel one should do so, outside of work. In such a manner, health work that offsets the poor health conditions of work can be seen to be a kind of free, surplus labor. Marx's theory of labor in capitalism divides labor into necessary and surplus labor. Necessary labor is the average workers need to maintain their lives and the lives of their children (to create new workers). On average, how many hamburgers must be sold to cover the costs of the materials, the process, and through the worker's pay, her food, rent, clothing, healthcare, and those costs for her children?

In order to create wealth, the capitalist must obtain surplus labor. It might take the average fast-food worker only three hours to cover necessary labor time and with the additional five hours all these hamburgers can be sold at a profit. Various means to extract more surplus labor exist. One could have fewer workers to do the same work, more machines to replace costly workers, move a factory to a lower-cost labor market, and increasingly today rely on work outside the office, such as the pervasiveness of email at all hours. In addition, another manner in which one might obtain more surplus labor is to reduce the need to provide benefits to workers, such as quality healthcare. This is a tricky proposition because, of course, one does need workers who are healthy. But if at least some of the burden of health work is part of the worker's docility in assuming that her self-care is something she must do herself outside of work to be a good person, then it seems less the responsibility of the employer to ensure that the working conditions are not deleterious for one's health. Problems caused by working conditions are now not issues that the larger social community or employer should address, but instead manifested within the unhealthy worker's body as a personal responsibility for that worker to take care of herself more carefully. If one works long hours at a desk, making it difficult to be physically active and maintain a healthy weight and all the other benefits of an active lifestyle, one often thinks the employee should spend more time outside of work to offset the unhealthy nature of her workplace, and not that such workplaces are themselves to blame. After all, if it is not what she wants to do-that is, do healthy things in her free time-she should do it nonetheless since it is good for her. The circling of the locus of responsibility on the individual increasingly makes it hard to even discuss such issues outside 
what the individual workers can do to be healthier. Moreover, the growing disparities between the health of worker-producers and citizen-consumers can now be explained away by the former simply not taking good care of themselves instead of the structural reasons why this is impossible.

In Marx, Capital, and the Madness of Economic Reason, David Harvey discusses how a "fetishism of technology" leads to the widespread belief that "there must be a technological solution to any social or economic problem." ${ }^{32}$ Influenced by the very real benefits of technological advancement in manufacturing and the rapid rise of Silicon Valley's profitable tech industries, businesses, governments, and individuals might all come to imagine that to any woe a technological solution is just on the horizon, and if one invests enough in it, it will spring forth and solve all ailments. In my own city of Chattanooga, Tennessee, a city with extraordinary and growing racial division of wealth between wealthy whites and poor Blacks, there is a well-touted desire to create it as a "smart city" with our "gigspeed" internet and a new "innovation district." These initiatives promote economic growth for those with such skills with little or no attention to the long history of gentrification that leaves some communities behind and the lack of any real investment in addressing social disparities other than through "innovation." My university, the city government, and local businesses all unite in their vision of the future to "change Chattanooga..." with no addressing of actual poverty and the reasons behind it. ${ }^{33}$ It is hard to see how the disenfranchised will benefit from tech start-ups and peerless internet service. Harvey notes that such a vision of smart cities "creates a fetish fog - a vast distraction - between political activism and the urban realities..." ${ }^{34}$ The self-produced healthy body as a fetish object can be seen as parallel to the idea of technology solving all of our troubles. The healthy body, bolstered by constant scientific and technological improvements in the healthcare field, will come to answer any individual ailment and any social woe. If one still finds one's body lacking, it is simply a matter of more personal investment, more labor, and more careful attention.

In "The Affirmative Character of Culture," Herbert Marcuse points out the great difference in art appreciation between the Ancient Greeks and what he considers the contemporary bourgeois view. For the Greeks, happiness enjoyed by the appreciation of beauty is reserved for the elite few. One needs the hierarchical division of the slaves and other attendant lower servants in order to provide the kind of space in which the higher men can have the luxurious lives needed for such pleasures. Today, we find such explicit elitism distasteful and are at pains to point out that beauty can now be enjoyed by all. The concept of the individual, instead of group identities, abounds where the enjoyment of culture is for everyone, not just the high born- "...the bourgeois liberations of the individual made possible a new happiness." 35 However, the problem is that since capitalist production only allows a few the possibility of purchasing the goods necessary to secure happiness, our actual concrete situation does not truly permit happiness for the masses. ${ }^{36}$ The culture of the rich is just as exclusive, but the ideology has changed. 
How is it possible to continue to affirm the capacity for all to be happy if only some can be happy? The response, Marcuse argues, is for the creation of an abstract ideal-of "affirmative culture." This is a culture that always postpones the true, material gratification of its consumers by producing works of disconnected beauty and escapism. Marcuse argues that bourgeois society "liberates" the mind while not changing the fundamental condition of the masses. "The freedom of the soul was used to excuse the poverty, martyrdom, and bondage of the body." ${ }^{37}$ Instead of considering culture in the manner Marcuse does, I am interested in how the idea of the future healthy body promoted by images and stories presents a similar kind of affirmative culture that creates a patina of "everyone can do it." The kind of lifestyle most conducive to allowing for exactly those activities that promote health-good medical care, a good diet, low stress, capacity and opportunity to be active, resources to overcome addictions, illnesses, and diseases-are only possible for the privileged few in our world. Yet the more one becomes convinced that only by some effort all persons can maximize their health, by repeated mantras of transformed bodies, the more the concrete differences fade into the world of possible future improvement. It is this false narrative that motivates the search for health without any interest in changing social conditions.

For Marcuse, in affirmative art, the medium of beauty decontaminates truth and sets it apart from the present. But importantly, this illusory world produced by art has real satisfaction; it is truly enjoyed by the masses. ${ }^{38}$ But, it obscures true suffering and doesn't allow true individuality to come forward. While Marcuse is interested in the possibility of rejecting such false culture, what is interesting here is to consider the idea of the good health imperative as a similar move to make an assumption of equality. If one assumes the equality of individuals, then the actual physical conditions of the masses of unhealthy poor bodies are now no longer crises that demand the examination of the social relations that permit such differences, but abstract, individual crises that call the subjects themselves to engage in certain behaviors to achieve the presented ideals of good healthy bodies. Fueled by the projection that such rituals will occur tomorrow if not today, the fantasies of affirmation become tools for further labor. Government sponsored social services and charities likewise work to create worlds in which everyone can make the choices that are actually only really viable for the rich.

Another element that requires constant fantasy creation to promote this idea of good health for all is that good health is not just predicated upon the time required to attend to one's health and the finances to purchase health goods, but the access to highly specialized and very expensive medical care. The fights in the United Kingdom over the National Health Service and the inability of the United States to provide quality medical care for the poor all center around the extraordinary cost of medical care. One option to this cost problem would be to live with a much-reduced form of care where specialized treatments would be few. But this would mean that the wealthiest 


\section{Marxism, reproductive labor}

individuals would not be able to enjoy the luxury of first-class healthcareboth currently and the new forms that have yet to arrive. The other would be to provide first class healthcare to all, but this is only possible if money is diverted from other areas, and the amount needed is so extraordinary that it would necessarily have to be the wealthiest who would fund such an endeavor either directly or by a serious reduction in their capacity to amass wealth. Instead, one function of the good health imperative is not just to mystify those who are the healthiest and why into the banality of the fetish ideal of healthy bodies for all, but to extract surplus health labor from the population so that the cost of healthcare can be reduced without actually spreading good quality care or reducing the excellence in care that the rich enjoy.

As previously noted, one of the challenges when considering health has been to acknowledge its rootedness in our basic natures, but still to find a way to consider its historical nature. After all, our cultural bodies are also natural bodies. But why are we so likely to fall into this belief that we can with some effort change ourselves? One can alter one's body through concentrated work. While such affirmative culture might include aspects of fantasy, the good health imperative offers real tales of personal transformation. The background in which they occur is not just one of various tales of personal transformation as one might read in popular self-help texts, but connected to the progressive healthcare sciences.

How I understand health as a middle-class person living in the developed world in the twenty-first century-is radically different than others in dissimilar situations or at times in which the science, technologies, and cultural norms around health had different forms. One feature of how our burgeoning field of health sciences has provided us with behavioral recommendations is that health is a state that $\mathrm{I}$ am at least in part responsible to produce in myself. My identity as producing a healthy body is not just determined by certain kinds of consumptive and productive activities, but also how these activities themselves take place within the frame of a large, progressive, and complex medical establishment that informs our relationship to our health activities. This is the backdrop for assessing whether one has produced the right kind of body project. The doctor can run a series of more sophisticated tests with tools I do not have, and outside the doctor's office I can test myself by measurements such as weight and size, days not smoking, hours exercised.

Consider how we understand medical care today. If I am very ill, I seek medical attention. If I am ill but the severity is unclear, I entertain the possibility of going to the doctor or taking some medication. Health and illness are always understood within a world in which medical care is integral to the understanding of health. It is hard for me to know how I would relate to illness in a world where there was no institutional medical care, where one suffered and perhaps prayed to one's god, and perhaps some healers offered some therapies, but the medical profession as we know it now did not exist. Critically, the existence of this field of knowledge and my awareness of it 
encourages thinking about health and illness as transitory states that may be altered by personal and medical practices.

I can easily imagine medical care being denied to me, not being able to afford medical care, or medical care not being able to aid me, but in all such cases medical care still operates as the background in which I understand my health and illness. Like everyone I know, I was born in a hospital. My entire existence is pervaded by contemporary medical care just as my food consumption is determined by capitalist food production. I understand the medical profession not as a collection of people with some skills in healing but as a complex progressive, professional, scientific, and technological set of institutions. Even if nothing is currently capable of aiding me or prolonging my life at this moment, I know that in the future such advances may happen. Such a view of the progressive nature of healthcare is, historically speaking, quite new, and is integral to how we understand our health and why we feel such responsibility for it. In phenomenologies of illness, stress is placed upon how the meaning of an illness is about not just physical states but virtual, imagined states-future possibilities, changes in relationships, capacities to engage in future projects. These imagined futures are both tightly connected to the individual's life, relationships, environment, and desires but also to the larger cultural ideologies and where the individual finds herself in society.

One might agree that while it is the case that my idea of my responsibility for health is quite different than it would have been 5,000 years ago, surely the human then and the human now experience health and illness the same way (even if the earlier human had no hope of medical intervention), since our bodies have not changed significantly. The fact that we see our own lives reflected in stories from foreign lands and ancient times suggests a common human thread of experience. Yet, health as that capacity to feel capable of going forth in the world and being-with others is affected by one's idea of possible scientific cures, new treatments, and new ways to better oneself that at any time might be discovered and developed-ideas foreign in other times where self-directed development did not operate within the medicalized world.

The healthcare sciences provide a virtual backdrop to my personal experiences of wellness and for the purposes of the good health imperative provide the ideology of constant future improvement. My lifeworld is one where health is not something outside my understanding of the healthcare sciences but something understood in relationship to them. The hope of a cure colors the experience of illnesses in ways unknown in the past. Maybe a medication will aid me; maybe a medication in development will aid me; maybe a doctor can cure me; maybe a hospital team can; maybe I can undergo a combination of treatments. In addition, we will discover more ways in the future to refine our health. I can, in the words of a health coach, constantly get better even in the case of a debilitating illness or aging. We are social, historical beings in highly developed social systems wherein we understand even natural needs such as the need for health. Health has 
become a produced object for us-produced by the histories, medical technologies, and ethical norms that shape our attitude toward it. This not only makes the way I understand health something that cannot be understood outside my situation as true for all persons at all times, but also, interestingly, something that shapes who I am fundamentally.

Consider the use of Assisted Reproductive Technologies (ART) today. Formerly infertility would have been seen as bad luck, but not something that had any possible solution. Now medical technologies have transformed the future of people wishing to be parents. One's infertility is not necessarily a hindrance to childbirth. Bjørn Hofmann and Fredrik Svenaeus point out that the existence of ART can make an experience go from one where one perceives oneself as unfortunate or unhappy to ill, "For example, assistive reproductive technologies have redefined the experience of childlessness from being faith or bad luck to be something to alter and treat by making it a disease (infertility)." ${ }^{39}$ While ART has greatly assisted many to become parents, it also has created a landscape where it is unclear when one should stop with such technological intervention. Is it after one failed attempt? Two? Five? As I wrote regarding my own experience with IVF, a highly medicalized world alters one futurity:

Testing makes the horizon of one's future shift from day to day. If one has embarked upon ART, one now will need to consider how to make one's day fit around such testing and will regard each test with concern. Will this be the end of this journey? Will this medication produce the proper result in my body? Testing shapes temporality, not just in the sense of the horizon that might hold a child and one that shifts with the medical practice, but also insofar as temporality returns again and again the past. The virtual possible child is tied up with evaluations of if one would need such elaborate measure if one's life had of been different, if one had of made different choices perhaps. Time extends strangely in the future even when one has received a bad result since the progressive nature of ART often means that one can always try again. Another IVF trial, or now perhaps get an egg donation, a sperm donation, an embryo donation. Or perhaps there will be some new advancements that currently aren't available but might be soon enough. ${ }^{40}$

Docility in biopolitical discourse is often conceived of as mystification as in Bartky's work - that is, one does not see oneself as docile but rather as fulfilling one's individual desires. These desires are manufactured due to an expanding world of normalized behavior bolstered by a variety of institutions and knowledges. Hence, many biopolitical theorists have been deeply skeptical of phenomenology's use of the first-person, since the first-person is exactly that being who is constituted by normalization, and indeed focusing on the first-person is itself exactly what docility demands: an obedient being who self-regulates.

However, I think a key to today's vision of the healthy body is that it can be understood as docility, but importantly also as a kind of self-conscious 
productive labor on the body-fostered by a fetish belief in the power of medical and technological progress to constantly help "perfect" that labor. This docility helps modify the worst excesses of capitalist oppression by creating healthy bodies that can work better and necessarily question less, given the amount of free time that must be used for this endeavor of healthy body production, but it also has to be understood as connected to something all-too-human-that is, the fear and concern with suffering and death. Thus, this labor is both a historically constituted labor as well as a labor that responds to something existential.

In The Problem of Work, Kathi Weeks discusses the work ethic in both capitalist and Marxist theory. In both, one sees a great valorization of work and its importance. The Protestant work ethic fits well into capitalism's fold by promoting individuals who will work hard- "work is understood and experienced in a field of individual agency as a sign of and path to self-reliance." ${ }^{41}$ The vision of work as a key to emancipation, self-reliance, and self-promotion in our capitalist world argues that with a little moxie, some determination, and a will to work one can rise above the conditions of one's birth. This illusion, increasingly incoherent in the face of post-1970s data in the developed world where the fortunes of the hardest working classes continue to fall along with the "middle class" as the fate of the wealthiest grows exponentially, is surprisingly robust. One can point to the various forces that uphold this meritocratic ideology that are not just about capitalism's use of such an ideology, but also in personal experiences of work.

There is something to the tale of "work will equal success" that must also lie at the heart of our love with working on ourselves. We can see in our own lives how effort is connected to achievement, how not just in tales told to us, but in personal and social experiences. My work as a professor-both in research as well as in my role aiding students-fosters certain kinds of deliberate efforts to yield better knowledge. And while body work does not yield the same immediate results as getting one's hair dyed does for one's appearance, it does yield results. Hence, the work ethic both operates as a large social indoctrination linking labor to results as well as to personal experiences of effort paying off and a lack of work often resulting in less success. If one does achieve some success through effort, Weeks argues that we increasingly only count work that permits more purchasing, that is work that is paid, as real success, writing that "the work ethic was always already also an ethics of consumption, one that avows the necessary, legitimate, and indeed ethical link between hard work and whatever might count in different economic phases as deserved and responsible spending." ${ }^{42}$ My students' hard work studying pays off in getting a college degree which increasingly, in particular for lower income students, is advertised as a means of earning a better salary, with no more romantic discussion of the inherent values of learning. As any philosophy major will testify, when one returns home, once declaring such a major the question is always-but what will you do? It doesn't make sense to say, "think critically" or "ponder life's great questions." The question is not what will one do? , but how will one earn 


\section{2}

money?. Weeks notes that such buy-ins to the value of certain kinds of hard work "constructs docile subjects." ${ }^{43}$ Yet this docility only makes sense if the subjects themselves clearly see how their work is tied to success. Often the success attached is minimal in the face of economic wealth disparity. One may use a college degree (with its attendant debt) to rise from working class to middle class, but it is almost impossible to rise to the level of the wealthiest of people if one was not born into such a circumstance. However, microlevels of differences are the ones we pay attention to, and within these levels one can see a correlation between effort and level. A student can get a B rather than her fellow students' Cs and feel good about her performance. I can get a merit raise over my less published colleague.

However, a curious thing seems to be occurring in the case of some self-directed body work. Something like significant attention to working outwhether in its most extreme forms like ultramarathons, or in everyday gym classes-is actually not revenue producing, but costs money. It might also take time away from one's paid labor. If we tend to devalue work that is not highly attached to monetary gain-like studying philosophy, say—why then do we spend so much time and money working on our bodies? Insofar as we become increasingly invested in the idea of a good person being a person who takes care of herself in a certain healthy way, one might simply see it as immoral to not engage in such practices even if the cost to one's other projects is high. In addition, the lack of compelling well-paid labor, the collapse of lifelong work in a company, the reduction in pensions, and the dissolution of jobs to overseas or to automation make the exchange of money for time itself something the individual must not just do, but constantly innovate herself to respond to a precarious shifting ground. The individual becomes a product not simply a laborer. The rise of healthism in the 1970s was linked to the recession, a lack of good work, and a sense that meaning and achievement must be found elsewhere. ${ }^{44}$ Surely some today invest in their body work as an alternative to off-set personally meaningless work, but increasingly self-modification is itself part of the "product" that one is going to sell. As cited in Chapter 3, Oksala's discusses how female beauty routines are not simply about receiving the desired male gaze, but to provide the proper visual cue to others of a successful person who should be desired for employment and promotion. ${ }^{45}$

Docility is not just that the body is obedient to some norm of behavior but that the body is also productive. The discipline of the work ethic, in Foucault's terms, "increases the force of the body (in economic terms of utility) and diminishes these same forces (in political terms of obedience)" producing both a productive and subjugated body. ${ }^{46}$ The individual as the locus of self-reliance and effort sees her work not just tied to success but as what she truly wants. One might do all sorts of things to earn some money, but not identify with these activities other than practically as an exchange of time and expertise for money. Such a worker is unlikely to devote free time to the job. What would be ideal is to have workers that see their true life's desire to have a certain position that remains above them and are willing to put in any number of unpaid hours to obtain it. 
In The Wellness Syndrome, Cederström and Spicer note that the idea of being a constantly adapting, flexible employee, always improving skills and responding "creatively" to new shifting economies creates a self as a constant virtual product:

We must be on the move, constantly. We are tweeting, posting, hosting, sharing, linking, liking. The flexible worker's wall is never dry. What is crucial is not what you have achieved, but what you can become. What counts if your potential self, not your actual self. ${ }^{47}$

The challenge to examining the good health imperative more closely is that one needs to get outside the individual's own potentiality and see the other factors that contribute to this desire. The question of whether this individual is healthy or not and what could better her health needs to be placed in brackets. Such discussions help reenact the location of health as a matter of personal responsibility. Instead of debating what produces good health we must ask more into why we insist locating it in the individual and insofar as it is an individual project what the value of this value is.

We are caught in a unique position-research continues apace to discover new ways in which bodies can be modified and can modify themselves to achieve different amounts of longevity or increased performance. Given this, it will only be likely that in whatever spare time we do have, we will be encouraged to spend it working on ourselves, and this demand will not decrease with time, but, like the paid laborer in Marx's vision, our work will only increase with diminishing returns. And unlike Marx's prescriptive vision, it is hard to really imagine what would possibly change this situation given the rapid development of more health-related sciences, products, and practices to return us again and again the body as modifiable object. There is no communist revolt possible in relationship to health normalization or rejection of it wholesale. Existential angst about suffering and death will follow us in any new political regime. Turning away from the individual toward the way in which such healthy behavior is another form of labor helps return our focus to the historical and economic situation in which such labor takes place. Chapter 6 looks toward thinking what ways might exist to take up healthy self-care in a more reflective manner that refuses easy moralization or abstraction.

\section{Notes}

1 Perri Klass, "The Impact of Disparities on Children's Health," The New York Times, June 15, 2020. https://nyti.ms/2Y2ehBq

2 Tulay Soylu G., Eman Elashkar, Fatemah Aloudah, Munir Ahmed, Panagiota Kitsantas, "Racial/Ethnic Differences in Health Insurance Adequacy and Consistency among Children: Evidence from the 2011/12 National Survey of Children's Health," Journal of Public Health Research 7 (2018): 56-62.

3 Shervin Assari and Maryam Moghani Lankarani, "Poverty Status and Childhood Asthma in White and Black Families: National Survey of Children's Health," Healthcare, 6, no. 62 (2018): doi:10.3390/healthcare602002. 


\section{Marxism, reproductive labor}

4 Assari and Lankarani, "Poverty," 2.

5 Shervin Assari, "Unequal Gain of Equal Resources across Racial Groups," International Journal of Health Policy and Management 7, no. 1 (2018): 1-9.

6 Klass, "The Impact."

7 Mignon Duffy, "Doing the Dirty Work: Gender, Race, and Reproductive Labor in Historical Perspective," Gender and Society 21, no. 3 (June 2007): 7.

8 Duffy, "Doing."

9 Duffy, "Doing," 328.

10 Chandra Talpade Mohanty, "Women Workers and Capitalist Scripts: Ideologies of Domination, Common Interests, and the Politics of Solidarity.” In Feminist Genealogies, Colonial Legacies, Democratic Futures, eds. M. Jacqui Alexander \& Chandra Talpade Mohanty. London: Routledge, 1997, 17.

11 Mohanty, "Women Workers," 5.

12 Mitchell, Juliet, "Woman's Estate." In Feminist Frameworks: Alternative Theoretical Accounts of the Relations Between Women and Men, eds. Alison Jaggar and Paula Rothenberg. New York: McGraw-Hill Book Company, 148.

13 Joe Pinsker, “'Intensive' Parenting Is Now the Norm in America," The Atlantic, January 16，2019. https://www.theatlantic.com/family/archive/2019/01/ intensive-helicopter-parenting-inequality/580528/

14 Kim Q. Hall, “Toward a Queer Crip Feminist Politics of Food,” philoSOPHIA, 4 (2), 2014: 183.

15 Gretchen Livingston, "The Changing Profile of Unmarried Parents," Pew Research Center. April 25, 2018. https://www.pewsocialtrends.org/2018/04/25/ the-changing-profile-of-unmarried-parents/\#: :text=Among \%20solo \% 20 parents $\% 2$ C $\% 2042 \% 25 \% 20$ are,cohabiting $\% 20$ moms $\% 20(30 \% 25 \% 20$ vs.

16 Elizabeth V. Spelman, "Gender \& Race: The Ampersand Problem in Feminist Thought." In Feminist Frameworks: Alternative Theoretical Accounts of the Relations Between Women and Men, eds. Alison Jaggar and Paula Rothenberg. New York: McGraw-Hill Book Company, 2007, 274.

17 Linda Villarosa, 'A Terrible Price': The Deadly Racial Disparities of Covid-19 in America," The New York Times, April 29, 2020. https://nyti.ms/2VKB8jO

18 Richard A. Oppel Jr., Robert Gebeloff, K.K. Rebecca Lai, Will Wright and Mitch Smith, "The Fullest Look Yet at the Racial Inequity of Coronavirus," The New York Times, July 5, 2020. https://nyti.ms/3f286n9

19 Oppel et al., "The Fullest."

20 Karl Marx, Grundrisse. Translated by Martin Nicolaus (London: Penguin, 1993), 92.

21 Marx, Grundrisse, 92.

22 Viktor E. Frankl, Man's Search for Meaning. Translated by Ilse Lasch (Boston: Beacon Press, 2006).

23 Todd Tucker, The Great Starvation Experiment: Ancel Keys and the Men Who Starved for Science (Minneapolis: University of Minnesota Press, 2007).

24 Karl Marx, Capital Volume I, 171-173.

25 Joan Druett, Island of the Lost: Shipwrecked at the Edge of the World (New York: Algonquin 2007).

26 Marx, Grundrisse, 91-92.

27 Karl Marx, "Economic and Philosophical Manuscripts." In The Marx-Engels Reader, ed. Robert C. Tucker (New York: W.W. Norton, 1978), 73.

28 Christopher Duarte Araujo, "Marx and Paci on the Question of Appearances (Or, Reading Capital as a Phenomenology)," Human Studies 40, (2017): 107.

29 Karl Marx, Capital Volume I, translated by Ben Fowkes (London: Penguin, 1976), 163.

30 Scott Douglas, "Number of Ultramarathons Has Doubled in the Last Decade." November 7, 2014. https://www.runnersworld.com/races-places/a20833701/ number-of-ultramarathons-has-doubled-in-the-last-decade/ 
31 La Rochefoucauld, Maxims. Translated by Leonard Tancock (London: Penguin Classics, 1959), 54.

32 David Harvey, Marx, Capital, and the Madness of Economic Reason (Oxford: Oxford University Press, 2018), 109.

33 Mike Pare, "Innovation District Plan Includes Greater UTC Presence Downtown, Housing, Research Opportunities," Chattanooga Times Free Press (Chattanooga, TN), March 21, 2018. http://www.timesfreepress.com/news/local/story/2018/ mar/21/visiinnovatidistrict-includes-greater-utc-pre/466462/

34 Harvey, Marx, Capital, 126.

35 Herbert Marcuse, “The Affirmative Character of Culture.” In Negations: Essays in Critical Theory, translated by Jeremy J. Shapiro (London: MayFly, 2009), 71.

36 Marcuse, "The Affirmative," 72.

37 Marcuse, "The Affirmative," 81.

38 Marcuse, "The Affirmative," 89.

39 Bjørn Hofmann and Fredrik Svenaeus, "How Medical Technologies Shape the Experience of Illness," Life Sciences, Society and Policy 14, no. 3 (2018): 5-6.

40 Talia Welsh, "Broken Pregnancies.” In Phenomenology of the Broken Body, eds. Espen Dahl, Cassandra Falke, Thor Eirik Ericksen, (London: Routledge, 2019), 208.

41 Kathi Weeks, The Problem with Work: Feminism, Marxism, Antiwork Politics, and Postwork Imaginaries (Durham: Duke U.P., 2011), 51.

42 Weeks, The Problem, 50.

43 Weeks, The Problem, 53.

44 Robert Crawford, "Healthism and the Medicalization of Everyday Life," International Journal of Health Services 10, no. 3 (1980): 365-388. https://doi. org/10.2190/3H2H-3XJN-3KAY-G9NY

45 Johanna Oksala, Feminist Experiences: Foucauldian and Phenomenological Investigations. (Evanston: Northwestern University Press, 2016): 118-119.

46 Michel Foucault, Discipline \& Punish: The Birth of the Prison. Translated by Alan Sheridan. (New York: Vintage, 1995): 138.

47 Spicer and Cederström, The Wellness Syndrome, 21.

\section{Bibliography}

Araujo, Christopher Duarte. "Marx and Paci on the Question of Appearances (Or, Reading Capital as a Phenomenology)," Human Studies 40, (2017): 101-119. https://doi.org/10.1007/s10746-016-9411-7.

Assari, Shervin. "Unequal Gain of Equal Resources across Racial Groups," International Journal of Health Policy and Management, 2018, 7(1): 1-9.

Assari, Shervin and Maryam Moghani Lankarani, "Poverty Status and Childhood Asthma in White and Black Families: National Survey of Children's Health," Healthcare, 2018, 6 (62): doi:10.3390/healthcare602002.

Cederström, Carl, and Andre Spicer. The Wellness Syndrome. Cambridge: Polity Press, 2015.

Crawford, Robert. "Healthism and the Medicalization of Everyday Life." International Journal of Health Services 10, no. 3 (1980): 365-388. https://doi. org/10.2190/3H2H-3XJN-3KAY-G9NY.

Douglas, Scott. "Number of Ultramarathons Has Doubled in the Last Decade." November 7, 2014. https://www.runnersworld.com/races-places/a20833701/ number-of-ultramarathons-has-doubled-in-the-last-decade/

Druett, Joan. Island of the Lost: Shipwrecked at the Edge of the World. New York: Algonquin, 2007. 


\section{Marxism, reproductive labor}

Duffy, Mignon. "Doing the Dirty Work: Gender, Race, and Reproductive Labor in Historical Perspective," Gender and Society, 21 (3) (2007): 313-336.

Foucault, Michel. Discipline \& Punish: The Birth of the Prison, translated by Alan Sheridan. New York: Vintage, 1995

Frankl, Viktor E. Man's Search for Meaning, translated by Ilse Lasch. Boston: Beacon Press, 2006.

Hall, Kim Q.. “Toward a Queer Crip Feminist Politics of Food,” philoSOPHIA, 4 (2), 2014: 177-196.

Harvey, David. Marx, Capital, and the Madness of Economic Reason. Oxford: Oxford University Press, 2018.

Klass, Perri. “The Impact of Disparities on Children's Health,” The New York Times, June 15, 2020. https://nyti.ms/2Y2ehBq.

Livingston, Gretchen, “The Changing Profile of Unmarried Parents," Pew Research Center. April 25, 2018. https://www.pewsocialtrends.org/2018/04/25/the-changing-profile-of-unmarriedparents/\#: :text=Among $\% 20$ solo $\% 20$ parents $\% 2 \mathrm{C} \% 20$ $42 \% 25 \% 20$ are,cohabiting $\% 20$ moms $\% 20$ (30\%25\%20vs.

Marx, Karl. Capital Volume I, translated by Ben Fowkes. London: Penguin, 1976.

Marx, Karl. "Economic and Philosophical Manuscripts." In the Marx-Engels Reader, edited by Robert C. Tucker, 66-125. New York: W.W. Norton, 1978.

Marx, Karl. Grundrisse, translated by Martin Nicolaus. London: Penguin, 1993.

Mitchell, Juliet, “Woman's Estate.” In Feminist Frameworks: Alternative Theoretical Accounts of the Relations Between Women and Men, edited by Alison Jaggar and Paula Rothenberg. New York: McGraw-Hill Book Company.

Mohanty, Chandra Talpade, "Women Workers and Capitalist Scripts: Ideologies of Domination, Common Interests, and the Politics of Solidarity." In Feminist Genealogies, Colonial Legacies, Democratic Futures, edited by M. Jacqui Alexander and Chandra Talpade Mohanty. London: Routledge, 1997

Oksala, Johanna. Feminist Experiences: Foucauldian and Phenomenological Investigations. Evanston: Northwestern University Press, 2016.

Oppel, Richard A. Jr., Robert Gebeloff, K.K. Rebecca Lai, Will Wright and Mitch Smith, "The Fullest Look Yet at the Racial Inequity of Coronavirus," The New York Times, July 5, 2020. https://nyti.ms/3f286n9.

Pare, Mike. "Innovation District Plan Includes Greater UTC Presence Downtown, Housing, Research Opportunities," Chattanooga Times Free Press (Chattanooga, TN), March 21, 2018. http://www.timesfreepress.com/news/local/story/2018/ mar/21/visiinnovatidistrict-includes-greater-utc-pre/466462/.

Pinsker, Joe. "'Intensive' Parenting Is Now the Norm in America," The Atlantic, January 16, 2019. https://www.theatlantic.com/family/archive/2019/01/ intensive-helicopter-parenting-inequality/580528/.

La Rochefoucauld. Maxims, translated by Leonard Tancock. London: Penguin Classics, 1959.

Spelman, Elizabeth V., "Gender \& Race: The Ampersand Problem in Feminist Thought." In Feminist Frameworks: Alternative Theoretical Accounts of the Relations Between Women and Men, edited by Alison Jaggar and Paula Rothenberg. New York: McGraw-Hill Book Company. 2007.

Svenaeus, Fredrick. "Das unheimliche-Toward a Phenomenology of Illness." Medicine, Health Care and Philosophy 3, no. 1 (2000): 3-16. https://doi. org/10.1023/A:1009943524301.

Tucker, Todd. The Great Starvation Experiment: Ancel Keys and the Men Who Starved for Science. Minneapolis: University of Minnesota Press, 2007. 
Tulay G. Soylu, Eman Elashkar, Fatemah Aloudah, Munir Ahmed, Panagiota Kitsantas, "Racial/Ethnic Differences in Health Insurance Adequacy and Consistency among Children: Evidence from the 2011/12 National Survey of Children's Health," Journal of Public Health Research 7, no. 1280 (2018): 56-62. Villarosa, Linda. “'A Terrible Price': The Deadly Racial Disparities of Covid-19 in America," The New York Times, April 29, 2020. https://nyti.ms/2VKB8jO.

Weeks, Kathi. The Problem with Work: Feminism, Marxism, Antiwork Politics, and Postwork Imaginaries. Durham: Duke U.P., 2011.

Welsh, Talia. "Broken Pregnancies.” In Phenomenology of the Broken Body, edited by Espen Dahl, Cassandra Falke, Thor Eirik Ericksen, (London: Routledge, 2019), 208. 


\section{Alternative visions of health- somaesthetics and innumerable healths}

\section{Create dangerously}

In a lecture entitled "Create Dangerously" given in 1957 at the University of Uppsala, Albert Camus argued that what differentiates the artist of today from that of generations past is the clear awareness of "the masses and their wretched condition ... We know that they exist, whereas we once had a tendency to forget them." ${ }^{1}$ Mozart did not compose his music with daily knowledge of the horror of war, environmental collapse, and social unrest. Since we now know such things (and today even with more frequency and rapidity than in Camus' time), artists must now ask whether or not they should address the condition of their world as part of their art. Even if the artist is not particularly inspired to create art that addresses human suffering, is this lack of inspiration possibly a kind of moral failure? Camus argues that the ideology of "art for art's sake" arose to isolate art from the troublesome, messy nature of our awareness. For Camus, the idea that one would absent oneself from the world and fall into one's art is a "voicing" of "irresponsibility." 2 The alternative, to make art the handmaiden of political action, Camus also rejects as "socialistic realism." Such a move makes art propaganda. Instead of these two approaches to our human condition today, Camus argues that:

Art is neither complete rejection nor complete acceptance of what is. It is simultaneously rejection and acceptance, and this is why it must be a perpetually renewed wrenching apart. The artist lives in such a state of ambiguity, incapable of negating the real and yet eternally bound to question it in its eternally unfinished aspects. ${ }^{3}$

Camus argues that the freedom of artists places them in an ambiguous space where they are of this world and yet have the capacity to create new ones.

In this chapter, I take up the question of creative artistic expression as one means of examining our body work. This work does not occur outside the knowledges of the healthcare sciences, nor is it beholden to that work; rather it permits us to think about the work on our bodies as akin to a personal art, rather than obeying a universally moral imperative. This

DOI: $10.4324 / 9781003168676-6$ 
provides some respite from the moralizing that serves the ends of others. It expands the possibilities of what a good life is outside of pre-packaged ones. To this end, I will use some of the themes brought up in Richard Shustermann's somaesthetics and Nietzsche's idea of innumerable healths. The idea of body work as somaesthetic practice draws our attention toward experience and away from objective measures of health (such as BMI, blood pressure, etc.). As such, it can allow for a self-conscious form of personal development that is not reducible to the good health imperative even if it considers health as one of the products of somaesthetic practice. Cressida Heyes and Marjorie Jolles see promise in somaesthetics as a way to provide feminist self-care that resists normalization. In the subsequent two sections, the limits of somaesthetics will be considered due to its reliance on the idea of a single form of self in its self-development model. In Nietzsche's model of "innumerable healths" and "many wills" the status of a unitary nature of health is disputed alongside the idea of the individual as having only one core self-identity. Finally, Kathi Weeks' use of Nietzsche's eternal return of the same as a way to reject self-improvement will complicate and complement the somaesthetic and phenomenological views of health and flourishing.

\section{Creative self-fashioning}

Richard Shusterman coined the term "somaesthetics" to provide a name around which to organize a diverse and interdisciplinary style of thought and practice. What Shusterman works toward, given some of his own theoretical reflections (as well as his personal work with body training technique "the Feldenkrais Method"), is that philosophy has for too long ignored thinking about the body. ${ }^{4}$ When it has, philosophy has shied away from advocating for particular kinds of body development. Instead, it leaves such work to other disciplines, such as those that support the various corporations, charities, and government institutions that use the good health imperative as their justification. Shusterman acknowledges that much of the attention to the body serves to profit companies, encourages sexist and racist views, and normalizes our behavior. However, he considers that "the critical study and meliorative cultivation of how we experience and use the living body (or soma) as the site of sensory appreciation (aesthesis) and creative self-fashioning" can provide a site that neither ignores the body nor takes our current methods of training it as sufficient. ${ }^{5}$ It also extends us far beyond the kind of theorizing that dominates Western thought, which tends to take the body at arm's length, if it considers the body at all. Somaesthetics instead is "devoted to the knowledge, discourses, practices, and bodily disciplines that structure somatic care or improve it," thus making consideration of things such as digestion, nutrition, physical therapies, sports, and the bodily arts integral. ${ }^{6}$ Yet, these practices, knowledges, and techniques are not merely practical for obtaining the ends of better health or reduced suffering. Rather, the idea of somaesthetics is to make such practices aesthetic 
experiences. One must also attend to how those practices contribute to a somaesthetic self-creation as an on-going experiential practice that betters one's appreciation of oneself, not merely whether one achieves the determined benchmark. In such a manner, somaesthetics is a practical philosophical attempt to embody what the good health imperative does with a more nuanced form that is attentive to varieties of pleasures and aesthetic delight.

Shusterman argues that "self-help was once philosophy's guiding goal" even though contemporary academic philosophy finds such a research agenda distasteful; somehow too common and base. ${ }^{7}$ Shusterman suggests that this is an unfortunate development, and that a multi-disciplinary somaesthetics could greatly improve the lives of many just as one might argue that the development of finer powers of critical philosophy cultivates the lives of many. Shusterman provides neither a "how-to" guide for somaesthetics nor a set of ways one can track whether one is succeeding or failing. However, he does outline three "fundamental branches" of somaesthetics. In the following, I will take up these ideas and detail how they dovetail with a critical examination of the good health imperative.

First, Shusterman thinks about "analytic somaesthetics," which is the "descriptive and theoretical enterprise devoted to explain the nature of our bodily perceptions and practices and their function in our knowledge and construction of the world." Merleau-Ponty's extensive work on the body, the work of feminist, race, and queer theorists, and Foucault's work discussed previously are examples of such work that explore how ignoring the body has greatly limited our capacity to understand the way that our sciences, knowledges, ethics, and ontologies come to be formed. Pragmatic somaesthetics proposes "specific methods of somatic improvement" and engages "in their comparative critique." It presupposes analytic work, thus avoiding the oppressive regimes of body discipline in a particular society, but it would extend beyond it "by proposing various methods to improve certain facts by remaking the body and society." ${ }^{10}$ Thus, in principle, the good health imperative could be adjusted by somaesthetics to achieve the morally valuable end of better health without the limiting kinds of moral policing and normalization.

Finally, there is also practical somaesthetics- "pursuing such care through intelligently disciplined practice aimed at somatic self-improvement." 11 Practical somaesthetics is the actual doing of that which the pragmatic somaesthetics proposes, "concerned not with saying but doing, this practical dimension is the most neglected by academic body philosophers." ${ }^{12}$ Importantly, practical somaesthetics is part of a "comprehensive philosophical discipline" and foreseeably something that philosophers as well as laypeople would employ. ${ }^{13}$ The various methods, protocols, practices, treatments, medicine, and testing done in the name of the good health imperative could be seen as practical, but not yet somaesthetic. What such disciplines would need is to focus on is the experiential manner in which something betters one's capacities for aesthetic pleasure, for development, and for creative expression. 
In Chapter 3, we examined how the obsession with molding the female body to ever more exacting forms of beauty presented us with a helpful example of how one may willingly enter into normalized body discipline. But simply to engage in critical work on body normalization fails to capture the pleasures and possibilities of positive body work. One aspect of somaesthetics is to increase pleasures by considering the way one treats and moves one's body as not just allowing one to not take blood pressure medication or lose weight, but to actually have greater, more nuanced sensations. One could think here of the pleasures of learning a new dance, developing one's palate for a cuisine, climbing a difficult rock, or learning how to meditate. Shusterman thinks about the appreciation of beauty not just as the contemplation of the object or even the contemplation of one's own body as an object, but "the beautiful experience of one's own body from within - the endorphin-enhanced glow of high-level cardio-vascular functioning, the slow savoring awareness of improved, deeper breathing, the tingling thrill of feeling into new parts of one's spine." ${ }^{14}$ Such pleasures, while perhaps encouraged by some of the practices celebrated in the good health imperative, are by no means exclusively held by the bodies that are seen as "appropriately healthy." Foreseeably, one would consider how to adapt an exercise regime, say, to focus less on weight loss and more on new capacities for experience.

Importantly, somaesthetics takes up the experience in total and not in quantifiable, objectified levels such as BMI or blood pressure. Eating food is not a matter simply of nutrition, for instance, it is part of the art of eatingone can explore not just different foods from other cultures, but also other cultural styles of eating to develop one's own somaesthetic practice. Eating food somaesthetically would entail paying attention to the dexterity of using utensils, palate, season, social company, environment, accompanying drinks, and how one feels when eating, sitting, and chatting. ${ }^{15}$ The shared experience of eating food well would thus be a socially constituted art that can be returned to repeatedly. This leaves us open to imagining many more different ideals of "good health" apart from simply analyses of caloric and nutritional details. Shusterman argues that somaesthetics, unlike other models, requires one to take up the importance of the larger social and environmental world that permits such self-fashioning. "Such lessons of somatic self-conscious eventually point toward the vision of an essentially situated, relational, and symbiotic self rather than the traditional concept of an autonomous self grounded in an individual, monadic, indestructible, and unchanging soul." ${ }^{16}$ Caring about the others at my meal and considering the situation in which I am eating draw upon how one's embodiment is not contained within the layer of skin that surrounds one's physical form, but is an extended, temporal, affective, and virtual world.

Interested in pursuing better ways to care for the self, some feminists have appealed to Shusterman's idea of somaesthetics as a possible place from which to develop better ideals of self-care. Cressida Heyes, Majories Jolles, and Shusterman have called for the use of somaesthetics to pursue feminist 


\section{Alternative visions of health-somaesthetics}

ethical concerns. ${ }^{17}$ Inherent in somaesthetics is a focus on the experience over the product. In standard ideas of delight in beauty self-fashioning, the delight is the creation of oneself as an object to be viewed. The beauty is not in the putting on of makeup, but when one stops and is "done." Instead, somaesthetics focuses on how the body achieves greater levels of beauty in the practice-such as Heyes describing her transformative work doing yoga. The delight of a deep pose held for a long time requires being in and with one's body, not displaying one's body. ${ }^{18}$ Heyes sees that this idea of the focus on experience runs counter to many gym and athletic cultures where exercise is seen as a tool to shape and discipline the body rather than an experience of delight in itself. ${ }^{19}$

The good health imperative's dependency on biometric markers and achieving results could possibly be replaced by a somaesthetic view that places priority on the experience and on movement, while distancing itself from health as any kind of particular achievement that can be understood external to the experience. However, one concern is that often the kinds of practices that somaesthetics proposes are very self-centered works on self-improvement, perhaps not subjectively the same, but at least externally quite similar to the kinds of practices encouraged by the good health imperative. One's fellow travelers in yoga or cuisine, for example, are valuable insofar as they help enlarge one's personal experience. While Shusterman does consider cultural, social, and other aspects of one's environment, the kinds of experiences he discusses-yoga, Zen meditation, developing one's culinary appreciation-are hard to imagine as ones that the busboy cleaning the table, the poor, or the disenfranchised could enjoy and develop. As Chapter 2 critiqued some phenomenologies of movement for their emphasis on adult solitary pursuits like playing tennis or riding a bike, the kinds of activities of someaesthetics are very often adult, individual, and privileged forms of embodiment. Surely, as Camus writes, there is something uncomfortable about these artistic pursuits in the face of the knowledge of the world.

Heyes highlights this concern among feminists by arguing that the kinds of self-care rituals and subtler approaches like somaesthetics discourage serious work toward solidarity and political change. "Feminists especially are concerned that care of the self will encourage a privileged, inward-looking attitude that merely taps into existing social trends toward fragmentation and lack of political responsibility or solidarity." ${ }^{20}$ However, a life turned always outward toward the group and the society likewise reproduces the subjugation of the disenfranchised groups, where their purpose is to better the lives of the husband, the boss, the man, or the leader. What Heyes appreciates about somaesthetics is that it provides a much-needed discussion for self-care that isn't sold to women in such a manner as to further their subjugation. Another problem with somaesthetics, as Shusterman expresses it, is that it doesn't address how I am represented will co-constitute how I experience myself. The experiences of delight at normalization rituals are not false-that is, experiences that are faked or inauthentic, even if they 
may indeed require docility and a lack of creative self-fashioning. There can be great collective and personal pleasure in engaging in highly commodified and limited kinds of body work. Jolles argues that Shusterman's work doesn't respond to the way in which our experiences are themselves based in cultural representations we have acquired. ${ }^{21}$ Jolles considers that instead of focusing on practices for certain kinds of somaesthetic development, such as thinking about food or movement, one could attune toward narratives that would include the capacity for greater freedom that springs from a complex look at experience. ${ }^{22}$ Jolles further argues that a feminist ethic of embodiment seeks to make the damaging effects of normalization visible so that we can better organize to work against them. Yet she cautions that "The obvious limitation of any program that interrogates the edges of normalization is that the subject who would take up such a program is likely to be already aware of those effects, and perhaps even already equipped to resist them." 23

The very fact that I can think about how I am shaped suggests that some part of my experience exceeds indoctrination. Not only do my experiences transcend in part any tools I'm given to explain them, which surely is part of the impetus for writers, artists, and musicians to create, but I am capable of thinking about how I am constituted without violating some rule of that very same constitution. It does not free me from anxieties that have been deeply embedded in my upbringing, but certainly being able to think about the question if a life spent concerned with my looks might be a pointless pursuit is itself a kind of space into which I might explore a new way of being. Feminist embodiment ethics' engagement with Foucault and other biopolitical theorists does not mean that they argue one cannot exit normalization in any manner. Heyes notes that there is "nothing in Foucault's work to suggest that we are incapable of critical reflection on normalization" even if the "larger historical and genealogical picture of normalization is beyond the control of any individual." ${ }^{24}$ Heyes situates the idea of critical reflection with her idea of self-transformation. Hence, feminist embodiment ethics can be viewed as sympathetic to analytic somaesthetics and its advocating for new styles of embodiment as a practical somaesthetics.

Chapter 5 explored the ways in which the good health imperative, despite its seeming benefits, produces a different kind of work that is now demanded of all subjects regardless of their embodied condition. Somaesthetics is a compelling way to think about long-standing forms of self-cultivation-such as developing one's palate, learning a sport, practicing experience-based forms of self-awareness (yoga, tai-chi, martial arts, or learning the art of using one's body to sing or play music)—as ways in which one may include health concerns without letting such concerns be about the production of the right kind of body. While it seems possible to draw out and expand upon some styles of self-directed body work in a more creative, experiential fashion as an alternative (or addition) to the medicalized "passing" of certain tests, such work relies upon a view of a self that has predetermined goals and will continue, more or less, as the same 


\section{Alternative visions of health-somaesthetics}

bodily subject over time. This greatly limits the creativity possible in such work. Instead, the idea of self-transformation in Heyes can help underline the idea of a new self or selves, not simply the same one with better aesthetic pleasures and tastes. Oksala writes that bodily agency needs to not be understood as a possession but as an opening:

There is "freedom" in the unpredictability of our embodied experiences that establishes the always incomplete character of the body's cultural constitution. This freedom is not to be understood as an inherent capacity or attribute of the body as such, but is more like a 'Foucaultian' understanding of freedom as the freeing or opening of new possibilities for living our bodies, sexualities and lives. ${ }^{25}$

While perhaps somaesthetics produces these kind of possibilities, its reliance on a self-same subject who works on her body also would seem to continue to place health on the front burner. After all, if I am ill to the degree that I cannot develop myself, this takes precedence over any creative self-fashioning. Development itself has at its core the idea that one is developing a self whose will and self are known and thus limit consideration of the unpredictability of our embodiment. Below, I will explore Nietzsche's idea of suffering as part of health and health as constituting a wide variety of states in various individuals. In conclusion, I will consider how in addition to a critique of a unitary, objective concept of health, one also finds in Nietzsche a view of a diversity of selves and wills. Self-development and self-transformation become much more complex and ambiguous in this reading.

\section{Nietzsche's innumerable healths}

There are two kinds of depictions of illness and health in Nietzsche. One is to diagnose moralists; in particular, Christian moralists and their partners in crime for most of the history of Western ethics, with sickness and weakness. In discussing the origin of morals in On the Genealogy of Morals, Nietzsche provides a psychological and language-based account of what might have motivated the first "moralists" - the first people who started seeing human experience as differing in value. He argues that prior to our contemporary morality, moral terms were to create distance from the low-born. Original master moralities were unsophisticated in that they did not depart from the experiences of the knightly-aristocratic class. They were not abstract, as no attempt was made to universalize them. What they espoused was a strong love of the physical and of health. "The knightly-aristocratic value judgments presupposed a powerful physicality, a flourishing, abundant, even overflowing health, together with that which serves to preserve it: war, adventure, hunt, dancing, war games, and in general all that involves vigorous, free, joyful activity." ${ }^{26}$ When Odysseus is praised for his looks, cleverness, and skill in battle, it is not hard to deduce the kinds of persons that might celebrate the values behind those attributes. Those not lucky enough 
to be born into bodies and conditions that fostered such physicality grew resentful and gave birth to what we would now think of as morality-a universal set of judgments that often are decidedly against the physical. Just as the knightly-aristocratic values sprang from the masters' own condition as powerful, the slave morality of the priestly class springs from their weakness. The impotence of the priests causes them to create values that reject the physical because of their own weakness. They do not create from a love of self, but a hatred of what they are not:

...As is well known, the priests are the most evil enemies - but why? Because they are the most impotent. It is because of their impotence that in them hatred grows to monstrous and uncanny proportions, to the most spiritual and poisonous kind of hatred. ${ }^{27}$

This hatred is borne out of a lack of having the kinds of positive qualities that make for a well-lived life. "While every noble morality develops from a triumphant affirmation of itself, slave morality from the outset says No to what is 'outside,' what is 'different,' what is 'not itself'; and this No is its creative deed." ${ }^{28}$ The sophistication of contemporary morality would be lost on Nietzsche's pre-moral knightly-aristocratic class since, to a large degree, their health is a simple affirmation of what they are, and not, as in contemporary Western morality, what they should be.

Shusterman sees some forces of inspiration for somaesthetics in Nietzsche and Foucault, but ultimately judges their work as too unconscious, wild, and without the kind of deliberate, recursive practice he calls for in pragmatic someaesthetics. For Shusterman, Nietzsche's main positive contribution is his emphasis on bodily sensation, passions, and emotions over the idealist mind and soul centered philosophies in the West. However, Shusterman thinks Nietzsche goes too far in his celebration of the body, arguing that what he calls "Nietzsche's hyperbolic somaticism" is ultimately unconvincing because of the body's weakness:

The problem is not simply that body over mind goes too much against the grain of philosophy's intellectualist tradition. Nor is it merely that the reversal seems to reinforce the same old rigid dualism of mind and body. Somatic deficiency is, unfortunately, such a pervasive part of experience that Nietzsche's inversion of the mind/body hierarchy seems too much like wishful thinking (particularly when we recall his own pathetic bodily weakness). ${ }^{29}$

For Shusterman, the body qua unconscious, silent force is fundamentally limited even if it is true, like Nietzsche argues, that it has powers beyond the mind's ability to control and introspect. We are not just beasts of prey; we are also fragile, sickly beings subject to illness, disease, and decay. We are also beings who can develop themselves, Shusterman argues, through conscious, mindful practice. 


\section{6}

Alternative visions of health-somaesthetics

One does not have to read much of Nietzsche's corpus to find thought that works against the idea that Nietzsche views master morality as some kind of animalistic, bodily strength. Nietzsche wrote often about frailty and sickness in ways that derail the theory that his work is merely "hyperbolic somaticism." The values Nietzsche clearly celebrates include not just elitist values that seem untimely today, but also the value of difference, including characteristics that we would normally think are at minimum undesirable, if not outright evil. Suffering is not an objection to a flourishing existence, but actually essential to it.

"We think that hardness, forcefulness, slavery, danger in the alley and in the heart, life in hiding, stoicism, the art of experiment and devilry of every kind, that everything evil, terrible, tyrannical in man, everything in him that is kin to beasts of prey and serpents, serves the enhancement of the species 'man' as much of its opposite does." ${ }^{30}$ In this passage from Beyond Good and Evil, one notes that improvement or progress is not made solely on the back of "positive" virtues such as charity. Thus, progress is garnered on the basis of danger as much as clear-headed rational planning.

In a similar vein, health is not the opposite of sickness, but something that takes place in a certain relation to it. Since change is inevitable and our condition leads us not just to the joys of life but the obvious difficulties, health outside of sickness is not any more possible than life without death. Nietzsche even counsels that sickness can be philosophically profound in that it portrays the vitality of life more explicitly:

For a typically healthy person, conversely, being sick can even become an energetic stimulus for life, for living more. This, in fact, is how that long period of sickness appears to me now: as it were, I discovered anew, including myself; I tasted all good and even little things, as others cannot easily taste them-I turned my will to health, to life, into a philosophy. ${ }^{31}$

Nietzsche celebrates his own "fickle health" as giving him a capacity above "robust squares." ${ }^{32}$ For Nietzsche, his moving between health and sickness and having different qualities of existence actually carries him through "an equal number of philosophies." ${ }^{33}$ Sickness creates the need to create a "spiritual form and distance" ${ }^{34}$ from such states, but this fundamental lesson is not to leave sickness behind, but to see its value in transfiguration. Philosophers

....are not thinking frogs, nor objectifying and registering mechanisms with their innards removed: constantly, we have to give birth to our thoughts out of our pain and, like mothers, endow them with all we have of blood, heart, fire, pleasure, passion, agony, conscience, fate, and catastrophe. ${ }^{35}$

Hence, while one might not pursue sickness, it is not the case that sickness is always limiting: it may be transforming. 
Sickness as perceived suffering, as the unthematic body forcing itself upon the individual requiring her to respond, is in not an objection to health. This would contradict the idea of illness as privation in Heidegger and, in Merleau-Ponty, the idea of illness as limiting the body's natural, spontaneous extension toward the world as discussed in Chapter 3. Upon reflection, extreme states of joy or passion are intense and bring us away from unthematic being-in-the-world, but are typically seen as states that give our lives great meaning. While certainly people must forgo at times in their lives, or even consistently, any great passion for fear they will lose their object of affection or fail to achieve their ambition, a life spent avoiding any possibility of suffering would be a diminished one. Even physical pain is not in-itself always to be avoided. Many experiences that are sought-after such as natural childbirth and running marathons are painful. We would find someone who avoided pain at all costs unreasonable and likely incapable of a life worth living.

The good health imperative works in this fear of suffering, and while Nietzsche's dramatic language might not seem particularly practical to the question of how to live in a world saturated with the moralizing about health, it does help to think about how our fear of ill health might encourage a kind of unquestioned value of one kind of health and hence our too quick willingness to submit to the good health imperative. Marc Letteri argues that Nietzsche teaches us the distinction between sickness and sickliness:

Health is, however, not simply the absence of weakness: it is, rather, the free admission of weakness into the arena of struggle with the aim of conquering it and thereby becoming stronger. An untested will is an unknown quantity, and a will which actually shirks tests is even worse-much worse. It suffers not from sickness but from sickliness: it is characterized by an inveterate inability, an inability to deal profitably with impediments and obstacles. ${ }^{36}$

Moralists blame the senses and thus the body for disrupting their search for "truth." They object to change, divergence, difference-all the elements that constitute our embodied existence. This springs not from a serious desire for universality, but rather from an inability to endure human existence and a search for a solution outside of it. The sickliness of the moralist is not physical sickness so much as a kind of inability to face being embodied with its vacillating states, including pain. The weakness is thus not necessarily connected to the weakness one has when one has the flu or when one is being treated for cancer, but rather a fear of variety, since variety brings with it great joys and ecstasies but also suffering and disintegration, in other words, what it is to live.

For Nietzsche, moralists want conformity of souls not because conformity exists, but because it serves the aim of creating distance from the body. Identity for Nietzsche cannot be universalized any more than morality can. The moralist who wants to deny the charming diversity of life will seek the idea of there being only one way to see health and one way to see suffering: 
Let us finally consider how naïve it is altogether to say: 'Man ought to be such and such!' Reality shows us an enchanting wealth of types, the abundance of a lavish play and change of forms - and some wretched loafer of a moralist comments: 'No! Man ought to be different.' He even knows what man should be like, this wretched bigot and prig: he paints himself on a wall and comments 'Ecce homo!'37

The changes of my body will bring transformations that may not be willed, and perhaps the willed ones will fail to take hold. In addition, as discussed in Chapter 2, any one person's sense of well-being or suffering is deeply intertwined with virtual, subjective aspects of her life. Thus, one cannot really say what it means to have a "normal" course of cancer as an experience even if many aspects of how cancer develops as a disease are known. It is also the case that those who on objective levels have good health likewise do not experience this in a similar manner. Of course, ceteris paribus, it would be odd to find someone who would in the abstract prefer ill health over good health. But it is not necessarily the case that improving one's health according to healthcare guidelines would always improve one's well-being if one assumes that one's well-being is more complex than biometric screenings.

Nietzsche's idea of "innumerable healths" is tied to his rejection of equality. For Nietzsche, what is healthy for one person might not be so for another. This idea would seem to run strongly counter to much of our sense of health being a medical matter that is determined objectivity. Nietzsche counsels that "there are innumerable healths of the body; and the more we allow the unique and incomparable to raise its head again, and the more we abjure the dogma of 'equality of men,' the more must the concept of a normal health, along with a normal diet and the normal course of an illness, be abandoned by medical men." ${ }^{38}$ Phenomenologists, in particular existential phenomenologists, would find much in common with Nietzsche's celebration of the senses, of change, of accepting aging, birth, death, and difference among humans. Merleau-Ponty writes that mechanistic models cannot explain the rich diversity of styles of embodiment. In his lectures on child psychology and pedagogy, Merleau-Ponty repeatedly draws attention to how physical maturation is necessary but not sufficient for development:

Development is as little a destiny as it is an unconditioned freedom, for the individual always accomplishes a decisive act of development in a particular corporeal field. We find here once again Hegel's idea of "surpassing while preserving." The individual only moves beyond his first states if he agrees to retain them. Thus, we rejoin our general conceptions of the personal and interpersonal dynamic. ${ }^{39}$

One can have precocious children or delayed children; it is a matter of their larger connection to others and the world around them. In the case of sexist societies, with the closing off of many possible worlds to the young 
girl, her development is shrunk..$^{40}$ Here we can see a tie back to the previous discussion of how health for phenomenologists is also about the possible, the virtual-my health is in part conditioned by how I imagine my future and not just my present physical state.

Yet despite these resonances with Nietzsche's texts, phenomenologists might pause at the discussion of illness as essential for health. After all, it is the suffering of illness that breaks the harmony of the body schema in its everyday actions. It is pain that commonly restricts one's life. However, Nietzsche's work does not in principle run counter to the kinds of ideas Svenaeus, Carel, Toombs, and others interested in more phenomenological approaches to medical practice offer. Instead, the idea of "innumerable healths," including pain, suffering, and illness offers an important existential rejoinder to considering just what health is. Peter Sedgwick notes that Nietzsche's view of health helps to counter the tendency to think of health as something that is the opposite of sickness, "Medical practitioners, therefore, ought to abandon the modern tendency to think of health as the opposite of sickness, and instead consider health as something tied to one's frailty and finitude." ${ }^{41}$ Similar to the idea of unheimlichkeit, illness is not a rejection of health but part of what it is to exist-to be both at home and not at home.

What Nietzsche's critique of sickliness, rather than sickness, and the illusion of a stable self provides the phenomenologist is a way to avoid thinking about health as a background in a reductive fashion. While it is valuable to think about how good health often recedes into the background when one takes up one's tasks, the possible danger is to then think of health as a kind of steady state where variance, both individual and social, is an objection to it. If we think about health as "innumerable healths," we capture both individual and social diversity more accurately.

If suffering and health are intertwined, we can look to Svenaeus' separation of suffering into different types. ${ }^{42} \mathrm{He}$ notes there is the suffering that arises from illness, what would be most often addressed in healthcare settings, but there is also political, existential, and bad luck suffering. Eliminating suffering is not in this account always beneficial to the individual. For instance, pharmaceuticals that flatten my anxieties to find a personally relevant existential quest for meaning in an ambiguous universe might actually detract from a true well-being, even if admittedly discomfort is alleviated. ${ }^{43}$ Noting that this would seem to work against his ideas of health as a homelike being-in-the-world, Svenaeus argues that this would be to confuse all suffering as illness-suffering. Rather, some suffering might be essential to a life well-lived. Sveneaus writes, "A flourishing life rests on authentic self-understanding, according to most phenomenological thinkers..." ${ }^{4}$ Such thinking can complement a more complex relationship to suffering rather than seeing all suffering as something to be eliminated.

If the solution to systemic economic and political inequalities is simply treating the individuals who are suffering as needing more medical treatment, one will fail to actually address the real source of suffering. More 
invasive intrusion into the bodies of fat children because of their fatness encourages not attending to the political reasons behind the disparities in weight between the rich and the poor. Moreover, suffering can be seen also as an impetus for advocating for change and for articulating ways in which one is unable to voice one's lived experience. As discussed in Chapter 3, feminists in the phenomenological tradition stress the importance of considering our experiences as epistemologically relevant. This is not to assert that they are relevant as we initially might interpret them, as this interpretation is often culturally bound, but that frustration and pain can themselves be important rejoinders not to change ourselves, but instead to change the world.

\section{Innumerable selves and eternal return of the same}

In the conclusion of her book The Problem of Work, Weeks also turns toward existentialist themes of trying to find new ways of considering meaning by taking up Nietzsche's much discussed, and perhaps little understood, idea of the eternal return of the same. One trend in scholarship is to see Nietzsche's idea of everything returning repeatedly as a kind of carpe diem: a practical existentialist ethics where we can affirm our lives and find joy in what is here and now, rather than religious and moral illusions. ${ }^{45}$ Weeks takes a similar view; she sees the eternal return of the same not as a grand cosmological statement that everything shall return again in time, but something we can use. She thinks of it as a kind of self-help idea that has an "affective impact" on our lives. ${ }^{46}$ To accept where one is and who one is unequivocally in order to reach into the future afresh. Refusing work is a way to accept what is without qualification and without the need to transform oneself through labor.

Weeks thinks that the affirmation of the eternal return acknowledges the past in order to move forward without resentment or circularity. "The eternal return acknowledges the lingering impact of the past on the present and future, and attempts to disallow a particular mode of that lingering that results in ressentiment and even nihilism." ${ }^{47}$ Using Nietzsche's concept of the eternal return at the end of a book on work might appear peculiar, but it allows Weeks to provide a kind of conceptual space in which to imagine what lives not organized around work might be. Given that discourses on work so dominate both right and left politics, all future models use from the idea of "solving" work by other kinds of work. The left might emphasize better paid work, more fulfilling work, more independence at work, and better working conditions. The right focuses on promoting competition and good incentives for high performers. Neither suggests that not working might be a viable space around which a society might organize itself. The eternal return might get out of this issue by taking a step away from the model of work as being a problem in need of a solution.

One reason for thinking that philosophy in its more difficult forms (not in easily acceptable "motivational" quotes or self-help guidelines for physical 
change) is valuable for self-development is in its focus on how a philosophical approach explores questioning unexamined cultural norms about what a good relationship to the self is. Philosophies like Nietzsche's, Foucault's, and Merleau-Ponty's pull apart our easy ideas of the "self." When considering a standard idea of self-mastery, I am split between the self who must obey and the self who orders. After all, I am not who I want to be, so this current self needs to change her behavior. Another part of me commonly called "the will" takes command. If I am inspired by the somaesthetic philosophy of Shusterman, and I think about how my life could become more directed and aesthetic, I should learn to see typically unreflective parts of my life as needing directed alteration-from my breathing to my eating habits. But anyone who has engaged in some kind of self-development project knows that the obeying self doesn't always follow orders. A standard notion is to say that here the will has failed. The commanding self gave up under the force of habitual behavior or was taken away to attend to more pressing issues. A common direction for many is trying to eat better, but then of course, a crisis at work, a bad night's sleep, and a particularly tempting candy bar is the cause of many failures. But is this really the correct way to see self-mastery? In such a view, the self that desires change is considered to be the mindful identity of the individual with the habitual and non-obedient parts of oneself taking the role of the animal, unconscious bodily self. Here I am trying to shape myself into a more mindful person in the same way I am struggling to shape my front yard into a flower garden. Yet, my resistant body is far more diverse and far more intentional than a piece of dirt (not to say that dirt doesn't have its own resistances).

What often breaks the commander is the desire of these other wills, not some kind of mindless habit or unconscious bodily imperative. It is an insistent and clear pressure that often takes the form of articulated desire. After all, I don't "find" myself eating a candy bar and think "what happened?!" I have a very clear desire that comes as a thought: "Chocolate—go get some chocolate," then "commander" self says, "you had enough chocolate" and, well, one knows who wins this battle. ${ }^{48}$ To claim that these other wills are not me seems to return me to the dualistic thinking where I disavow my bodily nature and try to isolate myself in one aspect of my being.

In addition, one cannot help but wonder whether the "commander" of self-development should be followed? Why not the rebellious "troops" refusing to obey this tyrant? Nietzsche writes about the problems of understanding our "manifold" will; we do not understand the complexity at play in our identity:

...[W]e are at the same time the commanding and the obeying parties, and as the obeying party we know the sensations of constraint, impulsion, pressure, resistance, and motion, which usually begin immediately after the act of will; inasmuch as, on the other hand, we are accustomed to disregard this duality, and to deceive ourselves about it by means of the synthetic concept 'I,' a whole series of erroneous conclusions, and 
consequently of false evaluations of the will itself, has become attached to the act of willing - to such a degree that he who wills believes sincerely that willing suffices for action. ${ }^{49}$

For Nietzsche, the "I" is a creation after the occurrence of the act. It gives the individual an extra pleasure to look to the past and say, "this was my commanding will that did this," but this is a creative story put upon a much more complex experience where many selves battle at times for dominance. One may find that one's consciously directed self-development presents one with new pleasures, new experiences, and possibly even true transformations that are unexpected products of self-fashioning. Yet perhaps the other recalcitrant selves, even rebellious ones, cannot be so easily led. Moreover, perhaps those other wills might know better than the commander.

In the pursuit of health as something I can develop in myself, one might assume that the real fear is illness, suffering, and death. Illness surely reminds us of our own mortality and that of those we love. Equally terrifying is how serious illnesses alter individuals. It is not unlikely that I might contract a disease in aging that in previous generations I would have died too early to have, such as Alzheimer's, cancer, or heart disease. Many of us in the developed world are pointed toward futures where advances in medical science will keep us existing in states radically different from those we occupy in health. This being-toward-illness means that I will not be when I die, but also, I will not be this same me when I am still here. The most striking examples are raised by those with illnesses that strongly alter one's capacity for self-understanding and of connecting various life experiences into a meaningful whole.

We see two kinds of themes of the self in Nietzsche that seem to work at cross purposes. On the one hand, Nietzsche often discusses self-improvement as a kind of willed overcoming of one's various desires, urges, and natural states toward a singular one-one goal, one focus-upon which to live out one's willto-power. On the other, there is an articulation of the thesis that an individual is a fated product of the past. In On the Uses and Disadvantages of History for Human Life, Nietzsche writes that "since we are the outcome of earlier generations, we are also the outcome of their aberrations, passions and errors, and indeed of their crimes; it is not possible to wholly free oneself from this chain." ${ }^{50}$ Rejecting our historical situation does not wipe our slate clean, "If we condemn these aberrations and regard ourselves as free of them, this does not alter the fact we originate in them." ${ }^{51}$ Every woman raised on Princess myths of beauty, charm, and the need of a male savior will need to wrestle with such ideas that determine her sense of self from an early age. Even outright rejection of them always operates in relief. It is impossible to know what it would mean to have a sense of sexuality that had no relationship to the norm of one's culture as one grows up in a world in which sexuality has been given a meaning that one may reject perhaps, but from which one cannot be entirely free.

To uncover what now appears necessary and see it in its contingent origins includes both the descriptive analysis as well as a potential for liberation. Nietzsche offers a sense of a kind of personal transformation we can 
make in response to our historical origin: "The best we can do is confront our inherited and hereditary nature with our knowledge of it, and through a new, stern discipline combat our inborn heritage and implant in ourselves a new habit, a new instinct, a second nature, so that our first nature withers away." ${ }^{2}$ This is a type of self-overcoming, where one rallies one's forces toward one goal and masters those bad historical habits in which one has been raised. Likewise, in the Twilight of the Idols, Nietzsche argues that "If we have our own why or life, we shall get along with almost any how," a dictum Frankl will stress in his survivor memoir and logotherapy masterpiece Man's Search for Meaning. ${ }^{53}$ While not necessarily somaesthetic, these kinds of statements encourage seeing the self as choosing a path and organizing its forces to achieve it. "The formula of my happiness: a Yes, a No, a straight line, a goal." ${ }^{44}$ Such discussions appear to be a kind of self-help discourse for those not beset by the sickliness of our age.

Yet at the same time, as with his discussion of health, there are discussions in Nietzsche that argue against the idea that any kind of masterful "self" even exists. The illusion of a stable identity that lies beneath the vicissitudes of the joyous, painful, and mortal body is needed to support certain ideologies of health. If health is a background state that permits me to engage in my projects, I might be tempted to fall into dualism, seeing the healthy body as a nicely functioning car I drive around in to get my destinations. When my car breaks down, I am inconvenienced, but I am still me. It also seems to suggest that bodies might differ, as cars do, but the passengers are all alike. Such a model is often supported in popular language where one "fights" the disease, where one is encouraged to "take charge" of one's health as if the healthy body were an object one can battle or master that is separate from the willing subject.

Peter Sedgwick writes that "A philosophy worthy of the name, Nietzsche thus argues, must celebrate embodiment in all its most painful possibilities, for suffering and illness are connected in an essential way to human identity." ${ }^{55} \mathrm{He}$ goes on to describe the experience of a dementia unit in the U.K. where the "victim of dementia" increasingly loses their "ability to narrate their own life..." but still continues to persist living. ${ }^{56}$ The commanding self-conscious self is lost, but there certainly remains a will to continue with life. This existence that is increasingly a loss of self, or at least a loss of the sense of a commanding unitary self, cannot help to bring us to an existential anxiety that can be more acute than the fear of death. Sedgwick argues that medical practice would benefit from giving up the idea of a stable identity:

The frailty of embodiment made manifest by individual suffering and vulnerability to disease shocks us into the uncomfortable acknowledgment of our own finitude. To be human, in other words, means to respond to the travails of arbitrary suffering (i.e., the casual onslaughts of pain that embodiment necessarily entails) by seeking meaning. ${ }^{57}$

Identity, both the identity of the self and the idea of an identity to health, misleads medical practice. 
Modern medicine's most pervasive and dubious metaphysical presupposition likewise resides here, for modern medicine's conception of health presupposes a stable and definable selfhood hidden behind the shifting and mysterious vicissitudes of the suffering body that, as Nietzsche's explorations of the domain of identity reveal, is a pure chimera. ${ }^{58}$

I do not desire my current self-conscious sense of self-possession to change since it is unclear what that would mean. Yet, to reflect upon my life so far is to realize how much of who I think I am is not a matter of my self-possession but rather an infinitely varied set of circumstances that radiate around each moment of my life: where I happened to be born, to whom, the nature of my body, what changes in culture, politics, the randomness of meeting certain people at certain times. If one is interested in creating, be it "dangerously" as Camus lectures, or in self-care somaesthetics, it might be most valuable to exit our sense of self-possession to find new openings.

It was noted above that many take up Foucault's interest in care of the self as a possible bulwark against the normalizing discourse in our contemporary neoliberal biopolitical world. Shusterman's earlier work reflected that he had not read later Foucault. Instead, as with Nietzsche, Shusterman also discusses how some parts of Foucault seem to engage in the same move to celebrate the unintentional and extreme over conscious deliberation. Shusterman presents Foucault as overemphasizing the unconscious and wild elements of embodiment, as opposed to the more delicate and deliberate work of self-transformation. Shusterman argues that what Foucault discovers in considering self-care is how it mirrors philosophical work that destabilizes a cohesive sense of self. ${ }^{59}$ Thus, one cannot really develop oneself: rather it seems the creative project in Foucault is to dismantle the self.

Foucault's use of limit-experiences, such as taking drugs and sadomasochism, can be seen as ways in which he pursued a body without a mind. Foucault contrasts his limit-experiences with phenomenology. Phenomenology is guilty of clinging to the subject, trying to "organize perception" and "grasp the significance of daily experience in order to reaffirm the fundamental character of the subject." ${ }^{60}$ Instead of this limited, unimaginative, Cartesian approach, Foucault celebrates the philosophies of Nietzsche, Bataille, and Blanchot who "try through experience to reach that point of life which lies as close as possible to the impossibility of living, which lies at the limit or extreme." ${ }^{61}$ Foucault argues that such authors provide a way to "'tearing' the subject from itself in such a way that it is no longer the subject as such, or that it is completely 'other' than itself so that it may arrive at its annihilation, its dissociation." ${ }^{62}$ Shusterman argues against this extremism in Foucault in Body Consciousness by arguing that Foucault takes up a common contemporary cultural obsession with the best somatic experience being that of "radicalization and violent sensationalism." ${ }^{63}$ Foucault sees direct and intimate connection with bodily experiences as philosophically revelatory; he prizes the disunity of the subject (qua self-controlled agent) to the chaotic and uncontrollable body. 
Unlike somaesthetics which has a practical application in one's life, it is hard to integrate such discussions into a critical reception of wellness doctrines that would have relevance for personal practice and social policy. Even if one accepts there are innumerable healths and many selves-what would this mean for how someone who seeks to live their life authentically? At the end of "Create Dangerously," Camus writes that the artists may need to stay in combat to find themselves, “'Every wall is a door,' Emerson correctly said. Let us now look for the door, and the way out, anywhere but in the wall against which we are living." ${ }^{64}$ For Camus, the tension the artist faces is that of being in reality but also extending beyond it. In the case of thinking of oneself as having "innumerable healths" and possibly many selves, the ambiguity is how to live with these possibilities in the world. What tenuous positions can we take without subsuming our freedom into obedience to the good health imperative, obedience to just one of our rich ways of being a self, or obedience to the whims of our mercurial physical natures? Chapter 7 will explore reasons to return to the question of freedom more seriously as a critical and existential imperative.

\section{Notes}

1 Camus, "Create Dangerously."

2 Camus, "Create Dangerously," 255.

3 Camus, "Create Dangerously," 264.

4 Feldenkrais Method is a system of self-conscious analysis of one's muscular control to improve ease and range of motion, often initially pursued to handle limited movement due to pain. It employs a model of teacher-student rather than healthcare worker to patient, to encourage seeing it as educational, instead of pathological. Richard Shusterman, Body Consciousness: A Philosophy of Mindfulness and Somaesthetics (Cambridge: Cambridge University Press, 2008), 25.

5 Shusterman, Body Consciousness, 1.

6 Richard Shusterman, "Somaesthetics: A Disciplinary Proposal," The Journal of Aesthetics and Art Criticism 57, no. 3 (Summer 1999): 302.

7 Richard Shusterman, Practicing Philosophy: Pragmatism and the Philosophical Life (New York: Routledge, 1997), 3.

8 Shusterman, Body Consciousness, 23.

9 Shusterman, Body Consciousness, 24.

10 Shusterman, "Somaesthetics: A Disciplinary," 305.

11 Shusterman, Body Consciousness, 29.

12 Shusterman, "Somaesthetics: A Disciplinary," 307.

13 Shusterman, Body Consciousness, 29.

14 Shusterman, "Somaesthetics: A Disciplinary," 299.

15 Richard Shusterman, "Somaesthetics and the Fine Art of Eating," in Body Aesthetics, ed. Sherri Irvin (Oxford: Oxford University Press, 2016), 261-280.

16 Shusterman, Body Consciousness, 8.

17 Cressida J. Heyes, Self-Transformations: Foucault, Ethics, and Normalized Bodies (Oxford: Oxford University Press, 2007), 111-132; Marjorie Jolles, "Between Embodied Subjects and Objects: Narrative Somaesthetics," Hypatia 27, no. 2 (Spring 2012): 301-318; Richard Shusterman, "Somaesthetics and The Second Sex: A Pragmatist Reading of a Feminist Classic,” Hypatia 18, no. 4 (2003): 106-136.

18 Heyes, Self-Transformations, 136.

19 Heyes, Self-Transformations, 130-132.

20 Heyes, Self-Transformations, 113. 
21 Jolles, "Between Embodied," 307.

22 Jolles, "Between Embodied," 308.

23 Jolles, "Between Embodied," 317.

24 Heyes, Self-Transformations, 116.

25 Johanna Oksala, Foucault on Freedom (Cambridge: Cambridge University Press, 2005), 152.

26 Friedrich Nietzsche, "On the Genealogy of Morals," in Basic Writings of Nietzsche, translated and edited by Walter Kaufmann (New York: The Modern Library, 1969), 469.

27 Nietzsche, "On the Genealogy of Morals," 469.

28 Nietzsche, "On the Genealogy of Morals," 472.

29 Shusterman, Body Consciousness, 52.

30 Friedrich Nietzsche, "Beyond Good and Evil," in Basic Writings of Nietzsche," translated and edited by Walter Kaufmann (New York: The Modern Library, 1969), 244-245.

31 Friedrich Nietzsche, "Ecce Homo," in Basic Writings of Nietzsche, translated and edited by Walter Kaufmann (New York: The Modern Library, 1969), 680.

32 Friedrich Nietzsche. The Gay Science, translated by Walter Kaufmann (New York: Vintage Books, 1974), 35.

33 Nietzsche, The Gay Science, 35.

34 Nietzsche, The Gay Science, 35.

35 Nietzsche, The Gay Science, 35.

36 Mark Letteri, “The Theme of Health in Nietzsche's Thought," Man and World 23, no. 4 (1990): 411.

37 Friedrich Nietzsche, "Twilight of the Idols," in The Portable Nietzsche, translated and edited by Walter Kaufmann (New York: Penguin, 1976), 491.

38 Nietzsche, The Gay Science, 177.

39 Merleau-Ponty, Child Psychology, 407.

40 "For Merleau-Ponty, development is flexible, but it is not, therefore, without necessary structure. Social norms can negatively influence our attitudes toward our bodies. A society that relegates women to a narrow set of possible roles will likely cause ambivalence if not outright rejection on the part of young women." Talia Welsh, The Child as Natural Phenomenologist: Primal and Primary Experience in MerleauPonty's Psychology (Evanston: Northwestern University Press, 2013): 131.

41 Peter Sedgwick, "Nietzsche, Illness and the Body's Quest for Narrative," Health Care Analysis 21, no. 4 (2013): 320.

42 Fredrik Svenaeus, Phenomenological Bioethics: Medical Technologies, Human Suffering, and the Meaning of Being Alive. (London: Routledge, 2018).

43 Svenaeus, Phenomenological Bioethics, 89.

44 Svenaeus, Phenomenological Bioethics, 92.

45 Alexander Nehamas, "The Eternal Recurrence," The Philosophical Review 89, no. 3 (1980): 331-356. This view is not universally held, see Paul Loeb, "Eternal Recurrence", in The Oxford Handbook of Nietzsche, eds. Ken Gemes and John Richardson (Oxford: Oxford University Press, 2013).

46 Weeks, Problem, 200.

47 Weeks, Problem, 200.

48 Throughout his works, Nietzsche offers various discussions on diets. In "Twilight of the Idols," he discusses the popular diet book by Cornaro where a "slender diet" is recommended for a long life. Nietzsche says, "I do not doubt that scarcely any book (except the Bible, as is meet) has done as much harm, has shortened as many lives, as this well-intentioned curiosum." Cornaro could not eat more due to his physiology and then he made a virtue of it, committing the first of the four great errors-“confusing cause and effect." Nietzsche, "Twilight of the Idols," 492.

49 Nietzsche, "Beyond Good and Evil," 216. 
50 Friedrich Nietzsche, "On the Uses and Disadvantages of History for Life," in Untimely Meditations, translated by R.J. Hollingdale (Cambridge: Cambridge University Press, 1983), 76.

51 Nietzsche, "On the Uses and Disadvantages."

52 Nietzsche, "On the Uses and Disadvantages."

53 Nietzsche, "Twilight of the Idols," 468.

54 Nietzsche, "Twilight of the Idols," 473.

55 Sedgwick, "Nietzsche, Illness," 308.

56 Sedgwick, "Nietzsche, Illness," 320-321.

57 Sedgwick, "Nietzsche, Illness," 316.

58 Sedgwick, "Nietzsche, Illness," 319.

59 Shusterman, Practicing Philosophy, 41.

60 Michel Foucault, "How an 'Experience-Book' is Born," in Remarks on Marx: Conversations with Duccio Trombadori, translated by R. James Goldstein and James Cascaito (New York: Semiotext(e), 1991), 31.

61 Foucault, "How an 'Experience-Book' is Born," 31.

62 Foucault, "How an 'Experience-Book' is Born," 31.

63 Shusterman, Body Consciousness, 31.

64 Camus, “Create Dangerously,” 272.

\section{Bibliography}

Camus, Albert. "Create Dangerously." In Resistance, Rebellion, and Death, translated by Justin O’Brien, 249-272. New York: Vintage Books, 1960.

Foucault, Michel. "How an 'Experience-Book' Is Born.” In Remarks on Marx: Conversations with Duccio Trombadori, translated by R. James Goldstein and James Cascaito, 25-42. New York: Semiotext(e), 1991.

Heyes, Cressida J. Self-Transformations: Foucault, Ethics, and Normalized Bodies. Oxford: Oxford University Press, 2007.

Jolles, Marjorie. "Between Embodied Subjects and Objects: Narrative Somaesthetics." Hypatia 27, no. 2 (Spring 2012): 301-318. https://doi. org/10.1111/j.1527-2001.2011.01262.x.

Letteri, Mark. "The Theme of Health in Nietzsche's Thought." Man and World 23, no. 4 (1990): 405-417. https://doi.org/10.1007/BF01271585.

Merleau-Ponty, Maurice. Child Psychology and Pedagogy: The Sorbonne Lectures 19491952, translated by Talia Welsh. Evanston: Northwestern University Press, 2010.

Nehamas, Alexander. “The Eternal Recurrence," The Philosophical Review 89, no. 3 (1980): 331-356. https://doi.org/10.2307/2184393.

Nietzsche, Friedrich. "Beyond Good and Evil.” In Basic Writings of Nietzsche, translated and edited by Walter Kaufmann, 179-436. New York: The Modern Library, 1969.

Nietzsche, Friedrich. "Ecce Homo.” In Basic Writings of Nietzsche, translated and edited by Walter Kaufmann, 655-802. New York: The Modern Library, 1969.

Nietzsche, Friedrich. "On the Genealogy of Morals.” In Basic Writings of Nietzsche, translated and edited by Walter Kaufmann, 437-600. New York: The Modern Library, 1969.

Nietzsche, Friedrich. The Gay Science, translated by Walter Kaufmann. New York: Vintage Books, 1974.

Nietzsche, Friedrich. "Twilight of the Idols.” In The Portable Nietzsche, translated and edited by Walter Kaufmann. New York: Penguin, 1976. 
Nietzsche, Friedrich. "On the Uses and Disadvantages of History for Life." In Untimely Meditations, translated by R.J. Hollingdale, 59-123. Cambridge: Cambridge University Press, 1983.

Oksala, Johanna. Foucault on Freedom. Cambridge: Cambridge University Press, 2005.

Sedgwick, Peter. "Nietzsche, Illness and the Body's Quest for Narrative." Health Care Analysis 21, no. 4 (2013): 306-322. https://doi.org/10.1007/s10728-013-0264-1.

Shusterman, Richard. Practicing Philosophy: Pragmatism and the Philosophical Life. New York: Routledge, 1997.

Shusterman, Richard. "Somaesthetics: A Disciplinary Proposal." The Journal of Aesthetics and Art Criticism 57, no. 3 (Summer 1999): 299-313. https://doi. org/10.2307/432196.

Shusterman, Richard. "Somaesthetics and The Second Sex: A Pragmatist Reading of a Feminist Classic.” Hypatia 18, no. 4 (2003): 106-136. https://doi.org/10.1353/ hyp.2003.0089.

Shusterman, Richard. Body Consciousness: A Philosophy of Mindfulness and Somaesthetics. Cambridge: Cambridge University Press, 2008.

Shusterman, Richard. "Somaesthetics and the Fine Art of Eating." In Body Aesthetics, edited by Sherri Irvin, 261-280. Oxford: Oxford University Press, 2016.

Svenaeus, Fredrik. Phenomenological Bioethics: Medical Technologies, Human Suffering, and the Meaning of Being Alive (London: Routledge, 2018).

Weeks, Kathi. The Problem with Work: Feminism, Marxism, Antiwork Politics, and Postwork Imaginaries. Durham: Duke U.P., 2011.

Welsh, Talia. The Child as Natural Phenomenologist: Primal and Primary Experience in Merleau-Ponty's Psychology. Evanston: Northwestern University Press, 2013. 


\section{Toward an existential ethics of working on the self}

\section{Existential anxiety and bracketing the good health imperative}

Another writer, in a much darker mood, also writes about walls. In Fyodor Dostoevsky's, Notes from Underground, the first-person narrator-the underground man-rails against bull-like men who tell him that the truths of math and science are the final word. The underground man-awkward, isolated, and painfully self-conscious-could not be more opposite to these confident purveyors of truth. In replying to his futile railings against the trials of his existence, the strong rational men, reply with-"Nature doesn't ask your advice. She isn't interested in whether or not you approve of her laws. You must accept nature as she is with all the consequences that that

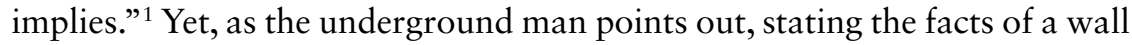
does not make the wall therapeutic:

But, good Lord, what do I care about the laws of nature and arithmetic if I have my reasons for disliking them, including the one about two and two make four! Of course, I won't be able to breach this wall with my head if I'm not strong enough....As if such a wall could really leave me resigned and bring me peace of mind because it is the same as twice two makes four. How stupid can one get? ${ }^{2}$

The underground man's increasing alienation from society is due in part to his refusal, or inability, to accept socially determined ideas of scientific "fact" as meaningful. He neither accommodates himself to the truth, nor does he expect this free choice will produce any outcome other than more misery. We find, after reading his shameful accounts of his youth, he refrains from further social interaction, staying in his room for the rest of his days.

The underground man points out that the bull-like man, the one who accepts and adjusts his behavior to nature, remains like every other man. His absurd and counterproductive behavior in the face of these "laws" defines the underground man as an individual, even if this individual is a rather pitiful character. It is only within irrational action that the underground man finds his freedom. In the underground man's anxious soliloquy on his own nature, he wonders if he should change himself even if he can: 
...I felt I was already up against the wall; that it was horrible but couldn't be otherwise; that there was no way out and it was no longer possible to make myself into a different person; that even if there were still time enough to change myself; and that, even if I wanted to, I still wouldn't have done anything about it, because actually, there wasn't anything to change into. ${ }^{3}$

One might see the existentialist view of how to live as one of freedom, but a freedom without purpose given the world provides us with no meaning in itself. This absurdity of our existence could lead one, perhaps, to a kind of nihilism about the value of any action.

Camus writes that the world appears absurd, but this is not the case. It is rather remote from our desire for clarity and purpose.

I said that the world is absurd, but I was too hasty. This world in itself is not reasonable, that is all that can be said. But what is absurd is the confrontation of this irrational and wild longing for clarity whose call echoes in the human heart. ${ }^{4}$

In a similar vein, the famous death of god passage in Nietzsche's The Gay Science has a madman crying at "many who did not believe" to awaken them to the ramifications of disbelief. To draw their attention to how significant disbelief is, he asks the fellow non-believers questions:

What were we doing when we unchained this earth from its sun? Whither is it moving now? Whither are we moving? Away from all suns? Are we not plunging continually? Backward, sideward, forward, in all directions? Is there still any up or down? Are we not straying, as through an infinite nothing? 5

Can one really establish what is valuable in a world deprived of an absolute source of sense? The death of god can be seen as the death of an inherent meaning where we are now left to "become gods" as the madman says in order to create our own values in the world. To answer the underground man's question-if we are not obligated to do what we are told is good or follow convention, what then should we do? If we can change, whom shall we change into?

Edmund Husserl called for phenomenologists to engage in a method called the epoché-a bracketing of previous forms of philosophy in order to "get at the things themselves." When one examines a perception, one should avoid investment in the reality or value of the perception-say if the tree I am looking at is as it appears-and focus instead on the structure and nature of any perceptual experience to highlight the necessary and contingent features of what it is to experience. One can also bracket moral investments. One goal of this book was to foster a more critical attitude toward the ethics and policies of the good health imperative. Since promoting health 
appears so obviously valuable, the claims of the good health imperative are not always examined. In conclusion, I want to think through what existential alternatives might appear if we bracket the universal moral imperative associated with self-directed good health labor.

This book had moved between two themes regarding the good health imperative. One theme is the value, pleasures, and possibilities inherent in working on one's health. Creating greater capacities to go forth in a homelike manner in the world can be a result of some self-directed health work. Moreover, as we are fragile beings easily able to suffer from illness, health work can help provide both a protection against illness as well as alleviating anxiety about our condition. As discussed in Chapter 6, working on one's health in a creative fashion might be a means in which to explore new, aesthetic styles of living. On the other part, this book has examined critical analyses of the good health imperative. The overwhelming disparities in the US on basic healthcare and protection against COVID-19 underline that it is not solely at the level of the individual that health is won or lost, but at the systemic level. Focusing on individual work and performance to produce good health increases ableism, racism, and classism by assuming those with good health have "deserved" it and likewise those without it haven't made enough effort. Population management for the economic benefit of the wealthy encourages limiting social solutions in favor of increasing the workload on the individual.

The idea of a constant need to work on all the aspects of one's life-health, relationships, career prospects, education, mental well-being-makes individuals see themselves as the source of and solution to all suffering. If one has not achieved "results" from working on the self, then what is demanded is not to look out, but to put one's head down and work more. A significant amount of discussion has surrounded the concern about the medicalization of all aspects of our lives under the need for ever better health. Does a life of testing and submission to every possible medical protocol make sense? Does such medicalization create illnesses? ${ }^{36}$ The good health imperative encourages social and political compliance since suffering is never directed outward, but now, always inward toward the individual. Everything becomes a matter of individual will; all problems can be treated as problems of the body and not problems of the social world. In such a manner a critical examination of the good health imperative lies both within concerns about the reach of the healthcare apparatus and within concerns about neoliberal political systems of oppression.

Yet developing oneself purposefully is not always the handmaiden of capitalist motivations or socially repressive ones that encourage the view that the problem lies within rather than without. Dedicating some time to self-care can be transformative and provide one greater capacities for a richer experience. At minimum, it might simply make life more livable. However, given that one can always improve one's health with finer and finer refinement, it is hard to know what limits to put on such a project. Due to the possible endlessness of the demand, what kind of labor on the self is worthwhile? How 


\section{Labor and project}

can one accept the existential value of individual health work, and retain a critical perspective on such work? In this final chapter, I will explore the idea of good health work as an existentially ambiguous project that should be situated within the larger context of our shared social world. First, I will discuss how heteronormativity and ableism are emboldened by a narrow view of lives worth living. The idea of normative paths, drawn from Sara Ahmed's work provides of model of how the good health imperative is about a kind of directionality. Simone de Beauvoir's discussion of roles and ambiguity in The Ethics of Ambiguity draws our attention toward the pitfalls of pre-established paths and the possibilities of accepting our ambiguous condition. The path this book problematized the most was the idea of health as a kind of work one does on the self. In appealing to Hannah Arendt's critique of work and labor in The Human Condition, I highlight that thinking is often overlooked in our interest in work. In conclusion, I turn toward our vulnerability rather than our capacity for self-directed work on the self, and explore how that might transform how we think about our responsibility for health.

\section{Paths and fitting}

One of the ways in which the good health imperative shapes us is it provides us what direction a life well lived should take. While certainly a life of health and vitality is ceteris paribus preferable to one of illness and suffering, one can question if the work involved in producing that life might be spent in other projects or investments. I argue that this is particularly the case when one considers the very thing such work cannot eliminate-one's eventual death. Imagine witnessing a eulogy of a good friend and hearing a tribute to how well she kept her blood pressure within normal levels or her good work eating in order to maintain an ideal weight instead of the impact her life had on others. One would be perhaps horrified, but at least one would find such comments bizarre-why mention such things? Such work in her life may have permitted her to do things otherwise she could not have, perhaps to have lived longer and better, but is this how she would want to be remembered?

In addition, the idea that one's individual agency can and should be directed toward the production of better health encourages seeing all bodies as bodies of possible intervention for future flexibility and adaptability to our current social and economic situation. Critical disability theory has drawn attention to how ideals of health are almost always tied to ideals of the right "kind" of workers. Robert McRuer illustrates how the idea of creating a future orientated worker who is not only able-bodied, but flexible to any new situation that arises encourages both compulsory able-bodiedness and compulsory heterosexuality. ${ }^{7}$ In a similar fashion, Sara Ahmed discusses the manner in which certain paths are drawn in advance for us as trajectories for what a "good" life is. ${ }^{8}$

Heteronormativity depends upon a set of implicit norms around gender and sexual orientation. Ahmed writes that that assumption that humans are all straight is a background created by repeated acts of "straightness." She 
asserts that "Following Husserl, we could say that heterosexuality functions as a background, as that which is behind actions that are repeated over time and with force, and that insofar as it is behind does not come into view." ${ }^{.9}$ To become straight is a matter of learning patterns of behavior. What we learn in our upbringing that is reinforced in adult social life is how to "become straight." ${ }^{10}$ Sex is given to us as "homework" in which we must learn appropriate behaviors, attitudes, and desires. Ahmed writes that, "compulsory heterosexuality operates as a straightening devise, which rereads signs of queer desire as deviations from the straight line." ${ }^{11}$ These acts of straightening are not just acts in a moment; they orientate us. We can think of how the heterosexual norms can be read a series of destination points along a route-the first opposite sex romantic experience, dating, marriage, and then children. These norms are not just about sexuality; they are about how one should organize one's life. As such, heteronormativity extends beyond sexual orientation to how societies are structured. The acts demanded to create the background appear obvious as they are learnt in development and socialization and thus appear as things are, as discussed in reference to docility in Chapter 4. Who receives the benefits of this organization are unlikely to want to see its nature be revealed as contingent.

Queerness disrupts organization-it makes the background become apparent and even in inclusive spaces is often marked out and noted as different. Individuals who do not engage in the acts of heterosexual partnership makes the path of such partnership become $a$ path, not the path. In critical phenomenology, stress is placed upon the need to understand the phenomenological attention to experience in such a manner that what is hidden in plain sight - the organization of our social world-becomes capable of being examined. In other words, to bring backgrounds into focus often does not expose something buried deep that motivates discrimination, but rather something all too present that shapes our worlds as a kind of atmosphere. In such a manner, seeing the straightening device of compulsory heterosexuality is not simply a matter of changing beliefs, but a matter of changing how lives are lived and understood and advocating for different possibilities. Ahmed writes that things appear "correct" when they are "rightly" aligned-that is when they repeat the normative paths, but it is when we understand this as a historical process and not a given that we can see this alignment as not natural; we can imagine other possibilities. ${ }^{12}$

The critical phenomenological project brings into focus how those backgrounds have created benefits for those who live seamlessly in them. Long-standing sexist, heteronormative, ableist, and racist institutions are comfortable for many because their orientation and organization is taken for granted and those who have benefited from them are reluctant to change for fear of losing their privileges. Ahmed examines how living outside the paths of compulsory heterosexuality and sexism interrupt the sexist structuring of our society..$^{13}$ Those who deviate are not just read as different or morally repugnant, they are threats - they disrupt the happiness of others. Feminists are famous for being killjoys—a term Ahmed takes up for herself 


\section{Labor and project}

and other killjoys. ${ }^{14}$ Everything from refusing to laugh at sexist jokes to refusing to ignore institutional discrimination makes people uncomfortable. It disrupts the flow of business as usual. One can think here of the violent and extreme reaction to Black Lives Matter (BLM) in the United States. BLM demands attention to systemic violence against Black and Brown people in the United States and it refuses to be absorbed into some trite declaration of "all lives matter." Some white people have gone out of their way to denounce it, to label it as terrorist, to take up arms against protestors, even though many of these people have no objective reason to feel threatened. BLM protests do not threaten their lives, their livelihoods, or their children's well-being. Rather the threat is an organizational threat-it brings what for white people operates as a background into uncomfortable focus. Racism is, as Helen Ngo discusses, a habit, a style of being that resists change. ${ }^{15}$ Pointing out racist systems means former patterns of behavior that seemed "normal" are now pushed into the forefront. They thus, like illness, interrupt everyday projects and styles of being and are felt as intrusive to those who have long had the privilege not to consider them.

Health is a curious thing to actively not want if one understands health as an absence of illness. Within the mantra of the inherent value of healthy self-labor, it is hard to get a clear picture of how attention toward the promotion of this value and its attendant paths of "good healthy behavior" entail a removal of focus on other issues. On the personal level, it can erase considerations of what one could do other than this project of health. On a social level, this focus makes it hard to see the systemic reasons that create possible healthy futures for some a likely path and for others not. Personal health promotion is the most achievable for those who have the leisure time and disposable income. As the economic divide between rich and poor grows, so too do health outcomes. ${ }^{16}$ While certainly the need for better healthcare services would greatly aid the situation of the poor, many are still fixated by the notion that what they most need first and foremost is better consumption. For instance, the British celebrity chef Jamie Oliver is famous (or infamous) for turning his attention toward the betterment of children's diets. ${ }^{17}$ Oliver likes to point out that his proposals, such as limiting junk food advertising and sin-taxing sugary drinks, are "common sense." 18 There is concrete evidence linking better diets to better health outcomes and increasingly worrisome news about the rate of childhood obesity and its likely lifelong implications. Proposals for better consumption are not necessarily unjust, but they tend to concentrate our focus on the issues of nutrition and diet in isolation. Systemic issues such as poverty are not ignored, but rather not seen as a situations that pervade all choices. The guiding principle seems to be that at least you would not be poor and unhealthy.

My university is becoming smoke-free this year. When I started 20 years ago, the buildings still had the remnants of being part of the tobacco belt; we had smoking rooms in most classroom buildings, and one could buy cigarettes at the student union. The rooms are closed; cigarettes are no 
longer sold, and now one cannot smoke on-campus at all. In this same time, research has found that the initial wave of research documenting a reduction in heart attacks in a smoke-free town (leading to the widely publicized conclusion that smoke-free areas save lives) has been shown to be misleading. The largest comparative study in 2010 by the Rand Corporation found "no evidence that legislated U.S. smoking bans were associated with short-term reductions in hospital admissions for acute myocardial infarction or other diseases in the elderly, children or working age adults." ${ }^{19}$ Little evidence has been able to support the cherished ideas that smoking bans promote health because second hand smoke is dangerous. ${ }^{20}$ Like most college campuses in the United States, the impact of this ban on the campus will be slight. Fewer and fewer students smoke, and fewer and fewer faculty and staff do.

Is it the case that such bans are really about health promotion, or simply about adherence to the norm of health promotion? The masses' poor health must be understood in relation to the good health of the wealthy. Insofar as any one person could improve her health cannot be taken as a reason to think of public health outside the history of how the good health of the wealthy is connected to their wealth and privilege in turn which is based in the lack of resources of the poor. A critical phenomenological bracketing over the concern about whether or not individuals made the "right" choice can help look at the situation of different classes. To examine the disjunction in health outcomes exposes differences in situations. The well-off have situations that permit the time, resources, and environment to improve one's health and opportunity for varied pleasures.

As outlined in Chapter 1, Guthman notes how the obsession with personal behavior, in particular the personal behavior of the poor and unhealthy, has occurred alongside the rollback of social services for those very poor. ${ }^{21}$ While the reasons for social service rollback are politically complex, given that access to high quality medical care is strongly associated with longevity the constant focus on the data that documents certain behaviors-smoking, diet, exercise-returns the conversation again and again to the individual's behavior and not the individual's situation as not having access to quality medical care, good working conditions, low stress, clean water, clean air, safe and affordable housing, and safe streets. While smoking remains the most preventable cause of early death, is it the case that one can abstract smoking from the individual's milieu any more than one can discuss drug addiction without attention to the addict's personal story?

Bracketing the moral value of any person engaging in healthy self-care does not mean that it is not a worthwhile endeavor. It also would not be to argue against good public health funding or various initiatives to encourage healthy behavior. Bracketing helps expose the path of healthy self-care as a path of privilege. Punitive charges such as higher insurance now become questionable instead of a "common sense" means to promote healthy behavior. I argue that we should see such body work as voluntary but not as a prerequisite to receive the same kind of treatment, care, and approval as others do. One could see such a move to bracket the moral value of such 


\section{Labor and project}

self-care work as similar to the feminist revision of beauty work. Many receive aesthetic and personal pleasures from such work. The idea that we could determine "good" and "bad" beauty work in some absolute fashion seems hard to imagine. At most, we could think about such work in context and consider if at times this work can be liberating or demeaning. The important feminist claim is to argue vehemently against the idea of the value of a woman as being based upon her performance of such work. ${ }^{22}$ In the case of health, loosening the grip of healthism would likewise permit a wider appreciation of different bodies and encourage looking away from individual consumption toward the larger situation in which that consumption takes place.

Paths operate as a means for the socially privileged to maintain their status quo. Since one can claim one has no racist or sexist views, one can continue living in a world that privileges whiteness, maleness, and straightness with a free conscience. Calling into question such habitual styles of social organization is met with resistance because it seems unjust- "I'm not a racist, I'm just living my life!" Paths help one "unnotice" the path itself-its directionality is not seen as a direction, but simply what is. Attending to the paths laid in advance requires more effortful critical reflection if that path suits one's desires, social situation, and ambitions. If one sees the world as being rightly aligned, one is unlikely to see the ways in which this is not the case for all subjects. In Chapters 4 and 5, I discussed how the serving the economic interests of the few in capitalism creates worlds where individuals are to be managed in order to extract the greatest profit from them. Individuals who are deemed replaceable, such as worker-producers are invisible in the paths of self-promotion qua individual economic and physical perfection. Individuals who hold no economic benefit, like the elderly or the disabled, are disposable, as we can see so blatantly in the COVID-19 pandemic.

Critical phenomenology also draws upon critical disability theory to complicate the seeming naturalness of some phenomenological descriptions. Christine Wieseler argues that this is a problem with many interpretations of phenomenology that come from Merleau-Ponty:

Merleau-Ponty seeks to clarify the characteristics of the "normal" subject, locating normality at the level of the individual. This is opposed to what many disability activists and theorists hold to be a central tenet: normality and disability are not traits of individual bodies but are instead the results of social values, attitudes, and practices that enable some types of bodies and disable others. ${ }^{23}$

As argued in previous chapters, the focus on ideals of fit and capacity drawn from solitary endeavors like playing tennis or riding a bike often pass over the complexly built environments in which those activities occur. Rosemarie Garland-Thomson speaks about the idea of misfitting and fitting in order to think critically about disability. In traditional phenomenologies, one could read "fit" when one can "naturally" extend out into the world and misfit 
when one is ill, or disabled, and cannot. But the idea of fit/misfit better explores how extending out into the world is as dependent upon the world as upon one's inherent capacity toward it. "Misfitting serves to theorize disability as a way of being in an environment, as a material arrangement." ${ }^{24} \mathrm{~A}$ welcoming environment depends upon built spaces, buildings, roads, communication devices, policies, procedures, laws, and the social world. The literal paths to a home, a store, or a workplace are designed for certain kinds of bodies, but this is neither necessary nor natural.

The good health imperative, as discussed in Chapter 2, also includes the idea that while disabled persons might be blameless, unlike those considered to have violated the standards of proper self-care, they are also individuals to make fit. As research develops into ways that we can perform genomic testing, alter fetuses in utero, and alter disabled bodies to better resemble able-bodied persons, we can see this too as the "path" for which disabled persons should embark upon willingly. The idea that a disability is always a reduced kind of being, instead of a different kind of being is most glaringly seen when prenatal testing is used to abort fetuses who have a likelihood of having future disabilities. The assumption is that the life of such children will be an unhappy one and the life of parenting will be suffering as well. As discussed above in reference to heteronormativity and sexism, the idea that disabled lives are doomed to be unhappy is about a sense of direction-of the path that life should take. Rosemarie Garland-Thomson explains these tests as "the modern existential dilemma" where we are presented with opportunities to manage future life in ways unthinkable before. ${ }^{25}$ Being able to extend into the world is a matter of what kind of body one has but also what kind of social world one finds oneself in, including what kind of orientation we associate with well-lived lives.

The rise of more and more complex medical testing permits humans to remove diversity in order to conform to ideas of what kinds of bodies are acceptable. Health functions not so much as the alleviation of suffering, but rather as an idea of what is a normal life course. For example, the use of prenatal tests to provide information to parents as to whether or not the fetus may have disabilities has already-and increasingly will-shape the nature of humanity. In The Atlantic, an article discusses the rapid decline of children with Down Syndrome being born in Denmark after universal prenatal screening was provided. ${ }^{26}$ Any parent-to-be worries about the life one's future child will live. Being handed a list of possible complications and living in an ableist world naturally induces many parents to opt for abortions, even in a country like Denmark where extensive socialized medicine and a robust social welfare system exists. Garland-Thomson argues that testing tells one little about what kind of person, what kind of life, that fetus might have.

Yet, such a preemptive diagnosis doesn't give us meaningful information about that person's capabilities, relationships, or actual lived life. Such genetic knowledge, like the knowledge that someone has the gene 
for maleness, really predicts little about how a particular lived life actually unfolds: genetic knowledge tells us something, but not very much. ${ }^{27}$

The wild contingency of existence has yet to be determined. Insofar as such decisions are made based in a view of health as progression, as betterment, we might ask what we lose when we accept this as our direction and the direction for others. We also fail to consider what kind of worlds we build, and how we are free to imagine and create worlds that do not yet exist. Studying the parents who decided to abort after having prenatal testing in Denmark, researchers found that they often assumed the worst possible scenarios for the future child, "In a study of 21 women who chose abortion after a prenatal diagnosis of Down Syndrome, she found that they had tended to base their decisions on worst-case scenarios." ${ }^{28}$ Testing reduces the possible child down solely to one possibility where if any likelihood of the worst case exists, the life is deemed untenable. Certainly, whether to continue a pregnancy or not is a personal question and not one that is merely about conformity to ableism or openness to diversity. Likewise, serious conditions are possible with Down Syndrome. Yet, it is striking how quick the end of Down Syndrome has come in Denmark given these prenatal tests, and this certainly tells us something about the difficulty parents have in imagining happy lives for themselves and their, possibly, disabled children.

\section{Roles, ambiguity, and natality}

Beauvoir does not locate freedom in satisfying one's consumption or producing what has been predetermined as valuable. Rather, freedom is the capacity to be authentic to one's ambiguous condition. Like Dostoevsky's Underground Man, Nietzsche's madman, and Camus' view of an unreasonable universe, Beauvoir thinks that before answering what a good life is and whether it is worth living, one must first wrestle with freedom..$^{29}$ The idea that the world is absurd is a declaration of a relativist incapacity to establish any sense, leaving us able to change but without direction of how we should change. Yet for Beauvoir, we only can intellectually occupy this kind of space. I do not live as if everything is meaningless, even if I might assert it in theory. Beauvoir appeals to the idea of ambiguity rather than Camus' idea of unreasonableness. "To declare that existence is absurd is to deny that it can ever be given a meaning; to say that it is ambiguous is to assert that its meaning is never fixed, that is must be constantly won." ${ }^{30}$ The difference between absurdity and ambiguity is that absurdity suggests nothing is better or worse than anything else. The idea that an existentialist ethics makes all choices equally valid is sensible only if removed from our experiences. Our existence is situated, and as such, it is imbued with significance. Any life is pervaded by meanings and values learned in one's upbringing, one's culture, one's education, and one's social group. Certainly, at times, working on one's blood pressure through exercise can seem a rather futile act if one thinks about something as grand as the universe's meaning, but 
this is merely a momentary reverie. In one's everyday life, one's investments are meaningful. Even in the most philosophical of moods, I do not find what I am going to have for lunch as relevant as the illness of my loved one. This threat of relativism only makes sense in the abstract. In actual life, I am always already invested in my situation, my history, my relationships, and my embodied condition.

We act in the world through following paths laid out for us and thus reinforcing them, or embarking upon different less common paths, or by forging new ones. In these actions, we constitute what is meaningful. Beauvoir writes that "...freedom realizes itself only by engaging itself in the world: to such as extent that man's project toward freedom is embodied for him in definite acts of behavior." ${ }^{31}$ The textbook example of not being free, being imprisoned, highlights the importance of the possibility of action. Thus, freedom is not just about some internal capacity of "free will" but importantly if one can follow one's intentions to act in the world. As such, our freedom is both made possible and limited by others-by whether or not their actions, projects, votes, and lifestyles permit our own. In our actions, we shape the world both for ourselves and others. As Ahmed describes the backgrounding of heteronormativity as a series of acts repeated over time to establish well-trodden routes of normality, Beauvoir highlights how when we see our acts as subject to freedom, they become ambiguous paths. We can commit to retreading them to continue affirming pre-existing meaning, or we can step off the well-trodden path to walk a new one.

In The Ethics of Ambiguity, Beauvoir outlines a series of "men"-kinds of roles that people fall into, which are manners of refusing the ambiguity of human existence: the sub-man, the serious man, the nihilist, the adventurer, and the passionate man. We might add today-the devotee of health. Each role provides a valuable psychological benefit to the individual—it frees the person from wrestling with certain kinds of freedom and from engaging in honest, vulnerable, and equitable relationships with others. We can think here of a boss who takes his charge so seriously he refuses to acknowledge the costs of his decisions on individual lives in the name of the well-being of the company. Or, based in concern over dire statistics, insurance companies push various kinds of higher costs for "bad" behaviors related to poor health outcomes. Beauvoir does not suggest we should reject scientific facts or the condition of our bodies as irrelevant, but she does not think that our bodies determine our paths, writing, "...the body itself is not a brute fact. It expresses our relationship to the world, and that is why it is an object of sympathy or repulsive. And on the other hand, it determines no behavior." ${ }^{32}$ Certainly, the nature of my body and the nature of the changes it undergoes in my life affect my experience and my possibilities. At the same time, the meaning of my embodied life extends far beyond my skin. My history, my relationships, and my actions have all determined who I am, what I desire, what I plan to do, and how I understand myself. These non-bodily parts of my sense of self cannot be explained by reference back to the material givens of my body. 
One role that encompasses many of the kind of "meaningful" ideas of what good lives look like are ones wherein one defines oneself as a certain kind of worker and then organizes one's identity accordingly: a teacher; a politician; a musician; a scientist. Other areas of one's life-such as health or parenting-are likewise conscious work projects to be taken up as seriously as one's paid labor is. Hannah Arendt argues that contemporary ideologies are concerned largely with work and labor, but that in so doing, they fail to address what make our human lives unique and valuable to us beyond the ways in which they might continue to serve to sustain our physical existence. Her idea of the importance of natality provides another way to stress the point raised by Garland-Thomson about the existential uncertainty of the life that will follow any birth.

The seeming political neutrality and evident value of health encourage working for it without reflection. In the critical phenomenological tradition, we can stop to reflect upon this drive to not think about health critically. In this space, one can ask about the work required by the good health imperative. Arendt thinks of labor as the cyclical work that sustains human existence-what for Marx would be reproductive labor. Work is the creation of objects, sometimes in the service of labor, and other times for their own sake-such as in the case of art. Objects of work often have lives that extend beyond those that create them. Arendt thinks contemporary society's focus on life and the possible pleasures from it have created a consumer-based society of labor, where work plays the subservient role. Our current society of consumption makes all work labor as the "leveling of all human activities to the common denominator of securing the necessities of life and providing for their abundance." ${ }^{33}$ In this society of consumption, the artist is "the only 'worker' left in a laboring society." 34 If we are no longer obligated by religion or social traditions to venerate religious or cultural products of work, then we are freed to just attend to our mortal existence and its pleasures and pains.

Marx, for Arendt, was mistaken in thinking that if humans were to be freed from the crushing nature of hard labor and provided free time, they would fill it with noble pursuits. Instead, we have become a society of endless waste consumption. We find that we do not, like Marx perhaps envisioned, become amateur artists freed from constant toil, but we instead simply consume more. "A hundred years after Marx, we know the fallacy of this reasoning; the spare time of the animal laborans is never spent in anything but consumption, and the more time to left to him, the greedier and more craving his appetites." ${ }^{35}$ Work in this manner becomes merely how to satisfy our desires, not devoted to the creation of new products for their own sake. Dorothea Olkowski summarizes Arendt's views saying that:

As Arendt points out, when there is no distinction between menial tasks and the making of durable things, between skilled and unskilled, manual and intellectual tasks, then social has arrived at a one-dimensional point of view, the social point of view, for which all things belong to the natural life process as objects of consumption. ${ }^{36}$ 
One can see such a world in the high estimation of salary over occupation. If one earns a good salary, if one is able to consume a great deal; ergo, one is successful. Arendt argues that in this kind of society life and its happiness qua consumption have become the highest goods. ${ }^{37}$ For the good health imperative, we can see that one typically needs no justification to argue for the value of health; it is assumed that the promotion of the pleasures of health are evident and that we would pursue its extension as a primary goal. In such a manner, all work is work in service of the citizen as consumer since much of health work, like beauty work, is deeply intertwined with purchasing products and programs.

From an existential point of view, why not attend only to one's life and one's health via consumption, as one is now freed from the need to obey antiquated traditions for their own sake? For Arendt, what such activity fails to do is think. Work devoted to an end already affirmed by the group, here attending to one's health as an obligation, is when thinking stops, or in phenomenological terms, when one fails to bracket one's pre-existing conceptions. In a society of labor, thinking becomes, like art, superfluous. To make this case, Arendt distinguishes cognition from thought. Cognition "always pursues a definite end." ${ }^{38}$ Once this end is reached, "the cognitive process has come to an end." ${ }^{39}$ Hence, cognition is the mental activity attached to work and labor with a predetermined goal. Thought, on the contrary, "has neither an end nor an aim outside itself." ${ }^{40}$ Arendt locates thought as an endless activity:

The activity of thinking is as relentless and repetitive as life itself, and the question whether thought has any meaning at all constitutes the same unanswerable riddle as the question for the meaning of life; its processes permeate the whole of human existence so intimately that its beginning and end coincide with the beginning and end of human life itself. $^{41}$

As such, thought is valueless to ideologies that prize results, such as the "the lovers of the results of the sciences" or products, such as the affection for work. ${ }^{42}$ Since thought does not produce things that can be consumed or "solved," it is held in little regard. Without a guiding principle behind thought, it can become, as Arendt noted above, a kind of endless project. It does not definitively answer the question that haunts existentialist thought as epitomized in the underground man's questioning - what is the meaning of life? What should one do with one's life? For many existentialist writers, this groundlessness and lack of a clear "product" of thought becomes an alienating experience.

If one takes such theories as arguing for a relativist falling into an abyss when divorced from the sureness of a definitive "answer," Arendt argues that one has failed to understand the generative power of thought. It is thought wherein Arendt finds the possibility of something new arising from human experience, rather than something that always already was to be 


\section{Labor and project}

performed. The idea of the new as a birth, familiar since Socrates claim of being a midwife, is connected to the facticity of actual birth. Labor's cyclical endless nature connects to the manner in which time exists before and after us-our short lives marking out a small moment. Work, while it can produce objects that extend beyond us, also tends to deemphasize our existential value-we become tools, or as Marx would say slaves, to the product of our labor. The birth of the new cuts into the cycles of work, labor, and nature-marking something whose tale is not predetermined and whose import cannot be known prior to its creation.

The oppression of thinking is part of totalitarian regimes, and it requires, importantly, the individual's acceptance of non-thinking in order to follow such regimes. Famously, in her study of Eichmann, Arendt is struck, sometimes even to the point of humor, at his inability to speak and think. "The longer one listened to him, the more obvious it became that his inability to speak was closely connected with an inability to think, namely to think from the standpoint of someone else." ${ }^{43}$ Beauvoir likewise, associates a certain brand of "sub-men" as those who are blindly subservient to others. Sub-men follow whatever cause allows them to flee from "the agonizing consciousness" of themselves including the fact they could choose to make their own path. ${ }^{44}$ Elaine explores how for both Arendt and Beauvoir, the capacity to take the other's perspective was critical to being able to fully think, and ultimately, to ethically engage with others politically. ${ }^{45}$ Eichmann appears unable or unwilling to think about his actions from any vantage point other than his own and like the sub-man refuses to be conscious of himself and hence cannot be conscious of others.

In our natural condition, we are caught in an endless cycle of maintaining life to only reach death. For Arendt, what saves us from the endless flow of life and death and a collapse of meaningful human interaction in the world is the fact of natality. The birth of a human being initiates the possibility of human active freedom from the repetitive forces of nature. "The miracle that saves the world, the realm of human affairs, from its normal, 'natural' ruin is ultimately the fact of natality, in which the faculty of action is ontologically rooted." ${ }^{6}$ Any new birth starts a story whose tale cannot be known in advance and whose story will change the course of other stories. "And this again is possible only because each man is unique, so that with each birth something uniquely new comes into the world." ${ }^{47}$ The cyclical patterns of nature- birth, death, growth, and decline encompass the human condition as well. However, human life has a linearity to it-a story with a beginning and an end that marks it as unique, unlike the repetitive cycles of the natural world.

The advent of a new person brings forward a new story; a story that has not been written before and whose end and import, we cannot tell in advance. We can see here how Garland-Thomson's eloquent statement above regarding how little some genetic data tells us about the future of a child can be read now with Arendt's idea of natality. Outside ideas of healthy bodies and lives directed toward certain kinds of work and certain 
kinds of lives, we cannot know in advance the value of the new creation any birth might bring. The good health imperative has decided in advance that this kind of lifestyle and these kinds of bodies are valuable to produce and as such discourages thinking more broadly about what lives worth living are. Importantly for Arendt, the newness of natality is not about its connection to work or labor. In the above example, part of the reason for aborting fetuses who have risk factors for disabilities is the tight focus on lives worth living as being lives that will fit into our contemporary capitalist world. One clear path that orientates our lives since birth is the question that we constantly ask any college student-what are you going to do post-graduation? By which we mean-what are you going to do to earn money? The focus on "responsible" parenting, discussed in Chapters 4 and 5, can be also seen as a way in which only some kinds of paths are considered valuable. If natality is the possibility of the new, the point of childrearing is not to produce a good citizen-consumer who will slide easily into the pre-existing system, but to permit the child the space to think and act beyond the pre-given values and lifestyles we currently promote.

Arendt ties the idea of birth again to her ideas of action where, with action, separate from the activity of work and labor, we can begin something new. Like human birth, this idea of action is always a social experience, and predicated upon the community of others in which my acts can take form. However, our free action, like our free thought, is not subject to the group in the way that one might be at work:

With word and deed we insert ourselves into the human world, and this insertion is like a second birth, in which we confirm and take upon ourselves the naked fact of our original physical appearance. This insertion is not forced upon us by necessity, like labor, and it is not prompted by utility, like work. It may be stimulated by the presence of others whose company we may wish to join, but it is never conditioned by them; its impulse springs from the beginning which came into the world when we were born and to which we respond by beginning something new on our own initiative. ${ }^{48}$

For Arendt, the exclusive focus on labor and work in many contemporary societies has erased places in which the new can come into being through one's own initiative. Free action for Arendt is the process of bringing something truly new to the world, not merely executing what has already been determined by others to be valuable. It is feared in totalitarian regimes because it cannot be controlled as it is not known what the action will be and what the outcome will be.

The reason why we are never able to foretell with certainty the outcome and end of any action is simply that action has no end. The process of a single deed can quite literally endure throughout time until mankind has come to an end. ${ }^{49}$ 


\section{Labor and project}

Hence, we are lost in thought and action only if we assume that we must know their value, qua their purpose, in advance. The value of the new is that is has no pre-given purpose; it brings forth new values.

Arendt argues that thinking about politics has likewise become hampered in its reach because of its inability, in phenomenological terms she does not use, to bracket its purpose. Arendt draws inspiration from the Ancient Greeks who celebrated the political world of free action and speech as fundamentally distinct from any kind of labor or work..$^{50}$ Once politics is tied to doing a particular thing, it has ceased to be about thinking and now is about work and labor. Arendt thinks that the long history of thinking politically has erased the idea of politics as a distinct practice from work. Instead, politics is about things that are actually not politics, but rather about labor and work concerns, such as fostering economic growth, safeguarding the citizenry, caring for people's health, and building infrastructure. Political philosophies become manuals of how to best achieve these ends, not free discussion-“...the greater part of political philosophy since Plato could easily be interpreted as various attempts to find theoretical foundations and practical ways for an escape from politics altogether." ${ }^{51}$ Politics is a matter of cognition in Arendt's terms, not thought. Political discussion is thus not valued in itself as an existential experience, but is valued only if it achieves some aim.

Arendt argues that when we think politics must be concerned only with the maintenance of life, we reduce politics to a matter of necessity, about which there is no point arguing the value, rather only the mechanics of how to best go about this project. In Between Past and Future, she writes that we must have the courage to not give life the primary and exclusive focus in the political realm, not because of an indifference to life, but because of the nature of our worldly existence. "For this world of ours, because it existed before us and is meant to outlast our lives in it, simply cannot afford to give primary concern to individual lives and the interests connected with them..." 52 Arendt says if we allow this conversation to dominate our political thinking, we will be unable to think beyond it. Akin to the discussion on biopolitics in Chapter 4, we can see how management of the population in order to serve the economy now has become what is seen to be the only legitimate focus of political discussions.

It is not within pleasure or even the maintenance of my own life that I find freedom. Rather it is in the political world where I or my fellow humans act in such a manner that there is no carved place or practical end into which we can immediately understand. We are also encouraged within labor to not see ourselves connected to those who do not further our labor through our mutual work or who do not lesson our burdens. For Arendt, the respect for those whom we do not care for and with whom we do not work with is the hallmark of free political action instead of these people being helpers or stumbling blocks to get what we want which dominates work-labor cognition. When politics becomes a politics of not doing politics, politics is the servant of work and labor. Arendt notes that the worker and the 
laborer see something like free political discussions not aimed at "solving" things as idle timewasting - what do such discussions do? What is the point, after all, of philosophy? Will it solve some "real-world" problems? Can its majors find paid labor? Here Arendt comes closer to the Marxist critique of capitalism where the tail wags the dog-that is, where politics follows corporate-not citizen-demands. The more politics is merely a function of ideologically serving repressive corporate interests by making us good workers, the less anything new will be thought. And the last and worst stage of labor's valorization is the political obsession with job creation-where we are nothing but a society of jobholders with no individuality or possibilities to think outside how we can best earn our paychecks to consume. ${ }^{53}$

\section{Vulnerability and health}

Ambiguity captures our nature as political beings, as Arendt discusses, and also our nature as ethical beings. Debra Bergoffen argues that there is a distinction between political and ethical in Beauvoir. She delineates the political as that which projects itself into the world to make a path that perhaps others might follow, whereas the ethical acknowledges others and the impact of others. ${ }^{54}$ Bergoffen highlights that in Beauvoir's theory, ethical acts are manners of providing the space for others to live their freedom,

From this perspective there are two ways of living our responsibility to/ for the other. One, the ethical, which sees itself as responsible for clearing the space for the other's lived freedom; two, the political, which sees itself as responsible for calling on the other to join it in the quest for freedom..$^{55}$

She likens the ethical to gifts that ask for nothing-that do not require the other participate in the political project. There is nothing inherently bad about bettering one's health, and likely much that helps one flourish. Others may wish to join such a project. However, as also ethical beings, we must attend to the impacts on others and the providing of spaces for others whether or not they wish to follow this project. The challenge of the good health imperative is that it is deeply connected to our immediate personal situation. However, its problem is that it is taken as a command for all without room to criticize it since it is seen, like the laws of mathematics, as obviously right and true. It has been pre-decided that individual work on one's health is what one should do and no more thought is required. Moreover, it decides for others-it removes spaces for discussion outside the production of healthier bodies, because who doesn't want a healthier body?

Stavro notes that to understand Beauvoir's thought, one must pay attention to her engaged embodied manner of understanding the perspectives of others: "Beauvoir, too, supports enlarged thinking, but unlike Arendt stresses the significance of embodiment and the effects of one's historical social situation on one's knowledge." ${ }^{56}$ Whether self-directed health 


\section{Labor and project}

work is liberating or confining requires thinking about if my project as a path is freely chosen and how my project affects others. Any project I engage in, such as getting in better shape, depends upon a variety of other humans engaging in their projects from the streets being safe, to my doctor's supervision, to my son's school providing aftercare so I can work out. "One can reveal the world only on a basis revealed by other men. No project can be defined except by its interference with other projects." ${ }^{57}$ The values I hold dear are also ones I have learned and share with others. However, as raised above, conditions of unequal status-such as wealth or illnessmake many lifeworlds radically different even if each might have some possibilities of freely chosen values within them. Systemic differences are not just about the prejudices of, say, ableism or racism, but the manner in which the privileged have the capacity to choose a variety of paths which they falsely assume exist for everyone. Throughout this book, stress was placed on the deliberative work needed to promote healthy body work. This work is not simply a matter of isolated persons taking up the mantle of responsibility to better their health, but requires our complex contemporary system of healthcare, affiliated corporate wellness products and programs. I have called into question the value of such work, given its obvious placement within a system of radically disparate possibilities and resources for healthy self-care.

Beauvoir points out that what is useful-that is what is valued by someone-is so because it has some relevance to that individual's life. In oppression, utility, as Arendt also argues, is used as a tool to impose itself on others and to make others labor. Do this, because it is good for you! Instead, it must be people themselves who define their projects. Beauvoir writes, "Oppression tries to defend itself by its utility...nothing is useful if it is not useful to man; nothing is useful to man if the latter is not in a position to define his own ends and values, if he is not free." ${ }^{58}$ Beauvoir writes of a young invalid who had to leave her home, her occupations, and her whole past life, being told to "get cured. The rest has no importance." ${ }^{59}$ One can picture the healthcare staff counseling her that her health must come first. Yet, if one could no longer live the way one wished with the people one cherished, why would one want to get better? Beauvoir says the invalid replied, "But if nothing has any importance, what good is it to get cured?" 60 For the woman, nothing in her possible virtual future called to her; the pursuit of health had little meaning. The difficulty of dictating what is valuable about health abstracted from the individual's situation helps highlight how universal decrees are senseless.

An examination of our human life suggests that the possibility to choose is itself not necessarily present for all. Worker-producers are not as free to choose their paths and projects as citizen-consumers are. Ambiguity is the refusal of seeing such policy decisions as isolated debates and instead seeing them as political and social. As Camus encourages the artist to not deny our contemporary knowledge of the suffering and exclusion of the many discussed in Chapter 6, so too does our health work take place in the relief 
of a world in which such work is not possible for all. It is the repeated acts, like Ahmed writes, that create the oppressive path that is followed without thinking. Sara Heinämaa explains that in the case of sexism, it is the acts of sexism that create oppression, not the ideology:

...this oppression is reestablished in our own acts of dismissal and neglect operative in the present. This means that we ourselves are responsible for the permanence of the sexual hierarchy, not society, not history, and not any of our predecessors, human or animal. ${ }^{61}$

When faced with the daunting freedom that our ambiguous condition provides us, it can be tempting to shirk our responsibility and assume oppression always comes from without, and is not bolstered by our unthoughtful actions.

When one reads Notes from Underground as a contemporary reader, one might suggest, as my students often do, that the underground man could do with some therapy. But, insofar as therapy reveals an inner self to one-a part of one that one was rejecting or ignoring - this seems inappropriate for his problems. If anything, he suffers consciously from an all-too acute self-knowledge, wondering, "can a man with my lucidity of perception respect himself?" ${ }_{2}$ His "friends," a set of brutish men seem to not suffer from this sense of their own ridiculous and base natures, act without self-reflection. The underground man finds himself unable to behave in the same manner, yet still wants not just their approval, but also their appreciation that he is a nobler person given his "refinement." His inability to give up the ridiculousness of romantic ideals in a world that does not reflect them leads to his absurd, perhaps self-inflicted condition. The only character who seems a whole person in the story is the prostitute, Liza. Having followed his friends to the whorehouse to prove he is every bit as good as them, he finds himself in the role of lecturing Liza. She feels a human, vulnerable connection to him, and comes to his apartment, only to catch him in a very ridiculous argument with his servant. He realizes that she sees him for who he truly is, not a "hero," but an exposed human, just like her. He cannot come to terms with this; he insults her in such a manner that she can only flee, and locks himself into his rooms in the suburbs thereafter.

What the underground man perhaps needs is not a better self-reflection per se, but more engaging and meaningful social interaction that would require that he might encounter something that cannot be predicted, neatly fit into his romantic ideals, or in the base scientism of the age. He would need to be vulnerable to others. If he had not insulted Liza by giving her money after they slept together, he would have been in a position of not knowing what their next interaction would be. Arendt's reflections on the value of social political action stress the existential value of interactions that are not predetermined. However, it is with Beauvoir that we can find the need for this vulnerability to others to live most authentically in our ambiguous situation. Indeed, one hallmark of a truly affectionate relationship is that one allows 
oneself to be transformed by the other in unpredictable ways. The underground man cannot open himself to Liza to be in position of change, perhaps due to his over-commitment to romantic ideologies, but also surely because he lacks ethical shared spaces. His life seems to be nothing but rooms of masculine jockeying for power or prestige, spaces in which he feels humiliated and debased, to his self-inflicted isolation where he gnashes his teeth, inwardly suffering. The underground man has found his freedom from society's norms and the facts of science, but he has not found a way to live with others authentically without being debased by them or debasing them.

Existentialism has often been seen as a solipsistic philosophy, where we are all lost in our own absurd universes, but as argued above, it need not be if one can get away from the tradition of thinking of freedom as an individual pursuit. 70 years ago, Beauvoir wrote that "Today, however, we are having a hard time living because we are so bent on outwitting death," portending our own turn inward toward ever more refined forms of consumption and self-production and our greater isolation from engaged ethical relationships with others. ${ }^{63}$ In Chapter 1, the increase in longevity over the last 200 years was noted. During the pandemic, longevity is predicted to have reduced by an average of 1.13 years in the United States; however, for Black and Latino populations, it is predicted to have reduced by 3 to 4 times that of whites. ${ }^{64}$ The pandemic has highlighted the need for better public health and the manner in which we are all deeply connected to others. Bracketing the good health imperative is not to bracket the value of health, but the value of health as a matter of good individual behavior. Researchers studying the historical and contemporary outcomes of pandemics noted that COVID-19 occurred during a time when health inequalities had been increasing.

COVID-19 has laid bare our longstanding social, economic and political inequalities-even before the COVID-19 pandemic, life expectancy amongst the poorest groups was already declining in the UK and the USA, and health inequalities in some European countries have been increasing over the last decade. ${ }^{65}$

If one continues to associate health with individual treatment and behavior, one will continue to pass over such systemic issues that affect health. Our deeply interconnected lives where infection passes because of a breath highlight how little the individual's solitary projects and health can be understood as individually owned. A return to our shared ambiguous condition might permit creating more expansive spaces outside the paths of work and consumption toward ones where we remain open to the new.

\section{Notes}

1 Fyodor Dostoevsky, Notes from Underground. Translated by Andrew R. MacAndrew (New York: Signet Classics, 1980), 99.

2 Dostoevsky, Notes from Underground, 99. 
3 Dostoevsky, Notes from Underground, 94.

4 Albert Camus, The Myth of Sisyphus and Other Essays. Translated by Justin O’Brien (New York: Vintage, 1983), 21.

5 Nietzsche, The Gay Science, $\$ 125,181$.

6 Bjørn Hofmann and Fredrik Svenaeus, "How Medical Technologies Shape the Experience of Illness," Life Sciences, Society and Policy 14, no. 3 (2018):1-11; Carl Elliott, Better Than Well: American Medicine Meets the American Dream (New York: W.W. Norton, 2004).

7 Robert McRuer, Crip Theory: Cultural Signs of Queerness and Disability (New York: New York University Press, 2006).

8 Sara Ahmed, Queer Phenomenology: Orientations, Objects, Others (Durham: Duke University Press, 2006).

9 Ahmed, Queer Phenomenology, 87.

10 Simone de Beauvoir, The Second Sex. Translated by Constance Borde and Sheila Malovany-Chevallier (New York: Knopf, 2010): 283

11 Ahmed, Queer Phenomenology, 23.

12 Ahmed, Queer Phenomenology, 66.

13 Ahmed, Queer Phenomenology, 134, 137.

14 Sara Ahmed, Living a Feminist Life (Durham: Duke University Press, 2017). See also her blog at www.feministkilljoys.com

15 Helen Ngo, The Habits of Racism: A Phenomenology of Racism and Radicalized Embodiment (New York: Lexington Books, 2017).

16 Sabrina Tavernise, "Disparity in Life Spans of the Rich and the Poor Is Growing," The New York Times, February 16, 2016, https://www.nytimes.com/2016/02/13/ health/disparity-in-life-spans-of-the-rich-and-the-poor-is-growing.html

17 Caroline Davies, "Jamie Oliver Urges MPs to Tackle 'catastrophe' of Childhood Obesity," The Guardian, Tuesday, May 1, 2018, https://www.theguardian.com/ lifeandstyle/2018/may/0 $1 /$ ja mie-oliver-mps-tackle-catastrophechildhood-obesity

18 Emine Saner, “Does the criticism affect me? Yes, massively': Jamie Oliver's War on Childhood Obesity," The Guardian, Sunday 29 April, 2018, https://www. theguardian.com/lifeandstyle/2018/apr/29/jamie-oliver-criticism-affect-mechildhood-obesity

19 Kanaka D. Shetty, Thomas DeLeire, Chapin White, Jayanta Bhattacharya, "Changes in U.S. Hospitalization and Morality Rates Following Smoking Bans," Journal of Policy Analysis and Management 30, no. 1 (2010): 6-28.

20 Jacob Grier, "We Used Terrible Science to Justify Smoking Bans," Slate, February 13, 2017, http://www.slate.com/articles/health_and_science/medical_examiner/2017/02/secondhand_smoke_isn_t_as_bad_as_we_thought.html

21 Julie Guthman, Weighing In: Obesity, Food Justice, and the Limits of Capitalism (Berkeley: University of California Press, 2011), 193.

22 Talia Welsh, "The Affirmative Culture of Healthy Self-Care: A Feminist Critique of the Good Health Imperative," IJFAB: International Journal of Feminist Approaches to Bioethics 13, no. 1 (2020): 27-44.

23 Christine Wieseler, "Challenging Conceptions of the 'Normal' Subject of Phenomenology," In Race as Phenomena: Between Phenomenology and Philosophy of Race, ed. Emily Lee (Lanham, MD: Rowman \& Littlefield, 2019), 69.

24 Rosemarie Garland-Thomson, "Misfitting," In 50 Concepts for a Critical Phenomenology, eds. Gail Weiss, Ann V. Murphy, and Gayle Salamon (Evanston: Northwestern University Press, 2020): 226.

25 Rosemarie Garland-Thomson, "How We Got to CRISPR: The Dilemma of Being Human," Perspectives in Biology and Medicine 63, no. 1 (2020): 28.

26 Sarah Zhang, "The Last Children of Down Syndrome," The Atlantic (December 2020).https://www.theatlantic.com/magazine/archive/2020/12/the-last-children-of-downsyndrome/616928/ 


\section{Labor and project}

27 Garland-Thomson, "How we Got," 35.

28 Zhang, "The Last."

29 Beauvoir, Ethics, 15.

30 Beauvoir, Ethics, 129.

31 Beauvoir, Ethics, 78.

32 Beauvoir, Ethics, 41.

33 Hannah Arendt, The Human Condition (Chicago: University of Chicago Press, 1958): 126.

34 Arendt, Human, 127.

35 Arendt, Human, 133.

36 Dorothea Olkowski, "Science and Human Nature: How to Go from Nature to Ethics." In Metacide: In the Pursuit of Excellence, ed. James R. Watson (Leiden: Brill, 2010): 54.

37 Arendt, Human, 313.

38 Arendt, Human, 170.

39 Arendt, Human, 170.

40 Arendt, Human, 170.

41 Arendt, Human, 171.

42 Arendt, Human, 170.

43 Hannah Arendt, Eichmann in Jerusalem: A Report on the Banality of Evil (New York: Penguin, 2006): 47. In an interview, Arendt noted that she laughed occasionally at how words got the better of Eichmann often saying when reading the police transcript of his arrest and interrogation, "I was really of the opinion that Eichmann was a buffoon...I read the transcript of his police investigation, thirtysix hundred pages, read it, and read it very carefully and I do not know how many times I laughed-laughed out loud!" Hannah Arendt, "What Remains? The Language Remains' a Conversation with Günter Gus.” Translated by Joan Stambaugh. In The Last Interview and Other Conversations (London: Melville House, 2013): 26-27.

44 Simone de Beauvoir, The Ethics of Ambiguity, Translated by Bernard Fretchman (New York: Citadel, 1976): 45.

45 Elaine Stavro, Emancipatory Thinking: Simone de Beauvoir and Contemporary Political Thought (Montreal: Mc-Gill-Queen's University Press, 2018): 47-48.

46 Arendt, Human, 247.

47 Arendt, Human, 178.

48 Arendt, Human, 176-177.

49 Arendt, Human, 233.

50 Arendt, Human, 31-33, 83.

51 Arendt, Human, 222.

52 Hannah Arendt, Between Past and Future (New York: Penguin, 2006): 155.

53 Arendt, Human, 322.

54 Debra B. Bergoffen, "Between the Ethical and the Political: The Difference of Ambiguity." In The Existential Phenomenology of Simone de Beauvoir, eds. Wendy O'Brien and Lester Embree (Dordrecht: Kluwer, 2001): 188.

55 Bergoffen, “Between," 190.

56 Stavro, Emancipatory Thinking, 48.

57 Beauvoir, Ethics, 71.

58 Beauvoir, Ethics, 95.

59 Beauvoir, Ethics, 106

60 Beauvoir, Ethics, 106.

61 Sara Heinämaa, "Ambiguity and Difference: Two Feminist Ethics of the Present.” In Differences: Rereading Beauvoir and Irigaray, eds. E. A. Parker ans A. van Leeuwen (New York: Oxford University Press): 141.

62 Dostoevsky, Notes from Underground, 101.

63 Beauvoir, Ethics, 120. 
64 Theresa Andrasfay and Noreen Goldman, "Reductions in 2020 US Life Expectancy Due to COVID-19 and the Disproportionate Impact on the Black and Latino Populations," Proceedings of the National Academy of Sciences of the United States of America 118, no. 5, February 2, 2021. https://doi. org/10.1073/pnas.2014746118

65 Clare Bambra, Ryan Riordan, John Ford, and Fiona Matthews, "The COVID-19 Pandemic and Health Inequalities," Journal of Epidemiology and Community Health 74, no. 11 (2020 Nov): 964-968. 10.1136/jech-2020-214401

\section{Bibliography}

Ahmed, Sara. Living a Feminist Life. Durham: Duke University Press, 2017.

Ahmed, Sara. Queer Phenomenology: Orientations, Objects, Others. Durham: Duke University Press, 2006.

Andrasfay, Theresa and Noreen Goldman, "Reductions in 2020 US life expectancy due to COVID-19 and the disproportionate impact on the Black and Latino populations." Proceedings of the National Academy of Sciences of the United States of America. 118, no. 5 (February 2, 2021). https://doi.org/10.1073/ pnas.2014746118.

Arendt, Hannah. Between Past and Future. New York: Penguin, 2006a.

Arendt, Hannah. Eichmann in Jerusalem: A Report on the Banality of Evil. New York: Penguin, 2006b.

Arendt, Hannah. The Human Condition. Chicago: University of Chicago Press, 1958.

Bambra, Clare, Ryan Riordan, John Ford, and Fiona Matthews, “The COVID-19 pandemic and health inequalities." Journal of Epidemiology and Community Health, 74, no. 11 (November 2020): 964-968. 10.1136/jech-2020-214401.

Bergoffen, Debra B. "Between the Ethical and the Political: The Difference of Ambiguity." In The Existential Phenomenology of Simone de Beauvoir, edited by Wendy O'Brien and Lester Embree. Dordrecht: Kluwer, 2001.

Camus, Albert. The Myth of Sisyphus and Other Essays, translated by Justin O’Brien. New York: Vintage, 1983.

Davies, Caroline. "Jamie Oliver urges MPs to tackle 'catastrophe' of childhood obesity", The Guardian, May 1, 2018, https:/www.theguardian.com/ lifeandstyle/2018/may/01/jamie-oliver-mps-tackle-catastrophe-childhood-obesity

De Beauvoir, Simone. The Ethics of Ambiguity. New York: Citadel, 1976.

De Beauvoir, Simone. The Second Sex, translated by Constance Borde and Sheila Malovany-Chevallier. New York: Knopf, 2010.

Dostoyevsky, Fydor. Notes from Underground, translated by Andrew R. MacAndrew. New York: Signet Classics, 1980.

Garland-Thomson, Rosemarie. "Misfitting." In 50 Concepts for a Critical Phenomenology, eds. Gail Weiss, Ann V. Murphy, and Gayle Salamon. Evanston: Northwestern University Press, 2020a.

Garland-Thomson, Rosemarie. "How We Got to CRISPR: The Dilemma of Being Human." Perspectives in Biology and Medicine, 63, no. 1 (2020b): 28.

Grier, Jacob. "We Used Terrible Science to Justify Smoking Bans," Slate, February 13, 2017. http://www.slate.com/articles/health_and_science/medical_examiner/2017/02/secondhand_smoke_isn_t_as_bad_as_we_thought.html.

Guthman, Julie. Weighing In: Obesity, Food Justice, and the Limits of Capitalism. Berkeley: University of California Press, 2011. 
Heinämaa, Sara. Toward a Phenomenology of Sexual Difference: Husserl, MerleauPonty, Beauvoir. London: Roman \& Littlefield, 2003.

Hofmann, Bjørn and Fredrik Svenaeus, "How Medical Technologies Shape the Experience of Illness," Life Sciences, Society and Policy 14, no. 3 (2018):1-11. https://doi.org/10.1186/s40504-018-0069-y.

McRuer, Robert. Crip Theory: Cultural Signs of Queerness and Disability. New York: New York University Press, 2006.

Nietzsche, Friedrich. The Gay Science, translated by Walter Kaufmann. New York: Vintage Books, 1974.

Ngo, Helen. The Habits of Racism: A Phenomenology of Racism and Radicalized Embodiment. New York: Lexington Books, 2017.

Olkowski, Dorothea. "Science and Human Nature: How to Go from Nature to Ethics.” In Metacide: In the Pursuit of Excellence. Ed. James R. Watson. Leiden: Brill, 2010.

Saner, Emine. “'Does the Criticism Affect Me? Yes, Massively': Jamie Oliver's War on Childhood Obesity," The Guardian, April 29, 2018, https:/www.theguardian. com/lifeandstyle/2018/apr/29/jamie-oliver-criticism-affect-me-childhood-obesity

Shetty, Kanaka D., Thomas DeLeire, Chapin White, and Jayanta Bhattacharya, "Changes in U.S. Hospitalization and Morality Rates Following Smoking Bans," Journal of Policy Analysis and Management, 30, no. 1 (2010): 6-28. https://doi. org/10.1002/pam.20548.

Stavro, Elaine. Emancipatory Thinking: Simone de Beauvoir and Contemporary Political Thought. Montreal: Mc-Gill-Queen's University Press, 2018.

Tavernise, Sabrina. "Disparity in Life Spans of the Rich and the Poor Is Growing," The New York Times, February 16, 2016, https://www.nytimes.com/2016/02/13/ health/disparity-in-life-spans-of-the-rich-and-the-poor-is-growing.html

Welsh, Talia. "The Affirmative Culture of Healthy Self-Care: A Feminist Critique of the Good Health Imperative." IJFAB: International Journal of Feminist Approaches to Bioethics, 13, no. 1 (2020): 27-41.

Wieseler, Christine. "Challenging Conceptions of the 'Normal' Subject of Phenomenology," In Race as Phenomena: Between Phenomenology and Philosophy of Race, ed. Emily Lee Lanham, MD: Rowman \& Littlefield, 2019.

Zhang, Sarah. "The Last Children of Down Syndrome." The Atlantic. December 2020. https://www.theatlantic.com/magazine/archive/2020/12/ the-last-children-of-down-syndrome/616928/ 


\section{Bibliography}

Aas, Sean. "Disabled-Therefore, Unhealthy?" Ethical Theory and Moral Practice 19 (2016): 1259-1274.

Abselsonnove, Reed. “The Smokers' Surcharge.” New York Times, November 16, 2011. http://www.nytimes.com/2011/11/17/health/policy/smokers-penalized-with-health-insurance-premiums.html?_r=1.

Acute Stress Cardiomyopathy, John Hopkins Medicine. (n.d.) "Frequently Asked Questions about Broken heart Syndrome.” Accessed June 13, 2015. http://www. hopkinsmedicine.org/asc/faqs.html.

Ahmed, Sara. 2021. www.feministkilljoys.com.

Ahmed, Sara. Living a Feminist Life. Durham: Duke University Press, 2017.

Ahmed, Sara. Queer Phenomenology: Orientations, Objects, Others. (Durham: Duke University Press, 2006).

Alcoff, Linda Martín. "Epistemologies of Ignorance-Three Types.” In Race and Epistemologies of Ignorance, edited by Shannon Sullivan and Nancy Tuana. (New York: State University of New York Press, 2007), 39-57.

American Public Health Association. "Prevention and Public Health Fund: Dedicated to Improving our Nation's Public Health.” APHA.org, 2015. https:// www.apha.org/ /media/files/pdf/topics/aca/2015_pphf_fact_sheet.ashx.

Andersen, Shaneda Warren, William J. Blot, Xiao-Ou Shu, Jennifer S. Sonderman, Mark Steinwandel, Margaret K. Hargreaves, and Wei Zheng. "Associations between Neighborhood Environment, Health Behaviors, and Mortality." American Journal of Preventative Medicine 54, no. 1 (January 2018): 87-95. https://doi.org/10.1016/j.amepre.2017.09.002

Anderson, Peter, Lars Møller, Gauden Galea, Kevin D. Shield, Tara AK KehoeChan, Gerrit Gmel, Maximilien X. Rehm et al.. Alcohol in the European Union: Consumption, Harm and Policy Approaches, edited by Peter Anderson, Lars Møller, and Gauden Galea. World Health Organization, The Regional Office for Europe. Denmark, 2012. http://www.euro.who.int/_data/assets/pdf_ file/0003/160680/e96457.pdf?ua=1.

Andrasfay, Theresa and Noreen Goldman, "Reductions in 2020 US Life Expectancy Due to COVID-19 and the Disproportionate Impact on the Black and Latino Populations." Proceedings of the National Academy of Sciences of the United States of America 118, no. 5 (February 2, 2021) https://doi.org/10.1073/ pnas. 2014746118

Araujo, Christopher Duarte. "Marx and Paci on the Question of Appearances (Or, Reading Capital as a Phenomenology)," Human Studies 40 (2017): 101-119. https://doi.org/10.1007/s10746-016-9411-7

Arendt, Hannah. Between Past and Future. New York: Penguin, 2006a. 


\section{Bibliography}

Arendt, Hannah. Eichmann in Jerusalem: A Report on the Banality of Evil. New York: Penguin, 2006b.

Arendt, Hannah. The Human Condition. Chicago: University of Chicago Press, 1958.

Arendt, Hannah. "'What Remains? The Language Remains' a Conversation with Günter Gus," translated by Joan Stambaugh. 1-38. In The Last Interview and Other Conversations. London: Melville House, 2013.

Agras, W., S. Bryson, L. Hammer, H. Kraemer. "Childhood Risk Factors for Thin Body Preoccupation and Social Pressure to be Thin." Journal of the American Academy of Child \& Adolescent Psychiatry, 46 (2007): 171-178.

Aruguete, M., A. Yates, and J. Edman. Gender Differences in Attitudes about Fat. North American Journal of Psychology, 8 (2006): 183-192.

Assari, Shervin. "Unequal Gain of Equal Resources across Racial Groups," International Journal of Health Policy and Management, 2018, 7, no. 1: 1-9.

Assari, Shervin and Maryam Moghani Lankarani, "Poverty Status and Childhood Asthma in White and Black Families: National Survey of Children's Health," Healthcare, 2018, 6, no. 62: doi:10.3390/healthcare602002.

Bacon, Linda. Health at Every Size. Dallas: BenBella, 2008.

Bambra, Clare, Ryan Riordan, John Ford, and Fiona Matthews, "The COVID-19 Pandemic and Health Inequalities." Journal of Epidemiology and Community Health. November 2020; 74, no. 11: 964-968. Doi: 10.1136/jech-2020-214401

Bartky, Sandra Lee. Femininity and Domination. New York: Routledge, 1990.

De Beauvoir, Simone. The Ethics of Ambiguity. New York: Citadel, 1976.

De Beauvoir, Simone. The Second Sex, translated by Constance Borde and Sheila Malovany-Chevallier. New York: Knopf, 2010.

Becker, Anne E., Rebecca A. Burwell, David B. Herzog, Paul Hamburg, and Stephen E. Gilman. "Eating Behaviours and Attitudes following Prolonged Exposure to Television among Ethnic Fijian Adolescent Girls." The British Journal of Psychiatry 180, no. 6 (June 2002): 509-514. https://doi.org/10.1192/bjp.180.6.509.

Bergoffen, Debra B. "Between the Ethical and the Political: The Difference of Ambiguity." In The Existential Phenomenology of Simone de Beauvoir. 187-204, edited by Wendy O'Brien and Lester Embree. Dordrecht: Kluwer, 2001.

Bongaarts, John. "How Long Will We Live?" Population and Development Review 32, no. 4 (2006): 605-628. https://doi.org/10.1111/j.1728-4457.2006.00144.x.

Bordo, Susan. Unbearable Weight: Feminism, Western Culture, and the Body. Berkeley: University of California Press, 1995.

Boseley, Sarah. "Low-carb and Mediterranean Diets Beat Low-fat Plans for Losing Weight-Report." The Guardian, October 29, 2015. http://www.theguardian. com/lifeandstyle/2015/oct/30/low-fat-diets-slammed-major-new-report.

Bouchery, Ellen E., Henrick J. Harwwod, Jeffrey J. Sacks, Carol J. Simon, and Robert D. Brewer. "Economic Costs of Excessive Alcohol Consumption in the U.S., 2006." American Journal of Preventive Medicine 41, no. 5 (November 5, 2011): 516-524. https://doi.org/10.1016/S0749-3797(11)00692-1.

Buote, V., A. Wilson, E. Strahan, S. Gazzola, F. Papps. "Setting the Bar: Divergent Sociocultural Norms for Women's and Men's Ideal Appearance in Real-World Contexts." Body Image, 8 (2011): 322-334.

Brenan, Megan. "American's Face Mask Usage Varies Greatly by Demographics.” News Gallup. July 13, 2020. https://news.gallup.com/poll/315590/americans-face-mask-usage-varies-greatly-demographics.aspx 
Cafaro, Philip J., Richard B. Primack, and Robert L. Zimdahl. "The Fat of the Land: Linking American Food Overconsumption, Obesity, and Biodiversity Loss." Journal of Agricultural and Environmental Ethics 19, no. 6 (2006): 541-561. https://doi.org/10.1007/s10806-006-9008-7.

“Campaign Resources.” CDC.gov. Last modified October 23, 2015. http://www. cdc.gov/tobacco/campaign/tips/resources/index.html.

Camus, Albert. "Create Dangerously." In Resistance, Rebellion, and Death, translated by Justin O’Brien, 249-272. New York: Vintage Books, 1960.

Carel, Havi. Illness. Stocksfield: Acumen, 2008. cdc.gov

Carman, Katherine G., Christine Eibner, and Susan M. Paddock. "Trends in Health Insurance Enrollment, 2013-15.” Health Affairs 35, no. 6 (June 2015): 10441048. https://doi.org/10.1377/hlthaff.2015.0266.

Cederström, Carl, and Andre Spicer. The Wellness Syndrome. Cambridge: Polity Press, 2015.

Chuang-Tzŭ. The Inner Chapters, translated by A.C. Graham. Indianapolis: Hackett, 1989.

Committee on Education and the Workforce. "Senate, House Leaders Introduce Bill to Provide Certainty to Employers Offering Innovative Employee Wellness Programs.” March 3, 2015. http://edworkforce.house.gov/news/documentsingle. aspx? DocumentID=398504

Crawford, Robert. "Healthism and the Medicalization of Everyday Life." International journal of Health Services 10, no. 3 (1980): 365-388. https://doi. org/10.2190/3H2H-3XJN-3KAY-G9NY

“Current Comment.” JAMA 56, no. 4 (1911): 1042.

Davies, Caroline. "Jamie Oliver Urges MPs to Tackle 'catastrophe' of Childhood Obesity, The Guardian, Tuesday, May 1, 2018, https://www.theguardian.com/ lifeandstyle/2018/may/01/jamie-oliver-mps-tackle-catastrophe-childhood-obesity

Descartes, René. "Optics.” In The Philosophical Writings of Descartes: Volume 1, translated by John Cottingham, Robert Stoothoff, and Dugald Murdoch. 152176. Cambridge: Cambridge University Press, 1985.

Diprose, Rosayln. The Bodies of Women: Ethics, Embodiment and Sexual Difference. London: Routledge, 1994.

Dostoyevsky, Fydor. Notes from Underground, translated by Andrew R. MacAndrew. New York: Signet Classics, 1980.

Dolezal, Luna. The Body and Shame: Phenomenology, Feminism, and the Socially Shaped Body. New York: Lexington, 2015.

Douglas, Scott. "Number of Ultramarathons Has Doubled in the Last Decade." November 7, 2014. https:/www.runnersworld.com/races-places/a20833701/ number-of-ultramarathons-has-doubled-in-the-last-decade/

Dreyfus, Hubert. "Intelligence without Representation-Merleau-Ponty's Critique of Mental Representation." Phenomenology and the Cognitive Sciences 1, (2002): 367-383. https://doi.org/10.1023/A:1021351606209.

Druett, Joan. Island of the Lost: Shipwrecked at the Edge of the World. New York: Algonquin, 2007.

Duffy, Mignon. "Doing the Dirty Work: Gender, Race, and Reproductive Labor in Historical Perspective," Gender and Society, Vol. 21, no. 3 (2007): 313-336.

Dutton, G., M. Perri, M. Dancer-Brown, M. Goble, N. Van Vessem. "Weight Loss Goals of Patients in a Health Maintenance Organization.” Eating Behaviors, 11 (2010): 74-78. 


\section{Bibliography}

Ehrenreich, Barbara. Bright-sided: How the Relentless Promotion of Positive Thinking Has Undermined America. New York: Metropolitan Books, 2009.

Elliott, Carl. Better Than Well: American Medicine Meets the American Dream. New York: W.W. Norton, 2004.

Emanuel,Ezekiel.“WhyI Hope to Dieat 75,"The Atlantic, October 2014, https://www. theatlantic.com/magazine/archive/2014/10/why-i-hope-to-die-at-75/379329/

CDC.gov, "Fact Sheets-Alcohol Use and Your Health.” Last modified December 17, 2015. http://www.cdc.gov/alcohol/fact-sheets/alcohol-use.htm.

Fassin, Didier, "Another Politics of Life is Possible," Theory, Culture \& Society 26, no. 5 (2009): 44-60.

Farrelly, Matthew C., Cheryl G. Healton, Kevin C. Davis, Peter Messeri, James C. Hersey, and M. Lyndon Haviland. "Getting To the Truth: Evaluating National Tobacco Countermarketing Campaigns.” American Journal of Public Health 92, no. 6 (2002): 901-907. https://doi.org/10.2105/AJPH.92.6.901.

Fielding, Helen. "Depth of Embodiment: Spatial and Temporal Bodies in Foucault and Merleau-Ponty." Philosophy Today 43, no. 1 (1999): 73-85. https://doi. org/10.5840/philtoday199943138.

Finch, Caleb E. "Evolution of the Human Lifespan and Diseases of Aging: Roles of Infection, Inflammation, and Nutrition." Proceedings of the National Academy of the Science of the United States of America 107, no. 1 (April 2009): 1718-1724. https://doi.org/10.1073/pnas.0909606106.

Fisher, Daniel. “Fewer Smokers Means Higher Taxpayer Costs, Study Finds.” Forbes, November 29, 2012. http://www.forbes.com/sites/danielfisher/2012/11/29/ fewer-smokers-means-higher-taxpayer-costs-study-finds/\#46ca1deb2d6f.

Fisher, Linda. "The Illness Experience: A Feminist Phenomenological Perspective." In Feminist Phenomenology and Medicine, edited by Kristin Zeiler and Lisa Folkmarson Käll. Albany: SUNY Press, 2014.

Frankl, Viktor E. Man's Search for Meaning, translated by Ilse Lasch. Boston: Beacon Press, 2006.

Flegal, Katherine M. "Prevalence and Trends in Obesity Among US Adults, 19992008." Journal of the American Medical Association 303, no. 3 (2010): 235-241. https://doi.org/10.1001/jama.2009.2014.

Freyne, Patrick, and Ronan McGreevy. "A History of Smoking Bans: Ireland and the World." The Irish Times, Last modified March 22, 2014. http://www. irishtimes.com/life-and-style/a-history-of-smoking-bans-ireland-and-theworld-1.1733943.

Foucault, Michel. Discipline \& Punish: The Birth of the Prison, translated by Alan Sheridan. New York: Vintage, 1995.

Foucault, Michel. "How an 'Experience-Book' is Born." In Remarks on Marx: Conversations with Duccio Trombadori, translated by R. James Goldstein and James Cascaito, 25-42. New York: Semiotext(e), 1991.

Foucault, Michel. "Polemics, Politics, and Problemizations: An Interview." In The Foucault Reader, translated by Lydia Davis, edited by Paul Rabinow, 381-390. New York: Vintage, 2010.

Foucault, Michel. "Society Must Be Defended": Lectures at the Collège de France 1975-1976, translated by David Macey. New York: Picador, 1997.

Foucault, Michel. "The Confession of the Flesh.” In Power/Knowledge: Selected Interviews \& Other Writings 1972-1977, translated by Colin Gordon, Leo Marshall, John Mepham, and Kate Soper, edited by Colin Gordon. 194-228. New York: Vintage, 1980. 
Foucault, Michel, The History of Sexuality: An Introduction, Volume I, translated by Robert Hurley. New York: Vintage, 1990.

Gadamer, Hans-Georg. The Enigma of Health, translated by Jason Gaiger and Nicolas Walker. Stanford: Stanford University Press, 1996.

Garland-Thomson, Rosemarie. "How We Got to CRISPR: The Dilemma of Being Human." Perspectives in Biology and Medicine, 63, 1 (2020a): 28-43

Garland-Thomson, Rosemarie. "Misfitting." In 50 Concepts for a Critical Phenomenology, edited by Gail Weiss, Ann V. Murphy, and Gayle Salamon. 225230. Evanston: Northwestern University Press. 2020b.

Gibbs, Wayt W. “Obesity: An Overblown Epidemic?” Scientific American 292, no. 6 (2005): 70-77. https://doi.org/10.1038/scientificamerican0605-70.

Graziozi, Graig. “Texas Mayor Resigns after Telling Residents He Owed them 'nothing' Following Storm Power Outage.” Independent. February 17, 2021.

Grier, Jacob. "We Used Terrible Science to Justify Smoking Bans," Slate, February 13, 2017, http://www.slate.com/articles/health_and_science/medical_examiner/2017/02/secondhand_smoke_isn_t_as_bad_as_we_thought.html

Grice, Elizabeth A. and Julia A. Segre, "The Skin Microbiome," National Review of Microbiology 9, no. 4 (2011): 244-253. https://doi.org/10.1038/nrmicro2537

Grosz, Elizabeth. Volatile Bodies: Toward a Corporeal Feminism. Bloomington, IN: Indiana University Press, 1994.

Groven, Karen Synne, and Gunn Engelsrud. "Negotiating Options in WeightLoss Surgery: 'Actually I didn't have any other option.'” Medicine Health Care and Philosophy 19, no. 3 (2016): 361-370. https://doi.org/10.1007/ s11019-015-9677-y.

Guenther, Lisa. "Critical Phenomenology." In 50 Concepts for a Critical Phenomenology, edited by Gail Weiss, Ann V. Murphy, and Gayle Salamon, 1116. Evanston: Northwestern University Press. 2020.

Guthman, Julie. Weighing In: Obesity, Food Justice, and the Limits of Capitalism. Berkeley: University of California Press, 2011.

Hall, Kim Q. "Toward a Queer Crip Feminist Politics of Food," philoSOPHIA, 4, no. 2, 2014: 177-196.

Halpern, Scott D., Benjamin French, Dylan S. Small, Kathryn Saulsgiver, Michael O. Harhay, Janet Audrain-Mcgovern, George Loewenstein et al. "Randomized Trial of Four Financial-Incentive Programs for Smoking Cessation.” New England Journal of Medicine 372, no. 22 (2015): 2108-2117. https://doi.org/10.1056/ NEJMoa1414293.

Hammond, Ross, and Levine Ruth. "The Economic Impact of Obesity in the United States." Diabetes, Metabolic Syndrome and Obesity: Targets and Therapy (DMSOTT) no. 3 (2010): 285-295. https://doi.org/10.2147/DMSOTT.S7384.

Hansen, Andrew R., Dustin T. Duncan, Yelena N. Tarasenko, Fei Yan, and Jian Zhang. "Generational Shift in Parental Perceptions of Overweight Among SchoolAged Children.” Pediatrics 134, no. 3 (September 2014): 481-488. https://doi. org/10.1542/peds.2014.

Harper, Barry. "Beauty, Stature and the Labour Market: A British Cohort Study." Oxford Bulletin of Economics and Statistics 62, no. 1 (2000): 771-800. https:// doi.org/10.1111/1468-0084.0620s1771.

Harvey, David. A Brief History of Neoliberalism. Oxford: Oxford University Press, 2005.

Harvey, David. Marx, Capital, and the Madness of Economic Reason. Oxford: Oxford University Press, 2018. 


\section{Bibliography}

Heinämaa, Sara. “Ambiguity and Difference: Two Feminist Ethics of the Present.” In Differences: Rereading Beauvoir and Irigaray, edited by E. A. Parker and A. van Leeuwen. 137-176. New York: Oxford University Press.

Heinämaa, Sara. Toward a Phenomenology of Sexual Difference: Husserl, MerleauPonty, Beauvoir. London: Roman \& Littlefield, 2003.

Heyes, Cressida J. Self-Transformations: Foucault, Ethics, and Normalized Bodies. Oxford: Oxford University Press, 2007.

Hoek, H.W., and D. van Hoeken. "Review of the Prevalence and Incidence of Eating Disorders." International Journal of Eating Disorders 34, no. 4 (2003): 383-396. https://doi.org/10.1002/eat.10222.

Hofmann, Bjørn and Fredrik Svenaeus, "How Medical Technologies Shape the Experience of Illness," Life Sciences, Society and Policy 14, no. 3 (2018):1-11. https://doi.org/10.1186/s40504-018-0069-y

Hogan, Elle, Laura Segal, and Susan Levine. "F as in Fat: How Obesity Threatens America's Future 2010." Trust for America's Health, June 29, 2010. http:// healthyamericans.org/newsroom/releases/?releaseid=216.

Horwitz, Jill R., Brenna D. Kelly and John DiNardo. "Wellness Incentives in the Workplace: Cost Savings through Cost Shifting to Unhealthy Workers." Health Affairs 32, no. 3 (2013): 468-472. https://doi.org/10.1377/hlthaff.2012.0683.

Jansen, Julia and Maren Wehrle, “The Normal Body: Female Bodies in Changing Contexts of Normalization and Optimization." In New Feminist Perspectives on Embodiment, eds. Clara Fischer and Luna Dolezal. Cham: Palgrave Macmillan, 2018): 37-55.

Jha, Prabhat, and Frank J. Chaloupka. Curbing the Epidemic-Governments and the Economics of Tobacco Control. Washington, DC: World Bank, 1999.

Johns Hopkins Coronavirus Resource Center. 2021.Global Map. https://coronavirus.jhu.edu/map.html

Jolles, Marjorie. "Between Embodied Subjects and Objects: Narrative Somaesthetics." Hypatia 27, no. 2 (Spring 2012): 301-318. https://doi.org/10.1111/j. 1527-2001.2011.01262.x.

Kaster, Carolyn. “15 Years Later, Where Did All The Cigarette Money Go?” NPR. Last modified October 13, 2013. http://www.npr.org/2013/10/13/233449505/15years-later-where-did-all-the-cigarette-money-go.

Keys, Ancel. Seven Countries: A Multivariate Analysis of Death and Coronary Heart Disease. Cambridge, MA: Harvard University Press, 1980.

Khuder, Sadik A., Sheryl Milz, Timothy Jordan, James Price, Kathi Silvestri, and Pam Butler. "The Impact of a Smoking Ban on Hospital Admissions for Coronary Heart Disease.” Preventive Medicine 45, no. 1 (2007): 3-8. https://doi.org/10.1016/j. ypmed.2007.03.011.

Kimm, Sue Y.S., and Eva Obarzanek. "Childhood Obesity: A New Pandemic of the New Millennium.” Pediatrics 110, no. 5 (2002): 1003-1007.

Klass, Perri. “The Impact of Disparities on Children's Health,” The New York Times, June 15, 2020. https://nyti.ms/2Y2ehBq

Klein, Richard. "What Is Health and How Do You Get It?" In Against Health: How Health Became the New Morality, edited by Jonathan Metzl and Anna Kirkland, 15-25. New York: New York University Press, 2010.

Kolata, Gina. "Costs for Dementia Care Far Exceeding Other Diseases, Study Finds.” New York Times, October 26, 2015. http://www.nytimes.com/2015/10/27/health/ costs-for-dementia-care-far-exceeding-other-diseases-study-finds.html?.

Kolata, Gina Bari. Rethinking Thin: The New Science of Weight Loss-and the Myths and Realities of Dieting. New York: Picador/Farrar, Straus and Giroux, 2007. 
Lao Tzu. Daodejing, translated by Hans-Georg Moeller. Chicago: Open Court, 2007.

Leder, Drew. The Absent Body. Chicago: University of Chicago Press, 1990.

Lee, Ronald. "The Demographic Transition: Three Centuries of Fundamental Change." Journal of Economic Perspectives 17, no. 4 (2003): 167-190. https:// doi.org/10.1257/089533003772034943.

Lemmens, Valery, Anke Oenema, Inge Knut, Klepp Knut, and Johannes Brug. "Effectiveness of Smoking Cessation Interventions among Adults: A Systematic Review of Reviews.” European Journal of Cancer Prevention 17, no. 6 (2008): 535-544. https://doi.org/10.1097/CEJ.0b013e3282f75e48.

Lemke, Thomas. Biopolitics: An Advanced Introduction. New York: New York University Press, 2011.

Letteri, Mark. "The Theme of Health in Nietzsche's Thought." Man and World 23, no. 4 (1990): 405-417. https://doi.org/10.1007/BF01271585.

Levin, Bess, "Texas Lt. Governor: Old People Should Volunteer to Die to Save the Economy." Vanity Fair, March 24, 2020. https://www.vanityfair.com/ news/2020/03/dan-patrick-coronavirus-grandparents

Livingston, Gretchen, "The Changing Profile of Unmarried Parents," Pew Research Center. April 25, 2018. https://www.pewsocialtrends.org/2018/04/25/ the-changing-profile-of-unmarried-parents/\#: : text=Among $\% 20$ solo $\% 20$ parents $\% 2$ C $\% 2042 \% 25 \% 20$ are,cohabiting $\% 20$ moms $\% 20(30 \% 25 \% 20 v s$.

Lochlann, Jain S. “Be Prepared.” In Against Health: How Health Became the New Morality, edited by Jonathan Metzl and Anna Kirkland, 170-182. New York: New York University Press, 2010.

Loeb, Paul. "Eternal Recurrence," in The Oxford Handbook of Nietzsche, edited by Ken Gemes and John Richardson, 645-671. Oxford: Oxford University Press, 2013.

Lohr, Kathy. “Controversy Swirls around Anti-Obesity Ads.” NPR, January 9, 2012. https://www.npr.org/2012/01/09/144799538/controversy-swirls-around-harshanti-obesity-ads.

Magallares, Alejando and José-Francisco Morales. "Gender Differences in Antifat Attitudes." Revista de Psicología Social: International Journal of Social Psychology, 28:1 (2013): 113-119.

Malnick, S.D.H., and H. Knobler. "The Medical Complications of Obesity." QJM: An International Journal of Medicine 99, no. 9 (2006): 565-579. https://doi. org/10.1093/qjmed/hcl085.

Mann, Traci A., Janet Tomiyama, Erika Westling, Ann-Marie Lew, Barbra Samuels, and Jason Chatman. "Medicare's Search for Effective Obesity Treatments: Diets Are Not the Answer." American Psychologist 62, no. 3 (2007): 220-233. http:// dx.doi.org/10.1037/0003-066X.62.3.220.

Marcuse, Herbert. “The Affirmative Character of Culture.” In Negations: Essays in Critical Theory, translated by Jeremy J. Shapiro, 65-98. London: MayFly, 2009.

Marietta, Martin. "Personal Choice Benefits Program Medical Plan Summary Plan Description 2015.” BCBSNC.com. Last modified January 2015. http://www. bcbsnc.com/assets/members/public/pdf/martinmarietta/summary_plan_description.pdf.

Marietta, Martin. "Personal Choice Benefits Program Medical Plan Summary Plan Description 2009.” BCBSNC.com. Last modified January 2009. http://www. bcbsnc.com/assets/members/public/pdf/martinmarietta/FAQ.pdf.

Martiny, Kristian Moltke. "How to Develop a Phenomenological of Disability." Medicine, Health Care, and Philosophy 18 (2015): 553-565. 
Marx, Karl, and Friedrich Engels. The Communist Manifesto, edited by Martin Malia. New York: Signet Classic, 1998.

Marx, Karl. "Economic and Philosophical Manuscripts." In The Marx-Engels Reader, edited by Robert C. Tucker, 66-125. New York: W.W. Norton, 1978.

Marx, Karl. Capital Volume I, translated by Ben Fowkes. London: Penguin, 1976.

Marx, Karl. Grundrisse, translated by Martin Nicolaus. London: Penguin, 1993.

May, Todd. The Political Philosophy of Poststructuralist Anarchism. University Park: Penn State Press, 2005.

McAfee, Tim, Kevin C Davis, Robert L Alexander, Terry F Pechacek, and Rebecca Bunnell. "Effect of the First Federally Funded US Antismoking National Media Campaign.” The Lancet 382, no. 9909 (2013): 2003-2011. https://doi. org/10.1016/S0140-6736(13)61686-4.

McDonnell, Orla. "Thomas Szasz's The Myth of Mental Illness.” In Mobilising Classics: Reading Radical Writing in Ireland, edited by Fiona Dukelow \& Orla O’Donovan, 88-104. Manchester University Press: Manchester, UK, 1966.

McIntosh, Kristin, Emily Moss, Ryan Nunn, and Jay Shambaugh, "Examining the Black-white wealth gap,” The Brookings Institute, February 27,2020. https://www. brookings.edu/blog/up-front/2020/02/27/examining-the-black-white-wealth-gap/

McRuer, Robert. "Compulsory Able-Bodiness." In 50 Concepts for a Critical Phenomenology, edited by Gail Weiss, Ann V. Murphy, and Gayle Salamon, 6167. Evanston: Northwestern University Press, 2020.

McRuer, Robert. Crip Theory: Cultural Signs of Queerness and Disability. New York: New York University Press, 2006.

Meltzoff, Andrew, and Wolfgang Prinz, editors. The Imitative Mind: Development, Evolution, and Brain Bases. Cambridge: Cambridge University Press, 2002.

Menotti, A., G.C. Descovich, M. Lanti, A. Spagnolo, A. Dormi, and F. Seccareccia. "Indexes of Obesity and All-Causes Mortality in Italian Epidemiologic Data." Preventive Medicine 22, no. 3 (1993): 293-303. https://doi.org/10.1006/ pmed.1993.1024.

Merleau-Ponty, Maurice. Child Psychology and Pedagogy: The Sorbonne Lectures 19491952, translated by Talia Welsh. Evanston: Northwestern University Press, 2010.

Merleau-Ponty, Maurice. Phenomenology of Perception, translated by Donald Landes. New York: Routledge, 2012.

Merleau-Ponty, Maurice. The Structure of Behavior, translated by Alden L. Fisher. Pittsburgh: Duquesne University, 1983.

Mestel, Rosie. “Arkansas Schoolchildren Getting Weight Report Cards.” Los Angeles Times, June 4, 2004. http://articles.latimes.com/2004/jun/04/science/sci-obese4.

Metzl, Jonathan. "Introduction: Why Against Health." In Against Health: How Health Became the New Morality, edited by Jonathan Metzl and Anna Kirkland, 1-12. New York: New York University Press, 2010.

Mitchell, Gordon R., and Kathleen M. McTigue. "The US Obesity "Epidemic": Metaphor, Method, or Madness?" Social Epistemology 21, no. 4 (2007): 391423. https://doi.org/10.1080/02691720701746557.

Mitchell, Juliet, “Woman's Estate.” In Feminist Frameworks: Alternative Theoretical Accounts of the Relations Between Women and Men, edited by Alison Jaggar and Paula Rothenberg. 130-141. New York: McGraw-Hill Book Company.

Moeller, Hans-Georg. The Philosophy of the Daodejing. New York: Columbia, 2006.

Mohanty, Chandra Talpade, "Women Workers and Capitalist Scripts: Ideologies of Domination, Common Interests, and the Politics of Solidarity." In Feminist 
Genealogies, Colonial Legacies, Democratic Futures, edited by M. Jacqui Alexander and Chandra Talpade Mohanty. London: Routledge, 1997

Morris, David. “Body.” In Merleau-Ponty: Key Concepts, edited by Rosalyn Diprose and Jack Reynolds. 111-120. Stocksfield: Acumen, 2008.

Moss, Donald McKenna. "Distortions in Human Embodiment: A Study of Surgically Treated Obesity." In Vol. 8 Phenomenology: Dialogues and Bridges, edited by Ronald Bruzina and Bruce W. Wilshire, 253-268. Albany: State University of New York Press, 1982.

Murray, Samantha. The 'Fat' Female Body. London: Palgrave Macmillian, 2008.

Murtagh, Lindsey, and David S. Ludwig. "State Intervention in Life-Threatening Childhood Obesity.” JAMA 306, no. 2 (2011): 206-207. https://doi.org/10.1001/ jama.2011.903.

NEDA (National Eating Disorders Association). "Eating Disorders Information Index." NEDA, 2011. http://www.nationaleatingdisorders.org/.

Nehamas, Alexander. “The Eternal Recurrence,” The Philosophical Review 89, no. 3 (1980): 331-356. https://doi.org/10.2307/2184393

News Agencies. “Obese Children Removed from Families.” The Telegraph, February 28, 2014. http://www.telegraph.co.uk/foodanddrink/healthyeating/10667066/ Obese-children-removed-from-families.html.

Ngo, Helen. The Habits of Racism: A Phenomenology of Racism and Radicalized Embodiment. New York: Lexington Books, 2017.

Nietzsche, Friedrich. “Beyond Good and Evil.” In Basic Writings of Nietzsche, translated and edited by Walter Kaufmann, 179-436. New York: The Modern Library, 1969a.

Nietzsche, Friedrich. "Ecce Homo.” In Basic Writings of Nietzsche, translated and edited by Walter Kaufmann, 655-802. New York: The Modern Library, 1969b.

Nietzsche, Friedrich. "On the Genealogy of Morals.” In Basic Writings of Nietzsche, translated and edited by Walter Kaufmann, 437-600. New York: The Modern Library, 1969c.

Nietzsche, Friedrich. "On the Uses and Disadvantages of History for Life." In Untimely Meditations, translated by R.J. Hollingdale, 59-123. Cambridge: Cambridge University Press, 1983.

Nietzsche, Friedrich. The Gay Science, translated by Walter Kaufmann. New York: Vintage Books, 1974.

Nietzsche, Friedrich. "Twilight of the Idols.” In The Portable Nietzsche, translated and edited by Walter Kaufmann. New York: Penguin, 1976.

Obama, Barack. "Remarks by the President on the Affordable Care Act and the New Patients'Bill of Rights." Whitehouse.gov.June 22,2010.https:/www.whitehouse.gov/ the-press-office/remarks-president-affordable-care-act-and-new-patients-bill-rights.

Oksala, Johanna. Feminist Experiences: Foucauldian and Phenomenological Investigations. Evanston: Northwestern University Press, 2016.

Oksala, Johanna. Foucault on Freedom. Cambridge: Cambridge University Press, 2005.

Oliver, J. Eric. Fat Politics: The Real Story Behind America's Obesity Epidemic. Oxford: Oxford University Press, 2006.

Olkowski, Dorothea. "Science and Human Nature: How to Go from Nature to Ethics." In Metacide: In the Pursuit of Excellence, edited by James R. Watson. Leiden: Brill, 2010: 43-71.

Oppel, Richard A. Jr., Robert Gebeloff, K.K. Rebecca Lai, Will Wright and Mitch Smith, "The Fullest Look Yet at the Racial Inequity of Coronavirus," The New York Times, July 5, 2020. https://nyti.ms/3f286n9 


\section{Bibliography}

Pare, Mike. "Innovation District plan Includes Greater UTC Presence Downtown, Housing, Research Opportunities," Chattanooga Times Free Press (Chattanooga, TN), March 21, 2018. http://www.timesfreepress.com/news/local/story/2018/ mar/21/visiinnovatidistrict-includes-greater-utc-pre/466462/.

Pascal, Blaise. (n.d.) Pensées, \#347. Project Gutenberg http://www.gutenberg.org/ files/18269/18269-h/18269-h.htm.

Pele, Antonio and Stephen Riley, "For a Right to Health Beyond Biopolitics: The Politics of the Pandemic and the "Politics of Life." Law, Culture and the Humanities (2021) 1-17.

Peres, Judy. "No Clear Link Between Passive Smoking and Lung Cancer." JNCI Journal of the National Cancer Institute 105, no. 24 (June 2013): 1844-1846. https://doi.org/10.1093/jnci/djt365.

Pinsker, Joe, “'Intensive' Parenting Is Now the Norm in America," The Atlantic, January 16, 2019. https://www.theatlantic.com/family/archive/2019/01/ intensive-helicopter-parenting-inequality/580528/

Poli, A., F. Marangoni, A. Avogaro, G. Barba, S. Bellentani, M. Bucci, R. Cambieri et al. "Moderate Alcohol Use and Health: A Consensus Document." Nutrition, Metabolism and Cardiovascular Diseases 23, no. 6 (2013): 487-504. https://doi. org/10.1016/j.numecd.2013.02.007.

Rajagopalan, Megha. "China Capital to Roll out Tough Anti-smoking Laws.” Reuters, May 31, 2015. http://www.reuters.com/article/us-china-smokingidUSKBN0OF0WN20150531\#YMg7ZIWmpFz5EHkz.97.

Redlener, Irwin, Jeffrey D. Sachs, Sean Hansen, and Nathaniel Hupert. "130,000210,000 Avoidable COVID-19 Deaths and Counting in the U.S." October 21, 2020. https://ncdp.columbia.edu/custom-content/uploads/2020/10/AvoidableCOVID-19-Deaths-US-NCDP.pdf

Reynolds, Joel Michael. "Merleau-Ponty, World-Creating Blindness, and the Phenomenology of Non-Normate Bodies." Chiasmi International 19 (2017):419-436

Romdenh-Romluc, Komarine. "Habit and Attention.” In The Phenomenology of Embodied Subjectivity, edited by R.T. Jensen and D. Moran, 3-20. Dordrecht: Springer, 2013.

La Rochefoucauld. Maxims, translated by Leonard Tancock. London: Penguin Classics, 1959.

Rosalsky, Greg. "How The Crisis Is Making Racial Inequality Worse," Planet Money-National Public Radio, May 26, 2020, https://www.npr.org/sections/ money/2020/05/26/860913793/how-the-crisis-is-making-racial-inequality-worse

Rose, Nikolas. The Politics of Life Itself: Biomedicine, Power, and Subjectivity in the Twenty-First Century. Princeton: Princeton University Press, 2009.

Salamon, Gayle. "The Phenomenology of Rheumatology: Disability, Merleau-Ponty, and the Fallacy of Maximal Grip." Hypatia 27, no. 2 (Spring 2012): 223-260. https://doi.org/10.1111/j.1527-2001.2012.01266.x.

Saner, Emine. “'Does the Criticism Affect Me? Yes, Massively': Jamie Oliver's War on Childhood Obesity," The Guardian, April 29, 2018, https://www.theguardian. com/lifeandstyle/2018/apr/29/jamie-oliver-criticism-affect-me-childhood-obesity

Scarborough, P., P. Bhatnagar, K. K. Wickramasinghe, S. Allender, C. Foster, and M. Rayner. "The Economic Burden of Ill Health Due to Diet, Physical Inactivity, Smoking, Alcohol and Obesity in the UK: an Update to 2006-07 NHS Costs." Journal of Public Health 33, no. 4 (November 2011): 527-535. https://doi. org/10.1093/pubmed/fdr033. 
Sedgwick, Peter. "Nietzsche, Illness and the Body's Quest for Narrative." Health Care Analysis 21, no. 4 (2013): 306-322. https://doi.org/10.1007/s10728-013-0264-1.

Sira, N. and C. White. "Individual and Familial Correlates of Body Satisfaction in Male and Female College Students." Journal of American College Health, 58 (2010): 507-514.

Shetty, Kanaka D., Thomas DeLeire, Chapin White, and Jayanta Bhattacharya, "Changes in U.S. Hospitalization and Morality Rates Following Smoking Bans," Journal of Policy Analysis and Management, 30, no. 1 (2010): 6-28.https://doi. org/10.1002/pam.20548

Shusterman, Richard. Body Consciousness: A Philosophy of Mindfulness and Somaesthetics. Cambridge: Cambridge University Press, 2008.

Shusterman, Richard. Practicing Philosophy: Pragmatism and the Philosophical Life. New York: Routledge, 1997.

Shusterman, Richard. "Somaesthetics: A Disciplinary Proposal." The Journal of Aesthetics and Art Criticism 57, no. 3 (Summer 1999): 299-313. https://doi. org/10.2307/432196.

Shusterman, Richard. "Somaesthetics and the Fine Art of Eating." In Body Aesthetics, edited by Sherri Irvin, 261-280. Oxford: Oxford University Press, 2016.

Shusterman, Richard. "Somaesthetics and The Second Sex: A Pragmatist Reading of a Feminist Classic.” Hypatia 18, no. 4 (2003): 106-136. https://doi.org/10.1353/ hyp.2003.0089.

Jenny Slatman, Our Strange Body: Philosophical Reflections on Identity and Medical Interventions. Amsterdam: Amsterdam University Press, 2008.

Spelman, Elizabeth V. "Gender \& Race: The Ampersand Problem in Feminist Thought." In The Feminist Philosophy Reader, edited by Alison Bailey and Chris Cuomo. 265-278. New York: McGraw-Hill Book Company, 2008.

New York Times (London), "Smokers and the Obese Cheaper to Care For, Study Shows.” February 5, 2008. http://www.nytimes.com/2008/02/05/health/05iht-obese.1.9748884.html.

Soylu, Tulay G., Eman Elashkar, Fatemah Aloudah, Munir Ahmed, Panagiota Kitsantas, "Racial/Ethnic Differences in Health Insurance Adequacy and Consistency among Children: Evidence from the 2011/12 National Survey of Children's Health," Journal of Public Health Research 2018; 7:1280: 56-62.

Starr, Penny. "Health Experts Call Obesity A Threat to National Security." CNSNews.com, September 10, 2009. http://cnsnews.com/news/article/ health-experts-call-obesity-threat-national-security.

Stavro, Elaine. Emancipatory Thinking: Simone de Beauvoir and Contemporary Political Thought. Montreal: Mc-Gill-Queen's University Press, 2018.

Surgeon General. "National Prevention Strategy." National Prevention Council, June 16, 2011. http://www.surgeongeneral.gov/priorities/prevention/strategy/ report.pdf.

Surgeon General. "The Health Consequences of Smoking-50 Years of Progress: A Report of the Surgeon General." U.S. Department of Health and Human Services. 2014. http://www.surgeongeneral.gov/library/reports/50-years-of-progress/ exec-summary.pdf.

Svenaeus, Fredrik. Phenomenological Bioethics: Medical Technologies, Human Suffering, and the Meaning of Being Alive. London: Routledge, 2018.

Svenaeus, Fredrick. "Das unheimliche-Toward a phenomenology of illness." Medicine, Health Care and Philosophy 3, no. 1 (2000): 3-16. https://doi. org/10.1023/A:1009943524301. 


\section{Bibliography}

Tavernise, Sabrina. "Disparity in Life Spans of the Rich and the Poor is Growing," The New York Times. February 16, 2016. https://www.nytimes.com/2016/02/13/ health/disparity-in-life-spans-of-the-rich-and-the-poor-is-growing.html

Tellenbach, Hubertus. "The Phenomenology of States of Health and Its Consequences for the Physician.” Morality within the Life-and Social World 22, (1987): 371381. https://doi.org/10.1007/978-94-009-3773-4_27.

Tiemersma, D., "Phenomenology and the Foundation of Medicine: Structures of the Lived Body and the Life-world and the Moral a Priori." Man and World 16, no. 2 (1983): 105-112. https://doi.org/10.1007/bf01260323D.

Tobacco Control Legal Consortium. "How the Affordable Care Act Affects Tobacco Use and Control." Public Health Law Center. Last modified December 2015. http://publichealthlawcenter.org/sites/default/files/resources/tclc-fs-aca- $\&$-tobacco-control-2014_0.pdf.

Tobias, Deirdre K., Mu Chen, Joann E. Manson, David S. Ludwig, Walter Willett, and Frank B. Hu. "Effect of Low-fat Diet Interventions versus Other Diet Interventions on Long-term Weight Change in Adults: A Systematic Review and Meta-analysis." The Lancet Diabetes \& Endocrinology 3, no. 12 (2015): 968979. https://doi.org/10.1016/S2213-8587(15)00367-8.

Tong, Rosemarie. "Taking on "Big Fat": The Relative Risks and Benefits of the War against Obesity." Public Health Policy and Ethics 19 (2005): 39-58. https://doi. org/10.1007/1-4020-2207-7_3.

Toombs, S. Kay. “The Lived Experience of Disability.” Human Studies 18, no. 1 (January 1995): 9-23. https://doi.org/10.1007/bf01322837.

Toombs, S. Kay. The Meaning of Illness: A Phenomenological Account of the Different Perspectives of the Physician and Patient. Dordrecht: Kluwer, 1992.

Tsai, A. G., D. F. Williamson, and H. A. Glick. "Direct Medical Cost of Overweight and Obesity in the USA: A Quantitative Systematic Review." Obesity Reviews 12, no. 1 (2010): 50-61. https://doi.org/10.1111/j.1467-789x.2009.00708.x.

Tucker, Todd. The Great Starvation Experiment: Ancel Keys and the Men Who Starved for Science. Minneapolis: University of Minnesota Press, 2007.

Villarosa, Linda. “'A Terrible Price': The Deadly Racial Disparities of COVID-19 in America," The New York Times, April 29, 2020. https://nyti.ms/2VKB8jO

Vogelmann, Frieder, The Spell of Responsibility: Labor, Criminality, Philosophy. In Essex Studies of Contemporary Critical Theory, translated by Daniel Steuer. New York: Rowman \& Littlefield, 2018.

Volpp, Kevin G., Andrea B. Troxel, Mark V. Pauly, Henry A. Glick, Andrea Puig, David A. Asch, Robert Galvin et al. "A Randomized, Controlled Trial of Financial Incentives for Smoking Cessation.” New England Journal of Medicine 360, no. 7 (2009): 699-709. https://doi.org/10.1056/NEJMsa0806819.

Von Soest, T., L. Wichstrom. "Gender Differences in the Development of Dieting from Adolescence to Early Adulthood: A Longitudinal Study." Journal of Research on Adolescence, 19 (2009): 509-529.

Waaler, H.T. "Height. Weight and Mortality the Norwegian Experience.” Acta Medica Scandinavica215,no.S679(2009):1-56.https://doi.org/10.1111/j.0954-6820.1984. tb12901.x.

Waltenburg, Michelle A., Charles E. Rose, Tristan Victoroff, Marilee Butterfield, Jennifer A. Dillaha, Amy Heinzerling, Meagan Chuey, Maria Fierro, Rachel H. Jervis, Kristen M. Fedak, Andrea Leapley, Julie A. Gabel, Amanda Feldpausch, Eileen M. Dunne, Connie Austin, Caitlin S. Pedati, Farah S. Ahmed, Sheri Tubach, Charles Rhea, Julius Tonzel, Anna Krueger, David A. Crum, Johanna Vostok, 
Michael J. Moore, Hannah Kempher, Joni Scheftel, George Turabelidze, Derry Stover, Matthew Donahue, Deepam Thomas, Karen Edge, Bernadette Gutierrez, Erica Berl, Meagan McLafferty, Kelly E. Kline, Nichole Martz, James C. Rajotte, Ernest Julian, Abdoulaye Diedhiou, Rachel Radcliffe, Joshua L. Clayton, Dustin Ortbahn, Jason Cummins, Bree Barbeau, Stacy Carpenter, Julia C. Pringle, Julia Murphy, Brandy Darby, Nicholas R. Graff, Tia K.H. Dostal, Ian W. Pray, Courtney Tillman, Dale A. Rose, Margaret A. Honein, and CDC COVID-19 Emergency Response Team, "Coronavirus Disease among Workers in Food Processing, Food Manufacturing, and Agriculture Workplaces." Emerging Infectious Diseases, January 27, no. 1 (2021), 243-249.

Washington State Health Care Authority. "PEBB - Tobacco Use Premium Surcharge.” 2015. http://www.hca.wa.gov/pebb/Pages/surcharge_tobacco.aspx.

Weeks, Kathi. The Problem with Work: Feminism, Marxism, Antiwork Politics, and Postwork Imaginaries. Durham: Duke U.P., 2011.

Weiss, Gail. "Uncosmetic Surgeries in an Age of Normativity." In Feminist Phenomenology and Medicine, edited by Kristin Zeiler and Lisa Folkmarson Käll, 101-118. Albany: SUNY Press, 2014.

Welsh, Talia. "The Affirmative Culture of Healthy Self-Care: A Feminist Critique of the Good Health Imperative." IJFAB: International Journal of Feminist Approaches to Bioethics, 2020. 13, no. 1: 27-34.

Welsh, Talia. "Broken Pregnancies." In Phenomenology of the Broken Body, edited by Espen Dahl, Cassandra Falke, Thor Eirik Ericksen, 202-214. London: Routledge, 2019.

Welsh, Talia. "Healthism and the Bodies of Women: Pleasure and Discipline in the War against Obesity." The Journal of Feminist Scholarship 1, (November 2011): 33-48.

Welsh, Talia. The Child as Natural Phenomenologist: Primal and Primary Experience in Merleau-Ponty's Psychology. Evanston: Northwestern University Press, 2013.

Welsh, Talia. "Do Neonates Display Innate Self-Awareness? Why Neonatal Imitation Fails to Provide Sufficient Grounds for Innate Self and OtherAwareness." Philosophical Psychology 19, no. 2 (2006): 221-238. https://doi. org/10.1080/09515080600554746.

Wieseler, Christine. "Challenging Conceptions of the 'Normal' Subject of Phenomenology," In Race as Phenomena: Between Phenomenology and Philosophy of Race, edited by Emily Lee. 69-86. Lanham, MD: Rowman \& Littlefield, 2019.

World Health Organization. “The World Health Report 2003: Shaping the Future.” Geneva, 2003.

Young, Iris Marion. Throwing Like a Girl and Other Essays in Feminist Philosophy and Social Theory. Bloomington, IN: Indiana University Press, 1990.

Yurekli, Ayda, and Anne-Marie Perucic. Assessment of the Economic Costs of Smoking. World Health Organization, Tobacco Free Initiative, Switzerland, 2011. http://apps.who.int/iris/bitstream/10665/44596/1/9789241501576_eng.pdf.

Zamora, Daniel, and Michael C. Behrent, editors. Foucault and Neoliberalism. London: Polity, 2015.

Zhang, Sarah. "The Last Children of Down Syndrome." The Atlantic. December 2020. https:/www.theatlantic.com/magazine/archive/2020/12/ the-last-children-of-down-syndrome/616928/ 


\section{Index}

Aas, Sean 47

ableism ix, xi, 47, 106, 151-152, 158,166

action, Arendt's view of 162-164, 167;

culturally situated 60, 110-114; developmentally learned 57-60, 64; free 48, 54, 57, 73, 82, 91; habitual, as learned paths $55,58,158-160$; irrational 149-150; representation of action 54, 56; responsibility for 55

affirmative culture 97, 114, 117-118

Affordable Care Act (ACA) 2-3, $6,11,15-16$

Ahmed, Sara xi, 66, 152-153, 159, 167 Alcoff, Linda Martín 95

alcohol, cost of abuse 9-10; rates of use 3,6 ; related diseases $7-8,29,86$, 108,111

ambiguity xi, 32, 44, 128, 145, 152, 158-159, 165-166

apparatus 89-90, 93, 95, 114, 151

Arendt, Hannah xi, 152, 160-167

Assari, Shervin 103

Bartky, Sandra Lee 60, 62, 69, 120

beauty 15, 48, 114, 116-117, 131, 142; as a result of work $61-69,71-73$, 122, 132, 156, 161

Bergoffen, Debra 165

biomorality $\mathrm{x}, 16-17$

biopolitics x, 73, 78-79, 83, 85-86, 90, 95,164

bio-power/biopower 68, 83, 86, 90

Bordo, Susan 66-67, 69

Camus, Albert xi, 128, 132, 144-145, $150,158,166$

Carel, Havi 39-40, 139

Cederström, Carl 16-17, 123 child/children 2, 10, 15, 36, 39-40, 44, 115, 153; childbirth 120; childhood 1, 53; development 37, 54-60, 108; disability and $157-158,162$; freedom of 54-55; health of x, 78, 90, 95-97, 154-155; obesity/overweight 8,78 , 86-89, 92-97, 103, 140, 154;

psychology of 57-59, 138; raising of $\mathrm{x}, 54-56,88-89,92-97,103-107$, 163; see also responsibility, parental citizen-consumers 105-107, 114, 116, 166

commodity $105,110,113$

consumption $\mathrm{x}-\mathrm{xi}, 17-18,20,65$, 106-112, 121, 154, 156, 158, 160-161, 168; alcohol 7-8; food consumption ix, 8, 10, 87, 107, 109, 111,119

COVID-19 viii, 86, 92-94, 96, 106-107, 151, 156, 168

Crawford, Robert 12-14, 18

critical disability theory $\mathrm{x}, 30,152,156$ critical phenomenology ix, 30, 32, 48, 153, 156

De Beauvoir, Simone xi, 54, 60, 63, 158-159, 162, 165-168

Descartes, René 33-34

diet/dieting 3, 13, 15, 44, 61, 63, 67-69, 72, 88, 109-111, 117, 138, 154-155; diet-exercise industry 69, 114

Diprose, Roslyn 60

disability $x, 3,7,30,32,37,41-43$, 46-47, 73, 156-157

disease 1, 3-4, 7-11, 19, 28-32, 34, 37, $45,67,80,85,87-88,112,117,120$, $135,138,142-143$

Dostoevsky, Fyodor 149, 158

Dreyfus, Hubert 42 
Ehrenreich, Barbara 19, 28, 43

exercise 3, 13-15, 17, 62-63, 66, 69, 71-72, 85, 88-89, 111, 131-132, 155, 158; see also diet/dieting, diet-exercise industry

Fielding, Helen 32

Fisher, Linda 33-34

Foucault, Michel, x 68, 78-86, 89-92, 122, 130, 133-135, 141, 144

Frankl, Viktor 143

freedom 13, 45, 54, 64-65, 68-69, 83, $90,95,117,128,133-134,138,145$, $150,158-159,162,164-165$, 167-168; as personal matter of choice 13, 105, 149; see also child/ children, freedom of

Gadamer, Hans-Georg ix, 29, 35-36, 38,41

Garland-Thomson, Rosemarie 156-157, 160, 162

Grosz, Elizabeth 64

Guenther, Lisa 47

Guthman, Julie 14-15, 18, 20, 155

Hall, Kim Q. 106-107

Harvey, David 90-91, 116

Health-At-Any-Size, (HAES) 70

healthcare sciences $118-119,128$

health insurance $2-3,6,11,16$, 86,111

healthism viii 12-18, 20, 122, 156

Heidegger, Martin 37-39, 137

heteronormativity xi, 152-153, 157, 159

Heyes, Cressida 68, 71, 129, 131-134

hunger 108-109

Husserl, Edmund 36, 38, 150, 153

illness ix-xi, 1, 11-12, 18, 67, 78, 95, 112, 152, 154, 159, 166; correlated with poor health habits 7,106 ; disability and 45-47; as a matter of personal responsibility 2, 16, 151; mental illness 81, 91; Nietzsche's view of 134-135, 138-139, 142-143; phenomenologies of 20, 28-43, 45-48, 137, 139; related to medical care 118-119

Jain, S. Lochlann 19-20

Jolles, Marjorie 129, 131, 133
Kant, Immanuel 17-18, 34

Klein, Richard 14, 18

labor $15,46,82,96,109-110,122$, 140; Arendt's view of labor xi, 152, $160-166$; beauty as $62,65,67,72$; healthy $69,83,112-118,121,123$, 151, 154; Marxist view of labor x, 103-110, 112, 160; necessary 115; reproductive $78,96-97,103-108$, 160; surplus 97, 115; wage 96-97; see also beauty, beauty as work; work

Leder, Drew 28, 35

Lemke, Thomas 84

Letteri, Marc 137

lifeworld 33-34, 119, 166

lived body $29,32,34,38,43$

longevity $1-2,7-8,10-11,20,73$, $123,155,168$

Marcuse, Herbert x, 114, 116-117

Marxist/Marxism, x 96, 121

Marx, Karl 104, 107-116, 123, 160, 162, 165

McRuer, Robert 46, 152

Merleau-Ponty, Maurice ix, 33, 35-42, 45-46, 53-59, 63-64, 130, 137-138, 141,156

Metzl, Jonathan 15, 18

Minorities' Diminished Return Theory 105, 107

Mitchell, Juliet 105

Mohanty, Chandra 105

Morris, David 36

Moss, Donald McKenna 44

Murray, Samantha 69-71

Natality 158, 160, 162-163

Ngo, Helen 154

Nietzsche, Friedrich xi, 86, 129, 134-144, 150, 158

normalization $65,68,78,82-83,86$, $96,120,123,129-133$

obesity $8-10,13,16,19,43,69-73,78$; costs of 9-10; phenomenology of 30, 45,48 ; relation to behavior ix, $6-7$, $14,47,85$, 95; see also child/children, obesity/overweight; overweight

Oksala, Johanna 63, 65, 89, 122, 134

overweight ix, 69-70, 92; relation to behavior 7-14; see also child/ children, obesity/overweight; obesity 


\section{Index}

Pascal, Blaise 11-12, 18

poverty $19,82,92-93,111,116-117$, 154; poor health outcomes due to 43, 94, 103

prenatal testing 157-158

prosthetics 5, 45-46

public health ix, 1-9, 16-17, 45, 69-71, $86,89,93-95,103,155,168$

racism ix, 16, 47, 58, 83, 93, 106, 151, 154, 166

reproductive labor x, 78, 96-97, 103-107, 160

responsibility 44; Beauvoir's view of 165-167; individual/personal viii-x, $13,15,18,73,82,92,106-107,119$, 123, 152; parental 93-95, 103, 105; public/social 15, 132; women's 61 , 63, 71; worker's 96-97, 115

Reynolds, Joel 47

Romdenh-Romluc, Komarine 55

Rose, Nikolas 95-96

Salamon, Gayle 42, 47

Schustermann, Richard 129-133, 135, 141, 144

Sedgwick, Peter 139, 143

sexism ix, 12, 64, 153, 157, 167

Slatman, Jenny 46

smoking 14, 18, 72, 85, 93, 108, 111, 118; anti-smoking ad campaigns 4-5, 8 ; bans/legislation against ix, 5 , 154-155; costs of 6, 9; insurance surcharges 6; related diseases ix, 3-4, 7-10, 14, 16-17, 29

social welfare $\mathrm{x}, 157$

somaesthetics xi, 129-135, 144-145

Spicer, André 16-17, 123

Stavro, Elaine 162, 165

Svenaeus, Fredrik ix, 37-39, 120, 139
Tiemersma, Douwe 32

Tong, Rosemarie 69

Toombs, S. Kay 38, 40, 46, 139

vaccine resistance/anti-vaccination 13-14, 106

Vogelmann, Frieder 96-97

vulnerability 80, 143, 152, 165, 167

wealth/wealthy $11,82,86,92,96-97$, 103-105, 107, 115-118, 121-122, $151,155,166$

Weeks, Kathi xi, 121-122, 129, 140

Wieseler, Christine 156

work 11, 17, 29, 32, 35, 38, 68, 79-80, 84, 97, 121-123; Arendt's view of xi, 152, 160-164; beauty 48, 60-64, 67, $69,72,108,156$; health ix, 19, 35, $46,59,69,71-73,82-83,85,93$, $112,118,128,151-152,155-156$, 165-166, 168; Marxist view of $\mathrm{x}$, 109,112 ; parenting 88,104 ; refusing to 140-141; reproductive 104-107; somaesthetic 129-134, 144; see also beauty, as a result of work; labor

worker-producers 105-106, 116, 156,166

workers 19, 40, 43, 81, 89-90, 92, 94, 96, 105-107, 112, 115-116, 123, $152,164-165$

workout/working out 3, 28, 43, 83, 114-115, 122-123, 166

workplace 3, 5, 80-81, 83, 90, 93, 115,157

Young, Iris Marion 67

Zhuangzi 90-91 